\title{
The Economics of Reprocessing Versus Direct Disposal of Spent Nuclear Fuel
}

\section{Citation}

Bunn, Matthew, John P. Holdren, Steve Fetter, and Bob van der Zwaan. 2003. The Economics of Reprocessing Versus Direct Disposal of Spent Nuclear Fuel. Project on Managing the Atom. Belfer Center for Science and International Affairs, Harvard Kennedy School.

\section{Published Version}

http://www.belfercenter.org/publication/economics-reprocessing-vs-direct-disposal-spentnuclear-fuel

\section{Permanent link}

http://nrs.harvard.edu/urn-3:HUL.InstRepos:30209100

\section{Terms of Use}

This article was downloaded from Harvard University's DASH repository, and is made available under the terms and conditions applicable to Other Posted Material, as set forth at http:// nrs.harvard.edu/urn-3:HUL.InstRepos:dash.current.terms-of-use\#LAA

\section{Share Your Story}

The Harvard community has made this article openly available.

Please share how this access benefits you. Submit a story.

\section{Accessibility}




\section{THE ECONOMICS OF REPROCESSING vS. Direct DisPosal OF SPENT NuClear Fuel}

Final Report

8/12/1999-7/30/2003

Matthew Bunn

Steve Fetter

John P. Holdren

Bob van der Zwaan

December 2003

DE-FG26-99FT4028

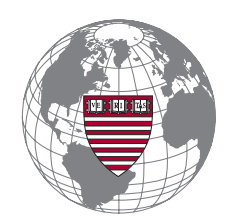

Project on Managing the Atom

BELFER CENTER FOR SCIENCE AND INTERNATIONAL AFFAIRS

JOHN F. KENNEDY SCHOOL OF GOVERNMENT

HARVARD UNIVERSITY

79 JOHN F. KENNEDY STREET

CAMBRIDGE, MASSACHUSETTS 02138 
(C) 2003 President and Fellows of Harvard University

Printed in the United States of America

This report was prepared as an account of work sponsored by an agency of the United States Government. Neither the United States Government nor any agency thereof, nor any of their employees, makes any warranty, express or implied, or assumes any legal liability or responsibility for the accuracy, completeness, or usefulness of any information, apparatus, product, or process disclosed, or represents that its use would not infringe privately owned rights. Reference herein to any specific commercial product, process, or service by trade name, trademark, manufacturer, or otherwise does not necessarily imply its endorsement, recommendation, or favoring by the United States Government or any agency thereof. The views and opinions of authors expressed herein do not necessarily state or reflect those of the United States Government or any agency thereof.

The authors of this report invite liberal use of the information provided in it for educational purposes, requiring only that the reproduced material clearly state: Reproduced from Matthew Bunn, Steve Fetter, John Holdren, and Bob van der Zwaan, The Economics of Reprocessing vs. Direct Disposal of Spent Nuclear Fuel (Cambridge, Mass.: Project on Managing the Atom, Harvard University, 2003).

\author{
Project on Managing the Atom \\ Belfer Center for Science and International Affairs \\ John F. Kennedy School of Government \\ Harvard University \\ 79 JFK Street \\ Cambridge, MA 02138 \\ Fax: (202) 495-8963 \\ Email: atom@harvard.edu \\ Web: http://www.ksg.harvard.edu/bcsia/atom
}




\begin{abstract}
This report assesses the economics of reprocessing versus direct disposal of spent nuclear fuel. The breakeven uranium price at which reprocessing spent nuclear fuel from existing light-water reactors (LWRs) and recycling the resulting plutonium and uranium in LWRs would become economic is assessed, using central estimates of the costs of different elements of the nuclear fuel cycle (and other fuel cycle input parameters), for a wide range of range of potential reprocessing prices. Sensitivity analysis is performed, showing that the conclusions reached are robust across a wide range of input parameters. The contribution of direct disposal or reprocessing and recycling to electricity cost is also assessed. The choice of particular central estimates and ranges for the input parameters of the fuel cycle model is justified through a review of the relevant literature. The impact of different fuel cycle approaches on the volume needed for geologic repositories is briefly discussed, as are the issues surrounding the possibility of performing separations and transmutation on spent nuclear fuel to reduce the need for additional repositories. A similar analysis is then performed of the breakeven uranium price at which deploying fast-neutron breeder reactors would become competitive compared with a once-through fuel cycle in LWRs, for a range of possible differences in capital cost between LWRs and fast-neutron reactors. Sensitivity analysis is again provided, as are an analysis of the contribution to electricity cost, and a justification of the choices of central estimates and ranges for the input parameters. The equations used in the economic model are derived and explained in an appendix. Another appendix assesses the quantities of uranium likely to be recoverable worldwide in the future at a range of different possible future prices.
\end{abstract}





\section{Table of Contents}

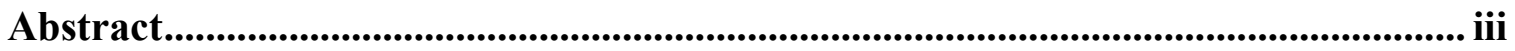

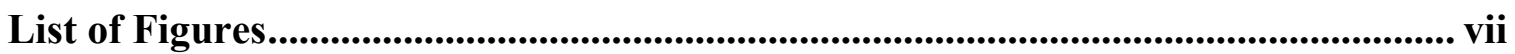

Acknowledgements ........................................................................................ viii

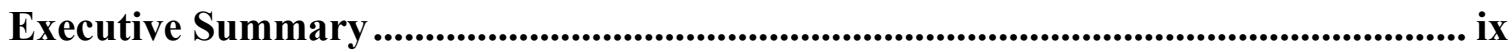

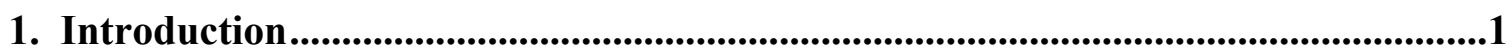

1.1. What Is Reprocessing?

1.2. Data and Sources

1.3. Cost vs. Price

1.4. Currency Conversion

1.5. Cost of Money, Discount Rate, and Taxes

1.6. Real vs. Nominal Dollars

1.7. Plan of the Report

2. Direct Disposal vs. Reprocessing and Recycling in Thermal Reactors

2.1. How to Compare Costs of Different Fuel Cycles

2.2. Calculating Breakeven Prices

2.3. Breakeven Price Sensitivity Analysis

2.4. Contribution to the Cost of Electricity

2.5. Component Costs of the Fuel Cycle

2.5.1. Uranium Prices

2.5.2. Reprocessing Costs and Prices

2.5.3. Costs of Disposal of Spent Fuel and Reprocessing Wastes

2.5.4. Costs and Prices for Mixed Oxide Fuel Fabrication and Use

2.5.5. Costs of Interim Storage of Spent Fuel

2.5.6. Enrichment Prices

2.5.7. Low Enriched Uranium Fuel Fabrication Prices

2.5.8. Premiums for Handling Reprocessed Uranium

2.5.9. Conversion Prices

2.5.10. Non-Price Factors: Fuel Burnup, Discount Rate

Sidebar: Volumes of Wastes From Direct Disposal and Reprocessing

Sidebar: Reprocessing to Reduce the Need for Additional Repositories

3. Direct Disposal vs. Recycling in Fast-Neutron Reactors

3.1. Plutonium Breeding and Recycling in Fast Reactors

3.2. Breakeven Uranium Price for Recycling in Fast Reactors

3.3. Cost of Electricity for Fast Reactors and Once-Through Systems

3.4. Cost Parameters and Variations

3.4.1. Difference in Capital Cost

3.4.2. Reactor Ownership and Financing Arrangements

3.4.3. Reprocessing Costs 
3.4.4. Core and Blanket Fuel Fabrication Costs

3.4.5. Geological Disposal of Reprocessing Waste

3.4.6. Breeding Ratio

3.4.7. Depleted Uranium Price

Sidebar: Thermal Neutron and Fast-Neutron Reactors

Sidebar: Characteristics of the Model Fast Reactor

4. Conclusions

Appendix A. Fuel Cycle Cost Calculations.

A.1. Direct Disposal vs. Reprocessing and Recycle in LWRs

A.1.1. Direct Disposal

A.1.2. Reprocessing-Recycle

A.1.2.1. Value of Recovered Plutonium

A.1.2.2. Value of Recovered Uranium

A.1.3. Uranium Breakeven Price

A.2. Direct Disposal vs. Recycling in Fast-Neutron Reactors

A.2.1. Capital Cost

A.2.1.1. Interest During Construction

A.2.2.2. Fixed Charge Rate

A.2.2. Operations and Maintenance Cost

A.2.3. Fuel Cost

A.2.3.1. LWR Fuel

A.2.3.2. LMR Fuel

A.2.4. Breakeven Uranium Price

Appendix B. World Uranium Resources .

B.1. Introduction

B.2. Fallacy of the Traditional Economic Resource Model

B.3. Estimates of Uranium Resources

B.4. Uranium From Seawater

B.5. Uranium Consumption 


\section{List of Figures and Tables}

Figure 2.1. Breakeven uranium price as a function of the cost of reprocessing ................18

Table 2.1. Estimates of fuel cycle costs (2003 dollars) and other parameters ..................19

Table 2.2. Breakeven prices of selected parameters ...................................................20

Figure 2.2. Sensitivity of the uranium breakeven price .................................................21

Figure 2.3. Additional cost of electricity for the reprocessing-recycle option ..................22

Figure 2.4. Uranium prices, 1972-2000 ...............................................................................24

Table 2.3. Notional cost reduction for disposal of reprocessing wastes .........................42

Figure 3.1. Breakeven uranium price for government-owned reactors ............................69

Figure 3.2. Breakeven uranium price for utility-owned reactors .......................................70

Figure 3.3. Breakeven uranium price for private venture ownership ................................70

Table 3.1. Sensitivity analysis for the breakeven uranium price ...................................71

Table 3.2. Breakeven price of selected parameters .............................................................73

Figure 3.4. Difference in the cost of electricity between an FR with recycling and an

LWR with direct disposal .............................................................................................74

Table A.1. Isotopic composition of fresh and spent LEU ............................................92

Table A.2. Isotopic composition of fresh MOX fuel ..................................................93

Table A.3. Optimum tails assay ...............................................................................95

Table A.4. Fixed charge rates.........................................................................101

Table B.1. Typical uranium concentrations ....................................................................106

Table B.2. Exponential uranium resource estimates ........................................................113 


\section{Acknowledgements}

This report was prepared with the support of the U.S. Department of Energy (DOE), under Award No. DE-FG26-99FT40281. However, any opinions, findings, conclusions, or recommendations expressed herein are those of the authors and do not necessarily reflect the views of DOE. Additional funding was provided by the John D. and Catherine T. MacArthur Foundation. The authors would like to thank Laure Mougeot for extensive research assistance in the early phases of the project, and Brian Torpy, Annaliis Abrego, and Anthony Wier for additional research assistance. We are grateful to Professors Mike Driscoll and Richard Lester of the Massachusetts Institute of Technology (MIT) for discussions of the finer points of cost levelization in the presence of corporate income taxes; to Marvin Miller of MIT for discussions of uranium resources; to Nigel Mote of International Nuclear Consultants and Geoff Varley and Dan Collier of the Nuclear Assurance Corporation, for discussions of the costs of some elements of the nuclear fuel cycle; and to David Wade of Argonne National Laboratory for data and discussions relating to recent analyses of recycling in fast-neutron reactors. We are also grateful to Driscoll, Chaim Braun, Jor-Chan Choi, and Per Peterson for useful comments on an earlier draft. All responsibility for remaining errors and misjudgments, of course, is our own. 


\section{$\underline{\text { Executive Summary }}$}

For decades, there has been an intense debate over the best approach to managing spent fuel from nuclear power reactors - whether it is better to dispose of it directly in geologic repositories, or reprocess it to recover and recycle the plutonium and uranium, disposing only of the wastes from reprocessing and recycling. The relative costs of reprocessing vs. not reprocessing are one important element of these debates. Economics is not the only or even the principal factor affecting decisions concerning reprocessing today. But economics is not unimportant, particularly in a nuclear industry facing an increasingly competitive environment. At a minimum, if reprocessing is being done to achieve objectives other than economic ones, it is worthwhile to know how much one is paying to achieve those other objectives.

While some analysts have argued in recent years that the costs of reprocessing and direct disposal are similar, and that reprocessing will soon be the more cost-effective approach as uranium prices increase, the data and analyses presented in this report demonstrate that the margin between the cost of reprocessing and recycling and that of direct disposal is wide, and is likely to persist for many decades to come.

In particular:

- At a reprocessing price of $\$ 1000$ per kilogram of heavy metal (kgHM), and with our other central estimates for the key fuel cycle parameters, reprocessing and recycling plutonium in existing light-water reactors (LWRs) will be more expensive than direct disposal of spent fuel until the uranium price reaches over $\$ 360$ per kilogram of uranium (kgU) - a price that is not likely to be seen for many decades, if then.

- At a uranium price of $\$ 40 / \mathrm{kgU}$ (comparable to current prices), reprocessing and recycling at a reprocessing price of $\$ 1000 / \mathrm{kgHM}$ would increase the cost of nuclear electricity by $1.3 \mathrm{mills} / \mathrm{kWh}$. Since the total back-end cost for the direct disposal is in the range of $1.5 \mathrm{mills} / \mathrm{kgWh}$, this represents more than an $80 \%$ increase in the costs attributable to spent fuel management (after taking account of appropriate credits or charges for recovered plutonium and uranium from reprocessing).

- These figures for breakeven uranium price and contribution to the cost of electricity are conservative, because, to ensure that our conclusions were robust, we have assumed:

- A central estimate of reprocessing cost, $\$ 1000 / \mathrm{kgHM}$, which is substantially below the cost that would pertain in privately financed facilities with identical costs and capacities to the large commercial facilities now in operation.

- A central estimate of plutonium fuel fabrication cost, $\$ 1500 / \mathrm{kgHM}$, which is significantly below the price actually offered to most utilities in the 1980 s and 1990s.

- Zero charges for storage of separated plutonium or removal of americium.

- Zero additional security, licensing, or shut-down expenses for the use of plutonium fuels in existing reactors.

- A full charge for 40 years of interim storage in dry casks for all fuel going to direct disposal, and no interim storage charge for fuel going to reprocessing- 
even though most new reactors are built with storage capacity for their lifetime fuel generation, so few additional costs for interim storage need be incurred.

- Geological disposal of spent MOX fuel at the same cost as disposal of spent LEU fuel.

- Reprocessing and recycling plutonium in fast-neutron reactors (FRs) with an additional capital cost, compared to new LWRs, of $\$ 200 / \mathrm{kW}_{\mathrm{e}}$ installed will not be economically competitive with a once-through cycle in LWRs until the price of uranium reaches some $\$ 340 / \mathrm{kgU}$, given our central estimates of the other parameters. Even if the capital cost of new FRs could be reduced to equal that of new LWRs, recycling in FRs would not be economic until the uranium price reached some $\$ 140 / \mathrm{kgU}$.

- At a uranium price of $\$ 40 / \mathrm{kgU}$, electricity from a plutonium-recycling FR with an additional capital cost of $\$ 200 / \mathrm{kW}_{\mathrm{e}}$, and with our central estimates of the other parameters, would cost more than 7 mills/ $\mathrm{kWh}$ more than electricity from a oncethrough LWR. Even if the additional capital cost could be eliminated, the extra electricity cost would be over 2 mills/kWh.

- As with reprocessing and recycling in LWRs, these figures on breakeven uranium price and extra electricity cost for FRs are conservative, as we have assumed:

- Zero cost for providing start-up plutonium for the FRs.

- Zero additional cost for reprocessing higher-plutonium-content FR fuel.

- Zero additional cost for manufacturing higher-plutonium-content FR fuel.

- Zero additional operations and maintenance costs for FRs, compared to LWRs.

- Costs for the far more complex chemical separations processes and more difficult fuel fabrication processes needed for more complete separation and transmutation of nuclear wastes would be substantially higher than those estimated here for traditional reprocessing. Therefore the extra electricity cost, were these approaches to be pursued, would be even higher. Arguments for separations and transmutation to limit the need for additional repositories rest on a number of critical assumptions that may or may not be borne out in practice.

- World resources of uranium likely to be economically recoverable in future decades at prices far below the breakeven price amount to tens of millions of tons, probably enough to fuel a rapidly-growing nuclear enterprise using a once-through fuel cycle for a century or more.

In this report, we have focused only on the economic issues, and have not examined other issues in the broader debate over reprocessing. Nevertheless, given (a) the costs outlined above; (b) the significant proliferation concerns that have been raised (particularly with respect to those reprocessing approaches that result in fully separated plutonium suitable for use in nuclear explosives); and (c) the availability of safe, proven, low-cost dry cask storage technology that will allow spent fuel to be stored for many decades, the burden of proof clearly rests on those in favor of investing in reprocessing in the near term. 


\section{Introduction}

For decades, there has been an intense debate over the best approach to managing spent fuel from nuclear power reactors - whether it is better to dispose of it directly in geologic repositories, or reprocess it to recover and recycle the plutonium and uranium, disposing only of the wastes from reprocessing and recycling. These debates have become even more salient in recent years, as increasing accumulations of both spent nuclear fuel and separated plutonium from reprocessing generate increasing concern worldwide. Countries that have chosen to reprocess are facing high costs and rising political controversies, while many of those that have chosen not to reprocess are facing significant political obstacles to providing adequate storage space for spent fuel. No country in the world has yet opened a permanent repository for either spent nuclear fuel or the high-level wastes from reprocessing. In several countries, proposals to separate and transmute not only plutonium and uranium, but other long-lived radioactive materials in spent fuel as well, have gained increasing attention in recent years.

The relative cost of reprocessing vs. direct-disposal is an important element of these debates. Economics, of course, is not the only or even the principal factor affecting decisions concerning reprocessing today - the inertia of fuel-cycle plans and contracts initiated long ago, hopes that plutonium recycling will contribute to energy security, lack of adequate storage space for spent fuel, environmental concerns, and other factors also play critical roles. ${ }^{1}$ But economics is not unimportant, particularly in a nuclear industry facing an increasingly competitive environment, where the difference between producing electricity at slightly higher or lower cost than competitors is the difference between bankruptcy and profit, and where fuel-cycle costs are among the few costs reactor operators can readily control. At a minimum, if reprocessing is being done to achieve objectives other than economic ones, it is worthwhile to know how much one is paying to achieve those other objectives.

There is general agreement in recent studies that with today's low uranium and enrichment prices, reprocessing and recycling is more expensive than direct disposal of spent fuel. $^{2}$ The only argument is over the magnitude of the difference and how long it is likely to

\footnotetext{
${ }^{1}$ For a useful (though now somewhat dated) overview of reprocessing and recycling of plutonium in countries around the world, with projections for the future and some suggestions for policies to address the relevant issues, see David Albright, Frans Berkhout, and William Walker, Plutonium and Highly Enriched Uranium 1996: World Inventories, Capabilities, and Policies (Oxford, UK: Oxford University Press for the Stockholm International Peace Research Institute, 1997).

${ }^{2}$ The studies on this topic are too numerous to list here. Official studies are of particular interest. For example, a recent study for the French government compared a scenario in which all of the low-enriched uranium fuel produced in French reactors was reprocessed to a hypothetical scenario in which reprocessing and recycling had never been introduced, and found that not reprocessing would have saved tens of billions of dollars compared to the all-reprocessing case, and would have reduced total electricity generation costs by more than 5 percent. See Jean-Michel Charpin, Benjamin Dessus, and René Pellat, Economic Forecast Study of the Nuclear Power Option (Paris, France: Office of the Prime Minister, July 2000, available as of December 16, 2003 at http://fire.pppl.gov/eu fr_fission_plan.pdf), Appendix 1. The 1994 study by the Nuclear Energy Agency of the Organization for Economic Cooperation and Development, The Economics of the Nuclear Fuel Cycle (Paris, France: OECD/NEA, 1994), while finding a total fuel cycle cost only about $14 \%$ greater for the reprocessing
} 
persist. Advocates of reprocessing often argue that the extra cost of reprocessing is small today, and will soon disappear as uranium supplies become scarce and their price rises. ${ }^{3}$ The data and analyses presented in this report, by contrast, demonstrate that the margin between the cost of reprocessing and recycling and that of direct disposal is wide, and is likely to persist for many decades to come.

These issues are increasingly important, as a number of countries face major decisions about future management of their spent fuel. In the United States in particular, the Bush administration has supported development of new reprocessing approaches that, it is argued, might be more proliferation-resistant than previous ones, while minimizing nuclear wastes; the Department of Energy plans to spend several hundred million dollars over the next several years on research and development related to reprocessing in the Advanced Fuel Cycle Initiative, ${ }^{4}$ although the idea of building a large (1500 metric tons of heavy metal per year) aqueous reprocessing plant in the United States around the middle of the next decade has apparently been abandoned. ${ }^{5}$

\subsection{What Is Reprocessing?}

Reprocessing does not eliminate any of the radioactive material in spent fuel — it merely divides that material into several categories (plutonium, uranium, and various types of

option, found a back-end cost twice as high for the reprocessing option as for the direct disposal option. In 2003, a major study from the Massachusetts Institute of Technology (MIT) (in which one of the present authors (Holdren) participated) came to conclusions quite similar to those we reach in this study. See John Deutch and Ernest J. Moniz, co-chairs, The Future of Nuclear Power: An Interdisciplinary MIT Study (Cambridge, MA: Massachusetts Institute of Technology, 2003, available as of December 16, 2003 at http://web.mit.edu/nuclearpower). The MIT study presents its results by considering the cost of reprocessing as part of the cost of preparing plutonium fuel (and the plutonium fuel therefore appears several times as expensive as uranium fuel of equivalent energy value), while we present our results with reprocessing counted as part of the cost of waste management - but this difference in presentation does not affect the contribution of reprocessing and recycling to total electricity cost. (The MIT study's central estimate of the increase in electricity price resulting from use of reprocessing rather than once-through fuel cycles is higher than the one in this study, primarily because they do not assign an extra cost for several decades of dry cask storage of spent fuel for the once-through cycle, as we do.) The RAND corporation also produced a commonly cited study of this subject in the early 1990s: see Brian G. Chow and Kenneth A. Solomon, Limiting the Spread of WeaponsUsable Fissile Materials (Santa Monica, CA: RAND, 1993). A useful summary of statements and studies on this subject from the mid-1990s and before can be found in Ingo Hensing and Walter Schulz, An Economic Comparison of Different Disposal Methods Used by Nuclear Power Plants: A Cost Simulation of Alternative Strategies From the German Point of View Energiewirtschafliches Institute (EWI), University of Cologne (Olenbourg-Vourlag,1995), which also finds significantly higher costs for the reprocessing fuel cycle.

${ }^{3}$ For a typical version of the argument, see James Lake (president of the American Nuclear Society), "Outdated Thinking is Holding Us Back," The Washington Post, May 12, 2001, which asserts that "the economic trade-off is approximately equal" today, and that for the future, reprocessing offers "significant advantages in sustaining low-cost nuclear fuel supplies."

${ }^{4}$ See, for example, U.S. Department of Energy (DOE), FY 2004 Detailed Budget Justifications-Office of Nuclear Energy, Science, and Technology (Washington, D.C.: DOE, February 2003; available as of December 16, 2003 at http://www.mbe.doe.gov/budget/04budget/content/es/nuclear.pdf), p. 18 and p. 45; see also DOE, Office of Nuclear Energy, Science, and Technology, Report to Congress on Advanced Fuel Cycle Initiative: The Future Path for Advanced Spent Fuel Treatment and Transmutation Research (Washington, DC: DOE, January, 2003, available as of December 16, 2003 at http://www.nuclear.gov/reports/AFCI_CongRpt2003.pdf). ${ }^{5}$ Ernest J. Moniz, presentation at the Second Moscow International Conference on Nonproliferation, September 20, 2003, summarizing Deutch and Moniz, co-chairs, The Future of Nuclear Power, op. cit. 
radioactive wastes). In a current-technology reprocessing plant, the spent fuel from nuclear reactors is chopped into pieces and dissolved in boiling nitric acid. The uranium and plutonium in the spent fuel are extracted from this nitric acid solution using organic solvents (typically tributyl phosphate). Since this extraction is accomplished by manipulating the chemical reduction-oxidation (redox) states of the plutonium and uranium ions in solution, this process (the only one that has been operated at commercial scale) is called the Plutonium-Uranium Redox Extraction (Purex) process. ${ }^{6}$

The result is that the original spent fuel is transformed into reprocessed uranium (representing approximately $95 \%$ of the mass of the original fuel material), plutonium (roughly $1 \%$ ), and a nitric acid solution containing the intensely radioactive fission products and other isotopes that make up the remaining $4 \%$ or so of the original spent fuel-a solution known as high-level waste (HLW). In addition, a variety of low-level and intermediate-level wastes (LLW and ILW, some of which are referred to in the U.S. system as transuranic wastes, or TRU) also result from the process. During the processing operation, a small portion of the radioactivity is released into the atmosphere or into liquid wastes from the reprocessing plant - releases which have been the focus of considerable controversies regarding the operation of existing plants.

The liquid HLW from reprocessing must eventually be solidified (usually by mixing it with molten glass, which is then hardened, a process known as vitrification), and is then slated for disposal in a geologic repository, the same destination as is planned for spent fuel in countries where spent fuel is not reprocessed, such as the United States. Despite occasional claims to the contrary, ${ }^{7}$ in traditional reprocessing many of the long-lived isotopes that pose particularly serious threats to the environment and human health remain in the HLW. Hence a repository would have to be designed to contain the material for many millennia, whether the material disposed of was spent fuel or HLW from reprocessing. The ILW from reprocessing also requires isolation in a geologic repository, because of its plutonium content. Substantially modified approaches - currently expected to have still higher costs - would be needed to separate out and recycle the other long-lived isotopes from spent fuel, for possible transmutation in a reactor or in an accelerator-reactor system. (Such concepts for separations and transmutation are discussed in Chapter 3.)

In principle, both the uranium and plutonium separated from spent fuel during reprocessing can be made into new reactor fuel and recycled. In practice, this is done for only a small fraction of the uranium recovered from reprocessing today, because freshly mined uranium is cheap enough that the uranium recovered from reprocessing (which is less

\footnotetext{
${ }^{6}$ For a useful description, see M. Benedict, T.H. Pigford, and H.W. Levi, Nuclear Chemical Engineering, $2^{\text {nd }}$ Ed. (New York, NY: McGraw-Hill, 1981).

${ }^{7}$ For a typical claim that after reprocessing it is only necessary to dispose of "shorter-lived fission products," which can be held in storage designed to last "for a few hundred years," see Lake, "Outdated Thinking is Holding Us Back," op. cit. In reality, expected doses from a nuclear repository over hundreds of thousands of years are dominated by long-lived fission products such as technetium and iodine, which are not removed in traditional reprocessing approaches. For a discussion of the effect of various reprocessing approaches on repository requirements and performance, see U.S. National Research Council, Committee on Separations Technology and Transmutation Systems, Nuclear Wastes: Technologies for Separations and Transmutation (Washington DC: National Academy Press, 1996), Appendix G, "Effects on Repository," pp. 315-353.
} 
desirable because of various isotopes created during irradiation in the reactor, including U234 and U-236) is not competitive for use in fresh fuel. So nearly all of the uranium recovered from reprocessing every year simply remains in storage.

Similarly, a substantial fraction of the plutonium recovered each year from reprocessing also remains in storage. The fabrication of uranium-plutonium mixed-oxide (MOX) fuel from this plutonium and its use in reactors has not kept pace with the continued separation of additional plutonium through more reprocessing. The result is that today, there are more than 200 metric tonnes of separated civilian plutonium in storage around the world. ${ }^{8}$ This separated plutonium, while "reactor-grade," is usable in nuclear weapons (by any state or group capable of making a nuclear weapon with weapon-grade plutonium), ${ }^{9}$ and the current world stock is enough for tens of thousands of nuclear weapons. For this reason, this growing accumulation - which will soon exceed the amount of separated plutonium in all of the world's nuclear weapon stockpiles combined - has been the subject of considerable controversy. Unfortunately, as this report will describe in detail, fabricating fuel from this plutonium is more expensive than making fuel from freshly mined uranium. The use of MOX from reprocessed plutonium has also been the subject of substantial political controversy, focused particularly on safety concerns. These economic and political factors continue to delay the use of MOX fuel in a number of countries, and alternatives such as immobilizing separated plutonium as waste have not yet been adopted. As a result it is not yet clear how or when the large world stockpile of separated plutonium will ultimately be reduced. ${ }^{10}$

Originally, no one intended that the plutonium recovered from reprocessing lightwater reactor (LWR) spent fuel would be recycled as fuel in LWRs. Rather, the nuclear power industry expected that there would be a rapid transition to fast-neutron reactors, which would use this plutonium as their start-up fuel. Commercialization of fast-neutron "breeder" reactors (so-called because they can be configured to produce more plutonium from uranium than they consume in their fuel) has been delayed decades longer than originally expected, however. Therefore, in addition to comparing once-through use of uranium to reprocessing and recycling in light-water reactors, this study will also compare once-through use of uranium fuel in light-water reactors to reprocessing spent fuel and using the plutonium (and, perhaps, other actinides) in future fast-neutron reactors.

\subsection{Data and Sources}

For some industries, reasonably good data on costs and prices are readily available. Data on uranium prices, enrichment prices, and conversion prices, for example, are widely

\footnotetext{
${ }^{8}$ See, for example, David Albright and Mark Gorwitz, "Tracking Civil Plutonium Inventories: End of 1999" (Washington, DC: Institute for Science and International Security, October 2000, available at http://www.isisonline.org/publications/puwatch/puwatch2000.html).

${ }^{9}$ For an authoritative discussion, see U.S. Department of Energy, Office of Arms Control and Nonproliferation, Final Nonproliferation and Arms Control Assessment of Weapons-Usable Fissile Material Storage and Excess Plutonium Disposition Alternatives, Washington DC: DOE/NN-0007, January 1997, pp. 37-39.

${ }^{10}$ See for example, Kevin O'Neill, ed., Addressing Excess Stocks of Civil and Military Plutonium: Proceedings of the December 10, 2001 Conference (Washington, DC: Institute for Science and International Security, 2002, available as of December 16, 2003 at http://www.isis-online.org/publications/2001 civilpu/2001 civilputoc.html).
} 
available from several reliable sources. This is not the case, however, for the reprocessing and MOX fuel fabrication industries. Dominated by a small number of state-owned firms, these industries have maintained strict secrecy over both their costs and their contract prices, in an effort to maintain a variety of commercial advantages.

Data are nevertheless available from several sources, which we have combined in preparing this report. First, some official data on costs associated with specific existing or proposed plants are available, and we have relied on these data where possible. Second, a variety of national or international studies over the years have provided cost estimates based on data provided by the industry, and we have relied heavily on these figures as well. Third, a variety of reported costs have found their way into the nuclear industry trade press, and where particular figures could be confirmed from other sources, we have also made use of these. Finally, we have had the opportunity to review generic, representative cost data prepared by the Nuclear Assurance Corporation (NAC), a major nuclear industry consulting firm, for the Department of Energy, and these figures have been helpful in confirming the estimates available from other sources. ${ }^{11}$

Fortunately, the sensitivity analysis provided in this report demonstrates that our conclusions are robust over a broad range of variations in the input parameters. Even changing the cost of reprocessing or of MOX fuel fabrication by a factor of two, for example, would not make the reprocessing fuel cycle more cost-effective than the once-through cycle under current conditions. Thus differences in estimates from different sources should not have any substantial effect on our conclusions.

Estimating the costs of disposal of spent fuel or high-level nuclear waste poses an even more knotty problem. No repository for spent fuel or high-level waste has yet been completed or operated anywhere in the world. Hard data on real costs are therefore nonexistent, and cost estimates inherently uncertain. Different countries are planning quite different types of repositories with a wide range of capacities, and hence their estimated unit costs (per ton of spent fuel or of solidified high-level waste) vary significantly; the quality and detail of the available estimates also varies. When comparing direct disposal of spent fuel to disposal of the wastes that would result from reprocessing it, one is comparing approaches that generate different volumes of waste, different physical and chemical forms of waste, different rates of heat generation from the wastes, and different degrees (and lifetimes) of the wastes' radiotoxicity. There is only a very modest literature analyzing how these different waste characteristics might affect repository cost. We have done our best with the literature available - focusing primarily on the projected cost for the U.S. repository, which is the one for which the most detailed and consistent cost information is availablebut this is clearly an area for additional research. Fortunately, here, too, even very broad variations in assumptions about the relative cost of disposing of spent fuel vs. disposing of reprocessing wastes do not change the basic conclusions of this study.

\footnotetext{
${ }^{11}$ Geoff Varley and Dan Collier, Fuel Cycle Cost Data (Atlanta, GA: NAC, October 1999). This report was prepared on contract to the U.S. Department of Energy, and while it includes no proprietary information on costs or prices at existing reprocessing or plutonium fuel fabrication plants, the compilation of available data it does contain is proprietary to NAC; hence the report is not publicly available.
} 


\subsection{Cost vs. Price}

In the classic model of a fully competitive market, the cost of providing a good or service and its market price are very closely related. The price is simply the long-run marginal cost of providing the good or service plus a rate of profit similar to what could be made by taking similar risks elsewhere in the economy. If the market price rises to a higher level, this will create opportunities for unusually high profits that will lead more producers to enter the market, and the resulting competition will drive the price back down to the competitive level. If the market price is below marginal cost plus a competitive profit, producers will choose to produce other, more profitable goods and services, and the decline in supply will drive the price back up again.

Few nuclear markets, however, match this classic competitive equilibrium model particularly well. The uranium and enrichment markets match the model at least slightly better than some of the other nuclear markets, in that competition in these markets is sufficiently intense that no producer can afford to charge greatly more than its costs for very long. Hence, in this report we will rely on price data for these elements of the nuclear fuel cycle, rather than attempting to separately assess the underlying costs of providing these goods and services.

The reprocessing and MOX fabrication industries, however, have been dominated by an oligopoly of only two or three firms, which have set prices that may in some cases be quite different from real long-run marginal costs. Originally, they were able to set reprocessing prices at levels above the full capital plus operating cost of reprocessing, because customer utilities faced government requirements to reprocess and had no other choice. Today, by contrast, with the capital costs of the reprocessing plants already paid for, they are able to set prices at levels that reflect only operating cost, future capital and decommissioning costs, and profit - and are therefore below a realistic estimate of the full cost of providing the reprocessing service. (These paid-off plants will not last forever, however, and if reprocessing were to continue, prices would have to rise to levels that would pay for both capital and operating costs for new plants to replace the existing facilities.) Thus, the fact that one of these services is being offered at a particular price does not in itself demonstrate that its full cost must be at that price or below-a common misconception. Hence, in this report, with respect to reprocessing and MOX fabrication, we will attempt to estimate both the cost to provide the service and the prices that have been charged in recent times for providing the service. As discussed below, what it actually costs to provide the service depends not only on the capital and operating costs of the plant, but on who owns it and what rate of return the investors who provided the money to build the plant expect to receive.

Similarly, we have focused on underlying cost rather than market price for the cost of waste disposal, as there is no market for this service as yet. In most countries, geologic disposal of nuclear waste is to be done either by the government or by a company owned by 
the generators of the waste, and hence one would expect that it would be done at cost or close to it.

\subsection{Currency Conversion}

The nuclear fuel markets are effectively global — and thus costs are reported in a wide range of currencies. Converting these estimates to dollars inevitably introduces some uncertainty, as currency fluctuations can easily change the apparent cost of a facility or the price of a contract (when that cost is converted into dollars) by 20 percent or more, with no underlying change in its real cost within the economy in which the cost was paid. In addition, costs that were incurred or reported at different times must be converted to the dollars of a particular year for fair comparison, to take account of inflation that has taken place in the interim.

In this study, the method we use is to convert estimates originally expressed in foreign currency to dollars using exchange rates prevailing at the time the estimate was made, and then inflate the resulting dollar estimates to 2003 dollars using U.S. GDP deflators. We use a three-year average of the currency exchange rate, centered on the year when the estimate was made, to smooth the effect of currency fluctuations somewhat. ${ }^{12}$

\subsection{Cost of Money, Discount Rate, and Taxes}

Estimates of the costs of services provided from large capital facilities (such as reprocessing plants or MOX fuel fabrication facilities - or power plants, for that matter) must take into account the cost of paying back the money used to build the plant, and providing a return on that investment. ${ }^{13}$ The amount of money needed to pay these capital costs, the operating costs, and other costs of the plant is known as the "revenue requirement"; the price

\footnotetext{
${ }^{12}$ The World Bank also uses a three-year average approach for converting estimates of costs from different currencies, but uses a complex formula known as Atlas that adjusts for changes in inflation and growth in the two economies being compared over the three years. (A discussion of the method was available as of December 16, 2003 at http://www.worldbank.org/data/working/working-meth.html.) For the purposes of this paper, the small possible increase in accuracy from using this method is not worth the large increase in complexity. Another possibility would be to use purchasing power parity (PPP) exchange rates, developed to reflect the actual cost of buying a typical basket of goods within different economies. (For a discussion of PPP rates and their uses, see, for example, OECD, "PPP Frequently Asked Questions," available at http://www.oecd.org/oecd/pages/home/displaygeneral/0,3380,EN-faq-513-15-no-no-322-513,FF.html.) We have chosen to use currency exchange rates rather than PPP rates in this study because (a) nuclear fuel services are internationally traded on a global basis, requiring frequent use of different currencies traded at market rates; (b) the basket of goods compared to produce PPP estimates is not appropriate for judging the costs of the large technical facilities considered in this paper; and (c) essentially all other nuclear fuel cycle cost estimates of which we are aware use currency exchange rates rather than PPP. The use of PPP rates rather than currency exchange rates would have the effect of significantly reducing the very high cost estimates for the Japanese reprocessing plant at Rokkasho-mura (though these would remain much higher than the costs of other comparable plants). Estimates of the cost of European facilities and services would also be reduced, but more modestly.

${ }^{13}$ See relevant equations in Appendix A.
} 
of the service provided by the plant must be set high enough to meet the revenue requirement.

The return that lenders and investors will demand depends on the risk of the projectand thus the revenue requirement and the minimum price that can be charged for the service depend on the risk as well. For a government-owned facility, money can be borrowed at an effectively risk-free rate (we use $4 \%$ above inflation in this study). ${ }^{14}$ A facility owned by a regulated utility with a rate of return effectively guaranteed by government regulators (or a group of such utilities) also represents a relatively low-risk investment, though the risk (and the resulting rate that lenders and stock investors will demand) would be higher than for government borrowing. ${ }^{15}$ A private venture subject to the whims of the competitive market, by contrast, would represent a significantly higher risk, and would have to offer still higher rates of return to lenders and investors to raise funds on commercial markets. ${ }^{16}$ Thus,

\footnotetext{
${ }^{14}$ For the United States, official instructions for discounting for government-financed programs can be found at Office of Management and Budget, "Guidelines and Discount Rates for Benefit-Cost Analysis of Federal Programs," Circular A-94, October 29, 1992, available as of December 16, 2003 at http://www.whitehouse.gov/omb/circulars/a094/a094.html. This document points out that government investments use funds that would otherwise have been available for private investments, and therefore recommends that for all projects that have an impact in the private sector or on the public (a category that certainly includes processing of spent nuclear fuel), a 7\% real discount rate be used, which it says "approximates the marginal pretax rate of return on an average investment in the private sector in recent years." Only for "internal" government investments, designed purely to increase government revenue or decrease government expenses (such as the purchase of a more energy-efficient government building) does it allow the use of a rate based on the real rate of return on U.S. government bonds (that is, the government's cost of borrowing). Nevertheless, we use a rate based on the government bond rate here, to distinguish the government-financed case more clearly from the privately-financed case. The bond rates to be used for such discounting are updated every year (see Office of Management and Budget, "OMB Circular No. A-94: Appendix C: Discount Rates for Cost Effectiveness, Lease-Purchase, and Related Analyses," updated February 2003, available as of December 16, 2003 at http://www.whitehouse.gov/omb/circulars/a094/a94 appx-c.html); while the real rate recommended for projects of 30 years or more duration in February, 2003, was 3.2\%, noticeably less than the figure we use, the rate recommended the previous year was $3.9 \%$, very close to our government rate. A tabulation of the government rates recommended for use in such discounting over the years was available as of December 16, 2003 at http://www.whitehouse.gov/omb/circulars/a094/DISCHIST-2003.pdf. ${ }^{15}$ In this study, we use the peer-reviewed estimates for financing arrangements in NAS, Nuclear Wastes: Technologies for Separations and Transmutation, op. cit., Appendix J, "Fuel Reprocessing Economics," pp. 413-446. For regulated utilities, this means facilities financed with $46 \%$ debt, $8 \%$ preferred stock, and $46 \%$ common stock, with real-dollar returns of $4.8 \%$ per year on debt, $4.1 \%$ on preferred stock, and $8.5 \%$ on common stock. With an income tax rate of $38 \%$, a tax depreciation period of 15 years, and a total facility life of 30 years, and with $2 \%$ per year added for property taxes and insurance, this leads to a fixed charge rate- the fraction of the initial capital requirement that has to be paid each year to cover taxes, interest on debt, and return to equity investors - of $12.3 \%$. See discussion and relevant equations in Appendix A. This rate is actually somewhat lower than the rates the Electric Power Research Institute (EPRI) recommends for regulated utilities: EPRI envisions a real debt rate of $5.8 \%$, a preferred stock rate of $5.3 \%$, and a common stock rate of $8.7 \%$. See Technical Assessment Guide: Volume 3, Revision 8: Fundamentals and Methods - Electricity Supply, TR100281-V3R8 (Palo Alto, CA: EPRI, 1999). The authors are grateful to George Booras of EPRI for discussions of these topics.

${ }^{16}$ For this unregulated case, NAS, Nuclear Wastes: Technologies for Separations and Transmutation, op. cit., Appendix J, "Fuel Reprocessing Economics," pp. 413-446 assumes 70\% common stock financing and 30\% debt, with a $9.0 \%$ real annual interest on debt and a $16.0 \%$ annual return on stock. With the same assumptions on taxes and life of the facility, this leads to an annual fixed charge rate of $20.8 \%$. See discussion in Appendix A. These are described as financing arrangements typical of large chemical facilities, and therefore do not
} 
following the approach taken by the Committee on Separations Technology and Transmutation Systems of the National Research Council, ${ }^{17}$ we will take these three types of entities (government, regulated utility, and private venture) as representative of the spectrum of possible financing approaches for facilities of this type, and estimate what the costs of reprocessing, MOX fabrication, and reactor-generated electricity would be for plants built and owned by each of these three.

Of course, actual financing arrangements for specific plants will differ from the representative cases we discuss here. The French UP3 reprocessing plant at La Hague and the British Thermal Oxide Reprocessing Plant (THORP) at Sellafield were both built with unique financing arrangements in which the customers paid the capital costs of the plants through pay-ahead contracts - meaning that the reprocessors themselves put very little of their own capital at risk and paid essentially no return on the capital invested in the plants. This was only possible because foreign utilities faced legal requirements to reprocess their spent fuel and no one else was offering the service. This seller's market for reprocessing services has disappeared, and such financing arrangements are therefore not likely to be repeated. (The same firms, for example, were unable to obtain similar financing arrangements for the construction of their MOX fuel fabrication facilities.) Similarly, the firm building the Japanese reprocessing plant at Rokkasho-mura is largely (though not entirely) owned by the utilities that will make use of its services, who face a combination of legal and political requirements to get the spent fuel out of the spent fuel pools at their reactors: while the financing arrangements for this plant remain confidential, it seems likely that the return on investment the utility owners expect is the solution of their spent fuel problems, not a profitable financial rate of return (and public estimates of the cost of reprocessing at this facility make no allowance for any return on investment). Here, too, however, with the increasing availability of dry cask storage, it appears unlikely that such a favorable financing package could be structured again in the future. ${ }^{18}$

Taxes are another important difference between government-owned and private facilities. Privately owned facilities must provide sufficient revenue to pay both corporate

reflect the unique political risks to investors that would be associated with building a privately financed reprocessing plant in the United States, or in most other developed countries.

${ }^{17}$ NAS, Nuclear Wastes: Technologies for Separations and Transmutation, op. cit., Appendix J, "Fuel Reprocessing Economics," pp. 413-446.

${ }^{18}$ One way of conceptualizing such pay-ahead contracts with a zero rate of return is to consider that the utilities are effectively treating the cost of reprocessing (including the capital cost of building the necessary plant) as an ordinary fuel expense, much like purchasing uranium - though in this case an expense incurred long before the service is actually used. The money for these pay-ahead contracts would have to come from somewhere either from (a) the utility being allowed to charge higher electricity rates to cover the cost (in the case of a regulated utility whose rates are set by the government); (b) utility borrowing (or, equivalently, paying off existing debts at a reduced rate), or (c) reduced returns to the utility's equity investors (for example, a reduction in dividend payments). Thus, while the cost of money might be zero from the point of view of the firm building the reprocessing plant for the utilities, a proper accounting from the point of view of the utilities even in that case would assign a cost of money at least as high as the rate at which the utility could borrow funds, and possibly as high as the average investors' discount rates. If reprocessing were analyzed on the assumption that the facility would be built with pay-ahead contracts paid for through utility borrowing, the resulting effective reprocessing price would be intermediate between the government case and the regulated utility case considered in this study. If the facility were paid for through a combination of utility borrowing and reduced returns to investors, the result would be effectively the same as the regulated utility case used in this study. 
income taxes and property taxes, as well as providing a competitive return to lenders and investors, while government-owned facilities are not subject to tax. This can make an enormous difference in the capital component of cost: if $\$ 100$ million a year is needed to pay investors, and the tax rate is $33 \%$, then $\$ 150$ million in revenue will be needed to pay taxes and still have enough left over to pay the investors-increasing the capital contribution to the price by $50 \%$ compared to what it would be with no taxes. The costs of property taxes are smaller, but still significant - and private firms typically have to pay insurance costs as well, while the government insures itself.

As we will show, the effect of these differences can be surprisingly large. For a reprocessing plant with the same capacity and costs as THORP, for example, the minimum price in a government-owned case (making reasonable assumptions for such matters as time to build and start-up costs) would be in the range of $\$ 1350$ per kilogram of spent fuel reprocessed. Ownership by a regulated utility paying taxes and higher rates to lenders and investors would put the total over $\$ 2000 / \mathrm{kgHM}$, and ownership by a private venture with no guaranteed rate of return would add more than $\$ 1000$ beyond that. ${ }^{19}$

Estimating how much must be set aside today to finance future obligations that there is a legal requirement to meet-such as funds for disposal of nuclear wastes or for decommissioning nuclear facilities_ - poses a somewhat different problem. In this case, rather than using the rates one would have to offer investors to finance a commercially risky new facility, one must use "risk free" rates - the rates of return that could be earned by effectively guaranteed investments, such as U.S. government bonds-because there is a legal obligation to ensure that the money will be there when the time comes. (Many analyses make the mistake of using one discount rate for these quite different situations.) In this study, we will use a rate of $3 \%$ above inflation (representing the U.S. government bond rate) for this risk-free discount rate. Indeed, while one can have good confidence that such investments will continue to provide the expected rate of return over the time required if that time is several decades, if the time involved is measured in centuries, then both the confidence in the investments and the uncertainties in estimating the future costs grow substantially. For this reason, and because of arguments related to inter-generational equity, a number of analysts argue that a zero discount rate should be used for times beyond a single generation. ${ }^{20}$ We will not use this zero discount rate in this report; if we did, the costs of reprocessing and MOX fabrication would increase (because the long-term costs of decommissioning these facilities would not be discounted) and the costs of geologic repositories would also increase (because the costs of operations at these facilities during the long times they will remain open would also not be discounted).

\subsection{Real vs. Nominal Dollars}

\footnotetext{
${ }^{19}$ See discussion in Chapter 2.

${ }^{20}$ For a useful discussion, see Charpin, Dessus, and Pellat, Economic Forecast Study of the Nuclear Power Option, op. cit. Appendix 8, "The Choice of a Discount Rate."
} 
Inflation is a fact of life in most economies - and it makes a substantial difference when thinking about the costs and revenues of facilities that may take a decade to build and may operate for thirty years or more.

There are two methods for presenting economic estimates in such situations - using the actual number of dollars that will be spent or received in a given year, without adjusting for the fact that those dollars in the future will each buy less than a dollar does today (socalled "nominal" or "then-year" dollars), or adjusting for the effects of inflation so that all dollar values are quoted in the dollars of a particular year, and can be directly compared against each other (so-called "constant" or "real" dollars). In this report, all estimates of costs and prices are in constant 2003 dollars.

\subsection{Plan of the Report}

In the remainder of this report, we proceed as follows. In Chapter 2, we provide an analysis comparing the costs of reprocessing and recycling vs. those of direct disposal in existing light-water reactors, using central estimates and estimated ranges for the costs of the various elements of the fuel cycle. This section answers the question: "if these central estimates and ranges are correct, how expensive would uranium have to become before reprocessing became economic, at various reprocessing prices?" The reverse (but equivalent) way of posing the question is: "how cheap would reprocessing have to get to be economic, over a range of possible future uranium prices?" We also analyze the contribution of the back end of the fuel cycle to electricity cost for both approaches, at various reprocessing and uranium prices. We then outline the reasons behind each of our cost estimates for the input parameters for the calculation, assessing both current prices and the likelihood of substantial and long-lasting changes in the future (either upward or downward).

In Chapter 3, we take the same approach for comparing the economics of LEU-fueled light-water reactors with direct disposal of spent fuel, to future fast-neutron breeder reactors with reprocessing and complete recycling of the recovered plutonium and uranium (and, perhaps, other actinides). Here a very important (and uncertain) factor is the future differential in capital cost between breeder reactors (which have traditionally been expected to have higher capital costs) and light-water reactors. This section answers the question: "how expensive would uranium have to become before building and operating plutoniumfueled breeder reactors became economic, at various capital costs for these plants?"-or, equivalently, "how much would the capital costs of breeders have to be reduced before they could offer a future energy alternative that was economically competitive with once-through use of uranium fuel in light-water reactors?" Chapter 3 also briefly discusses possible future fast-neutron systems built more for the purpose of transmutation of wastes than for breeding additional nuclear fuel.

In Chapter 4 we briefly outline the conclusions we draw from these analyses. Appendix A provides a complete description and derivation of the equations used in these analyses, while Appendix B discusses estimates of the quantity of uranium likely to be recoverable worldwide at various possible future prices. 



\section{Direct Disposal vs. Reprocessing and Recycling in Thermal Reactors}

\subsection{How to Compare Costs of Different Fuel Cycles}

A valid comparison of the costs of direct disposal of spent nuclear fuel to those of reprocessing and recycle requires a full life-cycle cost assessment for each route, not just an assessment of the costs of individual services. One cannot simply compare, for example, the cost of reprocessing to the cost of direct disposal, for this ignores other costs for both fuel cycles (as well as the potential value of the uranium and plutonium recovered by reprocessing). In short, the right question is: what are the full costs that a reactor operator making a decision between reprocessing and recycling the spent fuel from a light-water reactor or disposing of it directly could expect to face on each route?

On the reprocessing route, the reactor operator will have to pay the costs of: (a) transporting the fuel to the reprocessing plant; (b) reprocessing; and (c) conditioning and disposal of the high-level, intermediate-level, and low-level wastes from reprocessing. The operator will then have available plutonium and uranium recovered from reprocessing, which can be used as fuel (once the costs of fabricating the plutonium into mixed-oxide (MOX) fuel and of enrichment and fabrication of the recovered uranium are paid). There may also be other costs associated with using these materials as fuel, such as the costs of transporting and safeguarding MOX fuel, licensing MOX use in reactors, changes in burnup strategy that may be required if the MOX is not licensed to go to as high burnups as LEU fuel, and so on.

On the direct disposal route, the reactor operator will have to pay the costs of: (a) interim storage of the spent fuel pending geologic disposal, (b) eventual transport to a repository site, and (c) encapsulation, conditioning, and disposal of the spent fuel. In addition, the operator in this case must continue to pay the cost of fueling the entire reactor core with fresh fuel (including the costs of natural uranium, enrichment services, and lowenriched uranium (LEU) fuel fabrication), rather than being able to replace some of it with plutonium and uranium recovered from reprocessing.

In general, if reprocessing and MOX fabrication prices are low, uranium and enrichment prices are high, and if the storage, encapsulation, and geologic disposal of the vitrified HLW from spent fuel would be significantly cheaper than storage, encapsulation and geologic disposal of the spent fuel itself, then the reprocessing-recycle option will be cheaper than the direct-disposal option. If reprocessing and MOX fabrication prices are high, the costs of waste disposal for the two approaches are similar, and uranium and enrichment costs are low, it will be cheaper to pursue the direct-disposal route. The value of the plutonium and uranium recovered by reprocessing - which needs to be high enough to make up for the extra cost of reprocessing - increases as the price of natural uranium increases, since the value of these recovered materials results from their potential to displace fuel that would be made from natural uranium. The price of uranium at which the net present cost of the two fuel cycles is exactly equal is the "breakeven" price, represented notionally by the following equation:

$$
\left[\begin{array}{c}
\text { cost of interim storage } \\
\& \text { disposal of spent fuel }
\end{array}\right]=\left[\begin{array}{c}
\text { cost of reprocessing } \\
\& \text { disposal of wastes }
\end{array}\right]-\left[\begin{array}{c}
\text { value of recovered } \\
\text { plutonium } \& \text { uranium }
\end{array}\right]
$$


If the uranium price is below the breakeven price, direct disposal is cheaper; if it is above the breakeven price, reprocessing and recycling is cheaper.

The terms on the left-hand side of equation (2.1), for interim storage and disposal of spent fuel, are simply the costs of particular services, whose costs are discussed in detail below (see sections 2.5.3-5). The same is true for the cost of reprocessing and the cost of disposal of reprocessing wastes, which is represented by the first set of brackets of the righthand side of the equation.

Matters become more complex for the right-most term of equation (2.1), as the value of the recovered plutonium and uranium depends on a wide range of factors. The value of the recovered plutonium and uranium is the value of the fuels that can be made from them minus the costs of making and using these fuels. Because the fuels made with recovered plutonium and uranium would substitute for LEU fuels made using natural uranium, their value is determined by the price of equivalent LEU fuel (i.e., fuel with the same design burnup). Thus the value of these recovered materials can be represented by:

$$
\left[\begin{array}{c}
\text { value of recovered } \\
\text { plutonium \& uranium }
\end{array}\right]=\left[\begin{array}{c}
\text { cost of LEU fuel made } \\
\text { with natural uranium }
\end{array}\right]-\left[\begin{array}{c}
\text { cost of equivalent fuel made } \\
\text { with recovered Pu \& U }
\end{array}\right]
$$

Consider a concrete (though simplified) example. Imagine that a utility is considering whether to reprocess a load of spent fuel from its reactor or place it in interim storage pending eventual direct disposal. The utility estimates that the present value of the cost of storing the material until a repository is ready (that is, the amount of money that must be paid today to get the job done for the entire period) is $\$ 200$ per kilogram of heavy metal (kgHM) in the spent fuel, and the present value of the cost of direct disposal, including transport to the repository site and encapsulation, is $\$ 400 / \mathrm{kgHM}$. (Our estimates for the prices of various fuel cycle services are discussed in detail later in this study; the numbers in this paragraph are round figures intended only for illustrative purposes.) The utility estimates the cost of reprocessing the spent fuel at $\$ 1000 / \mathrm{kgHM}$, and the present value of the cost of eventually disposing of the radioactive wastes from reprocessing at $\$ 200 / \mathrm{kgHM}$ - less than the cost of direct disposal, but not by any means enough less to pay for the cost of reprocessing. So the total cost on the direct disposal route is $\$ 600 / \mathrm{kgHM}$, while that on the reprocessing route is $\$ 1200 / \mathrm{kgHM}-\$ 600 / \mathrm{kgHM}$ more. Hence, in this case reprocessing would begin to make economic sense when the value of the plutonium and uranium recovered from the reprocessing was $\$ 600 / \mathrm{kgHM}$ or more.

How much would this recovered plutonium and uranium be worth? For the rough purposes of illustration, we can assume that $1 \%$ of the spent fuel- -10 grams of every kilogram - is plutonium and 95\% is uranium (with the remaining $4 \%$ being radioactive fission products and minor actinides). Let us assume that the uranium is worth the same amount as fresh natural uranium (as discussed below, this is not the case, because of the buildup of undesirable uranium isotopes during irradiation, but this is not important for the illustrative purposes of this discussion). If the utility estimates that the uranium price is $\$ 50 / \mathrm{kg}$, then the uranium recovered from reprocessing a kilogram of spent fuel will be worth about $\$ 48$. 
Estimating the value of the recovered plutonium requires a bit more work. To make fuel from the plutonium equivalent in energy content to typical LEU fuel, roughly 6 kilograms of fuel would have to be reprocessed for every kilogram of fresh fuel fabricated. The utility estimates that fabricating each kilogram of fresh plutonium fuel (after mixing the plutonium oxide with uranium oxide to form a mixed oxide, or MOX) would cost $\$ 1500$. Each such kilogram of plutonium fuel could replace a kilogram of LEU fuel, whose costs include the cost of the natural uranium that goes into making it (let us say 7 kilograms, for this example, at $\$ 50 / \mathrm{kg}$ ), the cost of converting that uranium from the form in which it is mined to the form in which it is enriched ( 7 kilograms again, at a cost the utility estimates at $\$ 5 / \mathrm{kg}$ ), the cost of enriching it to a level usable in the reactor (6 separative work units, or SWU- the unit by which enrichment work is measured, at a cost the utility estimates at $\$ 100 / \mathrm{SWU})$, and the cost of fabrication, about $\$ 250 / \mathrm{kg}$ :

\begin{tabular}{lrr} 
Uranium & $7 \mathrm{~kg} @ \$ 50 / \mathrm{kg}$ & $\$ 350$ \\
Conversion & $7 \mathrm{~kg} @ \$ 5 / \mathrm{kg}$ & $\$ 35$ \\
Enrichment & $6 \mathrm{SWU} @ \$ 100 / \mathrm{SWU}$ & $\$ 600$ \\
Fabrication & $1 \mathrm{~kg} @ \$ 200 / \mathrm{kg}$ & $\$ 250$ \\
\hline Total & & $\$ 1235$
\end{tabular}

Unfortunately for the utility, at these prices the recovered plutonium not only will not provide enough value to pay the extra cost of reprocessing, it poses an additional liability, since making fuel from it costs $\$ 1500$ and the fuel the plutonium fuel replaces costs less than $\$ 1300$. In this simplified case, if all other prices stayed the same, the uranium price would have to increase to $\$ 88 / \mathrm{kg}$ before the plutonium would have any value at all. The total value of the recovered uranium and plutonium in this simplified case, as a function of the price of uranium, $C_{u}$, is:

$$
\begin{aligned}
{\left[\begin{array}{c}
\text { value of recovered } \\
\text { uranium \& plutonium }
\end{array}\right] } & =\left[\begin{array}{c}
\text { value of recovered } \\
\text { uranium }
\end{array}\right]+\left[\begin{array}{c}
\text { value of recovered } \\
\text { plutonium }
\end{array}\right] \\
& =0.95 C_{u}+\left[\frac{(\text { cost of LEU })-(\text { cost of MOX })}{6}\right] \\
& =0.95 C_{u}+\left[\frac{\left(7 C_{u}+885\right)-1500}{6}\right] \\
& =2.12 C_{u}-102.5
\end{aligned}
$$


Substituting this into equation (2.1), we have

$\left[\begin{array}{c}\text { cost of interim storage } \& \\ \text { disposal of spent fuel }\end{array}\right]=\left[\begin{array}{c}\text { cost of reprocessing } \\ \& \text { disposal of wastes }\end{array}\right]-\left[\begin{array}{c}\text { value of recovered } \\ \text { uranium \& plutonium }\end{array}\right]$

$$
\begin{aligned}
{[600] } & =[1200]-\left[2.12 C_{u}-102.5\right] \\
2.12 C_{u} & =702.5 \\
C_{u} & =332
\end{aligned}
$$

In this simplified case, the uranium price would have to rise to over $\$ 330 / \mathrm{kg}$ - roughly ten times current prices, a price no one realistically expects to see for many decades - before the value of the recovered plutonium and uranium would be sufficient to cover the $\$ 600$ extra cost of the reprocessing approach. This would be the "breakeven" uranium price at which reprocessing would be economically competitive with direct disposal.

Of course, there are a wide variety of economic factors a complete calculation has to take into account that are not included in this simple illustration-carrying charges on the cost of the material during its processing and use, changes in the quantities of uranium and enrichment work that would be used to produce each kilogram of LEU as the uranium price increased, the isotopic composition of the uranium and plutonium recovered from reprocessing and the resulting plutonium concentrations or uranium enrichment levels required to achieve given burnups, and so on. The equations we have used in this study, which take these other factors into account, are explained and derived in Appendix A. ${ }^{21}$

Rather than holding other prices constant and varying the uranium price until the costs of the two fuel cycles are equal, it is also possible to hold the uranium price constant and find the "breakeven" price for some other commodity or service-for example, how low the price of reprocessing would have to go for reprocessing and recycle to be economic at a particular uranium price. In the simplified case we just examined, if the uranium price is $\$ 50 / \mathrm{kg}$, and all the remaining prices remain the same, the reprocessing price would have to be reduced from $\$ 1000$ to roughly $\$ 400 / \mathrm{kgHM}$ before reprocessing would be economically competitive. Like a uranium price of $\$ 350 / \mathrm{kg}$, a total reprocessing cost (including pay-back of reprocessing plant capital) of $\$ 400 / \mathrm{kgHM}$ is not likely to be seen for a very long time to come.

Another way to analyze the problem, besides considering such "breakeven" prices, is to consider the total contribution to electricity price from each of the two fuel cycles, for given sets of estimates of the costs of the various services and commodities concerned. This answers the question: how much extra electricity cost is incurred by choosing one fuel cycle rather than another? In this case, the costs on each side of Equation (2.1) are simply

\footnotetext{
${ }^{21}$ In the interests of openness and reproducibility, we have made the Excel file in which we have implemented these equations available on the internet, at http://www.puaf.umd.edu/faculty/papers/fetter/publications.htm. Anyone with an interest in doing so can review the equations, input their own assumptions about the cost of different elements of the fuel cycle, and come to their own conclusions.
} 
converted into dollars per kilowatt-hour of electricity produced. (The specific equations used for calculating the contribution to electricity cost are also explained in detail in Appendix A.)

In the remainder of this chapter, we will (a) show the breakeven uranium price as a function of the cost of reprocessing, for a given set of central, high, and low estimates of the costs of other parameters; (b) provide an analysis of the sensitivity of that result to the various different cost parameters of the fuel cycle; (c) show the contribution of each fuel cycle to the cost of electricity, again as a function of reprocessing price, for the same set of parameters; (d) analyze the sensitivity of the cost of electricity to changes in selected input cost parameters; and (e) justify our estimates of the prices of all the various parameters involved, with discussions of near-term price projections and their possible longer-term evolution.

\subsection{Calculating Breakeven Prices}

Figure 2.1 plots the breakeven uranium price as a function of the price of reprocessing (including transportation of fuel to the reprocessing plant, short-term storage of spent fuel and plutonium, treatment and disposal of low- and intermediate-level wastes, and interim storage of HLW). Table 2.1 displays our central estimates of various parameters in the calculation, as well as estimates that reflect best and worst cases for reprocessing:

(a) the cost savings from geologic disposal of reprocessing wastes compared to geological disposal of spent fuel ( $\$ / \mathrm{kgHM}$ of original spent fuel);

(b) the cost of fabricating MOX fuel ( $\$ / \mathrm{kgHM}$ of MOX fuel);

(c) the cost of interim storage of spent fuel pending ultimate disposal on the direct disposal route $(\$ / \mathrm{kgHM})$;

(d) the price of enrichment (dollars per separative work unit, \$/SWU);

(e) the burnup of the spent fuel being reprocessed and of the fresh fuel to be produced (thermal megawatt-days per kilogram of heavy metal, $\mathrm{MW}_{\mathrm{t}} / \mathrm{kgHM}$ );

(f) whether or not the enrichment work is done using laser isotope separation, which would make it possible to remove the undesirable isotopes from the uranium recovered from reprocessing without extra work;

(g) the discount rate used for the carrying charges $(\% / y)$;

(h) the price of LEU fuel fabrication $(\$ / \mathrm{kgHM})$;

(i) the premiums charged for conversion, enrichment, and fabrication of recovered uranium rather than natural uranium $(\$ / \mathrm{kgU}, \$ / \mathrm{SWU}, \$ / \mathrm{kgHM})$; and

(j) the price of uranium conversion $(\$ / \mathrm{kgU})$. 
Figure 2.1. Breakeven uranium price as a function of the cost of reprocessing, for various sets of assumptions about the cost of other fuel-cycle services.

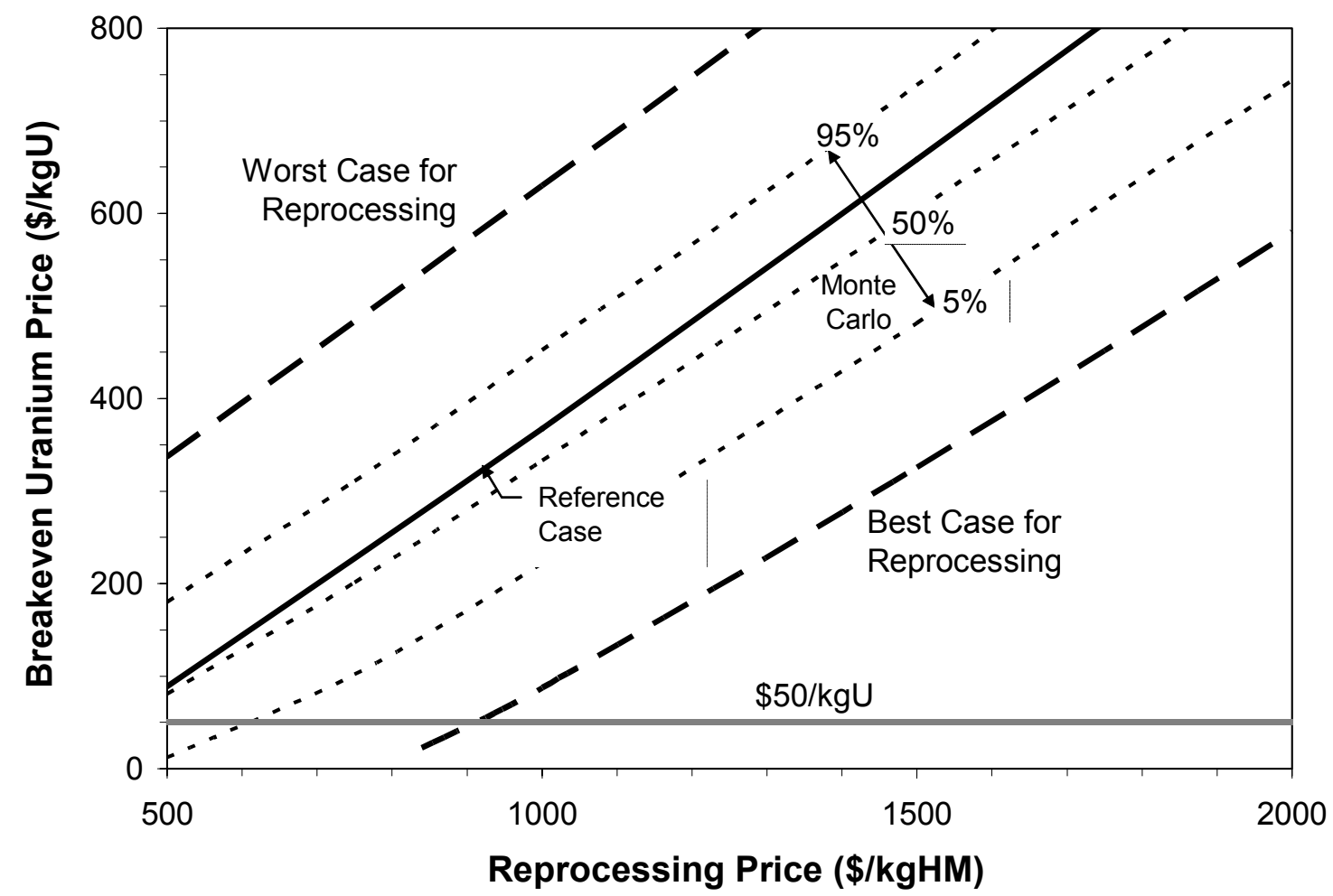

The estimates for these parameters we have used are based on a review of the recent literature; current prices and projections for the future, with sources for these figures, are described in more detail in a subsequent section of this chapter. ${ }^{22}$

The solid central line in figure 2.1 shows the breakeven uranium price as a function of the price of reprocessing, using the central estimates given in table 2.1 for other fuel-cycle prices and parameters. The dotted lines labeled "Monte Carlo" show the result of a simulation in which the values of other parameters are selected randomly from independent normal distributions with $5^{\text {th }}$ and $95^{\text {th }}$ percentiles defined by the values given in table 2.1 for the best and worst case for reprocessing. (This is a very rough estimate of the uncertainty in

\footnotetext{
${ }^{22}$ We have not included explicitly charges for the various transportation steps included in the fuel cycleranging from transportation of uranium from the mine to the mill and from there to the conversion facility to transportation of spent fuel to a reprocessing plant or a permanent repository-instead incorporating these into our estimates of the prices of the individual services. Hence, the reprocessing cost estimate includes transport to the reprocessing plant, and the estimate of the difference in disposal cost between disposing of spent fuel and disposing of reprocessing wastes includes differences in the cost of transporting these materials to their final repositories.
} 
the calculation, since there is no formal justification for assuming independent normal distributions for each parameter.) The outer dashed lines on the figure represent the result of setting all of the parameters equal to those we estimated as either the best case for reprocessing or the worst case for reprocessing.

Table 2.1. Estimates of fuel-cycle costs (2003 dollars) and other parameters and sensitivity analysis for the breakeven uranium price for a reprocessing price of $\$ 1000 / \mathrm{kgHM}$.

\begin{tabular}{|c|c|c|c|c|c|c|}
\hline \multirow[b]{2}{*}{ Parameter } & \multicolumn{3}{|c|}{ Parameter Value* } & \multicolumn{2}{|c|}{$\begin{array}{l}\text { Breakeven U price } \\
\text { (central }=\$ 368 / \mathrm{kgU})\end{array}$} & \multirow{2}{*}{$\begin{array}{l}\text { change } \\
\text { compared } \\
\text { to central }\end{array}$} \\
\hline & low & central & high & low & high & \\
\hline Disposal cost diff. (\$/kgHM) & 300 & 200 & 100 & 298 & 438 & \pm 70 \\
\hline MOX fuel fabrication ( $\$ / \mathrm{kgHM})$ & 700 & 1500 & 2300 & 302 & 434 & \pm 66 \\
\hline Interim fuel storage ( $\$ / \mathrm{kgHM})$ & 300 & 200 & 100 & 310 & 425 & \pm 57 \\
\hline Enrichment (\$/SWU) & 150 & 100 & 50 & 338 & 404 & $\begin{array}{l}-29 \\
+36\end{array}$ \\
\hline Spent-fuel burnup (MWd/kgHM) & 33 & 43 & 43 & 313 & 368 & -54 \\
\hline Fresh-fuel burnup (MWd/kgHM) & 53 & 43 & 43 & 350 & 368 & -18 \\
\hline Laser enrichment & Yes & No & No & 329 & 368 & -39 \\
\hline Discount rate $(\% / y$, real $)$ & 8 & 5 & 2 & 353 & 380 & $\begin{array}{l}-15 \\
+13\end{array}$ \\
\hline LEU fuel fabrication $(\$ / \mathrm{kgHM})$ & 350 & 250 & 150 & 359 & 376 & \pm 8 \\
\hline \multicolumn{7}{|l|}{ Premium for recovered uranium } \\
\hline Conversion $(\$ / \mathrm{kgU})$ & 5 & 15 & 25 & 362 & 373 & \pm 5 \\
\hline Enrichment (\$/SWU) & 0 & 5 & 10 & 364 & 371 & \pm 3 \\
\hline Fuel fabrication (\$/kgHM) & 0 & 10 & 20 & 367 & 369 & \pm 1 \\
\hline Conversion $(\$ / \mathrm{kgU})$ & 8 & 6 & 4 & 367 & 639 & \pm 1 \\
\hline
\end{tabular}

"low = best case for reprocessing, high = worst case for reprocessing

As can be seen, including the additional complications of a full calculation leads to a result similar to the illustrative calculations provided above. At the same $\$ 1000 / \mathrm{kgHM}$ reprocessing price considered in the illustration, the breakeven uranium price is about $\$ 370 / \mathrm{kgU}$ for our central estimates of the other parameters. Again, this is a price far higher than any likely to be seen for many decades to come. Even the 5\% boundary of the Monte Carlo simulation represents a breakeven uranium price of about $\$ 220 / \mathrm{kgU}$ for a $\$ 1000 / \mathrm{kgHM}$ reprocessing price. The reason that uranium prices must increase so much to reach breakeven is that the cost of purchasing uranium is only a small fraction of the overall fuel cost in the once-through fuel cycle, and hence to affect the overall fuel cycle price very much, the uranium price has to increase dramatically. 
Table 2.2 shows the results of breakeven calculations for selected cost parameters, holding uranium price at $\$ 50 / \mathrm{kgU}$ and setting other costs equal to the central values listed in table 2.1. Thus, if the price of uranium price is $\$ 50 / \mathrm{kgU}$, the reprocessing price would have to be reduced to about $\$ 420 / \mathrm{kgHM}$ for reprocessing to be as cost-effective as direct disposal. As will be discussed below, achieving such a low reprocessing price would be an extraordinary challenge, particularly for privately-owned facilities which must pay both taxes and higher costs of money on invested capital.

Table 2.2. Breakeven prices of selected parameters, assuming a uranium price of $\$ 50 / \mathrm{kgU}$ and central values for other parameters.

\begin{tabular}{lccc}
\hline Parameter & $\begin{array}{c}\text { Central } \\
\text { Estimate }\end{array}$ & $\begin{array}{c}\text { Breakeven } \\
\text { Value }\end{array}$ & $\begin{array}{c}\text { Breakeven } \\
\text { Central }\end{array}$ \\
\hline Disposal cost difference $(\$ / \mathrm{kgHM})$ & 200 & 630 & 3.2 \\
Interim spent fuel storage $(\$ / \mathrm{kgHM})$ & 200 & 780 & 3.9 \\
Enrichment $(\$ / \mathrm{SWU})$ & 100 & 1200 & 12 \\
Reprocessing $(\$ / \mathrm{kgHM})$ & 1000 & 420 & 0.42 \\
Uranium $(\$ / \mathrm{kgU})$ & 50 & 370 & 7.4 \\
\hline
\end{tabular}

\subsection{Breakeven Price Sensitivity Analysis}

Figure 2.2 illustrates the sensitivity of the breakeven uranium price to changes in the various fuel-cycle parameters. It shows how much the breakeven price would increase or decrease when each of the parameters is varied from our central estimate to our worst-case and best-case estimates, for reprocessing prices of $\$ 500 / \mathrm{kgHM}, \$ 1000 / \mathrm{kgHM}$, and $\$ 2000 / \mathrm{kgHM}$.

The parameters that have the largest impact on the outcome are the reprocessing price, the difference in price between disposal of spent fuel and high-level wastes from reprocessing, and the price of MOX fuel fabrication. The costs of each of these particularly important parameters are discussed in detail below. (The costs of interim storage of spent fuel pending disposal are also important; they are addressed briefly below, and more extensively in an earlier report on interim storage of spent fuel, by a different group of coauthors. $)^{23}$ Appendix B reviews the resources of uranium likely to be economically recoverable in the future at different prices.

\footnotetext{
${ }^{23}$ Matthew Bunn, John P. Holdren, Allison Macfarlane, Susan E. Pickett, Atsuyuki Suzuki, Tatsujiro Suzuki, and Jennifer Weeks, Interim Storage of Spent Nuclear Fuel: A Safe, Flexible, and Cost-Effective Approach to Spent Fuel Management (Cambridge, MA: Managing the Atom Project, Harvard University, and Project on Sociotechnics of Nuclear Energy, University of Tokyo, June 2001, available as of December 16, 2003 at http://bcsia.ksg.harvard.edu/BCSIA_content/documents/spentfuel.pdf).
} 
Figure 2.2. Sensitivity of the breakeven uranium price to changes in various parameters, relative reference-case values of about $\$ 90, \$ 370$, and $\$ 950 / \mathrm{kgU}$ for reprocessing costs of $\$ 500, \$ 1000$, and $\$ 2000 / \mathrm{kgHM}$, respectively.

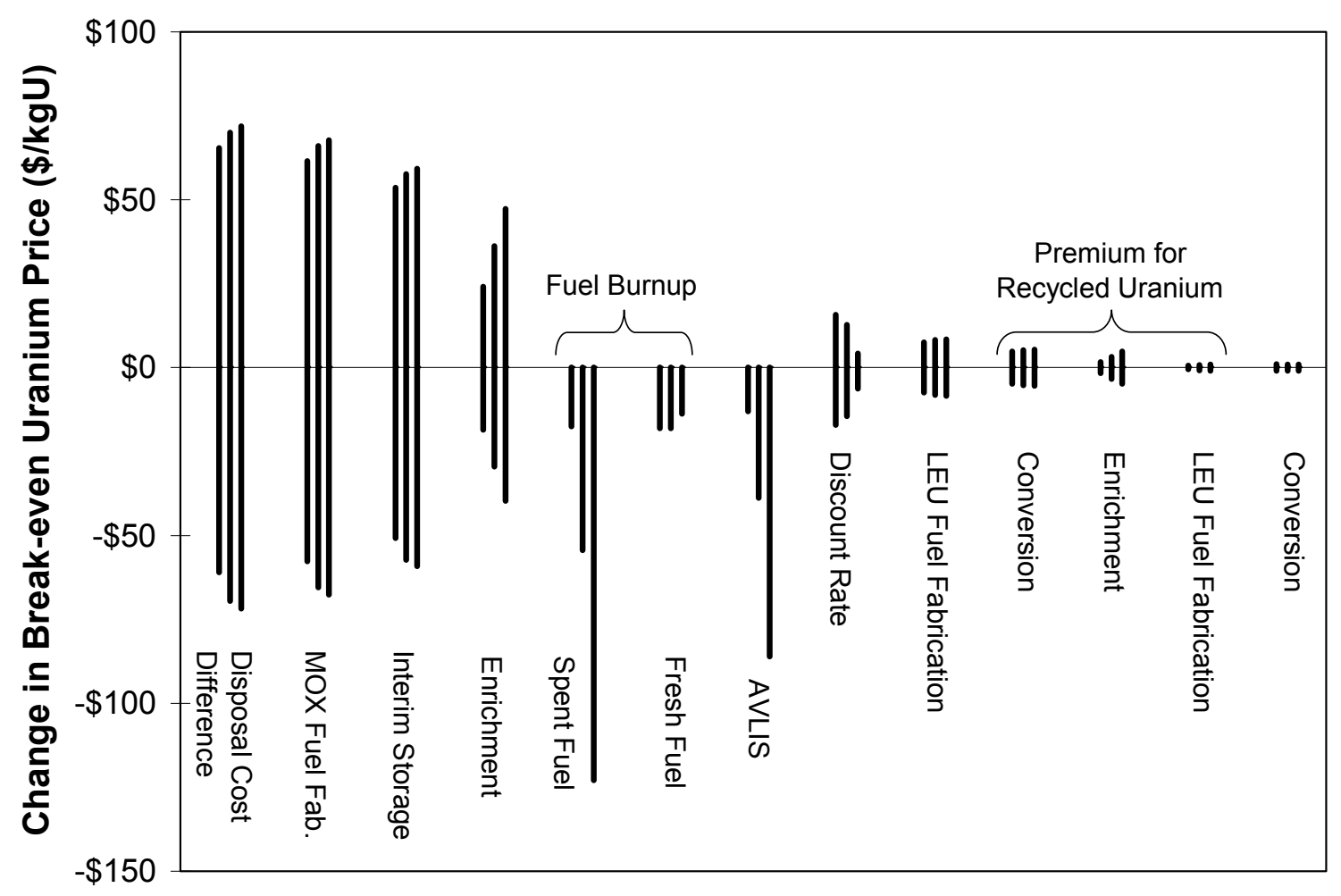

Reprocessing price. Given the wide range we have chosen to display, the breakeven uranium price is extremely sensitive to reprocessing price, ranging from roughly $\$ 90 / \mathrm{kgU}$ for a "best case" reprocessing price of $\$ 500 / \mathrm{kgHM}$, to $\$ 370 / \mathrm{kgU}$ for a reprocessing price of $\$ 1000 / \mathrm{kgHM}$, to $\$ 950 / \mathrm{kgU}$ for a reprocessing price of $\$ 2000 / \mathrm{kgHM}$. As will be discussed below, this is by no means the upper limit of plausible reprocessing prices (the plant now under construction in Japan is expected to have a higher reprocessing cost, even if no allowance is made for return on capital invested), but there is little point in calculating breakeven uranium prices at higher reprocessing costs, since there is no prospect that such uranium prices would be reached in this century.

Difference in waste disposal costs. The next most sensitive parameter is the savings in waste disposal costs resulting from disposing of the high-level wastes from reprocessing, as compared with the direct disposal of the spent fuel. In a best case for reprocessing, if the savings is $\$ 300 / \mathrm{kgHM}$ (75 percent of the $\$ 400 / \mathrm{kgHM}$ estimated net present cost of disposal of spent fuel at the time of discharge), then the breakeven uranium price would be reduced by some $\$ 70 / \mathrm{kgU}$ dollars below the $\$ 370 / \mathrm{kgU}$ breakeven price for our central estimate of 
$\$ 200 / \mathrm{kgHM}$ in disposal cost savings, at a $\$ 1000 / \mathrm{kgHM}$ reprocessing price. If the savings was only $\$ 100 / \mathrm{kgHM}$, the breakeven price would be increased by a similar amount.

MOX fuel fabrication cost. The other particularly sensitive parameter is the MOX fuel fabrication price. If this price was $\$ 2300 / \mathrm{kgHM}$, the breakeven uranium price would increase by some $\$ 65 / \mathrm{kgU}$; if the MOX price were $\$ 700 / \mathrm{kgHM}$, breakeven price would be reduced by $\$ 65 / \mathrm{kgU}$.

\subsection{Contribution to the Cost of Electricity}

Figure 2.3 shows the additional electricity cost involved in reprocessing and recycling, compared to direct disposal of spent fuel, as a function of uranium price, for several reprocessing prices. (The other fuel cycle cost parameters are set at the central estimates described above.) As can be seen, at a reprocessing price of $\$ 1000 / \mathrm{kgHM}$ and a uranium price of $\$ 40 / \mathrm{kgU}$ (modestly above recent prices), reprocessing would involve an additional electricity cost of $1.3 \mathrm{mill} / \mathrm{kWh}$. (A mill is a tenth of a cent.) Even at a uranium price of $\$ 130 / \mathrm{kgHM}$ - a price not likely to be seen for many decades, if not longer - the penalty for reprocessing is still about $1 \mathrm{mill} / \mathrm{kWh}$. If the reprocessing price were $\$ 1500 / \mathrm{kgHM}$, the electricity price penalty at a uranium price of $\$ 40 / \mathrm{kgU}$ would be nearly doubled, to about $2.5 \mathrm{mill} / \mathrm{kWh}$.

Figure 2.3. The additional cost of electricity (COE, mill/KWh) for the reprocessingrecycle option, for reprocessing prices of $\$ 500,1000,1500$, and $\$ 2000 / \mathrm{kgHM}$, compared to the cost of electricity for the direct-disposal option.

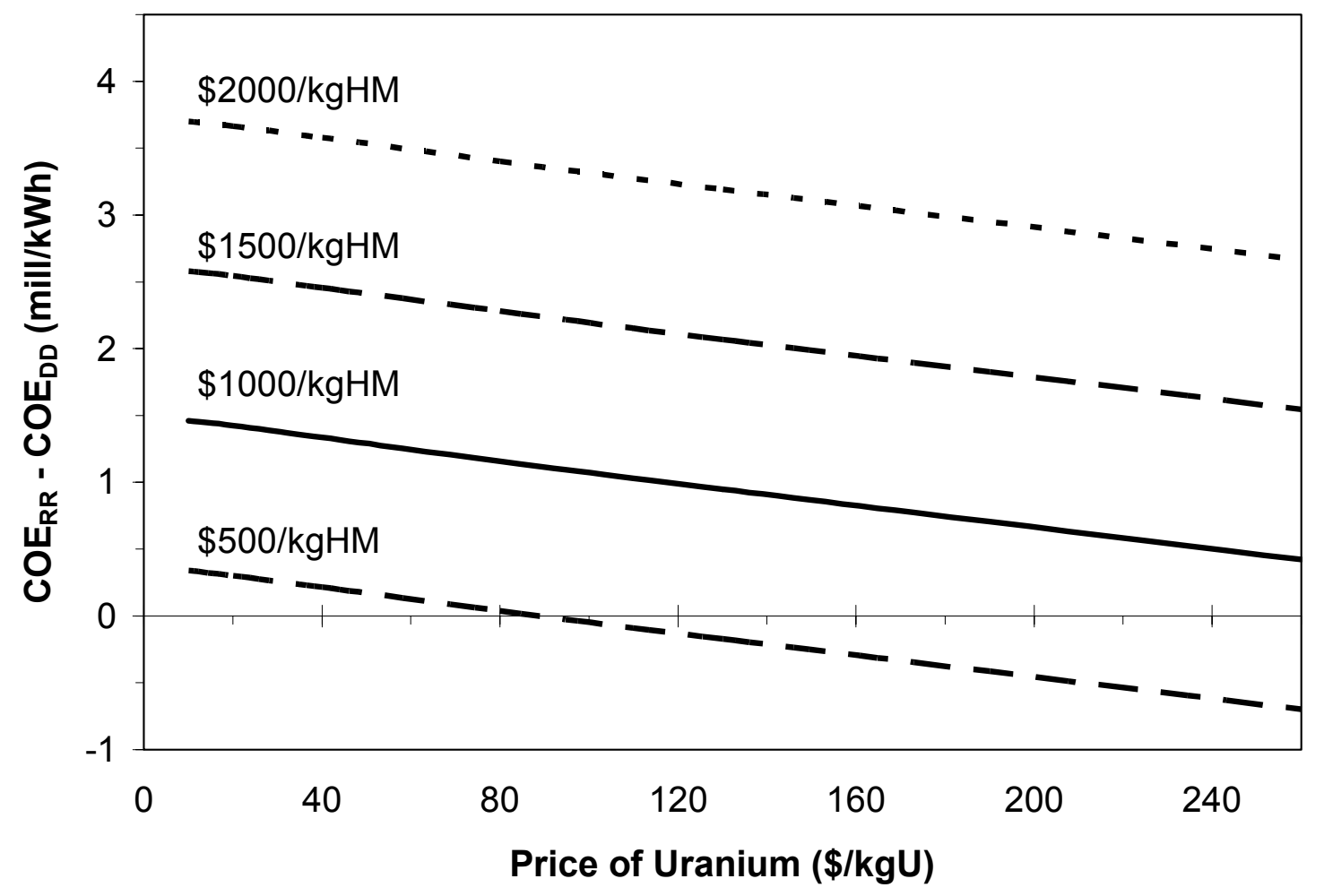


While 1-2 mill/kWh does not represent a large fraction of total electricity costs, it is a significant fraction of the costs that owners of existing plants can control-particularly the back-end costs. At $\$ 1000 / \mathrm{kgHM}$ and $\$ 40 / \mathrm{kgU}$, the full costs attributable to spent fuel management (after taking account of appropriate credits or charges for the recovered plutonium and uranium from reprocessing) are $87 \%$ greater for reprocessing and recycling than for direct disposal, and amount to an additional expense of roughly $\$ 1$ million per year for a typical LWR. ${ }^{24}$

\subsection{Component Costs of the Fuel Cycle}

In this section, we discuss our estimates of the various prices and other parameters that enter into the fuel cycle cost calculation. In most cases, we focus on the near term (which we take to be the next 10-15 years); in the case of uranium prices and reprocessing costs (which are, in a sense, the key factors to be traded off against each other in considering whether it makes economic sense to recycle), we offer some more speculation about the longer term.

\subsubsection{Uranium Prices}

Uranium prices are particularly important in our analysis, since we have focused significantly on estimating how much the uranium price would have to increase for reprocessing and recycling in existing LWRs to be economic.

\section{Near Term}

Current uranium prices are generally in the range of $\$ 25-\$ 35 / \mathrm{kgU}$, some ten times lower than the breakeven price we estimate for a reprocessing price of $\$ 1000 / \mathrm{kgHM}$. The average uranium price paid by U.S. utilities in 2002 was $\$ 26.93 / \mathrm{kgU}^{25}$ In the European Union, the average price paid for deliveries under long-term contracts in 2002 (the most recent year for which averages are available) was higher, at $\$ 32.30 .^{26}$ Uranium sold under long-term contracts is usually more expensive than uranium sold on the "spot" marketreflecting a premium paid for the added security to the utility of having long-term contracts in place for its fuel supply. In the United States in 2002, for example, the average long-term

\footnotetext{
${ }^{24}$ With a $\$ 200 / \mathrm{kgHM}$ charge for interim storage pending geologic disposal, and a $\$ 400 / \mathrm{kgHM}$ charge for direct disposal (including transport to the repository), the total back-end cost of direct disposal is in the range of 1.5 mill $/ \mathrm{kWh}$. With a reprocessing price of $\$ 1000 / \mathrm{kgHM}$ (including transport to the reprocessing plant), a $\$ 200 / \mathrm{kgHM}$ charge for disposal of reprocessing wastes, and adjustments for the net value/cost of both the recovered plutonium and the recovered uranium, the total back-end cost of reprocessing and recycling is almost $2.9 \mathrm{mill} / \mathrm{kWh}$. (For the details of the equations used in these calculations, see Appendix A.) For a 1-GW reactor operating with an $85 \%$ capacity factor, an extra $1.3 \mathrm{mill} / \mathrm{kWh}$ is equal to $\$ 1 \mathrm{million} / \mathrm{y}$.

${ }^{25}$ U.S. Department of Energy, Energy Information Administration, Uranium Industry Annual 2002

(Washington DC: Department of Energy, May 2003, available as of December 16, 2003 at http://www.eia.doe.gov/cneaf/nuclear/uia/uia.pdf), Table D6. Such prices are often expressed in dollars per pound U308; such figures must be multiplied by 2.6 to find the price in dollars per kilogram of uranium. For the rest of the chapter, all prices are in constant 2003 dollars, converted using GDP deflators, unless otherwise specified.

${ }^{26}$ Euratom Supply Agency, Annual Report 2002 (Brussels: Euratom Supply Agency, 2003, available as of December 16, 2003 at http://europa.eu.int/comm/euratom/ar/ar2002.pdf), p. 22, converted from euros to dollars at the $0.95 \$$ /euro average rate for 2002 .
} 
contract price was $\$ 29.00$, while the average spot price was $\$ 24.15$, and spot purchases represented $17 \%$ of deliveries. ${ }^{27}$ In the European Union, the average long-term contract price was $\$ 32.30$, the average spot price was $\$ 24.22$, and only $8 \%$ of deliveries were spot purchases - both the modestly smaller amount of the spot purchases and the modestly higher price for the long-term contracts reflecting European utilities' preference for the security of long-term contracts (though these differences are much less than they once were) ${ }^{28}$ As of the summer of 2003, the spot uranium price was in the range of $\$ 28-\$ 28.50 / \mathrm{kgU}^{29}$

Indeed, as shown in Figure 2.4, ${ }^{30}$ while uranium prices are somewhat volatile, on average world uranium prices have been declining steadily for two decades. Also notable in the figure is that the gaps between U.S. and European prices, and between spot and long-term prices, have declined significantly in recent years.

Figure 2.4. Uranium prices, 1972-2000.

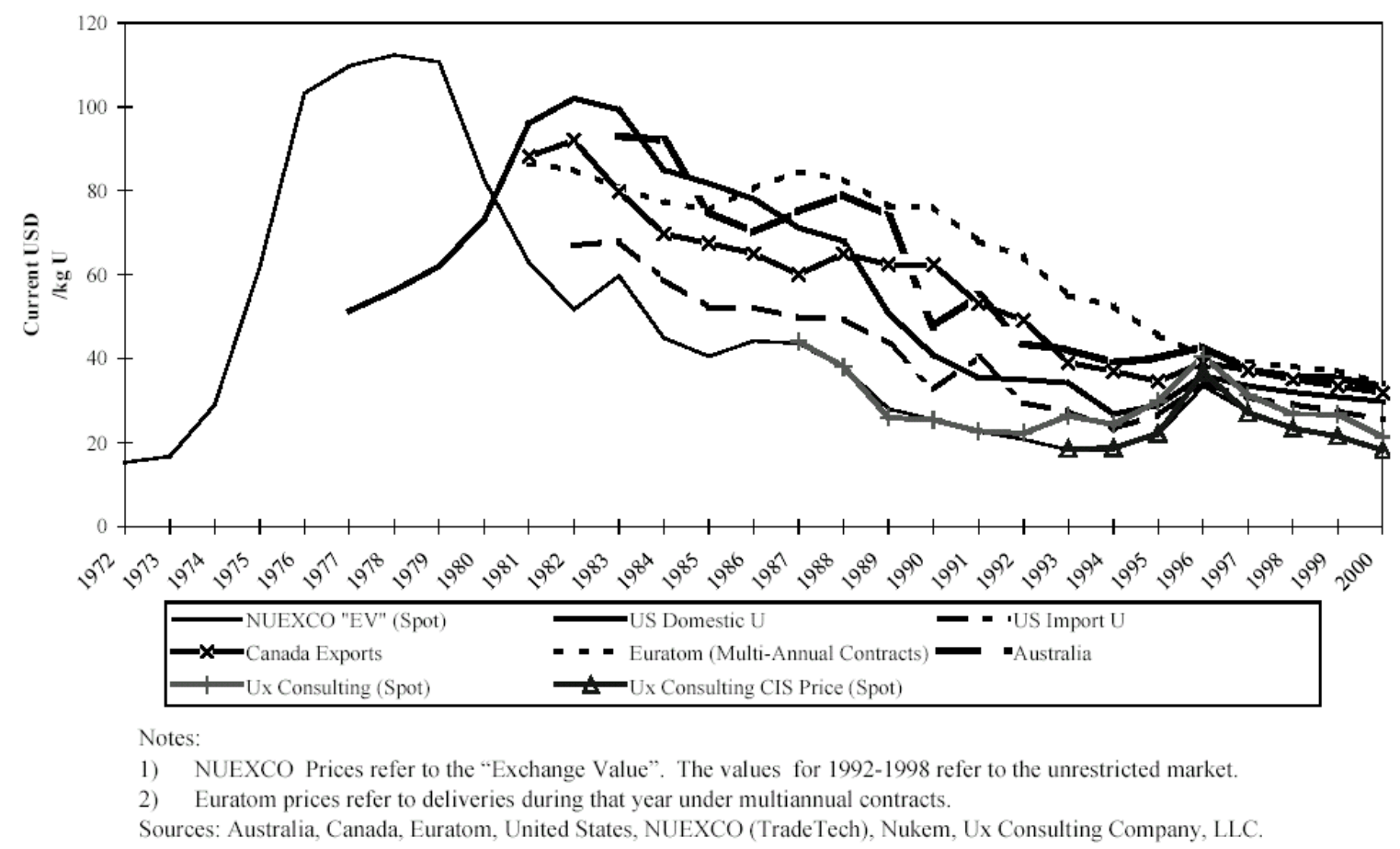

Uranium prices are still being depressed by the use of both military and civilian uranium inventories: while world uranium production increased by $12 \%$ in 2000 , that still

\footnotetext{
${ }^{27}$ Uranium Industry Annual 2002, op. cit., p. 19.

${ }^{28}$ Euratom Supply Agency, Annual Report 2002, op. cit., Annex 3.

${ }^{29}$ Spot uranium prices are freely available from Ux Consulting, at http://www.uxc.com.

${ }^{30}$ Reproduced from Organization for Economic Cooperation and Development, Nuclear Energy Agency, and International Atomic Energy Agency, Uranium 2001: Resources, Production, and Demand (Paris, France: NEA and IAEA, 2002), p. 68.
} 
filled only $56 \%$ of world reactor requirements of some 64,000 metric tons of uranium $(\mathrm{tU}) .^{31}$ It is expected that this situation will continue to exist for some time. The initial 500-ton U.S.-Russian Highly Enriched Uranium (HEU) Purchase Agreement is scheduled to continue to provide LEU blended from 30 tons a year of HEU through 2013, and there are widespread expectations that additional excess HEU may enter the market after that; estimates suggest that commercial uranium inventories still amounted to $140,000 \mathrm{tU}$ at the end of 2000 , having declined from 168,500 at the end of $1998 .{ }^{32}$ Ultimately, as existing inventories are consumed, prices will have to rise sufficiently to bring additional production onto the market to meet demand. Relatively modest price increases would be sufficient to result in producers supplying additional material to the market: already demonstrated reserves recoverable at $\$ 40 / \mathrm{kgU}$ or less are reported to include more than 2 million $\mathrm{tU}$, and more resources would surely be converted to reserves as prices increased. ${ }^{33}$ Hence it is quite unlikely that uranium prices will increase above $\$ 50 / \mathrm{kgU}$ for any sustained period over the next couple of decades. $^{34}$ One projection in the summer of 2003 suggested that uranium prices in long-term contracts would rise to $\$ 32.50 / \mathrm{kgU}$ in 2005 , and to $\$ 41.60 / \mathrm{kgU}$ by 2013 , where they would remain for an extended period. ${ }^{35}$

We have not chosen central or high and low estimates for uranium prices, instead treating breakeven uranium price as the dependent variable resulting from the other factors in the fuel cycle cost equation.

\section{Longer Term}

Longer-term price predictions are notoriously difficult. For much of the nuclear age, forecasters have routinely predicted that the uranium price would imminently begin a steady rise, and have just as routinely been proved wrong. Throughout the $20^{\text {th }}$ century, the world has been finding more of most resources and developing new and cheaper ways to recover them faster than these resources have been consumed. The result, for a wide range of nonrenewable resources, has been prices that have been declining in real terms rather than increasing. In the United States, for example, the real price of a broad range of metals declined throughout the $20^{\text {th }}$ century (just as the uranium price has been doing for the last 20 years). ${ }^{36}$ Based on the estimates of uranium resources described in Appendix B, there is clearly enough uranium available at costs far below the breakeven price for reprocessing at $\$ 1000 / \mathrm{kgHM}$ to last for many decades; indeed, as described in Appendix B, it appears unlikely that the uranium price will rise to the breakeven price anytime in the $21^{\text {st }}$ century,

\footnotetext{
${ }^{31}$ Uranium 2001: Resources, Production, and Demand, op. cit., p. 10.

${ }^{32}$ Uranium 2001: Resources, Production, and Demand, op. cit., p. 59, citing a 2001 study by the World Nuclear Association (formerly the Uranium Institute).

${ }^{33}$ Uranium 2001: Resources, Production, and Demand, op. cit., p. 21.

${ }^{34}$ See, for example, U.S. Department of Energy, Energy Information Administration, Nuclear Power Generation and Fuel Cycle Report 1997 (Washington, DC: DOE, September 1997), p. 116, projecting a spot market price essentially stable at between $\$ 40 / \mathrm{kgU}$ and $\$ 41 / \mathrm{kgU}$ (1996 dollars) from 2004-2010. This is the last year for which this report is available.

${ }^{35}$ See Michael Knapik, "LES Hires Advisers to Prime Renewed Push to Site Tennessee Plant; PACE Slams USEC," Nuclear Fuel, May 26, 2003, reporting projections from Energy Resources International.

${ }^{36}$ Daniel E. Sullivan, John L. Sznopek, and Lorie A. Wagner, " $20{ }^{\text {th }}$ Century U.S. Mineral Prices Decline in Constant Dollars" (Washington DC: U.S. Geological Survey, Open File Report 00-389, available as of December 16, 2003 at http://pubs.usgs.gov/openfile/of00-389/of00-389.pdf).
} 
even with substantial growth in nuclear power. Appendix B also addresses the long-term possibility of recovery of the huge uranium resource in seawater, which, if it could be done on an industrial scale at a price comparable to or less than the breakeven price, would provide a long-term competitor to reprocessing and recycling of plutonium for fueling the future of fission-based nuclear energy.

\subsubsection{Reprocessing Costs and Prices}

Our analysis is also particularly sensitive to the price of reprocessing, and therefore we discuss reprocessing costs and prices in some detail. Commercial reprocessing is expensive. Chemically processing intensely radioactive spent fuel while maintaining adequate safety standards requires large, complex facilities and substantial numbers of highly trained personnel, and results in significant quantities of radioactive and chemical wastes that must be managed. For example, the French UP2 and UP3 facilities at La Hague, the world's largest commercial reprocessing center, cost 90 billion francs to build (over \$16 billion 2003 dollars) and employ $6,000-8,000$ people. $^{37}$

Exactly how expensive reprocessing is depends, of course, on the specifics of individual facilities. The actual experience of existing facilities provides a far better basis for judging the cost of future facilities than paper studies by optimistic designers, but this actual experience is limited: only two companies outside the former Soviet Union operate large commercial reprocessing plants today (COGEMA, now part of the Areva group, in France, and British Nuclear Fuels Limited (BNFL) in the United Kingdom), and these plants only began operation in the 1990s. More is known about the costs at BNFL's Thermal Oxide Reprocessing Plant (THORP), because of the extended debates that have surrounded that facility since its inception. Unlike cost parameters such as uranium and enrichment prices, for which published prices are widely available, virtually all aspects of the economics of reprocessing are considered proprietary information. The cost estimates in this study are therefore based on the limited statements that are available from the reprocessors, studies from other sources, and press reports. The sections below discuss costs and prices charged at existing plants, followed by a discussion of possible costs at new facilities in the longer-term future.

\section{Costs}

The THORP facility cost some $\$ 5.9$ billion (2003 dollars) to build. ${ }^{38}$ While there has been considerable controversy over its annual reprocessing capacity (arising from its frequent

\footnotetext{
${ }^{37}$ Christian Bataille and Robert Galley, L'Aval du Cycle Nucléaire (The Back End of the Nuclear Fuel Cycle), Part 1, General Study, Report to the Parliamentary Office for the Evaluation of Scientific and Technological Choices (Paris, France: French Senate, June 1998, available as of December 16, 2003 at http://www.senat.fr/rap/o97-612/097-612.html). As discussed in Chapter 1, the cost estimate in francs has been converted to dollars using a three-year average of exchange rates centered on the year of the estimate, and then inflated to 2003 dollars using U.S. GDP deflators. The employment figure covers both employees of COGEMA and subcontractors.

${ }^{38}$ British Nuclear Fuels Limited, The Economic and Commercial Justification for THORP (Risley, UK: BNFL, 1993), p. 22. BNFL states that the "construction cost of THORP, spread over the ten years 1983-1992, equates to around $£ 1.9 \mathrm{Bn}$. However, taking account of other projects which are directly related to THORP, the overall capital cost of the programme was around $£ 2.85 \mathrm{Bn}$.” These estimates have been converted to dollars using a
} 
failure to meet targets), we will use an estimate of 800 tons of heavy metal per year (tHM/y). BNFL has never provided an official figure for THORP's operating costs, but before THORP began operating, BNFL provided a public estimate that a similar plant would cost some $\$ 560$ million per year (2003 dollars) to operate (or roughly $\$ 700 / \mathrm{kgHM}) .{ }^{39} \mathrm{BNFL}$ in this period frequently underestimated future costs, and indeed, on a per-kilogram basis BNFL has concluded that costs are higher than originally anticipated, and has asked for additional payments from customers to cover these higher costs. ${ }^{40}$ Nevertheless, to be conservative, we will rely on this early BNFL estimate.

Both THORP and UP-3 were built with very favorable financing arrangements - payahead contracts from their utility customers paid essentially the entire capital cost over a 10year "baseload" period, with no interest or return to investors required. Amortizing a \$5.9 billion capital cost over 10 years of operation at $800 \mathrm{tHM} / \mathrm{y}$ would result in a capital contribution to reprocessing cost of $\$ 740 / \mathrm{kgHM}$. With capital and operating costs added together, this comes to $\$ 1440 / \mathrm{kgHM}$. If we assume (conservatively) that start-up costs amount to one year of operational costs (also amortized over the ten-year baseload), this adds some \$70/kgHM; conservative allowances for refurbishment and decommissioning add a further $\$ 100 / \mathrm{kgHM}$. Thus the total cost under this financing arrangement would be in the range of $\$ 1760 / \mathrm{kgHM}^{41}$

The cost of reprocessing at new facilities with capital and operating costs comparable to THORP would depend crucially on how they were financed (see appendix A.) Financing with pay-ahead contracts and without requirements for return on investment was possible only because the reprocessors' customers were legally obliged by their governments to enter into reprocessing contracts and BNFL and Cogema were the only firms offering the service; this seller's market for reprocessing services will not occur again. A government-owned facility able to borrow money at low, risk-free government rates, and amortize the capital

three-year average of exchange rates centered on the time of the estimate, and then inflated to 2003 dollars using U.S. GDP deflators. Other estimates (including from BNFL) lead to somewhat higher figures in 2003 dollars, but these variations may be more a matter of currency fluctuations than real differences in the estimated cost of the facility when built. In 2000-2001, BNFL asked customers to cover $£ 100$ million in additional capital costs not initially anticipated (approximately $\$ 150$ million in 2003 dollars), but to be conservative, we have not added these additional costs to our estimates of THORP capital costs. See, for example, Ann MacLachlan, "BNFL, Overseas Customers Agree on New Reprocessing Contract Terms," Nuclear Fuel, October 15, 2001. ${ }^{39}$ Organization for Economic Cooperation and Development, Nuclear Energy Agency, The Economics of the Nuclear Fuel Cycle (Paris: NEA, 1994), p. 113. The costs estimated in that study are in 1991 money values (p. 23), and have been converted to 2003 dollars using the same method as used for capital costs.

${ }^{40}$ See, for example, MacLachlan, "BNFL, Overseas Customers Agree on New Reprocessing Contract Terms," op. cit.

${ }^{41}$ The assumptions used here for capital, operating, refurbishment, startup, and decommissioning costs lead to a total cost, if the plant were only to operate for the 10-year baseload, of $\$ 11.8$ billion, quite comparable to BNFL's estimate, before the plant began to operate, of total costs of $\$ 11.3$ billion. (See BNFL, The Economic and Commercial Justification for THORP, op. cit., p. 22, converted to current dollars by the same methods described above). The difference is likely attributable largely to our assumptions on capital refurbishment costs, which we treat as levelized throughout the plant's life, but BNFL may have assumed could largely be postponed until after the baseload period (and hence these costs may have not have been fully included in an accounting limited to costs incurred during the baseload period); refurbishment is not even mentioned in this BNFL document, and in the OECD study, major refurbishments are assumed to occur at 10 years (just after the baseload) and 20 years after the plant begins operations (OECD/NEA, The Economics of the Nuclear Fuel Cycle, op. cit., p. 120. 
cost over 30 years rather than only 10, would have a total cost, using otherwise similar assumptions, just under $\$ 1350 / \mathrm{kgHM}$; a private facility with a guaranteed rate of return (and therefore a low cost of money, though not as low as the government's rate, and also facing a requirement to pay taxes and insurance) would have a total cost of over $\$ 2000 / \mathrm{kgHM}$; and a private facility with no guaranteed rate of return would have a total cost of over $\$ 3100 / \mathrm{kgHM}$ - all for the same capital and operating costs as BNFL estimated for THORP. ${ }^{42}$ These figures are consistent with those estimated by a committee of the National Academy of Sciences in the mid-1990s (also on the basis of reported THORP costs), when those estimates are converted from 1992 to 2003 dollars. ${ }^{43}$ Such private-capital costs would take the cost of

\footnotetext{
${ }^{42}$ These figures assume, in addition to the capital and operating costs for THORP described in the text: (a) a 10year construction time, as assumed in OECD/NEA, The Economics of the Nuclear Fuel Cycle, op. cit., p. 120, comparable to the construction times for UP3 and THORP; (b) an annual refurbishment cost of $1 \%$ of overnight capital cost; (c) property taxes and insurance for the private facilities of $2 \%$ of overnight capital cost; (d) an annuity for decommissioning, with decommissioning costing $30 \%$ of overnight capital cost, and occurring 20 years after the 30-year operational life of the plant, and funds set aside in a fund that generates a $3 \%$ real interest rate, resulting in a decommissioning charge of roughly $\$ 26 / \mathrm{kgHM}$; (e) continuous operation at $800 \mathrm{tHM} / \mathrm{yr}$ throughout the 30-year life of the plant; and (f) startup costs equal to one year of operations costs, adding just over $\$ 560$ million to total capital costs. As discussed in Chapter 1, annual fixed charge rates are assumed to be $5.8 \%$ for government financing, $10.3 \%$ for a private entity with a guaranteed rate of return, and $18.8 \%$ for a private entity with no guarantee of revenues - plus $2 \%$, as just noted, for property taxes and insurance in the case of the private facilities. Describing the spend-out of funds during construction with the beta-binomial Scurve described in Appendix A, and assuming real rates for interest during construction (IDC) of $4 \%, 6.4 \%$, and $9 \%$ for the government-owned, regulated-utility-owned, and private-venture-owned cases, respectively, leads to adding $18 \%, 31 \%$, and $46 \%$ to the overnight construction costs to find the total capital cost including interest during construction. (Although it seems very unlikely that lenders would be willing to finance $100 \%$ of the cost of building such a facility with no equity investment, even if equity shares were to be sold to pay off some of the debt once the facility was operational, we have nonetheless used the lower rate for all-debt financing for the private venture case, as otherwise the cost of interest during construction over 10 years of construction would be prohibitive. This follows the approach taken in U.S. National Research Council, Committee on Separations Technology and Transmutation Systems, Nuclear Wastes: Technologies for Separations and Transmutation (Washington DC: National Academy Press, 1996), Appendix J, “Fuel Reprocessing Economics," pp. 413-445.) Thus for a government-owned facility, the total capital cost, including overnight cost, IDC, and startup costs, would be roughly $\$ 7.5$ billion; the annual capital contribution to the revenue requirement would be nearly $\$ 440$ million; and the capital contribution to per-kilogram cost would be just under $\$ 550 / \mathrm{kgHM}$. Adding just over $\$ 700 / \mathrm{kgHM}$ in operations cost would bring the per-kilogram cost to some $\$ 1250 / \mathrm{kgHM}$, and refurbishment and decommissioning set-asides would bring the total to some $\$ 1350 / \mathrm{kgHM}$. For a facility owned by a regulated utility, the total capital cost would be $\$ 8.3$ billion, contributing an annual revenue requirement of some $\$ 850$ million, or just over $\$ 1060 / \mathrm{kgHM}$; operating, refurbishment, and decommissioning costs are assumed to be the same, but there would also be a cost of some $\$ 150 / \mathrm{kgHM}$ for property taxes and insurance, bringing total costs to some $\$ 2020 / \mathrm{kgHM}$. For a facility owned by a private venture without a regulated rate of return, the total capital cost would be $\$ 9.2$ billion, the annual revenue requirement would be $\$ 1.7$ billion, the capital contribution to per-kilogram cost would be over $\$ 2150 / \mathrm{kgHM}$, and the total reprocessing cost would be over $\$ 3100 / \mathrm{kgHM}$. Assumptions on fixed charge rates, refurbishment, property insurance, and taxes, are drawn from U.S. National Research Council, Committee on Separations Technology and Transmutation Systems, Nuclear Wastes: Technologies for Separations and Transmutation, Washington DC: National Academy Press, 1996, Appendix J, "Fuel Reprocessing Economics," pp. 413-445; assumptions on decommissioning are drawn from BNFL's own assumptions in OECD/NEA, The Economics of the Nuclear Fuel Cycle, op. cit., p. 114. We have charged property taxes and insurance separately from the fixed charge rate on total capital cost (so as to apply these charges only to overnight cost, not to total capital cost), and our annual fixed charge rates are therefore $2 \%$ lower for both of the private cases than the figures used by the NAS panel. Thee NAS panel appears not to have included its estimated $1 \%$ annual charge for refurbishment in its fixed charge rates. (Ray Sandburg, private communication, July 2003.)

${ }^{43}$ See NAS, Nuclear Wastes: Technologies for Separations and Transmutation, op. cit., pp. 413-445.
} 
reprocessing to the edge of Figure 2.1 and beyond, to a region where the breakeven uranium price would be in the range of $\$ 1000 / \mathrm{kgU}$, or far higher than that for reprocessing at a private facility without a guaranteed rate of return.

Costs for the French UP3 plant, built at roughly the same time to meet essentially the same market, have been reported to be generally similar to those for THORP, though much less detail is available. ${ }^{44}$ Costs for the most recent large reprocessing plant, the RokkashoMura plant nearing completion in Japan, have been astronomically higher-despite the design having been modeled on UP3 - not lower, as might be expected from having the benefit of the experience of the plants in France and the United Kingdom. The capital cost of the Rokkasho-Mura plant is now expected to be 2.14 trillion yen (roughly $\$ 18$ billion at exchange rates that prevailed in the first half of 2003) and the operations cost over 40 years is expected to be 6.8 trillion yen (over $\$ 1.4$ billion per year) ${ }^{45}$ - both about three times the THORP costs discussed above. Even amortized over 40 years, with zero return on capital and no allowances for interest during construction, startup costs, refurbishment, or decommissioning, this would come to over $\$ 2300 / \mathrm{kgHM}$. Total costs including these other costs are expected to be dramatically higher still, at over $\$ 4100 / \mathrm{kgHM}$ - though it is not entirely clear which components of the reprocessing-recycling-waste disposal program are included in that huge total-prompting the Japanese utilities to ask for a government subsidy to pay all costs other than operations. ${ }^{46}$

In short, the $\$ 1000 / \mathrm{kgHM}$ reprocessing cost we have used as our central estimate is quite conservative. For facilities with capital and operating costs comparable to THORP, per-kilogram costs in this range could only be achieved for facilities whose capital cost has already been paid off, or which are government-financed. If, as seems likely, future plants would not be built by governments, but would have to raise funds on private capital markets (and pay taxes and insurance), then simply achieving our central estimate of $\$ 1000 / \mathrm{kgHM}$ would require more than a 50 percent reduction in the capital and operating costs experienced

\footnotetext{
${ }^{44}$ One press report indicates that COGEMA estimated the capital cost of UP3 at 27.8 billion francs in 1992, roughly $\$ 6.2$ billion 2003 dollars. See Ann MacLachlan, "COGEMA Inaugurates UP3 with Promise of More Upgrades," Nuclear Fuel, April 27, 1992. Similarly, an earlier press account reported that COGEMA had estimated the total cost of building the UP3 plant (with a capacity of $800 \mathrm{MTHM} / \mathrm{yr}$ ) and expanding UP2 from a capacity of $400 \mathrm{MTHM} / \mathrm{yr}$ to $800 \mathrm{MTHM}$ was 50 billion francs; if two-thirds of this, or 33.3 billion francs, was for UP3, that would be roughly similar to the 27.8 billion franc estimate reported in MacLachlan. See NAS, Nuclear Wastes: Technologies for Separations and Transmutation, op. cit., p.418, quoting Reprocessing News, "Design and Characteristics of the UP-3 Plant," Hanover, Germany: United Reprocessors, 1990. While COGEMA has not revealed operating costs, BNFL has indicated that UP3 operating and decommissioning costs are "comparable" to those estimated for THORP. See BNFL, The Economic and Commercial Justification for THORP, op. cit., p. 18. More recently, a French study relying on figures from COGEMA has reported that the capital cost of UP3's sister plant, UP2, was 37 billion francs (2000 money values, some $\$ 5.7$ billion in 2003 dollars, quite similar to the THORP estimate), and the continuing variable cost is 4 million francs per ton reprocessed (some \$619/kgHM in 2003 dollars). See Yves Marignac, "Briefing: Results of the 'CharpinDessus-Pellat' Mission Economic Forecast Study of the Nuclear Power Option" (Paris, France: World Information Service Energy-Paris, January 18, 2001), p. 7. Marignac was one of two authors of the supporting study to the Charpin et al. study, on the economics of the existing nuclear power infrastructure in France.

${ }^{45}$ See, for example, "Nuke Fuel Reprocessing to Cost 15 Trillion Yen," Japan Economic Newswire, May 15, 2003.

${ }^{46}$ Total cost for reprocessing at Rokkasho-mura is estimated at 15.9 trillion yen. See "Nuke Fuel Reprocessing to Cost 15 Trillion Yen," op. cit.
} 
at past large commercial reprocessing plants (excluding Rokkasho-Mura) - even if the facility had the advantage of the low investor risks associated with a guaranteed rate of return.

It is also important to note that for simplicity, in our model the reprocessing cost includes the cost of transport to the reprocessing plant, which is not in fact included in the above estimates of the per kilogram costs at existing facilities. Over modest distances, spent fuel transport is typically estimated as costing an additional $\$ 50 / \mathrm{kgHM}^{47}$ Transport between Europe and Japan is significantly more expensive.

Prices

BNFL figures indicate that the "baseload" contracts for THORP, designed to retire the entire capital cost of the plants in the first 10 years of operation, were in the range of \$1600/kgHM (1989 dollars), over \$2300 in 2003 dollars. ${ }^{48}$ This would be consistent with suggestions that the baseload contracts were based on expected costs plus a fee in the range of $20 \%$. UP3 contract prices have been reported to be similar to THORP's. Some sources, however, suggest somewhat lower baseload contract prices, in the range of $\$ 1700$ $1800 / \mathrm{kgHM}$ (2003 dollars); this difference may be attributable more to uncertainties introduced by currency conversion in the presence of currency fluctuations than by real differences in estimations of the prices paid. ${ }^{49}$ In some cases, domestic customers (such as Eléctricité de France for COGEMA, both largely owned by the French government) received modestly lower prices. These baseload contracts were not fixed-price contracts, but cost-plus contracts, allowing BNFL and COGEMA to pass on cost increases to the customers. Both have sought increases over the prices originally negotiated, as a result of higher than expected costs (though in COGEMA's case, this occurred before the plant began operations). ${ }^{50}$

\footnotetext{
${ }^{47}$ See, for example, Organization for Economic Cooperation and Development, Nuclear Energy Agency, Accelerator-Driven Systems (ADS) and Fast Reactors (FR) in Advanced Nuclear Fuel Cycles: A Comparative Study (Paris, France: NEA, 2002, available as of December 16, 2003 at http://www.nea.fr/html/ndd/reports/2002/nea3109-ads.pdf), p. 211.

${ }^{48}$ See, for example, BNFL, The Economic and Commercial Justification for THORP, op. cit., p. 18. The 1990 BNFL analysis referenced therein indicated that roughly 6000 metric tons heavy metal (MTHM) of baseload contracts were worth $£ 6$ billion (1989 money values), meaning that the average price was $1000 £ / \mathrm{kgHM}$, or over $\$ 1600 / \mathrm{kgHM}$ at the average exchange rate for the three years centered on 1989 . An identical figure of $\$ 1600 / \mathrm{kgHM}$ was provided in an interview by one of the authors with an industry participant in March 1994, referring to contract offers from both COGEMA and BNFL as being roughly similar. A number of other studies from the early $1990 \mathrm{~s}$ refer to prices in the range of $\$ 1600 / \mathrm{kgHM}$ (then-year dollars).

${ }^{49}$ For example, a 1995 German study done by authors with access to data from the German utilities reported a baseload price of $2400 \mathrm{DM} / \mathrm{kgHM}$. If we assume that this is in 1994 money values (rather than the amount at the time the baseload contracts were concluded, more than a decade earlier), then this comes to just over $\$ 1800 / \mathrm{kgHM}$ (2003 dollars); see Ingo Hensing and Walter Schulz, An Economic Comparison of Different BackEnd Paths of Nuclear Power Plants: A Cost Simulation of Different Strategies From a German Point of View, Energiewirtschafliches Institute (EWI), University of Cologne (Olenbourg-Vourlag,1995). Similarly, the Nuclear Assurance Corporation (NAC) reports typical baseload prices at $\$ 1500-\$ 1700 / \mathrm{kgHM}$ in 1999 dollars (\$1630-\$1850 2003 dollars); see Geoff Varley and Dan Collier, Fuel Cycle Cost Data (Atlanta, GA: NAC, October 1999). As noted in Chapter 1, this NAC report was prepared on contract to the U.S. Department of Energy, and is not publicly available because it contains information that is proprietary to NAC.

${ }^{50}$ MacLachlan, "BNFL, Overseas Customers Agree on New Reprocessing Contract Terms," op. cit.
} 
Early post-baseload contracts, no longer including payback of capital costs, were reportedly concluded in 1989-1990 at prices in the range of \$1000-\$1500/kgHM (2003 dollars). ${ }^{51}$ More recently, however, with significant competition between BNFL and COGEMA for post-baseload contracts, prices offered for new reprocessing contracts have reportedly fallen to the range of $\$ 600-900 / \mathrm{kgHM}^{52}$ representing, in essence, the operations cost of the plants plus a modest allocation for profit. These prices are only possible because amortization of capital is no longer included, and therefore do not represent long-term sustainable prices for reprocessing services.

\section{Longer Term Prospects in New Facilities}

If reprocessing is to play any significant part in the nuclear future, new plants would have to be built to replace the existing plants. An obvious question is: can the cost of reprocessing be reduced substantially compared to the cost experience in existing facilities? As noted earlier, at a uranium price of $\$ 50 / \mathrm{kgU}$, for our central estimates of the other parameters, the breakeven reprocessing price would be in the range of $\$ 425 / \mathrm{kgHM}$; if the uranium price rose to $\$ 80 / \mathrm{kgHM}$ decades from now, the breakeven reprocessing price would be in the range of $\$ 480 / \mathrm{kgHM}$. These figures represent a reduction by $75 \%$ or more compared to the reprocessing price that would pertain at a facility with identical capital and operating costs to THORP, financed at the rates that would pertain for a regulated utility with a guaranteed rate of return. Is it plausible that reprocessing prices this low might be achieved in the future?

The Plutonium Redox Extraction (PUREX) process used in existing commercial reprocessing facilities has been used and perfected over more than five decades, for both military and commercial reprocessing. While refinements are possible (and ongoing), the technology is highly mature. It seems unlikely, therefore, that dramatic cost reductions could be achieved using this same technology, or other variants that would also involve chopping the spent fuel, dissolving it in acid solutions, and using organic solvents to extract the plutonium and uranium from the fission products. BNFL and COGEMA have argued that, using the experience gained from their existing plants, and taking advantage of process

\footnotetext{
${ }^{51}$ See, for example, Mark Hibbs, "More Downward Pressure Expected By Germans on Reprocessing Price," Nuclear Fuel, February 9, 1998, reporting post-baseload German contracts with BNFL at 5500 french francs per kilogram of heavy metal, or roughly $\$ 1275 / \mathrm{kgHM}$ in 2003 dollars; BNFL, The Commercial and Economic Justification for THORP, reports that if the 275 MTHM of reserve capacity were sold at the "same price" as the first post-baseload contracts with German utilities, signed in 1989, it would be worth $£ 200$ million in additional profit (1992 money values), or $727 \mathrm{f} / \mathrm{kgHM}$ (roughly $\$ 1500 / \mathrm{kgHM}$ in 2003 dollars) - note that BNFL appeared to be assuming that with the plant operating in any case, there would be minimal or zero additional costs from reprocessing this additional amount of fuel; the EWI study reported a post-baseload price of $1800 \mathrm{DM} / \mathrm{kgHM}$, or about $\$ 1350 / \mathrm{kgHM}$ in 2003 dollars (Hensing and Schulz, An Economic Comparison of Different Back-End Paths); and in OECD/NEA, The Economics of the Nuclear Fuel Cycle, op. cit., it is reported that contracts were available to utilities at a price in the range of $720 \mathrm{ECU} / \mathrm{kgHM}$, roughly $\$ 1150 \mathrm{in} 2003$ dollars. Here again, the NAC study provides figures on the low end, estimating \$900-\$1100/kgHM (1999 dollars, roughly \$980-\$1170 2003 dollars), Varley and Collier, Fuel Cycle Cost Data, op. cit.

${ }^{52}$ See, for example, Varley and Collier, Fuel Cycle Cost Data, op. cit, who indicate that offers have been made (though never concluded in a contract) in the range of \$700/ $\mathrm{kgHM}$ (1999 dollars), and describe \$600$\$ 900 / \mathrm{kgHM}$ (1999 dollars) as a "plausible" range for future offers from these plants.
} 
simplifications that might be possible if they were allowed to leave a somewhat larger portion of the plutonium in the waste, costs could be reduced by some $30 \%{ }^{53}$ On the other hand, increasingly stringent environmental and safety regulations could put upward pressure on costs; in negotiations over marine pollution of the Atlantic, for example, there has been substantial pressure on Britain and France to agree to reduce emissions from their reprocessing plants toward zero, and both BNFL and COGEMA have argued that extreme emissions requirements could drive up their costs. ${ }^{54}$ It appears that more stringent safety and environmental requirements (particularly seismic safety requirements, which may be less severe in other countries) may have been a significant factor in driving the enormous cost of the Rokkasho-Mura reprocessing plant. ${ }^{55}$ In the end, the official estimate in a recent report to the French government, based on COGEMA data, concluded that building a new plant similar to UP3 would still cost $\$ 6.0$ billion (2003 dollars), the same as the cost of the original plant. $^{56}$ In short, if the cost is to be reduced four-fold, PUREX and similar aqueous processes are not likely to be the answer.

Economies of scale may have a significant impact on per-kilogram costs, depending on the size of new plants. A common rule of thumb is that both capital and operating costs scale roughly with the 0.6 power of throughput. (This may or may not be the case for reprocessing plants even larger than the large commercial facilities now in operation: the fact that COGEMA chose both to double the capacity of the UP2 facility and to build the new UP3 facility at the same time suggests that it did not believe that substantial economies of scale would be achieved by having all the new capacity in one facility.) If this rule of thumb did hold, then a new $2000 \mathrm{tHM} / \mathrm{yr}$ reprocessing plant, if scaled from the capital and operating costs for THORP described above, would have reprocessing costs in the range of $\$ 940 / \mathrm{kgHM}$ if government-financed, $\$ 1400 / \mathrm{kgHM}$ if privately financed with a guaranteed rate of return, and $\$ 2150$ if privately financed without a guaranteed rate of return. ${ }^{57}$ By contrast, the new $50 \mathrm{tHM} / \mathrm{yr}$ reprocessing plant in China would be expected to have much higher per-kilogram costs, even if it achieved the same technological level as THORP: at a government-financed rate, the cost scaled from THORP would be in the range of $\$ 4200 / \mathrm{kgHM}$, while for a privately financed facility with a guaranteed rate of return, the cost would be over $\$ 6700 / \mathrm{kgHM}^{58}$ (Actual costs at that facility may not be quite so high, as both

\footnotetext{
${ }^{53}$ See, for example, discussion in Oxford Research Group, Nuclear Reprocessing: Has it a Future? Views From Inside and Outside the Industry (Oxford, UK: Oxford Research Group, October 1999).

${ }^{54}$ These discussions have been taking place primarily in the context of the Oslo Paris Commission (OSPAR), which oversees implementation of the Convention for the Protection of the Marine Environment of the NorthEast Atlantic, which has directed that by 2020, emissions be reduced to the point that additional concentrations resulting from them are "close to zero." See OSPAR Commission, "Strategy With Regard to Radioactive Substances," 1998, available as of December 16, 2003 at http://www.ospar.org/eng/html/sap/radstrat.htm. ${ }^{55}$ Shiro Sasaki, "Changes in the Construction Program of Rokkasho Reprocessing Plant," Plutonium, No. 13, Spring 1996, Council for the Nuclear Fuel Cycle, Tokyo, available as of December 16, 2003 at http://www.cnfc.or.jp/pdf/plutonium 013e.pdf.

${ }^{56}$ Bataille and Galley, The Back End of the Fuel Cycle, op. cit., estimate of 32 billion francs.

${ }^{57}$ Authors' calculations.

${ }^{58}$ Authors' calculations. The Chinese plant is government-financed - but in a rapidly growing economy where availability of capital is a major constraint, estimates of the real cost of a government project should be based on a discount rate that reflects the opportunity cost of not spending those resources elsewhere. Hence, we report both the cost for a facility financed at the U.S. government borrowing rate and the cost for a privately financed facility.
} 
labor rates and the costs of construction materials in China are presumably substantially lower than they are in the United Kingdom.)

A wide range of alternative chemical separations processes have been proposed over the years, which might contribute to reducing costs. ${ }^{59}$ The family of non-aqueous processes that has been the focus of most research and development has been eletrometallurgical processing or pyroprocessing, in which the spent fuel would be dissolved in some type of molten salt, to which a voltage would be applied, and some of the constituents would gather on the anode and others on the cathode. Because the chemistry of the minor actinides tends to be similar to that of plutonium in such a molten salt environment, using such methods it is difficult to separate "clean" plutonium from spent fuel, and therefore such systems have generally been proposed for use in systems for separations and transmutation for nuclear waste, where both the plutonium and the minor actinides would be incorporated in fresh fuel for irradiation. Proponents have argued that eletrometallurgical processes could dramatically reduce reprocessing costs. A 1996 review by a committee of the National Academy of Sciences, however, concluded that the cost estimates provided in studies of new separations processes in the mid-1990s were "inexplicably low," that "it is by no means certain that pyroprocessing will prove more economical than aqueous processing," and that the costs of current plants such as THORP and UP-3 "provide the most reliable basis for estimating the costs of future plants." 60 More recently, official reviews have concluded that even using such techniques, the types of reprocessing required for separations and transmutation are likely to be substantially more expensive than traditional aqueous reprocessing - a nominal estimate of $\$ 2000 / \mathrm{kgHM}$ (2.5 times higher than their too-low nominal estimate of $\$ 800 / \mathrm{kgHM}$ for traditional reprocessing) in two of the most recent analyses. ${ }^{61}$ At the same time, however, there continue to be official analyses whose estimates can only be described as "inexplicably low," in the words of the NAS committee. ${ }^{62}$

\footnotetext{
${ }^{59}$ For a useful review, see NAS, Nuclear Wastes: Technologies for Separations and Transmutation, op. cit., Appendix D, "Separations Technology_Additional Information," pp. 147-190.

${ }^{60}$ NAS, Nuclear Wastes: Technologies for Separations and Transmutation, op. cit., p. 417 and p. 421.

${ }^{61}$ See NEA, Accelerator-Driven Systems (ADS) and Fast Reactors (FR) in Advanced Nuclear Fuel Cycles, op. cit., p. 211 and p. 216, and U.S. Department of Energy, Office of Nuclear Energy, Generation IV Roadmap: Report of the Fuel Cycle Crosscut Group (Washington, DC: DOE, March 18, 2001, available as of July 25, 2003 at

http://www.ne.doe.gov/reports/GenIVRoadmapFCCG.pdf.), p. A2-6 and p. A2-8. For a discussion of the remaining difficulties facing pyroprocessing also N. Donaldson, G. Lamorlette, R. Thied, and D. Greneche, "Pyroprocessing: From Flowsheet to Industrial Facility," in Proceedings of Global 2001: Back End of the Fuel Cycle: From Research to Solutions, Paris, France, September 9-13, 2001 (Paris: Commissariat à l'Energie Atomique, 2001).

${ }^{62}$ For example, in R.I. Smith et al., Estimated Cost of an ATW System (Richland, WA: Pacific Northwest Laboratory, October 1999), which provided the background for the $\$ 280$ billion undiscounted cost figure for deployment of an Accelerator Transmutation of Waste (ATW) system in U.S. Department of Energy, $A$ Roadmap for Developing Accelerator Transmutation of Waste (ATW) Technology: A Report to Congress (Washington, DC: DOE, October 1999), it is estimated that design and construction of a $685 \mathrm{tHM} / \mathrm{yr}$ reprocessing plant using UREX technology (a variant on PUREX which is designed to separate only the uranium) and pyroprocessing of the resulting raffinate with plutonium, minor actinides, and fission products, would cost $\$ 1.5$ billion (1999 dollars, some $\$ 1.6$ billion 2003 dollars). This amounts to some $\$ 2400 / \mathrm{kgHM}$ of annual capacity, two-thirds less than THORP's $\$ 7400 / \mathrm{kgHM}$ of annual capacity — despite a lower throughput (which should result in higher per-kilogram costs) and the need to add two quite separate chemical processes together. Operations were estimated at $\$ 114$ million per year (1999 dollars, \$124 million/yr in 2003 dollars), or
} 
The discussion to this point has been entirely about reprocessing that simply separates the plutonium and the uranium from everything else. In the case of aqueous separations processes, also separating the minor actinides (and, perhaps, those fission products that make major contributions to estimated doses from a geologic repository, such as technetium and iodine) would involve adding additional complex separations steps, inevitably involving additional costs. ${ }^{63}$ In the case of pyroprocessing, as just described, the minor actinides come with the plutonium as a matter of course, but current official estimates still suggest that costs for the complete separation of actinides from fission products will be substantially higher than the costs of traditional reprocessing. ${ }^{64}$

In short, while future technological developments hold some promise, it does not appear likely that within the next few decades the cost of reprocessing, including payback of capital costs of facilities (likely at commercial costs of money), will be reduced to prices that would allow reprocessing to compete economically with uranium at prices likely to pertain for most of this century. As noted earlier, it is also conceivable that costs could increase significantly - as suggested by the remarkable increase in cost of Rokkasho-Mura compared to THORP and UP-3 - driven by the costs of meeting more stringent requirements as societal attitudes change.

\subsubsection{Costs of Disposal of Spent Fuel and Reprocessing Wastes}

The costs for treatment and final disposal of wastes are perhaps the most uncertain of the various fuel cycle costs, and vary from country to country depending on national approaches. ${ }^{65}$ Neither geologic disposal of spent fuel nor geologic disposal of HLW has yet been done, making cost estimates inherently uncertain. In most countries, geologic disposal of nuclear wastes is to be managed either by the government, or by a monopoly firm reactor operators are required to contribute to: hence there is not really a market for disposal services with real prices offered, and this section will discuss only costs, not prices. For the present purposes, the difference in costs between the two fuel cycles is more important than the

\footnotetext{
\$180/kgHM, compared to THORP's \$700/kgHM. Decommissioning was estimated at only $10 \%$ of construction cost, one-third BNFL's expectation for THORP. These cost estimates are totally implausible. Moreover, the levelized costs per-kilogram costs are then determined using a 3\% real discount rate with no allowance for taxes and insurance, appropriate only to a government-owned operation.

${ }^{63}$ See, for example, the discussion in NAS, Nuclear Wastes: Technologies for Separations and Transmutation, op. cit., pp. 147-190. See also D. Greneche, P. Rance, and C. Zimmerman, "The Partitioning and Transmutation Issue: An Industrial Point of View," in Proceedings of Global 2001: Back End of the Fuel Cycle: From Research to Solutions, Paris, France, September 9-13, 2001 (Paris: Commissariat à l'Energie Atomique, 2001).

${ }^{64}$ In the NEA review, for example, not only was their central estimate for reprocessing the main plutoniumbearing fuels 2.5 times higher than their estimate for reprocessing LEU LWR fuel, their estimate for reprocessing specialty transuranic or minor actinide fuels that might be needed in an accelerator-driven transmutation system was 7,000/ $\mathrm{kgHM}$, more than 8 times their estimate of the cost of reprocessing in existing PUREX facilities. See NEA, Accelerator-Driven Systems (ADS) and Fast Reactors (FR) in Advanced Nuclear Fuel Cycles, op. cit., p. 211 and p. 216.

${ }^{65}$ See, for example, OECD Nuclear Energy Agency, The Cost of High-Level Waste Disposal in Geologic

Repositories (Paris, France: OECD/NEA, 1993).
} 
absolute magnitude of these costs, as costs that are the same for each fuel cycle do not affect the comparison between them.

To estimate the costs of disposal of spent fuel and those of reprocessing wastes, it is important first to understand what activities are included. For either approach, a permanent high-level waste repository must be sited, licensed, built, operated, and eventually closed; depending on the specific circumstances, more than one such repository in a particular country may eventually needed, if nuclear energy is to continue into the future. In the case of direct disposal of spent nuclear fuel, the fuel must be transported to the repository, packaged for disposal (often referred to as "encapsulation"), and emplaced in the repository. In some national programs, it is also expected that spent fuel will be conditioned before encapsulation, for example by removing the fuel pins from the fuel assemblies to reduce the overall fuel volume and the size of the needed final disposal containers. In the case of disposal of reprocessing wastes, canisters of vitrified high-level waste (HLW) must similarly be transported to the repository, placed in appropriate waste packages for permanent disposal, and emplaced in the repository. Much of the low-level wastes generated by reprocessing can be buried in cheaper low-level waste disposal sites. For those intermediatelevel wastes contaminated with plutonium and other long-lived species, however-referred to in the U.S. waste classification system as transuranic or TRU wastes - disposal in a permanent geologic repository, with its attendant costs, is likely to be needed.

\section{Spent Fuel Disposal Costs}

The U.S. geologic repository program has prepared some of the most detailed and upto-date cost analyses of any program in the world. The most recent (May, 2001) undiscounted cost estimate for the entire U.S. geologic waste disposal program is $\$ 57.5$ billion (2000 dollars - \$59.8 2003 dollars). ${ }^{66}$ Of this $\$ 57.5$ billion total, $\$ 41.84$ billion is for an assumed total of $83,800 \mathrm{tHM}$ of civilian spent fuel (the remainder being for disposal of military spent fuel and reprocessing wastes). In 2003 dollars, this comes to $\$ 520 / \mathrm{kgHM}$ as the total cost of direct disposal of spent fuel. This is financed by charging utilities a fee of 1 mill (a tenth of a cent) per kilowatt-hour. With a burnup of 43,000 megawatt-days per ton of heavy metal (MWd/tHM), an efficiency of 33\%, four years in the reactor, and the fee discounted to time of discharge at a 5\% real annual rate, this comes to $\$ 370 / \mathrm{kgHM}$ (the central estimate of spent fuel disposal costs used in this study is $\$ 400 / \mathrm{kgHM}$ ). With interest accumulated over the time between discharge and disposal, this is expected to be sufficient to fund the full costs of transport to the repository, encapsulation, and disposal of the spent fuel, including all future repository construction and operations costs. ${ }^{67}$ Indeed, DOE is required by law to periodically reassess whether this fee will be sufficient. (The relatively modest difference between the $\$ 520 / \mathrm{kgHM}$ undiscounted figure and the $\$ 370 / \mathrm{kgHM}$ figure for present value of the cost at time of discharge arises because a substantial portion of the

\footnotetext{
${ }^{66}$ U.S. Department of Energy, Office of Civilian Radioactive Waste Management, Analysis of the Total System Life Cycle Cost of the Civilian Radioactive Waste Management Program (Washington, DC: DOE, May 2001, available as of December 16, 2003 at http://www.ocrwm.doe.gov/pm/pdf/tslccr1.pdf).

${ }^{67}$ Office of Civilian Radioactive Waste Management, Nuclear Waste Fund Fee Adequacy: An Assessment, DOE/RW-0534 (Washington DC: U.S. Department of Energy, May 2001, available as of December 16, 2003 at http://www.ocrwm.doe.gov/documents/feeadr/index.htm).
} 
disposal costs - initial repository development and construction, transportation of spent fuel, and the like - occurs early on in the program, rather than decades later when the fuel is actually emplaced in the repository.)

While in the past, a number of other countries with smaller nuclear power programs had projected per-kilogram waste disposal costs far higher than U.S. projected costs, U.S. costs have, in essence, grown to match other countries' estimates. Sweden, for example, which in earlier studies had some of the highest per-kilogram disposal cost estimates in the world, ${ }^{68}$ because of its small nuclear program (with fewer economies of scale), and its plan to use of particularly expensive waste packages, released a cost estimate in 1998 that comes to $\$ 300-\$ 350 / \mathrm{kgHM}$, more or less comparable to the U.S. estimates. ${ }^{69}$ While it remains possible that these total cost estimates will continue to grow in the future, the figure of $\$ 400 / \mathrm{kgHM}$ present value at time of discharge is a reasonable current benchmark for total disposal cost. Thus, our central estimate of $\$ 200 / \mathrm{kgHM}$ as the cost savings for disposal of wastes from reprocessing as compared to direct disposal of spent fuel implies that reprocessing would reduce waste disposal costs a full 50 percent. This cost saving would have to rise to almost $\$ 700 / \mathrm{kgHM}$ - far more than current estimates of the total cost of disposal of spent fuel-for reprocessing at $\$ 1000 / \mathrm{kgHM}$ to be economic at a uranium price of $\$ 50 / \mathrm{kgU}$.

\section{Factors Affecting Costs of Disposal of Spent Fuel and Reprocessing Wastes}

Spent fuel and the wastes that result from reprocessing it differ in a number of ways that could affect the costs of their disposal-in volume, in heat generation, in the number of waste packages per ton of original spent fuel, in types of materials, in radiotoxicity, and so on. In general, the most important of these variables in determining disposal cost are likely to be the heat, the volume or mass, and the number of waste packages to be handled.

Heat. The heat output from waste packages determines how close to each other they can be placed while remaining within the repository's maximum temperature constraints (which in turn are set based on judgments related to the effect of temperature on repository performance and behavior of the various materials within the repository) ${ }^{70}$ Thus, size and number of repository tunnels that have to be dug out for a given amount of waste is driven not by the waste's physical volume, but by its heat output. At thirty years after discharge, the heat output from the vitrified HLW from a given amount of spent fuel is about $70 \%$ of the heat output of the original spent fuel-and the heat output of the HLW declines more rapidly than that from the spent fuel thereafter. ${ }^{71}$ This reduction of almost one-third in heat output at

\footnotetext{
${ }^{68}$ See NEA, The Cost of High-Level Waste Disposal in Geologic Repositories, op. cit.

${ }^{69}$ Cited in Shigekazu Matsuura, Analysis of the History of Cost Evaluation of High-Level Radioactive Waste Disposal (Cambridge, MA: Harvard University Managing the Atom Project, forthcoming 2003).

${ }^{70}$ See discussion in NAS, Nuclear Wastes: Technologies for Separations and Transmutation, pp. 323-328. As described there, this appears to apply to both dry repositories (like Yucca Mountain) and wet ones (as planned in Sweden and some other countries).

${ }^{71}$ See NAS, Nuclear Wastes: Technologies for Separations and Transmutation, op. cit., p. 325. In fact, this comparison is for "actinide free" HLW, whereas HLW from reprocessing as currently practiced includes all of the heat-generating minor actinides. Hence the heat from the HLW for this traditional type of reprocessing would be closer to that from spent fuel than this calculation would indicate. Even at 100 years after discharge from the reactor - that is, after more than two more 30-year half-lives of the dominant heat-generating fission
} 
30 years may offer much more than $30 \%$ packing efficiencies, as (a) some of the thermal limits on repository capacity are dependent on integrated long-term heat output, rather than on thermal power when first emplaced, and (b) strategies for emplacement of the waste over the decades that a repository would be operating could take advantage of the roughly 30 -year half-life of the thermal power of the HLW (for example leaving spaces between HLW packages empty at first, and then filling them decades later when the heat of the original packages had declined substantially). (While a similar strategy could be pursued with spent fuel, it does not offer as dramatic a benefit, as the spent fuel cools more slowly.) Thus, particularly if the actinides were removed from reprocessing wastes entirely (as is not the case with current reprocessing approaches, but might be if more extensive separations were performed in the future as part of a nuclear waste separations and transmutation program), it may be possible to multiply by many times the amount of waste a repository of given volume could hold. ${ }^{72}$

products-HLW from traditional reprocessing retains roughly half the heat output of spent fuel. See NEA, The Cost of High-Level Waste Disposal in Geologic Repositories, op. cit.

${ }^{72}$ How much more HLW could be disposed in a given volume, if limited only by heat, depends on a wide range of factors that go beyond the scope of this study, including repository design (dry vs. wet, actively cooled vs. not, what temperature constraints are considered binding, and the like), what radioactive isotopes remain in the HLW (e.g., how much americium and curium was in the spent fuel when reprocessed, and whether these go to the HLW), the strategy for emplacing the wastes, and more. For the Yucca Mountain repository, there are a variety of different thermal limits that may be binding in different cases: for example, the constraint on the maximum temperature the waste packages may reach limits the thermal power of the waste at the time (currently projected as about 75 years) when active cooling would be turned off, which is when this peak temperature is likely to occur; by contrast, the constraint on the maximum temperature in the rock between the emplacement tunnels is limited more by the total heat output over the first couple of millennia after emplacement. These constraints therefore have very different effects on spent fuel and on HLW with actinides that dominate heat after the first 100 years removed. One early treatment of this subject estimated that in a dry repository such as Yucca Mountain, removing the actinides and leaving only fission products, combined with clever approaches to emplacing the wastes over time to take advantage of the 30-year half-life of the dominant fission products, could increase repository capacity by 4-9 times compared to disposal of unreprocessed spent fuel. See Lawrence D. Ramspott et al., Impacts of New Developments in Partitioning and Transmutation on the Disposal of High-Level Nuclear Waste in a Mined Geologic Repositor, UCRL-ID-109203 (Livermore, CA: Lawrence Livermore National Laboratory, March 1992), pp. 7-5-7-11; NAS, Nuclear Wastes: Technologies for Separations and Transmutation, op. cit., p. 325 estimates a factor of 4-5, including HLW emplacement strategies that take advantage of the cooling over time, compared to an "aggressive" schedule for emplacement of unreprocessed spent fuel; a more recent study, using a repository model based on the current design of Yucca Mountain, with active cooling finds that waste from 3.2-3.4 times as much spent fuel could be emplaced in each length of tunnel if $99-99.9 \%$ of the actinides were removed. This estimate assumes all the waste is emplaced at once (hence does not use an emplacement strategy taking advantage of the cooling of the HLW over time), and it is clear from the analysis that, in addition to the 3 -fold increase in linear loading in the tunnels, the tunnels could also be placed closer together while meeting the criterion that the space between them must remain below the boiling point of water, so the total factor by which capacity could be increased might be as much as 10 or more. See Roald A. Wigeland, Theodore H. Bauer, Thomas H. Fanning, and Edgar E. Morris, Repository Benefit Analyses - Series I Impact, ANL-AFCI-089 (Argonne, IL: Argonne National Laboratory, August 2003). Only if the major heat-generating fission products (cesium and strontium) are allowed to decay before emplacement (which could be accomplished by an additional separation focused on managing these radionuclides separately, or simply by delaying disposal of the HLW from processing by some 300 years) can the even larger packing factors that are sometimes discussed be achieved, such as the factor of 20-59 for 90$99.9 \%$ efficient separations of the major heat generating species estimated in Wigeland et al. 
There are, however, a wide variety of strategies other than reprocessing that could be pursued to increase repository capacity—allowing longer storage periods before emplacement, expanding the area covered by a given repository, adding a second or third emplacement layer, mixing older and newer spent fuel, and the like. These approaches could provide alternative means of expanding the available repository volume within fixed temperature limits. At the same time, these other approaches can be complements to, rather than alternatives to, the heat reduction offered by disposing of HLW rather than spent fuel. ${ }^{73}$

In repositories in geologic media such as the volcanic tuff of Yucca Mountain, the cost of digging additional tunnels is a relatively modest part of the overall waste disposal program cost. Even in hard rock repositories, this cost is not very large. In the 1987 U.S. document laying out the method for calculating the assignment of costs to different types of waste, for example, the portion of the cost related to the "areal dispersion" of the waste within the repository - driven by the heat output - came to only $10-17 \%$ of the total waste program cost (depending in part on whether the envisioned repository was to be in hard rock, granite, tuff, or salt). ${ }^{74}$ In the latest design of the Yucca Mountain repository, the amount of area that had to be covered by the expensive titanium drip shield would also be related to the spacing of the packages and thus to the heat. (In the latest cost estimate, the entire cost of actual underground construction at the repository and of the drip shield - the two cost elements most determined by heat - comes to $19 \%$ of total waste disposal program cost.) $)^{75}$ Thus, if considers the costs that do not change with the type of fuel emplaced are fixed, even a four-fold improvement in the amount of waste that could be packed into a given area of the repository would only result in a $7-13 \%$ overall cost reduction. If, on the other hand, one assumes that the total cost does not change with the type and amount of waste, a four-fold packing improvement would imply a $75 \%$ reduction in unit cost, at least for those waste program costs related to the repository itself (as opposed to the manufacture of the waste packages, transport to the repository, and the like).

For the United States, which has chosen a repository site in a mountain with fixed sides (and therefore a limit on the ultimately available capacity), a substantial packing improvement would also lead to a large increase in the amount of nuclear energy that could be generated before taking on the political uncertainties and economic costs of building another repository. Some have argued that the cost of a second repository would likely be significantly higher than the cost of the first, and is in any case highly uncertain - and that therefore a substantial uncertainty premium should be factored in to the cost of disposal if the United States is going to continue to rely on direct disposal of spent fuel. ${ }^{76}$ While siting and building a second repository in the United States would certainly be a task fraught with uncertainities, we would argue that (a) a second repository is likely to be cheaper than the first, per unit of capacity (though politically controversial), given the extensive experience

\footnotetext{
${ }^{73}$ See discussion in Ramspott et al., Impacts of New Developments in Partitioning and Transmutation, op. cit.

74 "Civilian Radioactive Waste Management: Calculating Nuclear Waste Fund Disposal Fees for Department of Energy Defense Program Waste: Notice," Federal Register, Vol. 52, No. 161, August 20, 1987, pp. 31,50731,524 .

${ }^{75}$ OCRWM, Analysis of the Total System Life Cycle Cost, op. cit. The drip shield is expected to cost $\$ 4.8$ billion (p. B-1), and subsurface construction and emplacement operations combined $\$ 6.1$ billion (p. A-2), out of $\$ 57.5$ billion total program cost.

${ }^{76}$ Per Peterson, personal communication, August 2003.
} 
developed in analyzing, licensing, building, and operating the first facility; (b) even with continued reliance on direct disposal, it is very likely that the capacity of the first repository can be extended sufficiently to be adequate for many decades to come (for example, by adding one or more additional emplacement levels, extending the area of the repository, and the like); and (c) the political, technical, and cost uncertainties involved in proposals for advanced separations and transmutation are at least as large, and probably larger, than those involved in continued reliance on direct disposal - meaning that any risk premium that might be considered should be added to both approaches, not just to direct disposal. (See "Reprocessing to Reduce the Need for Additional Repositories," p. 64.)

An important point to keep in mind when considering issues related to heat output is that the uranium and plutonium separated by reprocessing do not simply disappear, but are returned to the fuel cycle. Most countries today are recycling plutonium only once, because of the buildup of undesirable isotopes in plutonium in spent MOX fuel. If spent MOX fuel is to be disposed of in geologic repositories, its heat output is dramatically higher than the output of spent LEU fuel (over 2,200 watts per ton of heavy metal for MOX fuel of 43 $\mathrm{MWd} / \mathrm{tHM}$ burnup 50 years after disposal, compared to just over $700 \mathrm{w} / \mathrm{tHM}$ for LEU fuel of comparable burnup and storage time). ${ }^{77}$ Indeed, the total heat output from the combination of HLW from reprocessing and disposal of MOX spent fuel is higher, per unit of electricity generated, than the total heat output from the LEU spent fuel from a direct disposal fuel cycle. ${ }^{78}$ Even if the MOX spent fuel is recycled continuously in a "self-generated recycle" mode, so that no spent fuel is ever disposed of, the total heat output from the HLW from that fuel cycle is still higher than the once-through heat, per unit of electricity generated, for the first 50 years after discharge from the reactor. ${ }^{79}$ (This results from the buildup of long-lived, heat-generating actinides such as americium and curium.) Only if the recycling soon switches to fast-neutron reactors or more complete separation and transmutation of the wastes would the near-term heat output from the HLW be less than from spent fuel from a once-through cycle.

Thus, reprocessing and recycle as traditionally practiced would likely increase, not decrease, the heat-determined waste disposal costs. A future separations and transmutation program might substantially decrease total per-kilogram repository costs, but at the expense of reprocessing and recycle costs estimated in the most recent official studies to be much higher than those discussed in this chapter. A recent review concluded that currently envisioned approaches to separations and transmutation would multiply total fuel cycle costs several fold, increasing total nuclear electricity generation costs by $10-50$ percent. ${ }^{80}$

Volume. The physical volume of the wastes to be disposed of affects waste package costs (though as noted above it does not determine the needed repository volume). In the case of the U.S. Yucca Mountain repository, the costs of waste packages amounts to $15 \%$ of

\footnotetext{
${ }^{77}$ Calculations by Jungmin Kang, using ORIGEN software. Personal communication.

${ }^{78}$ See Brian G. Chow and Gregory S. Jones, Managing Wastes With and Without Plutonium Separation, Report P-8035 (Santa Monica, CA: RAND Corporation, 1999).

${ }^{79} \mathrm{Ibid}$. This is because of the buildup of heat-generating minor actinides in the HLW as the plutonium is recycled multiple times.

${ }^{80}$ NEA, Accelerator-Driven Systems (ADS) and Fast Reactors (FR) in Advanced Nuclear Fuel Cycles, op. cit.
} 
the total waste program costs. ${ }^{81}$ In some other repository designs (such as the Swedish and Finnish designs), the waste packages may be even more expensive and represent a larger total fraction of cost. Waste package cost will not scale linearly down as the volume of waste contained gets smaller, however: a substantial fraction of the waste package cost is devoted to having a waste package robust enough to prevent radionuclides from getting out for thousands of years, and this involves a substantial fixed cost even for a relatively small volume of contained material. Volume (and mass) presumably also affect transportation costs, which account for another $10 \%$ of total project costs in the U.S. case. The volume of vitrified HLW waste containers with no final waste package around them is roughly one quarter the volume of the spent fuel the HLW came from, also with no final waste package included. When the volume of the waste packages for each type of waste is included, the total volume per ton of original heavy metal in fuel ranges from roughly equal to roughly half as large for the HLW; this is presumably the better comparison, if the concern is the cost of fabricating and transporting the necessary volume of waste packages. (See sidebar, "Volume of Wastes From Direct Disposal and Reprocessing.") If ILW that also requires permanent geologic disposal is included, the volumes are actually larger for reprocessing wastes - but if spent fuel and HLW waste packages are expensive, one would expect that ILW would be put in cheaper, less impressive packages. If spent fuel and HLW waste packages are expensive, however, presumably ILW will be put in less impressive packages. Hence, it is reasonable to think that the smaller volume of reprocessing wastes might reduce these aspects of disposal costs by as much as 50 percent.

Number of packages and canisters. There are some costs which are associated with the sheer number of "piece parts" that must be handled-fuel assemblies or HLW canisters to be loaded into waste packages, waste packages to be emplaced, and the like. Where the advantage lies here depends on the design of HLW canisters and waste packages; in general, since each canister of HLW glass typically contains HLW from reprocessing somewhat more than one fuel assembly, one might expect a modestly lower number of packages for HLW than for spent fuel. In the 1987 U.S. analysis of cost allocation for the U.S. repository, costs driven by "piece count" represented approximately $10 \%$ of total program costs. ${ }^{82}$ The real number is presumably higher than this, as this figure did not include costs that were directly assignable to spent fuel or HLW, such as the costs of packaging and transportation, many of which may be significantly affected by the number of items to be handled. One of the most explicit recent studies on this point is a paper by NIREX, the UK radioactive waste management organization (based on a study for the European Union) which estimates that each HLW waste package would hold 2 canisters of HLW glass, each containing the HLW from reprocessing roughly $1.2 \mathrm{tHM}$ of spent fuel, so that for reprocessing, there would be .8 HLW canisters and .4 waste packages per ton of heavy metal; for disposal of LEU spent fuel, there would be 4 PWR fuel assemblies (containing $461 \mathrm{kgHM}$ each) per waste package, so that for this approach there would be 2.2 fuel assemblies and .54 waste packages per ton of heavy metal. Overall, the reduction in the number of items to be handled might reduce these

\footnotetext{
${ }^{81}$ The waste packages and drip shields together cost $\$ 13.29$ billion, but $\$ 4.8$ of this is the drip shield, as noted earlier. See OCRWM, Analysis of the Total System Life Cycle Cost, op. cit., p. A-2.

82 “Civilian Radioactive Waste Management," Federal Register, op. cit.
} 
piece-count related costs by something like $30 \%{ }^{83}$ Here, too, the increased heat from MOX spent fuel would come into play, if it was to be disposed of after one recycling, as NIREX has also estimated that the intense heat from MOX spent fuel would reduce the amount of spent fuel that could be put in each waste package four-fold, driving up the number of waste packages to be handled.

Costs from ILW and $L L W$ management. All of these potential cost reductions from disposing of HLW from reprocessing rather than of spent fuel, however, come at the price of having to incur the costs of managing ILW and LLW from reprocessing. As noted in the box on waste volumes, this may be addressed through substitution, which would increase volumes of HLW returned to customers (and their corresponding costs per ton of original spent fuel) by about $20 \%$. (If this is not addressed through substitution, the costs to the customers for transporting and disposing of the LLW and ILW are expected to be still higher.)

\section{Likely Reductions in Cost for Disposing of Reprocessing Wastes}

We can get a rough idea as to how much the total disposal cost per kilogram might be reduced by reprocessing by dividing the total disposal program cost estimate described above into components that are affected in different ways by heat, volume, or number of packages (or not affected by any of these), and then, for each of these categories, assigning a notional reduction factor for the disposal of reprocessing wastes rather than direct disposal of spent fuel. This breakdown of costs by category will vary depending on the specific disposal program design. For the U.S. program (which has published the most detailed cost information), a notional breakdown might be that (a) the elements that are significantly driven by repository size, and therefore by heat output from the wastes, would include repository construction and fabrication of the drip shield (which must be large enough to cover the whole area where waste packages are emplaced); (b) the elements significantly driven by volume, mass, or number of waste packages would include repository emplacement operations and monitoring, waste package fabrication, and transportation; and (c) the cost elements unrelated to whether the waste emplaced is spent fuel or HLW would include siting, licensing, design and engineering, and the like. These distinctions, of course, are by no means absolute: the cost of fabricating waste packages, for example, may well be affected not only by the volume of the material the packages are to contain, but to a modest degree by its heat generation as well. This breakdown is shown in table 2.2, which indicates that the items related to heat constitute $19 \%$ of the most recent $\$ 57.5$ billion cost estimate; those related to volume, mass, or number of items 53\%; and those not related to type of material emplaced $28 \%$.

Neglecting the extra heat from MOX fuel that would arise in traditional reprocessing approaches, we have notionally assigned a four-fold reduction factor for those items related to heat, or not related to type of material emplaced (corresponding to a potential four-fold increase in the amount of fuel that could be emplaced in the repository), and a $50 \%$ reduction

\footnotetext{
83 "Scoping Assessment of Implications of Reprocessing Scenarios for Disposal Options: Paper to RWMAC [Royal Waste Management Advisory Committee]," NIREX Doc. 334004 (London, UK: United Kingdom Nirex Limited, May 2000).
} 
factor for those items related to volume, mass, or number of packages (which is somewhat generous on the basis of the volume discussions above and in the accompanying sidebar). All costs, however, are also assumed to be multiplied by 1.2, to reflect the larger amount of HLW returned to customers due to substitution (or, if substitution does not occur, due to the extra costs of managing ILW and LLW from reprocessing). Overall, this results in an estimate of total cost for disposal of HLW rather than spent fuel that is reduced by some $45 \%$.

This corresponds very well with our central estimate of $\$ 200 / \mathrm{kgHM}$ for disposal of reprocessing wastes, compared to $\$ 400 / \mathrm{kgHM}$ for disposal of spent fuel-that is, a $50 \%$ savings for disposal of reprocessing wastes. Given the very large uncertainties in such estimates, we have used a range from a difference of $\$ 100 / \mathrm{kgHM}(25 \%$ savings $)$ to $\$ 300 / \mathrm{kgHM}$ (75\% savings).

Table 2.3. Notional Cost Reduction for Disposal of Reprocessing Wastes (Billions)

\begin{tabular}{|c|c|c|c|c|}
\hline Cost Category & $\begin{array}{c}2001 \\
\text { Estimate }\end{array}$ & $\begin{array}{c}\text { Percent of } \\
\text { Total }\end{array}$ & $\begin{array}{c}\text { Reduction } \\
\text { Factor }\end{array}$ & $\begin{array}{c}\text { Reprocessing } \\
\text { Waste Cost }\end{array}$ \\
\hline \multicolumn{5}{|c|}{ Significantly Driven By Heat } \\
\hline Repository & $\$ 6.1$ & \multirow{3}{*}{$19 \%$} & $0.25 * 1.2$ & $\$ 1.8$ \\
\hline Construction & & & & \\
\hline Drip Shield & $\$ 4.8$ & & $0.25 * 1.2$ & $\$ 1.4$ \\
\hline \multicolumn{5}{|c|}{ Significantly Driven By Volume, Mass, or Packages } \\
\hline Repository Operation & $\$ 4.9$ & \multirow{5}{*}{$53 \%$} & $0.5 * 1.2$ & $\$ 2.9$ \\
\hline Waste Package & $\$ 8.5$ & & $0.5 * 1.2$ & $\$ 5.1$ \\
\hline Monitoring & $\$ 5.9$ & & $0.5 * 1.2$ & $\$ 3.5$ \\
\hline Surface Operations & $\$ 4.9$ & & $0.5 * 1.2$ & $\$ 2.9$ \\
\hline Transportation & $\$ 6.0$ & & $0.5 * 1.2$ & $\$ 3.6$ \\
\hline \multicolumn{5}{|c|}{ Not Affected By Waste Type } \\
\hline Other Costs & $\$ 16.4$ & $28 \%$ & $0.25 * 1.2$ & $\$ 4.9$ \\
\hline Total & $\$ 57.5$ & $100 \%$ & 0.46 & $\$ 26.3$ \\
\hline
\end{tabular}

In our reference case we have assumed equal costs for the geological disposal of spent LEU and MOX fuels of the same discharge burnup. ${ }^{84}$ If, as seems likely, the greater heat output of spent MOX fuel render its disposal more expensive than equivalent spent LEU fuel, then the economics of reprocessing and recycle become even less attractive. For

\footnotetext{
${ }^{84}$ In the breakeven case, equal disposal costs is economically equivalent to reprocessing of spent MOX fuel, although we have not made adjustments for the isotopic composition of the plutonium in spent MOX fuel, which would be less valuable.
} 
example, if disposal of spent MOX costs $\$ 400 / \mathrm{kgHM}$ more than spent LEU (i.e., double the reference value of $\$ 400 / \mathrm{kgHM}$ for LEU), the breakeven uranium price would increase by $\$ 26 / \mathrm{kgU}$.

Results of other studies. Unfortunately, most recent studies of disposal costs are country-specific, and focus on one option or the other, making direct comparisons between direct disposal of spent fuel and disposal of reprocessing wastes difficult. A 1993 OECDNEA study, however, compared the estimated repository costs for many countries (considering only the encapsulation and disposal costs, not the siting, licensing, and transportation costs), and found that the weighted average cost was $\$ 144 / \mathrm{kgHM}$ for direct disposal (in then-year dollars), and \$82/kgHM (43\% less) for disposal of HLW. ${ }^{85}$ Obviously total costs have increased substantially since then, but this percentage difference is very close to that estimated by different methods above.

A recent study by NIREX, the UK nuclear waste organization, calculated a rather high total cost for HLW disposal of $\$ 770 / \mathrm{kgHM}$ (though the incremental cost of additional HLW disposal was much lower). ${ }^{86}$ The total cost of direct disposal of LWR spent fuel was not estimated, but NIREX estimates that the quantity of spent fuel that could be emplaced per unit area of the repository would be only $12 \%$ less than the quantity of HLW that could be emplaced. The amount of MOX that could be placed in each tunnel would be four-fold less, because of its greater heat generation. ${ }^{87}$ By contrast, a recent French study offers substantially more optimistic figures for the costs of disposal of both spent fuel and HLW than those used here- - some $\$ 130 / \mathrm{kgHM}$ for direct disposal of LEU spent fuel, and just under $\$ 80 / \mathrm{kgHM}$ for disposal of vitrified HLW. That study also estimated that costs for disposal of MOX fuel would be dramatically higher, some $\$ 1,200 / \mathrm{kgHM}$, because of its higher heat generation (even at a lower burnup than the LEU, and after storage for 150 years before disposal rather than 50 in the case of LEU). ${ }^{88}$ The difference between HLW and spent fuel

\footnotetext{
${ }^{85}$ OECD/NEA 1994, op. cit., pp. 149-152, providing additional analysis of the data from OECD/NEA 1993, op. cit.

${ }^{86}$ NIREX, "Scoping Assessment," op. cit., estimates $£ 2.633$ billion (1999 money values) for a repository to hold 710 cubic meters of HLW, with each tHM of spent fuel resulting in 0.12 cubic meters of HLW. Converted to dollars at a 3-year currency exchange rate average and inflated to 2003 dollars using GDP deflators.

${ }^{87}$ NIREX, "Response to Questions Raised Based on Reference 334004," letter to Mike Sadnicki, November 22, 2000. This document shows that each 500-ft tunnel could hold 192.24 tHM of spent fuel, or 26 cubic meters of vitrified HLW (with .12 cubic meters for each tHM of spent fuel reprocessed).

${ }^{88}$ These estimates were provided by the French radioactive waste management organization, ANDRA, as inputs to Jean-Michel Charpin, Benjamin Dessus, and René Pellat, Economic Forecast Study of the Nuclear Power Option (Paris, France: Office of the Prime Minister, July 2000, available as of December 16, 2003 at http://fire.pppl.gov/eu fr fission plan.pdf). Per-kilogram figures for LEU disposal and MOX disposal are provided in the study itself (F 850,000/tHM for LEU, F 3.8 million/tHM for MOX), on p. 214. The HLW figure in the text comes from Marignac, "Briefing: Results of the 'Charpin-Dessus-Pellat' Mission Economic Forecast Study of the Nuclear Power Option" op. cit., p. 7. As noted earlier, Marignac was one of two authors of the supporting study on the economics of the existing nuclear power infrastructure in France. Marignac's figure of $4.2 \mathrm{million} / \mathrm{m}^{3}$ for HLW was converted at $.12 \mathrm{~m}^{3} / \mathrm{tHM}$. (Marignac offers higher figures for what is translated as "storage," but from context clearly includes disposal, of LEU and MOX spent fuel, of F1.8 million/tHM for LEU and F 7.8 million/tHM for MOX; this difference is not explained, but may relate to including interim storage and transport in Marignac's figures, but not in the figures in the main report. Using Marignac's figures for LEU disposal rather than those in the main report would put the difference between LEU and HLW disposal in the range of our $\$ 200 / \mathrm{kgHM}$ central estimate.)
} 
disposal in this French study is much less than we assume, because the total prices for each are much less than we assume: the roughly 40 percent reduction in cost for disposal of HLW in the French study is similar in percentage terms to our central estimate.

A recent review of future fuel cycle options by a group advising the U.S. Department of Energy estimated a cost of $\$ 300 / \mathrm{kgHM}$ (2000 dollars) for conditioning and disposal of spent fuel (with a range from $\$ 130-\$ 500 / \mathrm{kgHM}$ ), compared to $\$ 200 / \mathrm{kgHM}$ for conditioning and disposal of vitrified HLW (with a range from $\$ 80 / \mathrm{kgHM}$ to $\$ 310 / \mathrm{kgHM}$ ). ${ }^{89}$ This estimate is consistent with the low end of our range for the difference in cost between disposal of spent fuel and disposal of HLW. An NEA review of transmutation technologies that included cost estimates for various elements of the fuel cycle provided central estimates of $\$ 210,000 / \mathrm{m}^{3}$ for spent fuel conditioning and disposal, compared to $\$ 400,000 / \mathrm{m}^{3}$ for HLW disposal (2000 dollars). If these are converted based on the volume of each type of waste encased in a waste package (using, to be conservative, a high figure of $2 \mathrm{~m}^{3} / \mathrm{tHM}$ for that volume in the case of spent fuel, and the lowest figure for HLW discussed in the volumes sidebar, $0.8 \mathrm{~m}^{3} / \mathrm{tHM}$ ), they come to $\$ 420 / \mathrm{kgHM}$ for spent fuel and $\$ 320 / \mathrm{kgHM}$ for HLW), with a difference of $\$ 100 / \mathrm{kgHM}$, again at the low end of our range. ${ }^{90}$

While the U.S. program has a legal requirement to assign costs fairly between spent fuel and reprocessing wastes, nonetheless current U.S. data do not provide a very good answer as to the relative costs of direct disposal of spent fuel vs. disposal of reprocessing wastes, as the fuel reprocessed to produce the U.S. HLW was low-burnup plutonium production reactor fuel, and working out the "comparable" number of kilograms of commercial spent fuel corresponding to the HLW in each canister is nearly impossible. In 1998, however, the program did provide data on the costs for disposal of HLW from the small amount of commercial reprocessing that took place at West Valley in the United States: this came to approximately $\$ 165$ million for 640 tons of fuel reprocessed, or approximately $\$ 260 / \mathrm{kgHM}^{91}$ If that estimate is increased proportionally with the total repository cost estimate in its 2001 version, the total would be approximately $\$ 320 / \mathrm{kgHM}$ (2003 dollars) just over $60 \%$ of the average spent fuel disposal cost calculated above. This HLW, of course,

\footnotetext{
${ }^{89}$ Generation IV Roadmap: Report of the Fuel Cycle Crosscut Group, op. cit. p. A2-6.

${ }^{90}$ NEA, Accelerator-Driven Systems (ADS) and Fast Reactors (FR) in Advanced Nuclear Fuel Cycles, op. cit., p. 211 and p. 214. The NEA study compares the volume of vitrified HLW canisters without packages for final disposal to the volume of spent fuel with packages for final disposal, and therefore concludes in the text that the volume of HLW from reprocessing is "four to ten times lower" than the volume of spent fuel-but in the footnote where the actual calculation is performed, they inexplicably use the low end of their volume range for HLW and the high end for spent fuel, resulting in the HLW having a volume 17 times less than the spent fuel, rather than four to ten times less. As a result, their per-kilogram estimates are $\$ 420 / \mathrm{kgHM}$ for spent fuel, and $\$ 46 / \mathrm{kgHM}$ for HLW - a ten-fold difference that in-depth analysis of the impact of different types of waste on disposal program costs would not be able to sustain. Using the "four to ten times lower" figure in their text, the cost for HLW disposal, if the cost for spent fuel disposal was $\$ 420 / \mathrm{kgHM}$, would be $\$ 80-\$ 200 / \mathrm{kgHM}$, with the upper bound identical to our estimate.

${ }^{91}$ Office of Civilian Radioactive Waste Management, Analysis of the Total System Life Cycle Cost of the Civilian Radioactive Waste Management Program, DOE/RW-0510 (Washington DC: U.S. Department of Energy, December 1998), p. 37, inflated to 2003 dollars. 640 tHM reprocessed at West Valley from U.S. Department of Energy, Ohio Field Office, West Valley Demonstration Project, "The West Valley Nuclear Timeline," available as of December 16, 2003 at http://www.wv.doe.gov/linkingpages/sitehistory.htm.
} 
has been cooling for decades, and originated from relatively low-burnup spent fuel, so it should have a larger-than-average cost advantage.

Estimates of waste management costs decades in the future will almost certainly be different from what they are today. Nevertheless, it appears unlikely that the qualitative factors affecting the relative balance between the costs of direct disposal of spent fuel and the costs of disposal of reprocessing wastes will change dramatically. Our range from $\$ 100$ $\$ 300 / \mathrm{kgHM}$ of cost savings for disposal of reprocessing wastes - from $25 \%$ to $75 \%$ of the currently estimated total cost of disposal of spent fuel-seems quite likely to contain the real value.

\section{Interim Storage: Postponing the Costs of Either Approach}

Whether a reactor operator chooses reprocessing or direct disposal for spent fuel, costs can be reduced by storing the spent fuel for decades before it is either disposed of or reprocessed, allowing the funds set aside for these purposes to accrue interest. (As discussed above, the accrual of interest is the reason why it is possible to finance the U.S. repository program at a charge of a tenth of a cent per kilowatt-hour generated.) Since interim storage in dry casks can be continued for decades at very little operational cost, utilities can save substantial sums by postponing near-term spent fuel management costs to the long term, thereby leaving all options open and leaving time for technology to develop further and choices to become clearer. This may help explain why the preponderance of the spent fuel generated every year around the world remains in storage, neither reprocessed nor buried in a geologic repository. As legal and political obstacles to dry cask storage are overcome, providing a viable alternative for spent fuel management, fewer and fewer utilities are likely to be willing to pay the extra costs of near-term reprocessing.

\subsubsection{Costs and Prices for Mixed Oxide Fuel Fabrication and Use}

The principal cost of using plutonium recovered from reprocessing as fuel is the fuel fabrication. Like reprocessing, fabricating plutonium into uranium-plutonium mixed oxide (MOX) fuel is expensive, because it requires large capital-intensive facilities with significant numbers of highly trained personnel. It is substantially more expensive than fabricating fuel from low-enriched uranium (LEU), primarily because of the safety requirements resulting from the much higher radioactivity of the plutonium, and also because of the greater safeguards and security requirements when handling weapons-usable material such as separated plutonium. As with reprocessing, the industry is dominated by a small number of firms (COGEMA, BNFL, and Belgonucléaire), and virtually no official information on costs and prices is made public. Here again, therefore, we have relied on what little information is publicly available from the firms themselves, combined with industry, government, and press reports.

\section{Costs}

Most recent reports of capital costs for large MOX plants cover a fairly narrow range. Again, because of the public controversies over it, of the operating facilities most is known 
about BNFL's Sellafield MOX Plant (SMP), designed for a capacity of $120 \mathrm{tHM} / \mathrm{yr}$. SMP is officially estimated to have cost $£ 300$ million to build, ${ }^{92}$ or some $\$ 540$ million in 2003 dollars. When the cost of financing SMP over the prolonged construction period and the subsequent delays in gaining approval are included, SMP was valued at $£ 462$ million in BNFL's accounts as of March 2000, ${ }^{93}$ or about $\$ 750$ million 2003 dollars. Similarly, Siemens' 120 tHM/yr plant at Hanau, Germany, which was built and never operated, reportedly cost DM 1 billion to build (a figure that appears to include interest during construction), or roughly $\$ 750$ million in 2003 dollars. ${ }^{94}$ Estimates of the construction cost of the COGEMA's MELOX plant are not publicly available. Similarly, in 1993, the U.S. Department of Energy (DOE) estimated that the overnight cost of building a facility with a nameplate capacity of $100 \mathrm{tHM} / \mathrm{yr}$ in the United States would be $\$ 440$ million (1992 dollars), or just under $\$ 550$ million in 2003 dollars. $^{95}$

Current capital cost estimates for planned new plants in Japan and the United States are substantially higher, however. The overnight cost of building a MOX plant in the United States for disposition of excess weapons plutonium is currently estimated at over $\$ 1$ billion (not counting over $\$ 300$ million in $R \& D$ and pre-capital expenses, or some $\$ 500$ million allocated for contingencies). ${ }^{96}$ A portion of the capital and operating cost of this facility will go to purifying the weapons plutonium to remove gallium and other impurities before it can be fabricated into MOX fuel; even if this cost represented $30 \%$ of the total, however, the plant would still have an overnight cost of some $\$ 700$ million, substantially more than that of the Sellafield plant. Similarly, the Rokkasho MOX Plant (RMP) in Japan, with a planned capacity of $130 \mathrm{tHM} / \mathrm{yr}$, is expected to cost 120 billion yen (roughly $\$ 1$ billion 2003 dollars).

Operating costs at existing MOX plants have not been published. A group of independent analysts critical of BNFL has estimated the operating costs of SMP, if operating at $100 \mathrm{tHM} / \mathrm{yr}$, at roughly $\$ 50$ million per year (2003 dollars). ${ }^{97}$ This is consistent with an industry analysis which concluded that operations costs in a large industrial MOX facility of this kind would amount to some $\$ 560 / \mathrm{kgHM}$ (2003 dollars) - roughly $\$ 56$ million per year at the same production rate. ${ }^{98}$ The $\$ 50$ million/yr figure is also consistent with the low end of

\footnotetext{
92 See UK Environment Agency, Radioactive Substances Act 1993: Document Containing the Agency's Proposed Decision on the Justification For the Plutonium Commissioning and Full Operation of the Mixed Oxide Fuel Plant (London, UK: UK Environment Agency, October 1998).

${ }^{93}$ See British Nuclear Fuels Limited, The Economic and Commercial Justification for the Sellafield MOX Plant (SMP) (Sellafield, UK: March 2001).

${ }^{94}$ See, for example, Mark Hibbs, "Utilities End Hanau MOX Support; Bonn Now Angling for Russian Pu," Nuclear Fuel, July 6, 1995.

${ }^{95}$ See National Academy of Sciences, Panel on Reactor-Related Options, Management and Disposition of Excess Weapons Plutonium: Reactor Related Options (Washington DC: National Academy Press, 1995), p. 297.

${ }^{96}$ National Nuclear Security Administration, Office of Fissile Materials Disposition, Report to Congress: Disposition of Surplus Defense Plutonium at Savannah River Site (Washington, D.C.: NNSA, February 15, 2002, available as of December 16, 2003 at http://www.nci.org/pdf/doe-pu-2152002.pdf), pp. 5-9.

${ }^{97}$ Mike Sadnicki, Fred Barker, and Gordon MacKerron, Re-Examination of the Economic Case for the Sellafield MOX Plant (Brighton, UK: Science Policy Research Unit, Sussex University, May 2000), p. 21. Their estimate was $£ 14.7$ million annually in fixed operating cost, plus $£ 0.157 /$ tHM in variable cost (2000 money values).

${ }^{98}$ Nigel Mote, "The Commercial Use of Mixed-Oxide Fuel in Light-Water Reactors," presented at "U.S.-

Department of Energy-RF Ministry of Atomic Energy Experts Workshop: Costing Methodologies for Economic
} 
an NEA estimate that the operating costs of such facilities are in the range of $10-25 \%$ of their capital costs. ${ }^{99}$ The 1993 DOE estimate cited above estimated annual operating costs (including an annuity for decommissioning) at \$76 million per year (2003 dollars), also consistent with the low-to-mid section of the NEA range. ${ }^{100}$ The operating costs for the planned U.S. MOX plant, however, are expected to be higher, in the range of $\$ 100$ million per year (2003 dollars). ${ }^{101}$ If $30 \%$ of this figure were for the operations of the facility to purify the weapons plutonium, not needed for a commercial facility, then this figure would be consistent with the 1993 DOE estimate. As with reprocessing, there will be additional costs for interest during construction, start-up, refurbishment, and decommissioning.

MOX plants generally do not produce at their full licensed capacity all the time. If a plant with the officially reported capital cost of SMP and the $\$ 560 / \mathrm{kgHM}$ operating cost reported in the industry study succeeded in producing $100 \mathrm{tHM} / \mathrm{yr}$ throughout a 30 -year life, then the fabrication cost (with assumptions similar to those above for reprocessing plants, except for a six-year construction time rather than a ten-year construction time) for a government-financed facility would be in the range of $\$ 1010 / \mathrm{kgHM}$; for a regulated private facility with a guaranteed rate of return, roughly $\$ 1460 / \mathrm{kgHM}$; and for a private facility with no guaranteed rate of return, approximately $\$ 2140 / \mathrm{kgHM} .{ }^{102}$ Transport of the resulting

Evaluation of Utilization Options of Weapons Plutonium from Defense Programs in the Course of Nuclear Disarmament," Obninsk, Russia, May 12-14, 1999. This figure includes plant operations and transport of uranium and plutonium to the MOX plant, but not transport of the resulting MOX fuel to the reactor.

${ }^{99}$ NEA, Accelerator-Driven Systems (ADS) and Fast Reactors (FR) in Advanced Nuclear Fuel Cycles, op. cit., p. 215.

${ }^{100}$ NAS, Management and Disposition of Excess Weapons Plutonium: Reactor Related Options, op. cit., p. 297.

${ }^{101}$ NNSA, Report to Congress: Disposition of Surplus Defense Plutonium at Savannah River Site, op. cit., pp. 5-9 (dividing their total operations by 13 years of full-scale operations and inflating to 2003 dollars).

102 These figures assume, in addition to the capital cost for SMP described in the text, and an operating cost of $\$ 560 / \mathrm{kgHM}$ : (a) a 6-year construction time; (b) an annual refurbishment cost of $1 \%$ of overnight capital cost; (c) property taxes and insurance for the private facilities of $2 \%$ of overnight capital cost; (d) an annuity for decommissioning, with decommissioning costing $30 \%$ of overnight capital cost, and occurring 20 years after the 30 -year operational life of the plant, and funds set aside in a fund that generates a $3 \%$ real interest rate, resulting in a decommissioning charge of roughly $\$ 19 / \mathrm{kgHM}$; (e) continuous operation at $100 \mathrm{tHM} / \mathrm{yr}$ throughout the 30year life of the plant; and (f) startup costs equal to one year of operations costs. As in the case of reprocessing plants, annual fixed charge rates are assumed to be $5.8 \%$ for government financing, $10.3 \%$ for a private entity with a guaranteed rate of return, and $18.8 \%$ for a private entity with no guarantee of revenues - plus $2 \%$, as just noted, for property taxes and insurance in the case of the private facilities. Describing the spend-out of funds during the six-year construction time with the beta-binomial S-curve described in Appendix A, and assuming real rates for interest during construction (IDC) of $4 \%, 6.4 \%$, and $9 \%$ for the government-owned, regulatedutility-owned, and private-venture-owned cases, respectively, leads to adding $11.5 \%, 19 \%$, and $27.4 \%$ to the overnight construction costs to find the total capital cost including interest during construction. Thus for a government-owned facility, the total capital cost, including overnight cost, IDC, and startup costs, would be roughly $\$ 660$ million; the annual capital contribution to the revenue requirement would be roughly $\$ 38$ million; and the capital contribution to per-kilogram cost would be just over $\$ 380 / \mathrm{kgHM}$. Adding $\$ 560 / \mathrm{kgHM}$ in operations cost would bring the per-kilogram cost to some $\$ 940 / \mathrm{kgHM}$, and refurbishment and decommissioning set-asides would bring the total to some $\$ 1010 / \mathrm{kgHM}$. For a facility owned by a regulated utility, the total capital cost would be roughly $\$ 700$ million, contributing an annual revenue requirement of nearly $\$ 72$ million, or nearly $\$ 720 / \mathrm{kgHM}$; operating, refurbishment, and decommissioning costs are assumed to be the same, but there would also be a cost of some $\$ 110 / \mathrm{kgHM}$ for property taxes and insurance, bringing total costs to some $\$ 1460 / \mathrm{kgHM}$. For a facility owned by a private venture without a regulated rate of return, the total capital cost would be over $\$ 740$ million, the annual revenue requirement would be roughly $\$ 140$ million, the capital contribution to per-kilogram cost would be $\$ 1400 / \mathrm{kgHM}$, and the total MOX fabrication cost would 
MOX fuel to the reactor will be significantly more expensive than transport of equivalent LEU (because of the additional safety and security issues involved in transporting MOX), and might add $\$ 120 / \mathrm{kgHM}$ to these figures, ${ }^{103}$ for totals of $\$ 1130$ (government), $\$ 1580$ (regulated), or $\$ 2260$ (private unregulated).

These costs apply for large fabrication campaigns of fuel of the same design. When a customer needs only a modest amount of MOX fuel, using different design parameters from those used by other customers, then the plant has to be shut down to change over more frequently, and throughput suffers. This is among the reasons why, as described below, prices reported by German and Swiss utilities (generally buying MOX in much smaller lots than the giant French utility, Eléctricité de France) are generally substantially higher. As with reprocessing, economies of scale also have their effect: fabrication in small, less automated facilities such as the Belgonucléaire plant or COGEMA's Caderache plant is significantly more expensive than fabrication in large, automated facilities. Per-kilogram costs would increase substantially if demand were not sufficient to keep the plant fully booked, so that the fixed costs of capital and operations have to be spread over a smaller number of kilograms of fuel. ${ }^{104}$

In many cases, there are additional costs to a reactor operator associated with using MOX fuel rather than LEU fuel, which, to be conservative, we have not included in this analysis. First, MOX fuel is often licensed to lower burnups than LEU fuel; in countries where this is the case, reactor operators with MOX fuel in part of their reactors will have to shut down for refueling more often than if they were using only LEU. Second, since fresh MOX fuel contains weapons-usable plutonium, after the fuel arrives at a reactor site and before it is loaded into a reactor, it typically requires more security than would fresh LEU fuel, imposing additional costs. (In some cases, however, the fresh MOX fuel is simply placed in the pool with the spent fuel until it is loaded, without any additional facilities or security arrangements, on the assumption that it would be difficult and dangerous for attackers to attempt to remove it from the pool.) Third, in a number of countries there are substantial political concerns over the use of MOX (which in some cases may require, for example, additional payments to local communities), and additional licensing requirements for reactors wishing to use both MOX and LEU fuels. Hence, the market value of a kilogram of MOX fuel, if there were an open market allowing utilities to choose their fuels, would not be the same as that of a kilogram of LEU fuel of equivalent energy value, as assumed here, but rather would be significantly less. In the case of the U.S. program for disposition of excess weapons plutonium, for example, to convince any U.S. utilities to use this fuel required offering it at a price some $40 \%$ below the price of LEU fuel of equivalent energy

be roughly $\$ 2140 / \mathrm{kgHM}$. As described above in the case of reprocessing plants, assumptions on fixed charge rates, refurbishment, property insurance, and taxes, are drawn from Nuclear Wastes: Technologies for Separations and Transmutation, op. cit., pp. 413-445; assumptions on decommissioning are drawn from BNFL's own assumptions in OECD/NEA, The Economics of the Nuclear Fuel Cycle, op. cit., p. 114.

${ }^{103}$ This is the figure, converted to 2003 dollars, cited in Mote, "The Commercial Use of Mixed-Oxide Fuel in Light-Water Reactors," op. cit.

${ }^{104}$ Whether there will be sufficient demand for SMP's services to allow the plant to break even (treating its initial capital cost as sunk) has been a substantial source of controversy between BNFL and its critics. See, for example, Sadnicki, Barker, and MacKerron, Re-Examination of the Economic Case for the Sellafield MOX Plant, op. cit. 
value $^{105}$ - equivalent to increasing the net fabrication price for the MOX fuel by several hundred dollars per kilogram. In addition, we have assumed a reprocessing and recycling system that is operating efficiently and in balance - so that there are no charges for storage of separated plutonium, or for separation of the americium that builds up if separated plutonium is stored for an extended period before fabrication. In the industry currently, such an efficient system has not been achieved, over 200 tons of separated civilian plutonium are in storage around the world, and charges for plutonium storage and americium removal represent a substantial cost to reactor operators - commercial rates being estimated at $\$ 1000$ $\$ 2000$ per kilogram of plutonium per year for storage, and $\$ 10,000-\$ 28,000$ per kilogram of plutonium for americium removal. ${ }^{106}$ Including several years of plutonium storage and one round of americium removal would dramatically increase the effective MOX cost in our model.

\section{Prices}

MOX fabrication prices, like costs, are not publicly divulged. For essentially all of the 1980s and 1990s, demand was higher than supply, and in this seller's market, prices were higher than one would expect based on the underlying plant costs described above. One review indicates that in the $1980 \mathrm{~s}$, real prices were in the range of $\$ 1900-\$ 2400$ (escalated to 2003 dollars), while in the 1990 s they were in the range of $\$ 2100-\$ 2700 .{ }^{107}$ A DOE survey of fabricators in 1993 reported a range of offers centering around $\$ 1850 / \mathrm{kgHM}$ (escalated to 2003 dollars). ${ }^{108}$ Eléctricité de France enjoys lower prices, as it buys very large quantities of a standard product, and has a special relationship with COGEMA and its MELOX plant (including having the same principal owner as COGEMA—the French government). ${ }^{109}$

${ }^{105}$ The Department of Energy has stated that the \$449 million difference between its 1996 estimate of \$1.027 billion (2001 dollars) for the fuel credit for the MOX fuel produced and the $\$ 578$ million (2001 dollars) it estimated in 1999 resulted from the 1996 estimate being based on equal per-kilogram value for the MOX and equivalent LEU fuel, and the 1999 estimate being based on the assumption that "the economic value of MOX fuel is lower than of the corresponding displayed LEU fuel." This represents a reduction in value by over 40 percent. See U.S. National Nuclear Security Administration, Office of Fissile Materials Disposition, Report to Congress on the Projected Life-Cycle Costs of the U.S. and Russian Fissile Materials Disposition Programs (Washington, DC: NNSA, March 30, 2001), pp. 4-9. This report was never publicly released, but was obtained and leaked by the Nuclear Control Institute.

${ }^{106}$ NEA, Accelerator-Driven Systems (ADS) and Fast Reactors (FR) in Advanced Nuclear Fuel Cycles, op. cit., p. 213. These figures are in 1987 dollars, but based on recent discussions, it appears that offered prices are still in similar ranges, so we have not inflated them to 2003 dollars.

${ }^{107}$ Varley and Collier, Fuel Cycle Cost Data, op. cit.

${ }^{108}$ See discussion in NAS, Management and Disposition of Excess Weapons Plutonium: Reactor Related Options, op. cit., pp. 295-297, reporting a 1992 dollar figure of \$1500/kgHM. That study, after an extensive review of the literature available at that time, provided a central estimate of fabrication cost of $\$ 1565 / \mathrm{kgHM}$ (1992 dollars), for a facility built with a 7\% real cost of money paying no taxes or insurance (see pp. 292-298). See also discussion of the $\$ 1500 / \mathrm{kgHM}$ (1992 dollars) figure used in Frans Berkhout et. al., "Disposition of Separated Plutonium," Science and Global Security, 1992, Vol. 3, pp. 1-53.

${ }^{109}$ Eléctricité de France reported a MOX fabrication price of 6,000 francs/kgHM in 1996 (roughly $\$ 1,200 / \mathrm{kgHM}$ in 2003 dollars); see Anne MacLachlan, "EDF Makes Case for Economic Advantage of Reprocessing Over Interim Storage," Nuclear Fuel, October 7, 1996. A more recent study for the French government referred to a price of 8,000 francs $/ \mathrm{kgHM}$ (2000 money values); while significantly higher in francs, with inflation in the intervening period and fluctuations in currency exchange rates, is approximately the same (\$1240/kgHM) in 2003 dollars. See Marignac, "Briefing: Results of the 'Charpin-Dessus-Pellat' Mission Economic Forecast Study of the Nuclear Power Option" op. cit., p. 7. 
German and Swiss utilities, on the other hand, tend to report much higher prices, which reflect their smaller purchases, and the fact that much of their fuel has been fabricated in smaller, less automated plants. ${ }^{110}$ With SMP now open, and the supply of MOX fabrication services likely outstripping demand in the future, prices may fall significantly from their 1990s levels - though the MOX fabrication firms will still have substantial leverage to demand high prices, since the only available alternative for utilities with plutonium stored at their sites is to pay ongoing plutonium storage costs determined by the same firms that offer the MOX fabrication service.

\section{Longer-Term Future in New Facilities}

Like reprocessing, if plutonium fuel is to play a significant part in the future of nuclear energy, new plutonium fuel fabrication facilities will ultimately be required. The MOX case is different from the reprocessing case, however, in that there is no large-scale military experience, and even more modest commercial experience in large, modern facilities. Overall, plutonium fuel fabrication is less thoroughly matured than is PUREX reprocessing, leaving more room for further improvement (and cost reduction) in the future. As one recent review put it, "new plants would benefit greatly from the extensive experience gained during the last decades, thereby allowing them to simplify the plants, decrease their size, and reduce maintenance requirements."

If, however, the focus remains on pellet-based fuels for LWRs similar to current LEU fuels, manufacturing each pellet to stringent standards will continue to be an exacting process, and there may be limits to the scope of potential cost reduction. Large modern facilities are already very highly automated and designed to minimize maintenance requirements as much as was possible at the time they were designed. Moreover, as with reprocessing, there may also be trends that would increase per-kilogram costs over timeincluding not only increasing societal demands for more stringent safety and security precautions (a substantial factor driving the high cost of the planned U.S. MOX plant), but also customer demands to fabricate fuels with higher plutonium content, using more radioactive plutonium recovered from higher-burnup spent fuels, and to be able to accept plutonium that has been stored longer and therefore includes more gamma-emitting americium. Thus, with current technologies, one might expect that future costs might be reduced, but not dramatically so. There may also be opportunities for new technologies that could simplify plutonium fuel fabrication, and potentially reduce cost: advocates have long argued, for example, that so-called "vibropak" fuels, in which the plutonium and uranium powders are packed into the fuel pins by vibration, with no pellet manufacturing involved, could significantly reduce costs. Initial studies for the weapons plutonium disposition

\footnotetext{
${ }^{110}$ See, for example, Hensing and Schulz, An Economic Comparison of Different Back-End Paths of Nuclear Power Plants, op. cit.. They give an estimate of $4000 \mathrm{DM} / \mathrm{kgHM}$ (over $\$ 3000 / \mathrm{kgHM}$ in 2003 dollars), and point out than an earlier study by the association of German utilities used a figure of $5000 \mathrm{DM} / \mathrm{kgHM}$ (over $\$ 3700 / \mathrm{kgHM}$ in 2003 dollars). Similarly, a German court ordered the state of Hesse to compensate Siemens for the state's closure of Siemens' small Hanau MOX plant, with an amount derived from an estimated price of $5300 \mathrm{DM} / \mathrm{kgHM}$ (almost \$4000/kgHM in 2003 dollars). See Mark Hibbs, "Court Says Hesse Must Pay Siemens for Costs of Shutting MOX Plant," Nuclear Fuel, April 26, 1993.

${ }^{111}$ NEA, Accelerator-Driven Systems (ADS) and Fast Reactors (FR) in Advanced Nuclear Fuel Cycles, op. cit., p. 213.
} 
program, however, suggest that the operational savings from using vibropak fuels for a portion of that program would not be sufficient to justify the necessary cost of building an additional MOX plant for that part of the effort - in other words, that using both pellet MOX technology and vibropak technology would be more expensive than using only pellet MOX technology. ${ }^{112}$ Further development is likely to be required to determine whether new approaches such as vibropak can offer substantial MOX fuel cost reductions.

The types of fabrication likely to be needed for systems designed for separations and transmutation of waste are likely to be significantly more expensive than traditional MOX fabrication - because the intensely radioactive fuel materials involved in such systems, including not only plutonium and uranium but minor actinides as well, will require the fuels to be fabricated remotely, in heavily shielded facilities. On the other hand, a variety of fuel types have been proposed for future systems that do not require manufacturing pellets to tight tolerances for size, shape, and density, as MOX fuel does (such as concepts for fluid fuels in which there would be no fuel fabrication, in the most extreme case), and these could, once demonstrated, involve lower fabrication costs. Two recent reviews both concluded that the per-kilogram cost of fabrication in fast-neutron reactor systems intended for transmutation would be more than twice as high as the cost of traditional MOX fabrication. ${ }^{113}$

Overall, our central estimate of $\$ 1500 / \mathrm{kgHM}$ is quite conservative with respect to prices actually being charged to most reactor operators at existing facilities, but is reasonable for a future world in which supply and demand was balanced and MOX prices closely reflected MOX production costs. Our $\$ 700 / \mathrm{kgHM}$ lower bound would require either very substantial technological innovation or sales from facilities whose capital costs are already amortized (and which do not, therefore, reflect a long-run sustainable cost for providing the service). The $\$ 2300 / \mathrm{kgHM}$ upper bound is in the range of prices already charged at existing facilities, and could reflect future prices if the societal and customer demands above drive costs higher than past experience in the future.

\section{Resulting Value (Cost) of Separated Plutonium}

If the cost of making and using MOX is less than the cost of making and using fresh LEU of equivalent energy value, then plutonium will be economically value. If, on the other hand, the cost of making and using MOX fuel is higher than the cost of making and using fresh LEU, plutonium will have a negative value (it will not simply be zero, because of the high costs of storing the separated plutonium if it is not used as fuel). With a $\$ 1500 / \mathrm{kgHM}$ fabrication price, and assuming that providing depleted or reprocessed uranium to mix with the plutonium is free (except for a $\$ 6 / \mathrm{kgU}$ price for converting the material to appropriate

\footnotetext{
${ }^{112}$ See Joint U.S.-Russian Working Group on Cost Analysis and Economics in Plutonium Disposition, Scenarios and Costs in the Disposition of Weapon-Grade Plutonium Withdrawn From Russia's Nuclear Military Programs (Washington, DC: U.S. Department of Energy, April 2003). The group did not examine an all-vibropak MOX program compared to an all-pelletized MOX program (the best basis for comparison of total costs), as vibropak fuel for the VVER-1000 reactors would not be ready and licensed in time to meet the program goals.

${ }^{113}$ NEA, Accelerator-Driven Systems (ADS) and Fast Reactors (FR) in Advanced Nuclear Fuel Cycles, op. cit., p. 211 and 216, and Generation IV Roadmap: Report of the Fuel Cycle Crosscut Group, op. cit. p. A2-6 and A2-8.
} 
oxide powder for fuel fabrication), then the cost for each kilogram of heavy metal in plutonium fuel (discounted to the time of fuel loading) will be roughly $\$ 1460 .{ }^{114}$ At a uranium price of $\$ 40 / \mathrm{kgU}$ (comparable to recent prices), and for the central estimates of the other values of the relevant parameters, the cost of a kilogram of fresh low-enriched uranium of equivalent energy value would be $\$ 1130$. Hence, every kilogram of MOX produced would represent an additional cost in the range of $\$ 330 / \mathrm{kgHM}$, and since some 15 kilograms of MOX could be produced from each kilogram of plutonium, each kilogram of separated plutonium would represent a liability to its owner (under these assumptions) of roughly $\$ 5000$. The uranium price would have to roughly double to bring this liability down to zero- - even if reprocessing of fuels with ever higher burnups (producing plutonium with more undesirable isotopes) did not increase the problem over time.

\subsubsection{Costs of Interim Storage of Spent Fuel}

For reactor operators who choose near-term reprocessing, interim storage of spent fuel for decades is not required. Storage for several decades generally is required for direct disposal, as most repositories are not expected to be available for decades to come. We have therefore counted interim storage as an extra cost for the direct disposal fuel cycle (though the latest reactors are being built with pools able to accommodate storage of all the fuel they will generate in their lifetime, reducing or eliminating this extra storage cost). Costs of interim storage can vary significantly depending on the specific technology chosen, whether fuel is to be transported to a centralized site or kept at reactor sites, whether taxes or other payments must be made to local, regional, or national governments, whether the fuel is stored at an operating reactor site and therefore can be a modest addition to license maintenance costs that must be paid in any case or is stored at sites with no other activity and therefore must bear all costs without sharing, and the like. Dry-cask storage of spent fuel, in particular, is now a well-established technology for storing spent fuel for decades with minimal operating costs.

In the United States, total upfront costs to establish a new dry storage facility at a reactor site (which are largely fixed, regardless of the amount of spent fuel to be stored) are estimated to be in the range of $\$ 10$ million. ${ }^{115}$ Costs to purchase and load the dry casks, including labor, consumables, and decommissioning, are estimated to be in the range of $\$ 70$ 90 per kilogram of heavy metal $(\mathrm{kgHM})$ in the spent fuel. ${ }^{116}$ Operating costs are very modest, since virtually nothing needs to be done to the casks each year once they are loaded; the principal operating costs relate to providing the security and safety monitoring needed to

\footnotetext{
${ }^{114}$ See calculation in Appendix A.

115 \$9 million (1998 dollars) in TRW Environmental Safety Systems Inc, CRWMS Modular

Design/Construction and Operation Options Report (Washington DC: Department of Energy, December 1998), table E-7; \$8-\$12 million (1998 dollars) in Eileen M. Supko, "Minimizing Risks Associated with PostShutdown Spent Fuel Storage and LLW Disposal," paper presented at the Infocast "Nuclear Power in the Competitive Era" post-conference workshop, "Developing Risk Strategies for Successful Decommissioning," January 30, 1998.

${ }^{116}$ TRW, CRWMS Modular Design, op. cit., estimates $\$ 80 / \mathrm{kgHM}$ for the total of all these costs (table E-7); Supko, "Minimizing Risks," op. cit, estimates $\$ 60-\$ 70 / \mathrm{kgHM}$ for casks and loading, with another $\$ 1 / \mathrm{kgHM}$ for eventual unloading, and a total of \$2-\$4 million for decommissioning of a 1000-ton facility (adding another \$2$\$ 4 / \mathrm{kgHM})$. These have been escalated to 2003 dollars in the text.
} 
maintain the NRC license for the facility. For storage sites co-located with operating reactors, many of these costs can be charged to the reactor operation, and the net additional operating costs are estimated to be only $\$ 820,000$ per year (largely independent of the amount of spent fuel to be stored). ${ }^{117}$ Thus the total undiscounted costs for 40 years of dry cask storage at an operating reactor site in the United States, for a 1000 tonnes of spent fuel, would be in the range of \$110-130/kgHM (assuming the higher cask and loading costs); with the modest annual operating costs discounted at a 3\% real annual rate, this figure would be in the range of $\$ 100-120 / \mathrm{kgHM}$.

For independent storage sites or storage sites at reactors which have been shut down, all of the costs of maintaining the license, including security and safety personnel, must be attributed to the storage facility, making its net additional operational cost substantially higher. For shutdown reactors with all their spent fuel in dry storage, operating costs are estimated to be \$3.3-4.4 million per year. ${ }^{118}$ Total undiscounted life-cycle costs for forty years in this case would range from $\$ 210-\$ 275 / \mathrm{kgHM}$ (for a 1000-tonne facility), or \$155$\$ 200 / \mathrm{kgHM}$ with the 40 years of operations cost discounted at a 3\% real annual rate. A large centralized facility could spread these operations costs over a larger amount of spent fuelbut there would be additional up-front costs for transportation to the centralized site. ${ }^{119}$

Somewhat higher costs have been estimated in Japan (where all fuel cycle costs are higher than they tend to be in the United States, as many other costs are). In an official 1998 study, total undiscounted costs for 40 years of storage in a 5,000-tonne centralized dry cask facility were estimated at 160.8 billion yen (some $\$ 290 / \mathrm{kgHM}) .{ }^{120}$ When the authors of that study applied a $5 \%$ discount rate over the 54 years considered from start of construction to completion of decommissioning and disposal, these total costs resulted in a discounted per kilogram cost of $\$ 280 / \mathrm{kgHM}$ (a small difference because operations and decommissioning costs were only estimated to be $15 \%$ of total undiscounted cost).

For both the United States and Japan, it should be noted that costs of the variety of benefits that may be paid to the local community to build public acceptance and gain government approvals are not included in these totals. These costs will vary from zero to significant additions to the total, depending on the circumstances of the individual case.

\footnotetext{
${ }^{117}$ TRW, CRWMS Modular Design, op. cit. (table E-7), escalated to 2003 dollars.

${ }^{118}$ Supko, “Minimizing Risks," op. cit. gives \$3-\$4 million; the estimate in TRW, CRWMS Modular Design, op. cit. (table E-7) is $\$ 4$ million/yr; these have been escalated to 2003 dollars in the text.

${ }^{119}$ See discussion in Bunn et al., Interim Storage of Spent Nuclear Fuel, pp. 13-16. We have not included in our cost estimate the possibility that reactor operators might have to pay for on-site dry cask storage, and then pay again for centralized dry-cask storage of the same fuel, before eventual disposal in a repository; it appears that relatively few reactor operators will face this kind of double whammy, and if we were to include the costs of such a dysfunctional fuel cycle for the once-through case, we should include comparable costs for the reprocessing case, such as the costs of extended storage of separated plutonium, and americium separation (neither of which are included in our estimates in this study, though both are resulting in substantial costs in the current nuclear fuel market).

${ }^{120}$ Toward Implementation of Interim Storage for Recycled Fuel Resources, Interim Report of the Nuclear Energy Working Group, Advisory Committee for Energy, Agency of Natural Resources and Energy, Ministry of Trade and Industry (Tokyo, Japan: June 11, 1998), with figures converted using a three-year average of currency exchange rates centered on 1998, and then inflated to 2003 dollars using U.S. GDP deflators.
} 
In some cases, significantly higher per-kilogram prices have been paid or considered, when very limited storage capacity was available in a particular country, and another country agreed to accept that country's fuel, for storage or for reprocessing. Russia, for example, recently passed a law allowing it to import foreign spent nuclear fuel, and expects substantially higher per-kilogram fees than just described for in-country storage. ${ }^{121}$ It must be recognized, however, that accepting spent fuel from a foreign country is a fundamentally different service than in-country interim storage - and once the fuel has arrived in the foreign country to which it is shipped, the economic factors relating to whether it should be reprocessed or stored and eventually disposed of directly will be similar to those described in this report.

We have chosen $\$ 200 / \mathrm{kgHM}$ as our central estimate of interim storage costs (substantially more than the cost of at-reactor dry cask storage in the United States, and comparable to the discounted present value of the cost of independent dry cask storage in the United States at small facilities), with a range of $\$ 100 / \mathrm{kgHM}$ to $\$ 300 / \mathrm{kgHM}$. In the future, the direct costs of storage are likely to decline (as reactors are built with sufficient storage for their lifetimes, and technology improves), but the indirect costs, including payments to nearby communities, could increase.

\subsubsection{Enrichment Prices}

In recent years, enrichment prices have been somewhat volatile, because of ups and downs of market competition, trade actions, and the U.S.-Russian Highly Enriched Uranium Purchase Agreement. Long-term contract prices for enrichment services fell from earlier levels of over $\$ 100 / \mathrm{SWU}$ (in then-year dollars) to the mid- $\$ 80$ s by late 1999 , only to increase back to some $\$ 110 / \mathrm{SWU}$ in 2001, as a result of market uncertainties caused by the U.S. Enrichment Corporation's trade actions against its European competitors. ${ }^{122}$ As with uranium prices, the gap between long-term and spot SWU prices has declined substantially as utilities have become more confident in supply and are less willing to pay large premiums for the security of long-term contracts. In the first half of 2003, the spot SWU price in the United States was in the range of $\$ 100-\$ 110 /$ SWU. ${ }^{123}$ Since the trade action does not affect purchases by European utilities (and, in fact, creates incentives for European enrichers to sell more of their service there than in the United States), prices in Europe are now lower than prices in the United States, though higher than they were in $1999 .{ }^{124}$ One projection in mid2003 suggested that SWU prices in long-term contracts would likely remain in the range of $\$ 105 /$ SWU for some years, and then rise slightly toward the end of the decade. ${ }^{125}$

Although it is possible that some combination of trade restraints and uncertainties in deliveries from Russian military supplies could drive prices temporarily to levels well above

\footnotetext{
${ }^{121}$ See discussion in Bunn et al., Interim Storage of Spent Nuclear Fuel, op. cit., Chapter 4.

${ }^{122}$ For a discussion, with a graph of long-term SWU contract prices over time, see Thomas L. Neff, "Decision Time for the HEU Deal," Arms Control Today, June 2001, available as of December 16, 2003 at http://www.armscontrol.org/act/2001 06/nefjun01.asp.

${ }^{123}$ Spot SWU prices are freely available from Ux Consulting, at http://www.uxc.com.

${ }^{124}$ Euratom Supply Agency, Annual Report 2002, op. cit., p. 15.

${ }^{125}$ See Knapik, "LES Hires Advisers to Prime Renewed Push to Site Tennessee Plant; PACE Slams USEC," op. cit., reporting on Energy Resources International projections.
} 
$\$ 100 /$ SWU, the enrichment market is competitive, new enrichment plants are being considered, and it is unlikely that prices would stabilize at significantly more than $\$ 100 / \mathrm{SWU}$ for long (as high prices would call forth investment in new supplies that would drive down prices). Gas-centrifuge enrichment is a mature technology, with a cost of production below \$80/SWU, and its cost appears highly unlikely to increase over the next few decades: rather, costs can be expected to decrease as the next generation of more efficient centrifuge designs are put in place. ${ }^{126}$ Additional supplies from military stockpiles would affect enrichment prices as well. The Nuclear Energy Agency (NEA) of the Organization for Economic Cooperation and Development (OECD) has estimated that enrichment prices in the "short to medium term" will be in the range $\$ 80-\$ 120 /$ SWU; over the longer term, the NEA reports that "it is hoped" that new facilities using advanced processes can reduce the cost of enrichment to the range of $\$ 50 /$ SWU. ${ }^{127}$

We have chosen a central estimate of $\$ 100 / \mathrm{SWU}$, with a high of $\$ 150 / \mathrm{SWU}$ and a low of $\$ 50$ per SWU, allowing a somewhat broader range of possibilities than the near-tomedium term NEA projection. Enrichment prices are unlikely to reach either the high or the low end of the price range for some decades to come, barring a substantial technological breakthrough or a substantial reduction in the number of suppliers in the market.

\subsubsection{Low Enriched Uranium Fuel Fabrication Prices}

Fabrication prices for LEU fuel vary depending on such factors as the burnup and neutronic efficiency desired, the competitiveness of different markets, and the type of reactor. In general, fabricating fuel for boiling-water reactors (BWRs) is more costly than fabricating fuel for pressurized-water reactors (PWRs). For either type of reactor, prices are somewhat higher in Europe, where the markets are less competitive, than in the United States, and are higher still in Japan (though Japanese prices have recently declined substantially due to the introduction of competition). ${ }^{128}$ Prices have not increased substantially with increased burnup; it appears that cost reductions are keeping pace with added technology, much as has been the case with personal computers in recent years, where prices remain roughly stable but capabilities increase over time. Past overcapacity in the fabrication market has made the market competitive, reducing prices and leading to substantial consolidation of the fabrication firms. ${ }^{129}$ Unlike uranium, conversion, or enrichment prices, LEU fabrication prices (which depend on the specifics of each company's design and processes) are considered proprietary information and are not regularly tabulated in published form. Nevertheless, there is sufficient information available to make a good judgment of prices.

\footnotetext{
${ }^{126}$ Varley and Collier, Fuel Cycle Cost Data, op. cit.

${ }^{127}$ Nuclear Energy Agency, Trends in the Nuclear Fuel Cycle: Economic, Environmental, and Social Aspects (Paris, France: NEA, 2001), p. 54 and p. 83.

${ }^{128}$ Personal communication with Japanese industry participant. See also discussion of this overall picture in Charles K. Anderson, "Developments in the U.S. and European LWR Fabrication Markets: A 1998 Update," in Uranium Institute: 23 ${ }^{\text {rd }}$ Annual Symposium, September 10-11, 1998.

${ }^{129}$ See, for example, NEA, Trends in the Nuclear Fuel Cycle, op. cit., p. 22.
} 
The NEA projects LEU fabrication prices in the short to medium term at \$200$\$ 300 / \mathrm{kgHM}$ (2001 dollars). ${ }^{130}$ A previous survey by a National Academy of Sciences committee chose a central estimate of $\$ 250 / \mathrm{kgHM}^{131}$ This central estimate is somewhat higher than recent prices in the highly competitive U.S. market, but somewhat lower than most prices in the European market. ${ }^{132}$ One projection in mid-2003 suggested that competitive bids in the U.S. market for PWR fuel were in the range of $\$ 220 / \mathrm{kgHM}$, and would remain largely flat; European market prices were said to be $25-30$ percent higher. ${ }^{133}$ Suppliers' actual fabrication cost is estimated to be below $\$ 200 / \mathrm{kgHM} .{ }^{134}$

We have chosen a central estimate of $\$ 250 / \mathrm{kgHM}$ for LEU fabrication cost, with a low of $\$ 150 / \mathrm{kgHM}$ and a high of $\$ 350 / \mathrm{kgHM}$, again allowing a somewhat broader range of possibilities than the NEA projections. (We consider the very high prices paid for fabrication services in Japan prior to the introduction of competition to be an outlier, not likely to be broadly applicable to prices available to utilities in the future.) The technology of LEU fuel fabrication is mature, the suppliers at least reasonably diverse, and the safety and health impacts modest, so it appears unlikely that this price would change substantially in the near future. Prices could go up if utilities decide to pursue still higher burnups, requiring new materials and designs - but that would also substantially reduce the desirability of reprocessing, as the high-burnup uranium and plutonium to be recovered would be much less attractive material for reactor fuel (see discussion below). Prices could also go up if ongoing consolidation created effective monopolies in some markets-but that artificial market situation would probably be corrected in the long term.

\subsubsection{Premiums for Handling Reprocessed Uranium}

Uranium recovered from reprocessing contains a variety of undesirable isotopes built up during its irradiation in the reactor. Chief among these are U-232 (whose radioactive daughter products emit highly penetrating gamma rays, increasing requirements for radiation protection for workers in facilities handling reprocessed uranium) and U-236 (which is a neutron absorber, requiring that the enrichment of LEU made from reprocessed uranium be higher than the enrichment of LEU made from fresh uranium to achieve the same burnup).

Because of the higher radioactivity, fuel cycle firms charge higher prices for conversion, enrichment, and fabrication of reprocessed uranium. If fresh uranium is cheap, reprocessed uranium typically has no value at all - though it is not a liability to the same degree that plutonium is, as its storage is very cheap. As a result of these factors, while recycling of reprocessed uranium has been demonstrated, and is being done on a modest scale, ${ }^{135}$ most utilities have not bothered to recycle their reprocessed uranium: the vast

\footnotetext{
${ }^{130}$ NEA, Trends in the Nuclear Fuel Cycle, op. cit, p. 54.

${ }^{131}$ NAS 1995, pp. 286-287, took \$200/kgHM (1992\$) as its central estimate, rounded from \$248 to \$250 2003 dollars.

${ }^{132}$ Varley and Collier, Fuel Cycle Cost Data, op. cit.

${ }^{133}$ Knapik, "LES Hires Advisers to Prime Renewed Push to Site Tennessee Plant; PACE Slams USEC," op. cit., reporting projections from Energy Resources International.

${ }^{134}$ Varley and Collier, Fuel Cycle Cost Data, op. cit.

${ }^{135}$ An ingenious approach, being pursued in a partnership between Russian and European firms, is to mix the reprocessed uranium with HEU made excess as a result of arms reductions. With this approach, the undesirable
} 
majority of all the uranium ever recovered from reprocessing of LWR fuel remains in storage. Market estimates of the relevant premiums are therefore somewhat uncertain, as the prices charged to date reflect a more or less pilot-scale market with few suppliers. ${ }^{136}$ Based on data provided by market participants, we have chosen a central estimate of $\$ 15 / \mathrm{kgU}$ for conversion (with a range from $\$ 5$ to $\$ 25$ ), $\$ 5$ for enrichment (with a range from $\$ 0$ to $\$ 10$ ), and $\$ 10$ for fuel fabrication (with a range from $\$ 0$ to $\$ 20) .{ }^{137}$ Over time, approaches to managing reprocessed uranium will probably improve, but the burnup of fuels will increase, making the reprocessed uranium less economically desirable.

The possibility of laser enrichment. For some decades to come, it appears that gas centrifuges will continue to be the dominant enrichment technology. They will only be replaced if some other technology appears which is significantly cheaper. Laser enrichment is one possibility for significant cost reduction, though both the United States and France have phased out most of their support for near-term commercialization efforts. If laser enrichment is eventually commercialized, this would lower the lines on figure 2.1 slightly, since the ability to easily remove undesirable isotopes would increase the value of uranium recovered from reprocessing. At the same time, significant decreases in enrichment prices would make the once-through cycle somewhat more attractive, and free up more uranium resources (as lower prices would make it attractive to strip more of the U-235 from each kilogram of natural uranium, leaving less in the enrichment tails).

\subsubsection{Conversion Prices}

Conversion of uranium from $\mathrm{U} 3 \mathrm{O} 8$ to uranium hexafluoride for enrichment is a relatively minor cost in the nuclear fuel cycle, which has little impact on the economic calculations presented in this report. We have chosen a central estimate of $\$ 6 / \mathrm{kgU}$, with a low of $\$ 4 / \mathrm{kgU}$ and a high of $\$ 8 / \mathrm{kgU}$. This is more than the depressed prices of $2000-2001$; the U.S. spot price in the first half of 2003 was under $\$ 5 / \mathrm{kgU}$, with the European price over $\$ 6 / \mathrm{kgU} .{ }^{138}$ Converdyn, the main U.S. supplier, estimates its production cost at $\$ 4.40$ -

isotopes are not further concentrated by additional enrichment, and there is no need to convert the reprocessed uranium to uranium hexafluoride and back again. This is currently being done at Elektrostal, in Russia, where the resulting blended LEU is fabricated into fuel for European reactors under license to Siemens (whose fuel fabrication division is now part of Framatome). See, for example, Ann MacLachlan, "Dutch Utility EPZ Buys Russian Fuel Made From Blending HEU, Reprocessed Uranium," Nuclear Fuel, September 30, 2002; Ann MacLachlan, "GKN Says Elektrostal Option Only Solution For Repu Use," Nuclear Fuel, September 30, 2002; and Mark Hibbs, "Framatome, Elektrostal Looking to Double Business in Downblended HEU Fuel," Nuclear Fuel, August 19, 2002.

${ }^{136}$ Collier and Varley, Fuel Cycle Cost Data, op. cit.

${ }^{137}$ NEA, Accelerator-Driven Systems (ADS) and Fast Reactors (FR) in Advanced Nuclear Fuel Cycles, op. cit., p. 212 , cites a central cost estimate of $\$ 24 / \mathrm{kgU}$ for conversion of reprocessed uranium, compared to $\$ 5 / \mathrm{kgU}$ for conversion of fresh uranium, a premium of $\$ 19 / \mathrm{kgU}$ for handling the irradiated material. The NEA study points out that such conversion costs can be avoided by using the recovered uranium for MOX fabrication, but (a) we have assumed in this analysis that uranium for MOX fabrication is free, so taking this approach would amount to assigning a zero value to the recovered uranium; and (b) there is much more recovered uranium arising from reprocessing than is needed for fabrication of MOX fuel, so this approach can only be taken with a fraction of the material.

${ }^{138}$ Conversion spot prices are freely available from Ux Consulting, at http://www.uxc.com. 
$\$ 4.70 / \mathrm{kgU}^{139}$ The NEA projects conversion prices in the short to medium term in the range of $\$ 3-\$ 8 / \mathrm{kgU}$, nearly identical to our range. ${ }^{140}$

\subsubsection{Non-Price Factors: Fuel Burnup and Discount Rate}

\section{Burnup of Reprocessed Fuel and Fresh Fuel}

The economic viability of reprocessing gets worse and worse as the burnup of the reprocessed spent fuel increases, because the isotopic quality of the recovered plutonium and uranium gets worse. ${ }^{141}$ The worldwide trend toward increased burnup in LWRs therefore casts additional doubt on the economic future of reprocessing and recycling in LWRs.

On the other hand, increased burnup of the fresh fuel to be produced-either MOX or LEU_-makes the comparison better for using plutonium that has already been separated as MOX, as additional enrichment has to be put into each kilogram of LEU to achieve the greater burnup, increasing the cost of the LEU the MOX would replace. ${ }^{142}$ The ideal situation for the economics of reprocessing is reprocessing of relatively low-burnup fuel, to make relatively high-burnup MOX. Thus we have taken as our "best case" for reprocessing plutonium and uranium recovered from reprocessing of spent fuel with a burnup lower than that used by most current utilities, of 33,000 megawatt-days per metric ton of heavy metal (MWD/MTHM), making MOX for a burnup of 43,000 MWD/MTHM. ${ }^{143}$ Our central estimate and "worst" estimate have equal burnups of 43,000 MWD/MTHM, but in fact higher burnups, now in wide use around the world, would be worse still for the reprocessing case. Thus our use of these burnups is conservative, understating the economic disadvantages of reprocessing.

\section{Disposal Time and Discount Rate}

Final factors in the calculation include the times at which various events take place (which effects how far in the future their costs should be discounted), and the discount rate.

The time factor and how it is treated is particularly important for the costs of disposal. We have assumed, as discussed above, that $\$ 400 / \mathrm{kgHM}$ has to be set aside at the time of discharge for disposal of spent fuel, even though the disposal itself may not take place until decades after the fuel is discharged. This is because, in the U.S. program (as is likely to be true in many other national nuclear waste disposal programs), many of the costs (such as

\footnotetext{
${ }^{139}$ Michael Knapik, "Help for Converdyn Still Seen Possible; Spot U Price in U.S. Continues to Slide," Nuclear Fuel, October 30, 2000.

${ }^{140}$ NEA, Trends in the Nuclear Fuel Cycle, op. cit.

${ }^{141}$ See, for example, Wolfgang Heni, "Evaluation of Direct Disposal From the Point of View of One Utility and Perspectives for Waste Management," Nuclear Technology, Vol. 121, pp. 120-127, February 1998. Heni is the fuel manager for the GNS utility in Germany.

${ }^{142}$ See, for example, discussion in NAS, Management and Disposition of Excess Weapons Plutonium: ReactorRelated Options, op. cit., pp. 301-302.

${ }^{143}$ We use the 33,000 and 43,000 figures because useful sets of consistent isotopic figures are provided for these burnups in Organization for Economic Cooperation and Development, Nuclear Energy Agency, Plutonium Fuel: An Assessment (Paris, France: OECD/NEA 1989).
} 
siting and building a repository and its associated infrastructure) occur early on, rather than at the later time when the fuel is actually emplaced. Had we followed the approach used in some other studies, and discounted a fixed per-kilogram disposal cost only modestly larger than the one we assumed to be paid at time of discharge for decades into the future, the present value of the costs for disposal of either spent fuel or high-level waste at time of discharge would have been much less, and hence the difference between them would have been much less than our $\$ 200 / \mathrm{kgHM}$ central estimate. ${ }^{144}$

Since we have assumed that the disposal costs are lower for the reprocessing and recycling case, it is better for the relative economics of reprocessing for disposal to occur sooner rather than later, so that this cost advantage is not shrunken by additional discounting. Nevertheless, in countries around the world a period of decades between discharge of spent fuel and permanent disposal of the spent fuel or reprocessing wastes is planned to be the norm. We have taken a central estimate of disposal 40 years after discharge of the spent fuel from the reactor (for either disposal of spent fuel or disposal of HLW from reprocessing) with a range of 20 to 60 years.

The issue of the discount rate is somewhat more complex. As noted in Chapter 1, for calculating the amount that must be set aside today to cover a future expense one is legally obligated to incur (such as disposal of spent fuel or decommissioning of a nuclear facility) it is appropriate to use a "risk free" discount rate. Thus in this study, for discounting the future costs of waste disposal or storage, we use a 3\% real rate, as advised by the U.S. Office of Management and Budget as being roughly equivalent to the return on long-term U.S. government bonds.

We use a separate rate for the cost of money during the various periods when fuel has been bought but has not yet been completely used (such as the time between purchasing the uranium and enrichment, the time between enrichment and fabrication, the time between fabrication and loading into the reactor, and the time the fuel is in the reactor). For this cost of money, we have chosen to use a 5\% real interest rate, roughly the real debt rate available to a regulated utility with a guaranteed rate of return, ${ }^{145}$ with a range from $2 \%$ to $8 \%$. This has only a modest effect on our calculations of breakeven price and cost of electricity.

\footnotetext{
${ }^{144}$ This is the approach taken in NEA, The Economics of the Nuclear Fuel Cycle, op. cit., with the result that although they envision a large difference in costs between disposal of HLW and disposal of spent fuel, those costs and the difference between them are discounted so heavily as to make very little contribution to the cost of electricity.

${ }^{145}$ See discussion in Appendix A. For such operating costs, pure debt financing would be appropriate.
} 


\section{Sidebar: Volumes of Wastes From Direct Disposal and Reprocessing}

Advocates of reprocessing frequently point out that reprocessing reduces the total volume of high-level waste. ${ }^{146}$ Unfortunately, in most cases neither the hazard from radioactive waste nor the cost of managing it is closely related to the physical volume of the waste. Nonetheless, it is of interest to compare the volumes and types of wastes generated by direct disposal of spent fuel and reprocessing of that spent fuel.

The principal waste generated in direct disposal of spent fuel is the spent fuel itself. The volume of wastes from the various handling steps after the reactor cooling pondtransport to the repository, packaging, and repository emplacement-is expected to be comparatively minor, as are the volumes of wastes from decommissioning the relevant facilities. (There are, of course, wastes generated in many other parts of the fuel cycle, but the costs of managing these is included in the costs charged for the various fuel cycle services, and is not addressed here.)

Reprocessing advocates frequently estimate the volume of spent fuel for direct disposal at 2 cubic meters per metric ton of heavy metal. ${ }^{147}$ This is roughly correct for spent fuel disposed of in the German Pollux cask, which is 5.52 meters long, 1.56 meters in diameter, and can hold $5.5 \mathrm{tHM}$ of spent fuel, for a volume of $1.9 \mathrm{~m}^{3} / \mathrm{tHM}^{148}$ The Swedish disposal program, which also has large waste packages, has an average planned volume of $1.6 \mathrm{~m}^{3} / \mathrm{tHM}$ for the packaged spent fuel, ${ }^{149}$ and a recent British study, based on a study for the European Union, came up with a similar figure. ${ }^{150}$ But in the case of the planned U.S. Yucca Mountain repository, the plan is to have larger waste packages with more fuel assemblies in each package, reducing the average volume: pressurized-water reactor (PWR) spent fuel will primarily be in large packages holding 21 assemblies each. These packages are planned to have a volume of $10.25 \mathrm{~m}^{3}$ and will contain $9660 \mathrm{kgHM}$ of spent fuel, for an average of $1.06 \mathrm{~m}^{3} / \mathrm{tHM}$, roughly half the 2 cubic meter estimate. ${ }^{151}$ This is the total waste package volume, much of which is empty space or waste package rather than the spent fuel itself. A typical PWR assembly has a volume of 0.19 cubic meters, and contains $460 \mathrm{kgHM}$ of fuel, for a volume of $0.41 \mathrm{~m}^{3} / \mathrm{tHM}$, less than half the packaged volume. ${ }^{152}$

\footnotetext{
${ }^{146}$ As one of many similar examples, see B. Barré and H. Masson (Cogema), "State of the Art in Nuclear Fuel Reprocessing," paper presented at "Safewaste 2000," October 2-4, 2000, Montpelier, France.

147 See, for example, Barré and Masson, "State of the Art in Nuclear Fuel Reprocessing," op. cit.

${ }^{148}$ Frank von Hippel, personal communication.

${ }^{149}$ OECD Nuclear Energy Agency, The Cost of High-Level Waste Disposal in Geologic Repositories (Paris, France: OECD/NEA, 1993), hereinafter OECD/NEA 1993, shows on p. 50 a planned 7,840 tHM of Swedish spent fuel going into waste packages with a total volume of $12,900 \mathrm{~m}^{3}$.

150 "Scoping Assessment of Implications of Reprocessing Scenarios for Disposal Options: Paper to RWMAC [Royal Waste Management Advisory Committee]," NIREX Doc. 334004 (London, UK: United Kingdom Nirex Limited, May 2000). This paper envisioned 4 PWR assemblies (which contain $461 \mathrm{kgHM}$ of fuel each) in canisters that would be $4.54 \mathrm{~m}$ long and $0.9 \mathrm{~m}$ in diameter, for an average of $1.57 \mathrm{~m}^{3} / \mathrm{tHM}$.

${ }^{151}$ These packages will be $5.335 \mathrm{~m}$ long, with an outer diameter of $1.564 \mathrm{~m}$.

152 Office of Civilian Radioactive Waste Management, Final Environmental Impact Statement for a Geologic Repository for the Disposal of Spent Nuclear Fuel and High-Level Radioactive Waste at Yucca Mountain, Nye County, Nevada DOE/EIS-0250 (Washington DC: U.S. Department of Energy, February 2002, available at http://www.ymp.gov:80/documents/feis_a/index.htm), p. A-25. Spent fuel from high-temperature gas reactors
} 
Reprocessing spent fuel does make it possible to concentrate the intensely radioactive materials in a much smaller volume of high-level waste (HLW). At the same time, however, reprocessing also results in significant volumes of intermediate-level waste (ILW) and lowlevel waste (LLW) which must also be disposed of. ${ }^{153}$ The ILW from reprocessing typically contains long-lived actinides (including plutonium), and therefore in most cases will probably have to be disposed of in deep geologic repositories along with the HLW. Indeed, COGEMA has developed a "Universal Canister" to hold both vitrified HLW and ILW, so that customers receive back some canisters with vitrified HLW and other outwardly identical canisters with lower-level wastes. ${ }^{154}$

The specific volumes of these types of waste generated during reprocessing have been the subject of some controversy, and have changed over the years as reprocessing technology has improved and the reprocessors have devoted more effort to further processing and compaction of these wastes. BNFL and COGEMA appear to be in agreement that for current processes and spent fuels of current and future burnups, the volume of vitrified HLW canisters is approximately $0.12 \mathrm{~m}^{3} / \mathrm{tHM} .{ }^{155}$ Hence, the volume of vitrified HLW resulting from reprocessing is roughly 4 times less than the volume of original spent fuel (with no container). The volume of intermediate-level waste is larger and more variable in different reports: recent estimates are $0.8 \mathrm{~m}^{3} / \mathrm{tHM}$ from BNFL, and $0.35 \mathrm{~m}^{3} / \mathrm{tHM}$ from COGEMA. ${ }^{156}$ The most recent waste volume estimates from these firms do not include low-level wastes which can be buried in cheaper low-level waste disposal sites. Previous estimates indicate that the amount of LLW generated during reprocessing is roughly $2.8 \mathrm{~m}^{3} / \mathrm{tHM}$ - that is, in sheer volume terms, more than the volume of spent fuel in its waste package. ${ }^{157}$

HLW canisters, like spent fuel assemblies, will in most countries be put in a waste package, which serves as an engineered barrier to release of radionuclides to the environment. As with spent fuel, the volume of the total package should be taken into account for HLW. One German study, for example, envisioned 6 Cogema vitrified waste

would have very much larger physical volume per unit of electricity generated, and would therefore require different packaging and repository design - but it is likely to remain true that repository volume and cost would be driven more by the heat generated from the fuel than by its physical volume.

${ }^{153}$ These are the European classifications. In the United States, the reprocessing wastes classified as ILW in Europe would be considered transuranic (TRU) wastes. For discussions of the wastes that have arisen to date, and are expected to arise in the future, from reprocessing, see BNFL National Stakeholder Dialogue Waste Working Group, Interim Report (London, UK: The Environmental Council, February 28, 2000 available at http://www.the-environment-council.org.uk/Dialogue/bnfl_national_dialogue.htm), and Frank Homberg, Mathie Pavageau, and Mycle Schneider, Cogema-La Hague: The Waste Production Techniques (Paris, France: World Information Service on Energy-Paris, May 1997).

${ }^{154}$ E. Blanc, F. Chotin (Cogema), "The Universal Canister Strategy,” paper presented at Global '99, Jackson Hole, Wyoming, August 30-September 2, 1999.

${ }^{155}$ For COGEMA, see Barré and Masson, "State of the Art in Nuclear Fuel Reprocessing," op. cit., citing a figure of $0.115 \mathrm{~m}^{3} / \mathrm{tHM}$. For BNFL, see BNFL input to the BNFL National Stakeholder Dialogue Waste Working Group, Interim Report, op. cit., Appendix 3. BNFL estimated $.08 \mathrm{~m}^{3} / \mathrm{tHM}$ for lower-burnup spent fuel that had been reprocessed in the past, and $.12 \mathrm{~m}^{3} / \mathrm{tHM}$ for fuel planned to be reprocessed in the coming years.

${ }^{156}$ Barré and Masson, "State of the Art in Nuclear Fuel Reprocessing," op. cit., and BNFL input to the BNFL National Stakeholder Dialogue Waste Working Group, Interim Report, op. cit., Appendix 3.

${ }^{157}$ See, for example, Mike Smith and Nigel Mote, Recommendations for Normalizing Reprocessing Waste Quantities and Characteristics (Atlanta, GA: Nuclear Assurance Corporation International, January 1998). 
canisters in a Pollux cask, resulting in a disposal package volume of $1.2 \mathrm{~m}^{3} / \mathrm{tHM}^{158}$ effectively identical to the packaged volume for spent fuel, rather than many times less. The UK study noted above envisioned 2 vitrified waste canisters, each containing $0.148 \mathrm{~m}^{3}$ of glass (the equivalent of $0.123 \mathrm{tHM}$ of fuel, at the rate of $0.12 \mathrm{~m}^{3} / \mathrm{tHM}$ appropriate for higherburnup fuel) would be placed in each waste package, which would be 3.2 meters long and 0.9 meters in diameter, for an average of $0.83 \mathrm{~m}^{3} / \mathrm{tHM}$-roughly half the volume envisioned in the same study for direct disposal of spent fuel. ${ }^{159}$ Packaging may also increase volumes for ILW and LLW, in some cases.

One important point is that wastes from decommissioning the reprocessing plant and associated facilities are not included in these waste volume estimates. The ILW and LLW from decommissioning the Sellafield and La Hague sites are expected to be substantial. Including these wastes, pro-rated over the quantity of fuel processed over these facilities' lifetimes, would be likely to increase significantly the estimates of volume of wastes generated per ton of fuel processed.

Overall, several points can be made:

- With no packaging, the volume of vitrified HLW is roughly four times less than the volume of the spent fuel from which it came.

- This changes substantially when ILW is included. With no waste package, the volume of spent fuel is equal to or less than the combined volume of the HLW and ILW resulting from reprocessing.

- If waste packages are included for spent fuel and HLW, the total volume for disposal ranges from roughly equal to approximately half as large for the HLW (not including the ILW).

- If low-level waste is also included, the total volume of waste arising from reprocessing is significantly larger than the total volume arising from direct disposal.

- More complete estimates should ultimately include decommissioning wastes from both fuel cycles.

\section{Costs of Managing ILW and LLW From Reprocessing}

From the point of view of a reactor operator attempting to decide whether to sign a contract to have spent fuel reprocessed or plan on disposing of it directly, the main waste volumes of interest are the ones that will get returned to the customer after reprocessingand the main fact of interest about those volumes is how much it will cost to manage and dispose of them. The costs of HLW disposal are discussed in the text.

Currently both Cogema and BNFL require customers to take back the wastes after reprocessing. It appears, however, that wastes from decommissioning may end up being the responsibility of the reprocessors, rather than the customers. ${ }^{160}$ The costs of managing these

\footnotetext{
${ }^{158}$ Cited in Homberg, Pavageau, and Schneider, Cogema-La Hague, op. cit., p. 90.

${ }^{159}$ NIREX, "Scoping Assessment," op. cit.

${ }^{160}$ Homberg, Pavageau, and Schneider, Cogema-La Hague, op. cit., p. 66. cite a document which says that decommissioning wastes "will not be returned," but report that "the situation is evolving," with new efforts to negotiate customers' "participation" in managing these wastes.
} 
wastes are included in the estimates of the decommissioning costs for these plants (which in turn are included in our discussion of the costs of reprocessing, elsewhere in this report). To date, plans for shipping wastes to customers focus primarily on the vitrified HLW and the ILW, not the LLW-whose large volume would make long-distance shipment expensive. BNFL has permission from the UK government to practice "substitution"- that is, an arrangement in which customers would take back a slightly larger amount of HLW in return for the reprocessors managing the LLW (on some equivalence basis to be negotiated) - and is proposing to follow the same approach with ILW as well. If substitution were implemented for ILW as well, BNFL estimates that the amount of HLW returned to foreign customers would increase by $17 \%$. BNFL does not describe how much additional HLW is being substituted for LLW under existing substitution arrangements, but presumably it will be at least a few percent. Therefore, under this approach, the costs of HLW disposal per ton of fuel reprocessed would be multiplied by roughly 1.2 , but there would be no cost to the customer for ILW or LLW management and disposal.

If substitution did not occur, then the customer would have to pay for transport and disposal of the ILW and LLW, which could add several tens of dollars per kilogram of original spent fuel to the waste disposal costs - or more, for countries with high disposal costs for these types of wastes, or requiring very long-distance transport of them. 


\section{Sidebar: Reprocessing to Reduce the Need for Additional Repositories}

In recent years, some advocates of reprocessing spent nuclear fuel have argued not that uranium will run out, but that available space for nuclear waste in geologic repositories will run out. Spent nuclear fuel must be processed, and heat-generating radionuclides must be transmuted, it is argued, to make it possible to pack the nuclear waste from the generation of a much larger amount of nuclear energy generation into planned repositories. This argument is one of the principal drivers of the Advanced Nuclear Fuel Cycle Initiative of the U.S. Department of Energy (DOE). ${ }^{161}$

In particular, DOE argues that existing nuclear power plants in the United States, discharging nearly 2000 tHM of spent fuel per year, will fill the 63,000 tHM legislative capacity limit for the Yucca Mountain repository by 2015, and a "theoretical" Yucca Mountain capacity of 120,000 tHM by roughly 2050 (if the current level of nuclear capacity were retained). ${ }^{162}$ The difficulty of gaining political acceptance and licensing for a second repository in the United States is assumed to be very high, but processing the fuel and transmuting the heat-generating radionuclides, it is argued, could make a second repository unnecessary, even if U.S. nuclear energy generation grows substantially in the future.

Several points should be made:

- First, whatever this argument's merits in the U.S. context, it only applies to the United States. Only the United States has chosen a repository site inside a mountain with fixed boundaries, whose capacity therefore cannot be increased indefinitely by simply digging more tunnels. Most other countries are examining sites in huge areas of rock, where the amount of waste from centuries of nuclear waste generation could be emplaced at a single site, if desired. ${ }^{163}$

- Second, it is important to understand that traditional approaches to reprocessing and recycling, such as those discussed in this chapter, do not lead to reductions in the amount

\footnotetext{
${ }^{161}$ See, U.S. Department of Energy, Office of Nuclear Energy, Science, and Technology, Report to Congress on Advanced Fuel Cycle Initiative: The Future Path for Advanced Spent Fuel Treatment and Transmutation Research (Washington, DC: January 2003, available as of December 16, 2003, at http://www.nuclear.gov/reports/AFCI_CongRpt2003.pdf). Similarly, see Per F. Peterson, "The Pros and Cons of Nuclear Fuel Recycling," letter, Science, Vol. 294, pp. 2093-2094, December 7, 2001. Peterson argues that "for sustainable fission energy production, the scarce resource will not be uranium, but will almost certainly be repository capacity... this why, in the longer term, it will likely make economic sense to recycle actinides back into reactors."

${ }^{162}$ See DOE, Report to Congress on Advanced Fuel Cycle Initiative, op. cit., p. I-3. This maximum theoretical capacity estimate is dependent on a wide range of assumptions, some of which might be changed in the future to increase the available capacity, such as the maximum temperature that will be allowed within the mountain, what kind of cooling arrangements will be used for the repository (and for how long), how long wastes will be allowed to cool above ground before emplacement, how older and newer wastes will be arranged within the mountain, and the like.

${ }^{163}$ Granite formations do often have faulting in some areas that could limit the total area that could be used at a particular repository site - but sites will presumably be chosen to be far from nearby faults, and very large amounts of total material can be emplaced at typical sites of this type. Even at Yucca Mountain, there are other mountain ridges in the same area that have similar geology, and could potentially be defined as part of the "same" repository. Ultimately the issue is less the technical limits on repository capacity than the political limits on how much material can be emplaced at a particular location.
} 
of repository space required per unit of electricity generated. As discussed in the text, the needed repository volume is determined by heat output of the wastes, and if plutonium is recycled as MOX fuel in existing LWRs, the resulting buildup of heat-generating minor actinides means that the total waste heat per unit of electricity generated in this cycle is higher than for direct disposal of spent nuclear fuel. Therefore, a separations and transmutation approach that would include separating and transmuting all the major longlived heat-generating radionuclides would be needed, if the goal was to avoid a second repository. As discussed in the text, the most recent official analyses suggest that the cost of the complex separations and transmutation that would be needed is likely to be substantially higher than the cost of traditional reprocessing and recycling. If we assume, as recent international reviews do, a higher reprocessing cost for these kinds of separations than the central estimate for traditional reprocessing used in the text, a higher fabrication cost (given the need for remote handling), and we assume that the needed transmutation reactors or accelerators would have a capital cost roughly $\$ 200 / \mathrm{kW}_{\mathrm{e}}$ higher than that of comparably advanced one-through systems, then separations and transmutation for this purpose would not be economic until the cost of disposal of spent fuel reached some $\$ 3000 / \mathrm{kgHM}$, many times its current level. ${ }^{164}$

- Third, the argument is based on the questionable assumption that while it would be very difficult to gain public acceptance and licensing approval for a second repository, it would not be very difficult to do so for the complex and expensive spent fuel processing and transmutation facilities needed to implement this approach. This assumption appears very likely to be wrong. Reprocessing of spent fuel has been fiercely opposed by a substantial section of the interested public in the United States for decades - and such a transmutation approach inevitably would involve the handling of large quantities of extremely dangerous radionuclides in the presence of much larger sources of chemical or nuclear energy that might distribute them in the event of an accident than they would ever be exposed to below the ground. Similarly, there seems little doubt that licensing and building the new reactor types required would be an enormous institutional and political challenge.

- Fourth, the argument is also based on a further questionable assumption - that even decades in the future, when repository space has become scarce and reactor operators become willing to pay a significant price for it, it will still not be possible to ship spent fuel from one country to another for disposal. If, in fact, repository capacity does become scarce in the future, reactor operators will likely be willing to pay a price for spent fuel disposal well above the cost of providing the service, and it seems quite likely that if the potential price gets high enough, the opportunity for enormous profit will motivate some country with an indefinitely-expandable repository to overcome the political obstacles

\footnotetext{
${ }^{164}$ NEA, Accelerator-Driven Systems (ADS) and Fast Reactors (FR) in Advanced Nuclear Fuel Cycles, op. cit., cites a cost of $\$ 2000 / \mathrm{kgHM}$ for reprocessing in fast reactors intended for transmutation of heat-generating actinides, and a fabrication cost of $\$ 2600 / \mathrm{kgHM}$ for the core fuel for such systems. DOE's Generation IV Fuel Cycle Crosscut group uses the same figures. Using these figures, and assuming that the whole job could be done with fast reactors with no need for accelerators (with the fast reactors having an additional capital cost of $\$ 200 / \mathrm{kW}_{\mathrm{e}}$, we calculated the spent fuel disposal price at which the cost of electricity would be the same for once-through LWRs as for these transmutation fast reactors, using the same method as used in Chapter 3, with equations described in Appendix A. We held the disposal cost for HLW constant, which is excessively generous, since this material also takes up repository volume, and if the cost of spent fuel disposal were rising dramatically, the cost of HLW disposal would also be increasing.
} 
that have blocked international storage and disposal of spent fuel in the past, and offer to accept spent fuel from other countries on a commercial basis. (It is worth noting that Russia has already passed legislation approving such imports of foreign spent fuel, though the prospects for implementation of that project remain uncertain.) ${ }^{165}$

In any case, given the availability of proven, low-cost dry cask storage technology that can store spent fuel safely for decades, ${ }^{166}$ there is no rush to resolve these debates. With time, technology, politics, and economic circumstances will evolve, and the costs of any approach that is ultimately chosen can be discounted into the future.

${ }^{165}$ For an extensive discussion of the political history and prospects for such concepts, see Bunn et. al, Interim Storage of Spent Nuclear Fuel, op. cit., Chapter 4.

${ }^{166}$ See discussion in Bunn et. al, Interim Storage of Spent Nuclear Fuel, op. cit., Chapter 2. 


\section{Direct Disposal vs. Recycling in Fast-Neutron Reactors}

\subsection{Plutonium Breeding and Recycling in Fast Reactors}

From the dawn of the nuclear age, the nuclear industry believed that uranium was relatively scarce and that the number of reactors would grow rapidly, and as a result the price of uranium would increase quickly. Hence, the industry projected that there would be a rapid transition from light-water reactors (LWRs), which primarily rely on fissioning the rare U235 isotope $(0.7 \%$ of natural uranium), to fast-neutron reactors (FRs), which would efficiently transform the common uranium isotope, U-238 (>99\% of natural uranium), into plutonium, which could then be recycled and used as fuel. The industry did not see recycling of plutonium in LWRs as a long-term solution, but only as a temporary expedient until the transition to FRs began. (See sidebar, "Thermal-Neutron and Fast-Neutron Reactors.")

This transition to FRs has taken much longer than once expected. Uranium has turned out to be abundant and cheap, the world's use of nuclear energy has grown much more slowly than expected, and FRs have so far been more expensive and problematic than anticipated. As a result, only Russia, India, and Japan still have near-term plans for commercializing FRs (and Japan's plans, stretching out to two to three decades from now, are more properly characterized as long-term). Russia is the only country in the world that currently operates a commercial-scale FR, the $\mathrm{BN}-600$; active construction of a slightly larger plant, the BN-800, has recently resumed after having been largely on hold since the 1980s. ${ }^{167}$ In the 1990s, the United States, France, Britain, Germany, and other countries terminated large-scale FR commercialization efforts, though in a number of countries some longer-term R\&D continued. More recently, as part of the various efforts to develop advanced systems for a possible future resurgence of nuclear energy, including the "Generation IV" initiative and others, FRs have again received increased attention as a longterm option. ${ }^{168}$

Hence, having found in the last chapter that reprocessing and recycling in LWRs will not be economic until uranium prices increase to some ten times their present level (or reprocessing costs are dramatically reduced), the next logical question is: at what point would recycling in fast-neutron reactors be economic? That is the subject of this chapter.

\footnotetext{
${ }^{167}$ For a discussion of the current status of the BN-600 and the construction on the BN-800, see "Director of the Beloyarskaya Power Plant: Results for 2002 and Priorities for 2003," (Interview) www.gazeta555.narod.ru, December 30, 2002 (translated by U.S. Department of Energy). Note, however, that another BN-800 at Mayak, whose construction had also been started but then put on hold, has been abandoned in favor of building a cheaper LWR at the same site. See Sergey Savenkov, "Minister Rumiantsev: Minatom Will Not be Privatized," (Interview), www.uralpress.ru, April 4, 2003 (translated by U.S. Department of Energy). Rumiantsev said "we do not cancel the BN-800 construction at Beloyarskaya NPP because it is our testing ground and we have tested all our reactors for peaceful purposes there," implying that he did not expect that this initial unit would be economically competitive or would soon lead to full commercialization.

${ }^{168}$ See, for example, U.S. Department of Energy, Nuclear Energy Research Advisory Committee and Generation IV International Forum, A Technology Roadmap for Generation IV Nuclear Energy Systems (Washington, DC: DOE, December 2002).
} 


\subsection{Breakeven Uranium Price for Fast Reactors}

This question introduces additional complications, because one must account not only for the differences in fuel-cycle costs but also the fact that the capital cost of FRs and LWRs may be different - and reactor capital cost is a much larger contributor to the overall cost of nuclear-generated electricity than are fuel-cycle costs. (We have assumed for the sake of simplicity that the non-fuel operations and maintenance (O\&M) costs of LWRs and FRs would be the same, so that only the capital costs and the fuel costs would vary; this is a generous assumption, as some studies have suggested that FRs would have higher non-fuel O\&M costs. ${ }^{169}$ )

Traditionally, the estimated capital costs of sodium-cooled fast-neutron reactors have been $10-50 \%$ higher than those of light-water reactors. In the last couple of decades, a significant portion of fast-neutron reactor R\&D has been focused on reducing the capital cost of FRs to a level roughly equal to that of LWRs - though at the same time there has been a continuing effort to reduce the capital cost of LWRs, and of other once-through thermal systems with which FRs must compete, such as high-temperature gas-cooled reactors. Hence, in the analyses in this chapter, in addition to varying the costs of the various fuel-cycle parameters, we also vary the capital cost difference between FRs and LWRs to explore this factor's impact on the breakeven price and on the cost of electricity.

In any assessment of the cost of services provided by large capital facilities (such as the cost of electricity from new reactors), the specifics of the financing arrangements, which depend on who owns the facility, turn out to be critical, as mentioned in Chapter 1. A government-owned facility can borrow money at low, risk-free rates, and typically does not have to pay taxes or insurance. A privately owned facility with a guaranteed rate of returnsuch as a reactor owned by a regulated utility - has to pay a higher cost of money (though still a modest one, given the low risk the investors face with guaranteed returns), and has to pay corporate income taxes, property taxes, and insurance, all of which drive up the cost significantly. A privately owned facility whose returns are unregulated - as is increasingly the case for power plants in a number of countries - has to pay still higher costs of money, reflecting the higher risks to investors. Our assumptions with respect to these three generic types of cases are discussed in more detail below, as are our assumptions with respect to the other cost parameters in this calculation.

Just as in the previous chapter, it will be cheaper to use LWRs with direct disposal of spent fuel until the uranium price gets high enough that the reduction in uranium cost from

\footnotetext{
${ }^{169}$ See, for example, J.G. Delene, J. Sheffield, K.A. Williams, R.L. Reid, and S. Hadley, An Assessment of the Economics of Future Electric Power Generation Options and the Implications for Fusion, ORNL/TM-1999-243 (Oak Ridge, TN: Oak Ridge National Laboratory, 1999), p. 11, which assumes non-fuel O\&M costs for an advanced FR 20\% higher (adding 1.8 mills $/ \mathrm{kW}$-hr) than those for an advanced LWR. Similarly, J.P. Crette, "Review of the Western European Breeder Programs," Energy, Vol. 23, No. 7/8, pp. 581-591 (1998), estimates that once both were in series production, the non-fuel O\&M cost of the European Fast Reactor (EFR) design would be $10 \%$ higher, per kilowatt-hour generated, than would that of an advanced PWR. See also Panel on Reactor-Related Options, Management and Disposition of Excess Weapons Plutonium: Reactor-Related Options (Washington, DC: National Academy Press, 1995), p. 318, which estimates non-fuel O\&M for small fast reactors at a somewhat higher cost per kilowatt-hour than those for large LWRs (though the estimate is the same as for small LWRs).
} 
breeding and recycling plutonium in FRs compensates for their additional capital and fuel cycle costs. Figures 3.1-3.3 show the breakeven uranium price as a function of the difference in capital cost between LWRs and FRs $\left(\$ / \mathrm{kW}_{\mathrm{e}}\right)$, for government-owned facilities, facilities owned by a regulated utility with a guaranteed rate of return, and facilities owned by a private entity without a guaranteed rate of return. ${ }^{170}$ (For a description of the generic FR used in these calculations, see the sidebar, "Characteristics of the Model Fast Reactor.") Table 3.1 shows our central, low, and high estimates for the various cost parameters used to produce these graphs, along with the sensitivity of the outcome to changes in each parameter. The equations used to produce these results are given in Appendix A.

Of these three cases, we have chosen the reactor owned by a regulated utility with a guaranteed rate of return as the reference case for the sensitivity analysis in table 3.1. This in itself may be a generous assumption, given the global trend toward increased reliance on

Figure 3.1. Breakeven uranium price for government-owned reactors, as a function of the capital cost difference between FRs and LWRs.

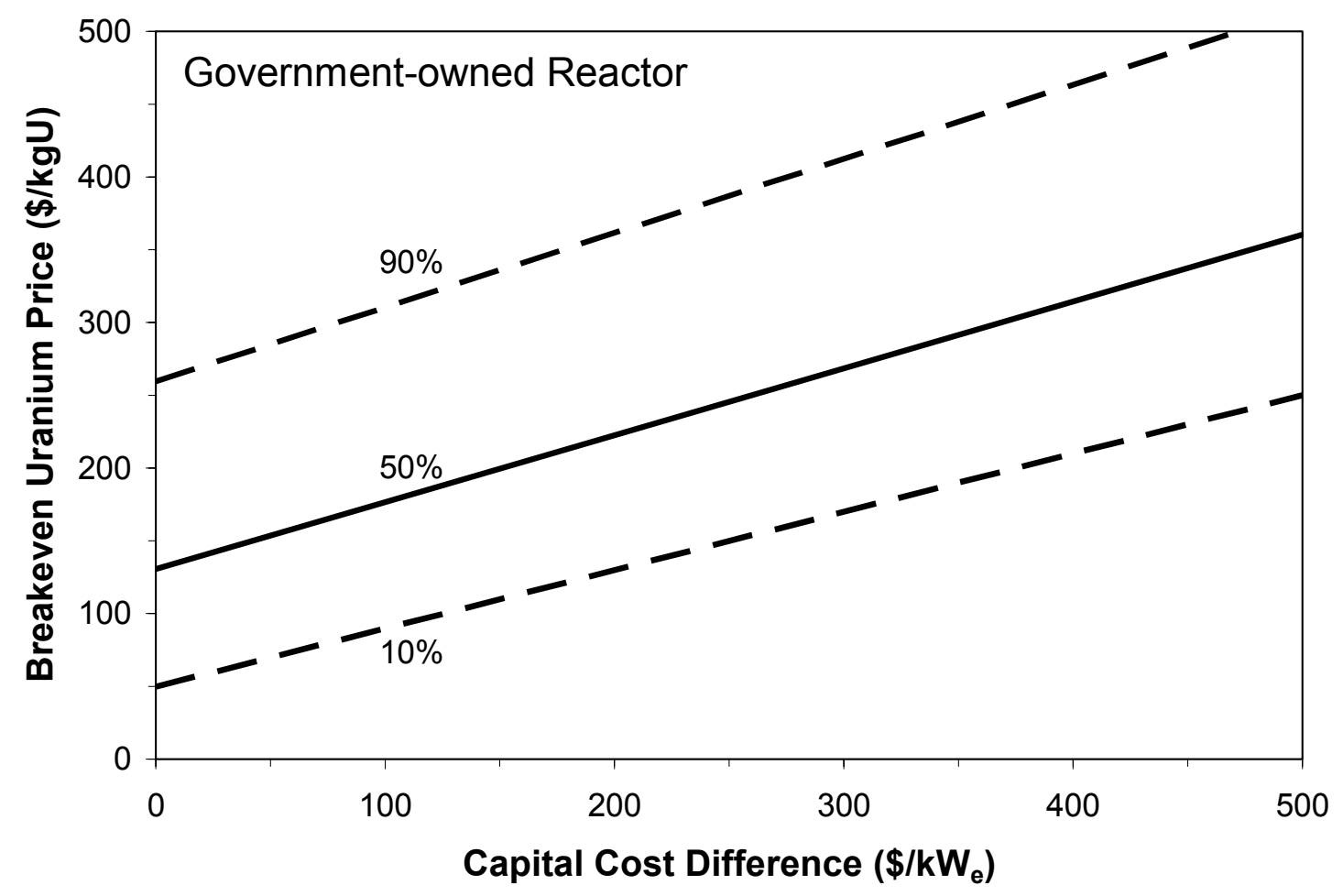

${ }^{170}$ The graphs give the $10^{\text {th }}, 50^{\text {th }}$, and $90^{\text {th }}$ percentiles of the breakeven uranium price for a given capital cost difference, estimated using a Monte Carlo simulation in which each of the parameters in table 3.1 was represented by an independent probability distribution. In most cases we assume truncated normal distributions with $5^{\text {th }}$ and $95^{\text {th }}$ percentiles given by the "low" and "high" values in table 3.1; we assume a log-normal distribution for reprocessing costs and a uniform distribution for breeding ratio. 
Figure 3.2. Breakeven uranium price for utility-owned reactors v. capital cost difference.

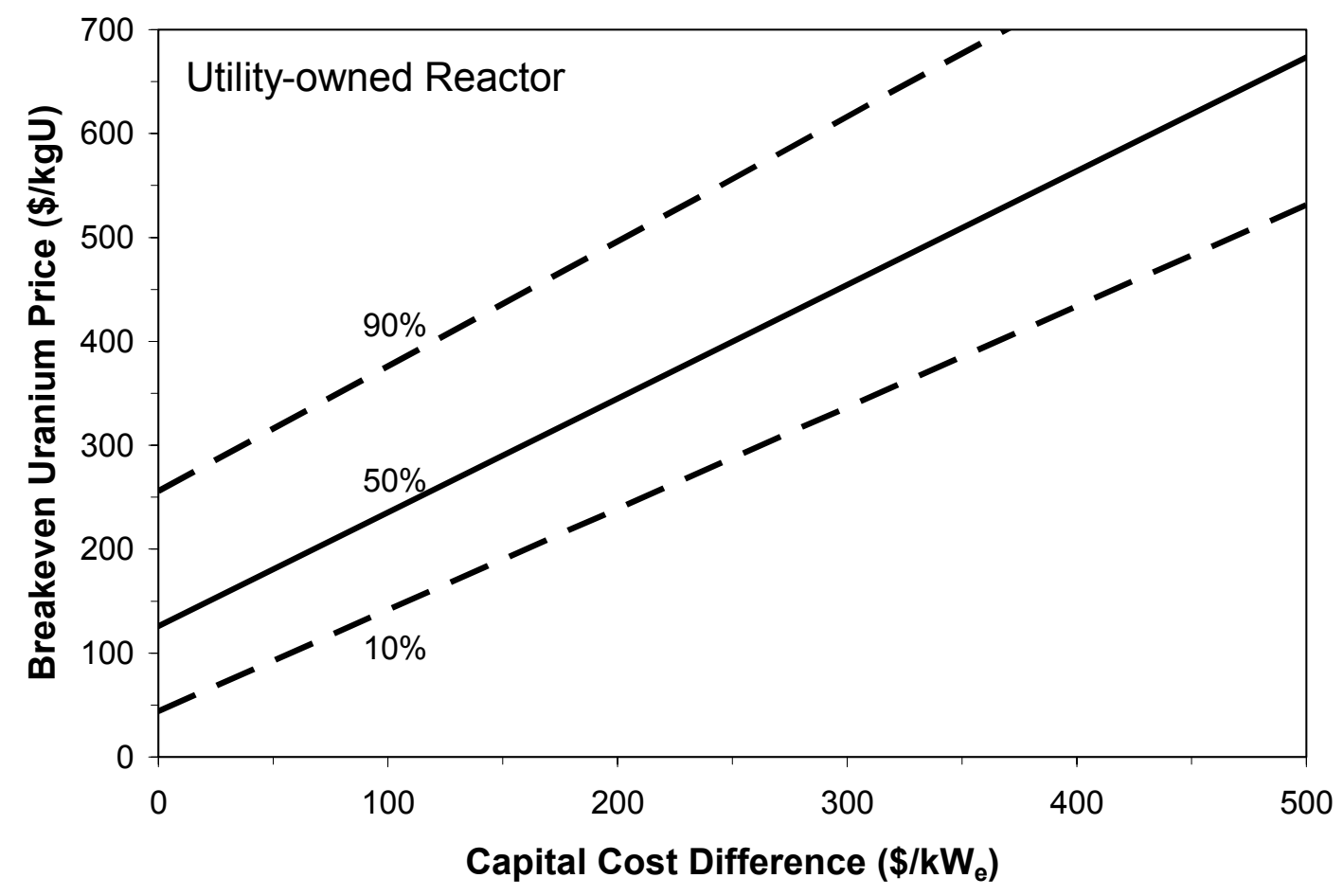

Figure 3.3. Breakeven uranium price for private venture ownership v. capital cost difference.

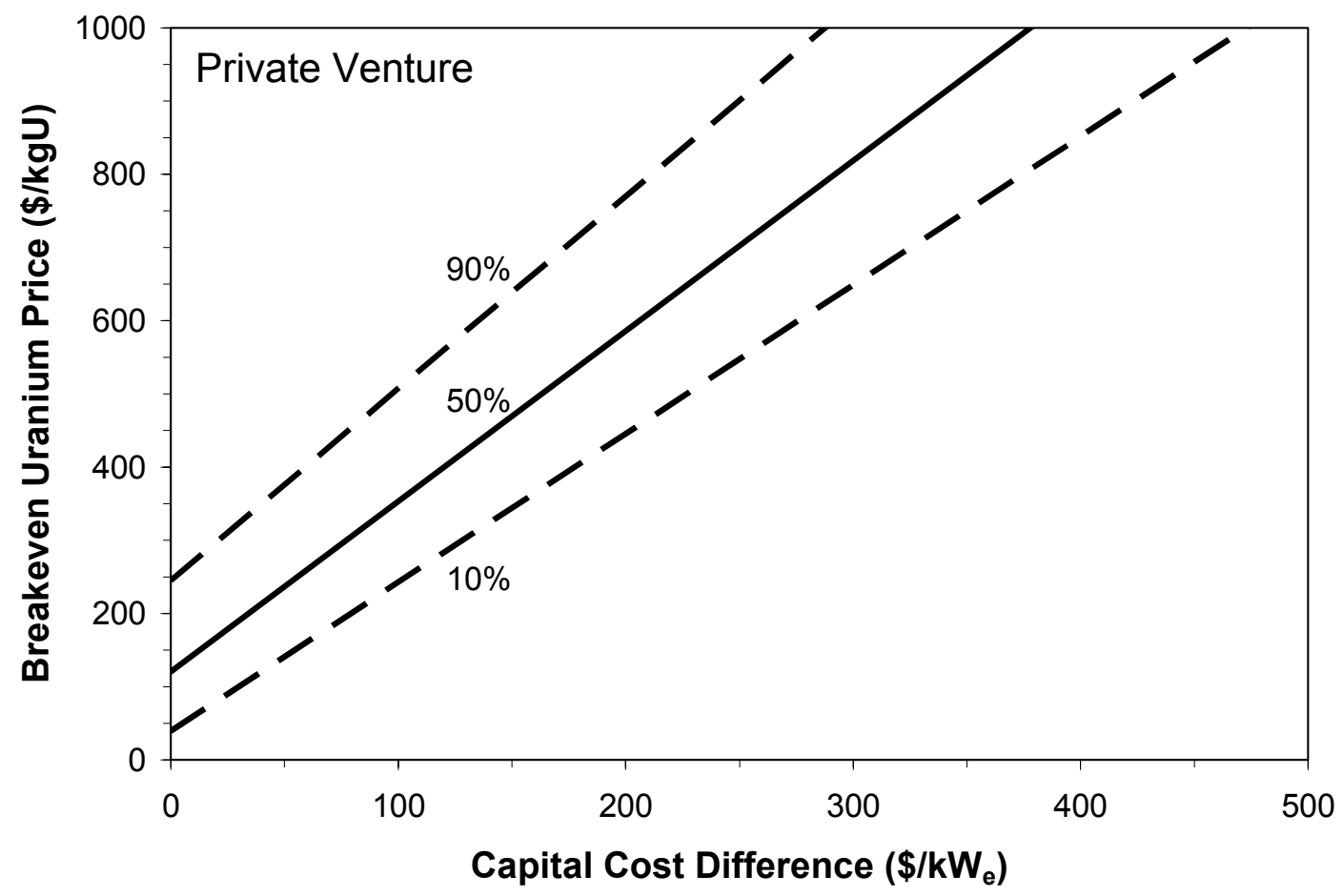


Table 3.1. Estimates of fuel-cycle costs and other parameters and sensitivity analysis for the breakeven uranium price when the reactor is owned by a regulated utility.

\begin{tabular}{|c|c|c|c|c|c|c|}
\hline \multirow[b]{2}{*}{ Parameter } & \multicolumn{3}{|c|}{ Parameter Value } & \multicolumn{2}{|c|}{$\begin{array}{l}\text { Breakeven U price } \\
\text { (central = \$340/kgU) }\end{array}$} & \multirow{2}{*}{$\begin{array}{l}\text { change } \\
\text { compared } \\
\text { to central }\end{array}$} \\
\hline & low & central & high & low & high & \\
\hline Capital cost difference $\left(\$ / \mathrm{kW}_{\mathrm{e}}\right)$ & 0 & 200 & 400 & 134 & 560 & $\begin{array}{l}-205 \\
+221\end{array}$ \\
\hline Reactor owner & govt & utility & private & 222 & 574 & $\begin{array}{l}-118 \\
+234\end{array}$ \\
\hline Reprocessing cost (\$/kgHM) & 500 & 1000 & 2000 & 255 & 516 & $\begin{array}{r}-85 \\
+176\end{array}$ \\
\hline Enrichment (\$/SWU) & 150 & 100 & 50 & 282 & 415 & $\begin{array}{l}-58 \\
+75\end{array}$ \\
\hline LMR core fabrication ( $\$ / \mathrm{kgHM})$ & 700 & 1500 & 2300 & 286 & 394 & \pm 54 \\
\hline LMR breeding ratio & 1.0 & 1.125 & 1.25 & 294 & 386 & \pm 46 \\
\hline $\begin{array}{l}\text { Geological disposal cost } \\
\text { difference }(\$ / \mathrm{kgHM})\end{array}$ & 300 & 200 & 100 & 322 & 358 & \pm 18 \\
\hline LEU burnup (MW $\mathrm{d} / \mathrm{kgHM})$ & 43 & 53 & 53 & 322 & 340 & -17 \\
\hline Construction time (yr) & 3 & 6 & 9 & 326 & 355 & \pm 15 \\
\hline LMR blanket fab. (\$/kgHM) & 150 & 250 & 350 & 325 & 355 & \pm 15 \\
\hline LEU fuel fabrication $(\$ / \mathrm{kgHM})$ & 350 & 250 & 150 & 327 & 353 & \pm 13 \\
\hline Capacity factor $(\%)$ & 90 & 85 & 80 & 328 & 353 & \pm 13 \\
\hline Preop, contingency costs $(\%)$ & 5 & 10 & 15 & 330 & 350 & \pm 10 \\
\hline Interim storage ( $\$ / \mathrm{kgHM})$ & 300 & 200 & 100 & 332 & 348 & \pm 8 \\
\hline Conversion $(\$ / k g U)$ & 8 & 6 & 4 & 338 & 342 & \pm 2 \\
\hline Depleted uranium (\$/kg) & 6 & 6 & U price & 340 & 341 & +1 \\
\hline
\end{tabular}

privatized power plants operating in competitive electricity markets without guaranteed rates of return. While there remain some major countries where power plants are built and operated by a government-owned monopoly, this is not likely to be the case in most countries that will have to consider the choice between once-through nuclear reactors and FRs with recycling. 
As shown in figure 3.2 and table 3.1 for the case of a utility-owned reactor, if the capital cost of FRs is $\$ 200 / \mathrm{kW}_{\mathrm{e}}$ greater than that of LWRs, and the other parameters are at the values listed as our central estimates, recycling plutonium in FRs will not be economic until the price of uranium rises to over $\$ 340 / \mathrm{kgU}$, which is not likely to occur for many decades, if ever. If the capital cost of FRs is equal to that of LWRs, the breakeven uranium price for our central estimates of the other parameters is roughly $\$ 130 / \mathrm{kgU}$ - still a price that remains far in the future. For a government-owned facility with its lower costs of money, possible differences in capital cost between FRs and LWRs would make less difference, while for a private entity without a regulated rate of return, these differences would be even more critical than in the utility case.

One generous assumption we have made in preparing these graphs should be noted. Since there are currently hundreds of tons of already separated plutonium in storage, awaiting use as reactor fuel, we have assigned zero cost to providing the plutonium needed for the initial FR reactor cores. A number of past analyses (including by FR advocates) have assumed that the cost of reprocessing LWR fuel to recover plutonium for the initial core must be charged to the cost of the FR; in general, this cost is then envisioned as being capitalized over the life of the reactor. ${ }^{171}$ This assumption may still be valid, if the switch to fast reactors is in fact driven by them becoming economically competitive with rising uranium prices: if fast reactors were then deployed in numbers large enough to make a substantial contribution to growing world electricity demand, existing stockpiles of separated plutonium would not be sufficient to start them up, and reprocessing of spent fuel to provide the necessary plutonium would be needed. Moreover, by the time uranium increases in price to a level at which deployment of FRs would be seriously considered, separated plutonium will begin to have substantial value. If the cost of reprocessing LWR fuel was $\$ 1000 / \mathrm{kgHM}$ and each kilogram of LWR fuel reprocessed provided roughly 10 grams of usable plutonium, then the cost of start-up plutonium would be $\$ 100,000$ per kilogram; taking full account of possible savings in storage and waste-disposal costs and the value of the recovered uranium, the cost is on the order of $\$ 30,000$ per kilogram. ${ }^{172}$ In that case, the cost of the plutonium for the start-up fuel would add over $\$ 300 / \mathrm{kW}_{\mathrm{e}}$ to the initial cost of the kind of FR we have been considering. ${ }^{173}$ (HEU could be used for the initial core, but cost per kilowatt would even higher than with

\footnotetext{
${ }^{171}$ See, for example, J.G. Delene, L.C. Fuller and C.R. Hudson, ALMR Deployment Economic Analysis, ORNL/TM-12344 (Oak Ridge, TN: Oak Ridge National Laboratory, 1993). See also Y.I. Chang and C.E. Till, "Economic Prospects of the Integral Fast Reactor (IFR) Fuel Cycle," undated paper (ca. 1991). Chang and Till conclude that at a cost of $\$ 1000 / \mathrm{kgHM}$, reprocessing LWR fuel "is too expensive for the LMR startup: including the ex-core inventory, the fissile inventory cost would run close to $\$ 1$ billion per GWe."

${ }^{172}$ This assumes that reprocessing would avoid interim storage of spent fuel (at $\$ 200 / \mathrm{kgHM}$ ) and would reduce the cost of geological disposal by $\$ 200 / \mathrm{kgHM}$, and that the value of the recovered uranium is $\$ 300 / \mathrm{kg}$ (appropriate for uranium prices of $\$ 360 / \mathrm{kgU}$ ).

${ }^{173}$ The characteristics of the generic fast reactor we have used in our calculations are drawn from those used in U.S. Department of Energy, Office of Nuclear Energy, Science, and Technology, Generation IV Roadmap: Report of the Fuel Cycle Crosscut Group (Washington, DC: DOE, March 18, 2001, available as of December 16, 2003 at http://www.ne.doe.gov/reports/GenIVRoadmapFCCG.pdf.). This generic system has a core loading of $11.5 \mathrm{kgHM} / \mathrm{MW}_{\mathrm{e}} \mathrm{y}(24.6 \%$ plutonium) and a core fuel residence time of 3 years, and hence an initial core loading of $0.0085 \mathrm{kgPu} / \mathrm{kW}_{\mathrm{e}}$; at $\$ 30,000 / \mathrm{kgPu}$, this amounts to about $\$ 250 / \mathrm{kW}_{\mathrm{e}}$. Including an additional onethird core for the initial reload brings the total cost to over $\$ 300 / \mathrm{kW}_{\mathrm{e}}$. The model system we have used is described further in As described in the sidebar, "Characteristics of the Model Fast Reactor."
} 
plutonium. ${ }^{174}$ ) This could be offset somewhat by the sale of excess plutonium generated during the operation of the reactor; rough calculations indicate that with a breeding ratio of 1.25 , such sales would reduce the net plutonium cost to about $\$ 200 / \mathrm{kW}_{\mathrm{e}}{ }^{175}$ Even if the other capital costs of the FR could be reduced to be equal to that of a once-through system, for the other nominal values of our parameters, the uranium breakeven price would still be at our central estimate of about $\$ 340 / \mathrm{kgU}$, a level at which the quantities of uranium resources available would likely be sufficient for 100 years or more, even with substantial nuclear growth.

Table 3.2 gives breakeven values of several other price parameters for the case of a regulated utility owner, assuming a uranium price of $\$ 50 / \mathrm{kgU}$ and central values for other parameters. Note that reductions in the price of reprocessing alone cannot make FRs economic so long as the FRs remain \$200/kWe more expensive than LWRs.

Table 3.2. Breakeven prices of selected parameters, assuming a regulated utility owner, a uranium price of $\$ 50 / \mathrm{kgU}$, and central values for other parameters.

\begin{tabular}{lccc}
\hline Parameter & $\begin{array}{c}\text { Central } \\
\text { Estimate }\end{array}$ & $\begin{array}{c}\text { Breakeven } \\
\text { Value }\end{array}$ & $\begin{array}{c}\text { Breakeven } \\
\text { Central }\end{array}$ \\
\hline Capital cost difference $(\$ / \mathrm{kWe})$ & 200 & -95 & \\
Disposal cost difference $(\$ / \mathrm{kgHM})$ & 200 & 3400 & 17 \\
Interim spent fuel storage $(\$ / \mathrm{kgHM})$ & 200 & 4100 & 21 \\
Enrichment $(\$ / \mathrm{SWU})$ & 100 & 570 & 5.7 \\
Reprocessing $(\$ / \mathrm{kgHM})$ & 1000 & $<0$ & \\
Uranium $(\$ / \mathrm{kgU})$ & 50 & 340 & 6.8 \\
\hline
\end{tabular}

\subsection{Cost of Electricity for Fast Reactors and Once-through Systems}

Figure 3.4 shows the difference between the cost of electricity from FRs with recycling and LWRs operating on a once-through cycle, as a function of the price of uranium, for difference in capital cost between the FRs and the LWRs of $\$ 0$ to $\$ 400 / \mathrm{kW}_{\mathrm{e}}$. (for the case of reactors owned by regulated utilities, with other parameters set at their nominal values). Since the FRs can rely on the very large existing stockpiles of depleted uranium for their make-up fuel (at least until those stockpiles are consumed), their electricity price is not affected by increasing uranium price, while the electricity price from once-through LWRs

\footnotetext{
${ }^{174}$ The start-up core and initial reload would require $46 \mathrm{~kg} / \mathrm{kW}_{\mathrm{e}}$ of HEU with an enrichment of about $25 \% \mathrm{U}$ 235 . Assuming uranium, conversion, and enrichment prices of $\$ 50 / \mathrm{kgU}, \$ 6 / \mathrm{kgU}$, and $\$ 100 / \mathrm{SWU}$, respectively, the cost would be $\$ 8,300 / \mathrm{kg}$ of HEU, equivalent to $\$ 380 / \mathrm{kW}_{\mathrm{e}}$. Using the breakeven price of uranium in our reference case $(\$ 340 / \mathrm{kgU})$ would increase these costs to $\$ 22,000 / \mathrm{kg}$ HEU and $\$ 1000 / \mathrm{kW}_{\mathrm{e}}$.

${ }^{175}$ The generic LMR with a breeding ratio of 1.25 produces an excess of $0.3 \mathrm{kgPu} / \mathrm{MW}_{\mathrm{e}} \mathrm{y}$; at $\$ 30,000 / \mathrm{kgPu}$ and a discount rate of $5 \% / \mathrm{y}$ over $30 \mathrm{y}$, and taking into account the plutonium recovered from the final core, the net present value of the recovered plutonium is about $\$ 130 / \mathrm{kW}_{\mathrm{e}}$.
} 
increases as the uranium price increases. Nevertheless, the electricity price for FRs will remain significantly higher than that for LWRs operating on a once-through cycle until uranium prices reach many times their current level—a development that is not likely to occur for many decades to come.

Figure 3.4. The difference in the cost of electricity between an FR with recycling and an LWR with direct disposal as a function of the price of uranium, for differences in the initial capital cost of $\$ 0, \$ 100, \$ 200, \$ 300$, and $400 / \mathrm{kW}_{\mathrm{e}}$, assuming a utility ownership.

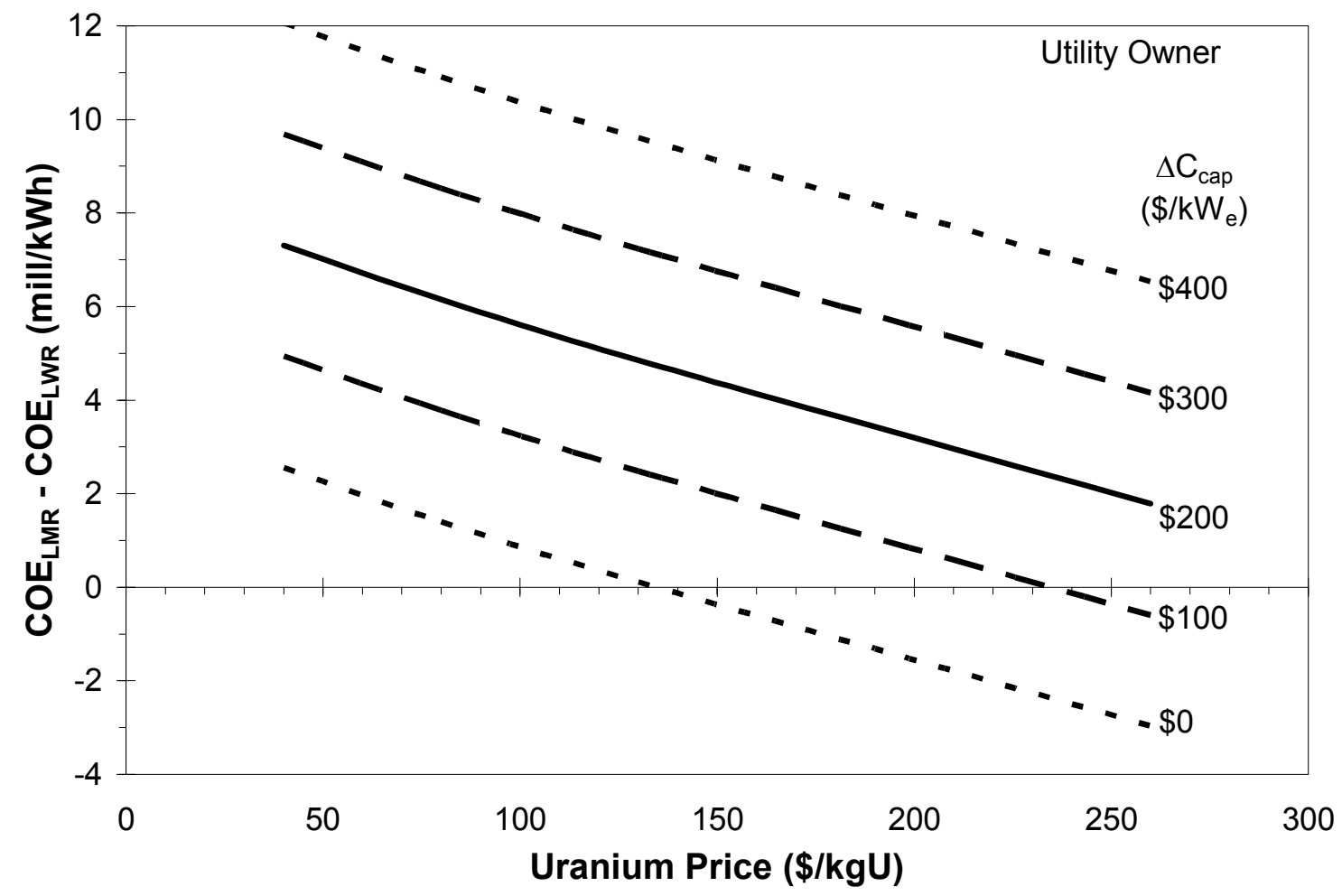

This overall finding is broadly consistent with recent studies by the Nuclear Energy Agency (NEA) of the Organization for Economic Cooperation and Development (OECD) and the Generation IV Fuel Cycle Crosscut Group. The NEA assessment found that all of the approaches it examined which included FRs resulted in higher electricity costs than a oncethrough approach using LWRs, with electricity generated entirely by FRs that recycled plutonium and minor actinides being roughly $50 \%$ more expensive than electricity generated by once-through LWRs. ${ }^{176}$ The NEA study, however, did not examine how this would be changed by possible future increases in uranium price. The Generation IV Fuel Cycle Crosscut Group examined the fuel cycle contribution to electricity costs for different types of nuclear energy mixes throughout the $21^{\text {st }}$ century, during which time they projected uranium prices to increase dramatically; despite those projected increases (and despite looking only at fuel cycle costs, and therefore not including any increased capital cost of fast reactors), the

${ }^{176}$ NEA, Accelerator-driven Systems (ADS) and Fast Reactors (FR) in Advanced Nuclear Fuel Cycles, op. cit., p. 219. 
costs for all the mixes that included fast reactors remained higher throughout the century than the price for electricity from once-through LWRs. ${ }^{177}$ Similarly, a mid-1990s study by a committee of the U.S. National Academy of Sciences (using somewhat different assumptions than our own, including charging the cost of separating plutonium for startup fuel to the cost of the FR) concluded that the electricity cost of FRs would be substantially higher than that of once-through LWRs until uranium reached a price of well over $\$ 250 / \mathrm{kgU}$ (1992\$), even if reprocessing costs for LWR fuel and FR fuel could be reduced to roughly the lower bound of our projected range. ${ }^{178}$

\subsection{Cost Parameters and Variations}

In the remainder of this chapter, we explain the particular central, high, and low values of the parameters we have chosen for modeling the economics of FRs, and discuss the sensitivity of the outcome to variations in these individual estimates. Since there are no commercial-scale FRs now operating that were built in countries that were market economies at the time, the parameters for the fast reactor case are largely based on studies of potential, but as-of-yet unrealized, breeder systems. We have relied heavily on recent overviews of fuel cycles including FRs, to provide an update of current thinking on costs of particular parameters. ${ }^{179}$

\subsubsection{Difference in capital cost}

The two most sensitive parameters in this analysis are the difference in capital cost between FRs and LWRs and the financing arrangements for capital costs. We have assumed a central value of $\$ 200 / \mathrm{kW}_{\mathrm{e}}$ for the difference in capital cost, with a low case of $\$ 0$ (equal capital cost) and a high case of $\$ 400 / \mathrm{kW}_{\mathrm{e}}$. For the reference case of a privately-owned utility with a regulated rate of return, this central estimate results in a breakeven uranium price of $\$ 340 / \mathrm{kgU}$; this breakeven price is reduced by about $\$ 200 / \mathrm{kgU}$ if the capital cost difference is eliminated, and increased by $\$ 220 / \mathrm{kgU}$ if the capital cost difference is doubled.

We chose our range to reflect past experience and current peer-reviewed estimates for the additional capital cost of fast reactors, and the expectation that there would be further progress in bringing costs down before fast reactors would be deployed. The most recent FR designs before major commercialization efforts were canceled in the United States and Western Europe were expected to be significantly more expensive than comparably advanced LWRs. The capital cost of the U.S. Advanced Liquid Metal Reactor (ALMR) was estimated in the mid-1990s, shortly before the program's termination, to be $20-30 \%$ higher than the capital costs of advanced LWRs - a difference amounting to an additional $\$ 400 / \mathrm{kW}_{\mathrm{e}}(1992$ dollars) compared to a small PWR or $\$ 600 / \mathrm{kW}_{\mathrm{e}}$ compared to a large PWR $\left(\$ 500-\$ 740 / \mathrm{kW}_{\mathrm{e}}\right.$

${ }^{177}$ DOE, Generation IV Roadmap: Report of the Fuel Cycle Crosscut Group, op. cit., pp. 3-53, 3-68, 3-72, 376, 3-79.

${ }^{178}$ U.S. National Research Council, Board on Radioactive Waste Management, Committee on Separations Technology and Transmutation Systems, Nuclear Wastes-Technologies for Separations and Transmutation (Washington, DC: National Academy Press, 1996), pp. 218-222.

${ }^{179}$ See particularly NEA, Accelerator-driven Systems (ADS) and Fast Reactors (FR) in Advanced Nuclear Fuel Cycles, op. cit., and DOE, Generation IV Roadmap: Report of the Fuel Cycle Crosscut Group, op. cit. 
in 2003 dollars, well above the range of extra costs we examine here). ${ }^{180}$ Similarly, the European Fast Reactor (EFR), after having achieved major reduc-tions in various elements of capital cost compared to earlier European FR designs, was expected to have a capital cost in series production 20-30\% higher than that of a comparable LWR. ${ }^{181}$ Even Russia's Ministry of Atomic Energy (MINATOM), in recent years one of the institutions most enthusiastic about the near-term commercialization of fast reactors, has acknowledged, in the words of Minister Alexander Rumiantsev, that "life has proved that a VVER-1000 reactor [a modern Russian LWR design] is one and a half times cheaper than a BN [fast neutron] reactor...[LWRs] are cheaper, safer, and economically more viable."182 Minister Rumiantsev's statement suggests that the capital cost of the new fast reactor is $50 \%$ higher than the capital cost of a comparable LWR. Some fast reactor designers argue, however, that recent developments would make it possible to build FRs at a cost no higher than that of LWRs, ${ }^{183}$ and the Japanese fast reactor program, among others, has set capital cost equality with LWRs as an explicit goal. ${ }^{184}$

New FR concepts being pursued for the long-term future of nuclear energy, such as leadcooled and gas-cooled FR systems, are hoped to have lower capital costs than traditional sodium-cooled FRs. ${ }^{185}$ The economic features of these proposed concepts remain undemonstrated, however. At the same time, new once-through systems are hoped to have significantly lower capital costs than traditional LWRs, so the target that FRs must reach to be equal in capital cost to once-through systems is moving. In the case of both advanced fast reactor concepts and once-through systems such as the proposed pebble-bed reactor, for example, it is hoped to reduce cost by avoiding the need for high-pressure containment structures.

\footnotetext{
${ }^{180}$ See, for example, Management and Disposition of Excess Weapons Plutonium: Reactor-Related Options, op. cit., p. 318. This study drew on a DOE technical review committee assessment of costs estimated by vendors proposing different reactor concepts, including the ALMR and several LWRs.

${ }_{181}$ The final report of the European Fast Reactor programme is European Fast Reactor 98: Outcome of Design Studies (Lyon, France: EFR Associates, 1998). The contribution of initial capital cost to generating cost is shown there to be $30 \%$ higher for the EFR in series production than for a comparably advanced LWR (p. 19). In a personal communication from J.C. Lefevre, head of the EFR design team, April 2003, however, he put the excess capital cost in the range of $20 \%$. See also Crette, "Review of the Western European Breeder Programs," op. cit., which estimates a capital difference of $26 \%$ in series production.

${ }^{182}$ Sergey Savenkov, "Minister Rumiantsev: Minatom Will Not be Privatized," (Interview), www.uralpress.ru, April 4, 2003 (translated by the U.S. Department of Energy).

${ }^{183}$ See, for example, C.E. Boardman, M. Hui, G. Carroll, and A. E. Dubberley, "Economic Assessment of SPRISM Including Development and Generating Costs" (San Jose, CA: GE Nuclear Energy, no date).

${ }^{184}$ See, for example, Hiroshi Noda and Tatsutoshi Inagaki, "Feasibility Study on Commercialized FR Cycle Systems in Japan - The Results in the First Phase and Future Plans of the Study," paper presented at "Global 2001: The Back End of the Fuel Cycle-From Research to Solutions," Paris, September 9-13, 2001. This paper specifies that initial demonstration fast reactors are expected to be far more expensive than LWRs, but it is hoped in the future to reduce their costs to 0.34 million yen $/ \mathrm{kW}_{\mathrm{e}}$ (compared to .3 million yen $/ \mathrm{kW}_{\mathrm{e}}$ for $\mathrm{LWRs}$ ), and then, after further cost reductions (now the target of feasibility studies), to reach the goal of 0.2 million yen/ $\mathrm{kW}_{\mathrm{e}}$, which is the cost expected for LWRs in the 2030 time frame. This corresponds to roughly $\$ 1800 / \mathrm{kW}_{\mathrm{e}}$ (2003 dollars). The same target was specified in Kiyoto Aizawa, Japan Nuclear Cycle Development Institute, "Feasibility Studies on Commercialized FR Cycle System," presentation, Aomori, Japan, July 22, 2000.

${ }^{185}$ See, for example, NERAC, A Technology Roadmap for Generation IV Nuclear Energy Systems, op. cit.
} 
Recent estimates of the cost of building LWRs cover a broad range. ${ }^{186}$ Estimates based on actual industrial experience - that is, the costs of advanced reactors that have been built in recent years - tend to be over $\$ 2000 / \mathrm{kW}_{\mathrm{e}}{ }^{187}$ Estimates for future construction from official peer-reviewed assessments are in the range of $\$ 1500-\$ 2000 / \mathrm{kW}_{\mathrm{e}}$. The Nuclear Energy Agency of the OECD, for example, reported overnight construction costs ranging from $\$ 1585$ to $\$ 2639 / \mathrm{kW}_{\mathrm{e}}$ (in 1996 dollars; $\$ 1800$ to $\$ 3000 / \mathrm{kW}_{\mathrm{e}}$ in 2003 dollars). Similarly, the U.S. Energy Information Administration (EIA), in its most recent Annual Energy Outlook, assumed overnight capital costs for advanced nuclear systems that could come on-line in 2007 of $\$ 1750 / \mathrm{kW}_{\mathrm{e}}$ (2001 dollars), or $\$ 2137 / \mathrm{kW}_{\mathrm{e}}$ when a $10 \%$ contingency factor and a $10 \%$ multiplier for technological optimism were included (with this higher figure declining, in the reference case, to $\$ 1906 / \mathrm{kW}_{\mathrm{e}}$ by 2025); the EIA also examined an "advanced nuclear cost" case, in which the higher figure including contingency and optimism factors started at $\$ 1535 / \mathrm{kW}_{\mathrm{e}}$ in 2010 , declining to $\$ 1228 / \mathrm{kW}_{\mathrm{e}}$ in $2025 .{ }^{188}$ By contrast, a wide range of reactor vendors have projected overnight capital costs for their proposed systems of $\$ 1000$ to $\$ 1500 / \mathrm{kW}_{\mathrm{e}}{ }^{189}$

If LWRs at the future date when FRs might begin to be deployed commercially had a capital cost of $\$ 1500 / \mathrm{kW}_{\mathrm{e}}$, then our range of $\$ 0-\$ 400 / \mathrm{kW}_{\mathrm{e}}$ difference in capital cost would translate to 0 to $27 \%$ - the high end of our range being comparable to the percentage of additional cost envisioned in the most recent fully designed commercial systems, and the low end representing success in current development efforts focused on equalizing the capital cost. The range we have chosen is substantially more generous to future fast reactor systems than the range chosen in the most recent NEA assessment, whose nominal estimate for future fast reactors was $\$ 400 / \mathrm{kW}_{\mathrm{e}}$ higher than their $\$ 1700 / \mathrm{kW}_{\mathrm{e}}$ nominal estimate for future LWRs, with a range from $\$ 150 / \mathrm{kW}_{\mathrm{e}}$ higher than the LWR figure to $\$ 900 / \mathrm{kW}_{\mathrm{e}}$ higher. ${ }^{190}$ Hence, we believe our range is a conservative estimate of the possible additional capital costs of building fast reactors. This is particularly the case given that recycling in future fast reactors must compete not only with LWRs but with other future once-through nuclear systems designed for low capital cost (such as the particle-bed high-temperature gas reactor, among others).

\subsubsection{Reactor ownership and financing arrangements}

The next most sensitive factor are the financing arrangements for the additional capital costs of the FR. As already mentioned, we consider three generic cases: government ownership and financing of the reactor; ownership and financing by a regulated utility with a guaranteed rate of return; and ownership and financing by a private company with no

\footnotetext{
${ }^{186}$ For a useful overview, see John M. Deutch and Ernest J. Moniz, co-chairs, The Future of Nuclear Power: An Interdisciplinary MIT Study (Cambridge, MA: Massachusetts Institute of Technology, July 2003, available as of July 30, 2003 at http://web.mit.edu/nuclearpower/).

${ }^{187}$ Tokyo Electric Power, for example, reports that its most recently completed plants (1,356 MWe GE Advanced Boiling Water Reactor designs) cost 418 billion yen and 367 billion yen (roughly $\$ 2200-\$ 2600 / \mathrm{kW}_{\mathrm{e}}$, at an exchange rate of $120 \mathrm{yen} / \$$ ). See Deutch and Moniz, co-chairs, The Future of Nuclear Power, op. cit.

${ }^{188}$ U.S. Energy Information Administration, Assumptions to the Annual Energy Outlook 2003 (Washington, DC: EIA, March 2003), p. 73, and p. 85.

${ }^{189}$ See, for example, the listing in Deutch and Moniz, co-chairs, The Future of Nuclear Power, op. cit.

${ }^{190}$ See NEA, Accelerator-driven Systems (ADS) and Fast Reactors (FR) in Advanced Nuclear Fuel Cycles, op. cit., p. 216.
} 
guaranteed rate of return. The differences in calculated uranium breakeven price between these three cases are large: if the difference in capital cost is $\$ 200 / \mathrm{kW}_{\mathrm{e}}$, government ownership would reduce the breakeven uranium price by about $\$ 120 / \mathrm{kgU}$ from the $\$ 340 / \mathrm{kgU}$ estimate for the nominal regulated utility case, while ownership by an entity with no guaranteed rate of return would increase the uranium breakeven price by $\$ 230 / \mathrm{kgU}$.

These changes are driven by the very different financial context for each of these three cases. For the government case, we assume a $4 \%$ real cost of money, and no taxes or insurance. With a 30-year recovery period, this leads to an annual fixed charge rate (FCR)the fraction of the initial capital cost that revenue must bring in every year-of $5.8 \%$. For the regulated utility case and the unregulated private venture case, we use substantially higher costs of money, reflecting the higher risks to investors in these cases, along with payment of corporate income taxes, property taxes, and insurance, leading to FCRs of $12.3 \%$ and $20.8 \%$ per year, respectively. These figures are drawn from a major National Academy of Sciences study of fuel cycle options, ${ }^{191}$ and are somewhat more optimistic (for the utility case) than the Electric Power Research Institute's approach to assessing the cost of new power plants. ${ }^{192}$

For these comparisons, we have assumed that the reactors take 6 years to build, with a range from 3 years to 9 years. Construction time enters into the economics by affecting the interest during construction (IDC), which is added to overnight cost; we have assumed a real average cost of money of $4 \%$ per year for the government, $6.4 \%$ per year for the regulated utility, and $13.9 \%$ per year for the unregulated private venture during the construction period. For the government, regulated utility, and unregulated private venture cases, IDC for this sixyear construction time and our assumed spend-out of the funds during construction adds about $11 \%, 19 \%$, and $45 \%$, respectively, to the overnight capital cost. Because the same period of construction is assumed for both the LWR and the FR in the comparison, construction time would not affect the uranium breakeven price if the difference in capital cost was zero; it only affects the outcome in cases where there is an additional capital cost (incurring additional IDC) for the FR. For the nominal regulated-utility-owned case with an extra overnight capital cost of $\$ 200 / \mathrm{kW}_{\mathrm{e}}$ for the $\mathrm{FR}$, reducing construction time to 3 years decreases breakeven uranium price by $\$ 14 / \mathrm{kgU}$, while increasing construction time to 9 years increases the breakeven price by $\$ 16 / \mathrm{kgU}$.

Once the power plant has been built, there are further costs in getting it ready for full operation, referred to as pre-operating costs. We have assumed a nominal figure for these pre-operating costs of $10 \%$ of overnight capital costs, with a low of $5 \%$ and a high of $15 \%$. The low figure reduces the breakeven uranium price by $\$ 10 / \mathrm{kgU}$, the high figure increases it by $\$ 10 / \mathrm{kgU}$.

In such calculations, a contingency factor is usually introduced to account for unexpected additional costs that may emerge as a reactor is being built. We have assigned a nominal value of $10 \%$ for both the FRs and the LWRs, with a low of 5\% and a high of $15 \%$. Here, too, the result of the variation is a change of $\pm \$ 10 / \mathrm{kgU}$ in the breakeven uranium price.

\footnotetext{
${ }^{191}$ NAS, Nuclear Wastes-Technologies for Separations and Transmutation, op. cit., p. 432.

${ }^{192}$ Electric Power Research Institute, Technical Assessment Guide: Volume 3, Revision 8: Fundamentals and Methods - Electricity Supply TR-100281-V3R8 (Palo Alto, CA: EPRI, 1999).
} 


\subsubsection{Reprocessing costs}

Uranium breakeven price for recycling in FRs is also sensitive to the cost of reprocessing FR fuel. For simplicity, we have chosen a central estimate of FR reprocessing cost (applied to both the core fuel and the blanket fuel) of $\$ 1000 / \mathrm{kgHM}$, with a low of $\$ 500 / \mathrm{kgHM}$ and a high of $\$ 2000 / \mathrm{kgHM}$ - the same range considered in the previous chapter for reprocessing of LWR fuel. (This is the only case where we have used a log-normal distribution, extending higher above the central estimate than below.) At the low reprocessing price, the calculated breakeven uranium price falls by $\$ 85 / \mathrm{kgU}$ from the nominal $\$ 340 / \mathrm{kgU}$, while at the high price, it increases by $\$ 175 / \mathrm{kgU}$.

Using a range equal to the range for reprocessing LWR fuel is a generous assumption, as reprocessing costs for higher-burnup FR fuels with much higher plutonium loadings generally will be significantly higher, given the greater difficulty of managing criticality with the higher plutonium content fuels, and increased complexity of dissolving them. The recent NEA review, for example, posited a range of 1000-2000-2500 \$/kgHM (low-central-high values) for the costs of core fuel reprocessing, and 900-1500-2500 \$/kgHM (low-central-high values) for the costs of blanket fuel reprocessing; both of these are substantially higher than our range. ${ }^{193}$ The $\$ 500 / \mathrm{kgHM}$ lower bound of our range is intended to cover the possibility of substantial technological advance in the future. The $\$ 2000 / \mathrm{kgHM}$ upper bound is by no means the actual upper bound of what FR reprocessing might cost, but if the actual reprocessing cost turns out to be higher there is little hope of uranium reaching the resulting breakeven price in the foreseeable future. Additional discussion of the cost of reprocessing in existing plants, and possible future developments, is provided in the previous chapter, and in Appendix B.

\subsubsection{Core and blanket fuel fabrication cost}

We have assumed that the fabrication costs of FR core fuel amount to $\$ 1500 / \mathrm{kgHM}$, with a range from $\$ 700 / \mathrm{kgHM}$ to $\$ 2300 / \mathrm{kgHM}$. The low-end fabrication cost would reduce the calculated breakeven uranium price by about $\$ 55 / \mathrm{kgU}$, while the high-end cost would increase it by $\$ 55 / \mathrm{kgU}$.

As with reprocessing cost, the range presented for plutonium fuel fabrication cost is the same range we used for the LWR recycling case. Here, too, the use of the same range is generous, since FRs will require fuel with much higher plutonium loadings, designed to reach much higher burnups, which will generally mean a significantly higher fabrication cost. ${ }^{194}$ The cost range we have assumed for core fuel element fabrication is approximately

\footnotetext{
${ }^{193}$ NEA, Accelerator-driven Systems (ADS) and Fast Reactors (FR) in Advanced Nuclear Fuel Cycles, op. cit., p. 216.

${ }^{194}$ The recent NEA study, for example, estimated fabrication prices for fast reactor MOX substantially higher than those for LWR MOX, and prices for fast reactor fuels containing minor actinides as well far higher still. See NEA, Accelerator-driven Systems (ADS) and Fast Reactors (FR) in Advanced Nuclear Fuel Cycles, op. cit., p. 216. Higher costs for fuel certified to higher burnups and higher plutonium concentrations (which mean, among other things, greater care required in maintaining criticality safety) have been traditional in the fuel fabrication business, although this may change if non-pelletized fuels are adopted in the future. The recent NEA study, for example, estimated fabrication prices for fast reactor MOX substantially higher than those for LWR MOX, and prices for fast reactor fuels containing minor actinides as well far higher still.
} 
equal to that employed in the recent NEA analysis for fast reactors using plutonium-uranium mixed oxide (MOX) fuels (their estimates are within 10\% of ours for the low, medium, and high figures). ${ }^{195}$ The large range between the lower and upper estimates employed by that study - obtained through consensus among international groups of experts - reflects the very modest industrial experience base for fabricating FR fuel. For metal-fueled reactors, where the NEA study assumed minor actinides would also be recycled with the plutonium, they envisioned that core fuel fabrication would be more expensive (because of the extra cost of handling the more radioactive minor actinides), with a range of 1400-2600-5000 \$/kgHM. (Recent estimates of metal FR fuel fabrication costs that do not also include minor actinides are rare, because so much of the current emphasis in fast reactor development is focused on transmutation of these minor actinides.)

We assume that fabrication costs of blanket fuel (made from depleted uranium without any plutonium content) are the same as those we assumed for LEU fuel for LWRs - a nominal figure of $\$ 250 / \mathrm{kgHM}$, ranging from a low of $\$ 150 / \mathrm{kgHM}$ (representing possible future technological advance) to a high of $\$ 350 / \mathrm{kgHM}$. This variable has only a small effect on the uranium breakeven price - about $\pm \$ 15 / \mathrm{kgU}$. This estimated range appears again to be generous to the FR case, as our range is a factor of two lower than that used in the recent NEA assessment. ${ }^{196}$ We have kept our estimates low because fuel that provides less power per kilogram generally costs less to fabricate (given the lower tolerances that are permitted), and FR blanket fuel typically provides little power.

\subsubsection{Geological disposal of reprocessing waste}

The cost of disposing of reprocessing wastes (as compared to the cost of direct disposal of LWR spent fuel) is another important parameter in finding the breakeven uranium price. It is less sensitive than reprocessing price because, with a relatively modest nominal estimate of $\$ 200 / \mathrm{kgHM}$, the range over which disposal cost might vary is substantially smaller than the range of possible reprocessing cost. Decreasing the present value at the time of fuel discharge of the cost of geological disposal of reprocessing waste to $\$ 100 / \mathrm{kgHM}$ or increasing it to $\$ 300 / \mathrm{kgHM}$ lowers or raises the uranium breakeven price by $\$ 18 / \mathrm{kgU}$. Since the costs of direct disposal of LWR spent fuel are assumed to be $\$ 400 / \mathrm{kgHM}$, the corresponding variation of the difference in costs between the disposal of reprocessing waste and the direct disposal of LWR spent fuel amounts to $\$ 200 \pm \$ 100 / \mathrm{kgHM}$, the same range discussed in the previous chapter. Using the same range for disposal of reprocessing waste from FR fuel as for reprocessing of LWR fuel is again generous, as one would expect in general that reprocessing wastes from higher-burnup fast reactor fuel would have higher activity and higher volume, increasing their costs of disposal. (This factor is compensated for, however, by the fact that we have chosen the same cost of disposal for wastes from reprocessing the blanket fuel, which will have low burnup, and the core fuel, which will have high burnup.) These cost estimates are discussed in the previous chapter.

\footnotetext{
${ }^{195}$ NEA, Accelerator-driven Systems (ADS) and Fast Reactors (FR) in Advanced Nuclear Fuel Cycles, op. cit., p. 216.

${ }^{196}$ NEA, Accelerator-driven Systems (ADS) and Fast Reactors (FR) in Advanced Nuclear Fuel Cycles, op. cit., p. 216; their range was 350-500-700 $\$ / \mathrm{kgHM}$ for either oxide or metal blanket fuel fabrication.
} 


\subsubsection{Breeding ratio}

The breeding ratio for the fast reactor - the ratio of fissile atoms produced to those consumed - is another sensitive parameter. In our model, the higher the breeding ratio, the worse the economics. This is because higher breeding ratios involve more blanket material that must be reprocessed each year, with the associated costs of reprocessing. This result, however, is in part an artifact of our assigning a zero cost to the initial core fuel; if producing fuel for startup of additional FRs was assigned a substantial value, then FRs with higher breeding ratios would be more competitive.

We have assumed a nominal breeding ratio of 1.125 , with a low of 1.0 and a high of 1.25 . FRs with lower breeding ratios (consuming more fuel than they produced) would presumably not be deployed if the concern was depletion of uranium resources leading to escalating uranium prices, though they might be deployed to consume plutonium and minor actinides as part of a waste-management strategy. For the nominal regulated-utility-owned case, the low breeding ratio would reduce the uranium breakeven price by $\$ 46 / \mathrm{kgU}$, while the high value would increase it by $\$ 46 / \mathrm{kgU}$.

\subsubsection{Depleted uranium price}

After their initial cores and first reloads, the only fuel FRs would require is additional depleted uranium as "make-up" material to replace uranium transformed into plutonium, fissioned, or lost in processing. Many thousands of tons of depleted uranium (DU) already exist in the stored waste from uranium enrichment plants. As long as uranium demand is driven by LWRs, there will be little use for this DU and its price will be low. On the other hand, once uranium prices increase enough that FRs would have some hope of being competitive, those holding stocks of DU may begin to assign some significant value to it, in anticipation of its use to fuel a large number of FRs in the future. In our study, we therefore assume a central DU price of $\$ 6 / \mathrm{kgU}$ - the price of converting the material from uranium hexafluoride. When the demand for uranium begins to be dominated by breeders, and previous stocks of DU begin to be drawn down, the price of DU should approach the price of natural uranium, since the use of DU and natural uranium are almost perfect substitutes for use in breeder blankets. Hence, we use the breakeven natural uranium price as the upper value for DU in our sensitivity analysis. Since the breakeven uranium price is likely to amount to hundreds of dollars per kilogram of uranium - according to our calculations at least - our sensitivity calculation change is highly asymmetric. In any case, even with such a high upper bound, the depleted uranium price has virtually no effect on the economics of FRs. 


\section{Sidebar: Thermal-Neutron and Fast-Neutron Reactors}

The likelihood that a neutron will split (or fission) an atom of U-235 or plutonium depends on the neutron's speed. If the neutrons from a nuclear chain reaction are slowed down to the point where they are traveling at roughly the speeds that would result from the normal motion of the atoms at that temperature - so-called "thermal" neutrons - then their likelihood of hitting a nucleus of one of these isotopes and splitting it (the "fission crosssection") is greatly increased. As a result, with thermal neutrons a nuclear chain reaction can be sustained without as high a density of these atoms - for example in a reactor using fuel with only a few percent of U-235. Reactors operating on this principle are known as thermalneutron reactors, or simply thermal reactors. Nuclear materials that can sustain a nuclear chain reaction in such a thermal neutron spectrum are referred to as "fissile" materials. ${ }^{197}$

This slowing down or "moderation" is accomplished by arranging the nuclear fuel amongst a substantial quantity of some light element; when the neutrons scatter off the light atoms, they lose some of their energy. The most common neutron moderators are water (either "heavy water," meaning water in which the hydrogen atoms have not just a proton and an electron but a neutron as well, or ordinary water, known in the nuclear world as "light water"), and carbon (usually in the form of very pure graphite - the purity being required because many of the common impurities are potent neutron absorbers). In systems with high "neutron efficiency," a very small fraction of the neutrons leak out or are absorbed by the moderator, and the nuclear reaction can be sustained with natural uranium (containing only $0.7 \% \mathrm{U}-235)$. This is the case, for example, with heavy-water moderated reactors such as the Canadian Deuterium-Uranium (CANDU) reactor. In systems with a lower neutron efficiency, such as in light-water reactors (LWRs), the fuel must be enriched to several percent U-235 to sustain the nuclear chain reaction.

Reactors that rely on a nuclear chain reaction using neutrons that have not been substantially slowed down are referred to as "fast-neutron reactors," or simply "fast reactors" (FRs). In this case, because the fission cross-section for these fast neutrons is much smaller, a much greater density of fuel atoms is needed to sustain the nuclear chain reaction. Typical FR fuels contain $20-30 \%$ U-235 or plutonium, compared to $3-4 \%$ for an LWR.

For decades, the main reason for focusing on FRs was a concern that uranium would run out, and it would be necessary to produce plutonium from the U-238 that makes up more than $99 \%$ of natural uranium, vastly extending the available uranium resource. Fast reactors could be designed with a core of $20-30 \%$ U-235 or plutonium to sustain the chain reaction, surrounded by "blankets" of U-238 that would absorb neutrons and produce plutonium; by that means, such reactors could produce more atoms of potential fuel than they consumed,

\footnotetext{
${ }^{197}$ The term "fissile material" is often mis-used to refer to materials that can sustain an explosive fast-neutron nuclear chain reaction, needed for a nuclear bomb. In reality, however, some materials (such as uranium enriched to 2-5\%) can sustain a thermal-neutron chain reaction — and are thus properly "fissile" — but cannot sustain a chain reaction with fast neutrons and hence cannot provide the core of a nuclear bomb, while some other materials that cannot sustain a thermal-neutron chain reaction — and are thus not "fissile" — can sustain an explosive fast-neutron chain reaction, and are thus usable in nuclear weapons (such as the even-numbered isotopes of plutonium).
} 
serving as "breeder" reactors. Hence FRs are often referred to as "fast breeder reactors," or FBRs. (Since the most common types were to be cooled by molten metals, they are also often called liquid-metal fast breeder reactors or LMFBRs.) However, by taking away parts of the blanket (or otherwise reducing the degree of absorption in the blanket), FRs can be operated producing exactly the same amount of fuel as they consume (a "converter" system), or consuming more plutonium than they produce (a "burner" system).

The nuclear material that absorbs neutrons to produce fissile material is referred to as "fertile" material (keeping the analogy implied by "breeding"). The most common fertile material considered is U-238, but the only naturally occurring isotope of thorium (Th-232) is another possibility that has been extensively examined; when it absorbs a neutron, it produces U-233, which is usable as fuel for either nuclear power plants or nuclear weapons.

It is also possible to have thermal reactors that "breed"- that is, produce more fissile material than they consume. This is the idea behind the molten salt reactor (MSR), for example, which uses molten salts containing uranium or plutonium as fuel, coolant, and moderator all in one. These systems, however, tend to breed new fuel relatively slowly. Because the full extent of world uranium resources has only begun to be recognized (and the slow pace of the growth of nuclear energy has only become apparent in recent decades), most of the international research and development focused on breeding has been directed toward reactors that could produce a rapidly growing supply of nuclear fuel, which would be needed for a rapidly growing world nuclear reactor fleet. FRs offer higher capacity for such rapid breeding - usually measured by the "doubling time," the time to double the amount of fissile fuel available - and hence have been the focus of most breeding research and development. ${ }^{198}$

\footnotetext{
${ }^{198}$ For a useful summary of these issues written by scientists for the non-technical reader, see Richard L. Garwin and Georges Charpak, Megawatts and Megatons: A Turning Point in the Nuclear Age? (New York: Knopf, 2001); for a more technical overview more specific to the issues discussed here, see, for example, Report to the American Physical Society by the Study Group on Nuclear Fuel Cycles and Waste Management, Reviews of Modern Physics, Volume 50, Number 1, Part 2, January 1978.
} 


\section{Sidebar: Characteristics of the Model Fast Reactor}

For the analyses in this chapter, we have based our calculations on a generic fast reactor, with characteristics drawn from those used in the recent report of the Generation IV Fuel Cycle Crosscut Team. ${ }^{199}$

Our model specifies only those characteristics of the reactor that enter into calculations of electricity cost. We do not specify its total power. Rather, the important characteristics are specified per unit of power. We specify:

- Capital cost in dollars per kilowatt-electric $\left(\$ / \mathrm{kW}_{\mathrm{e}}\right)$, as compared to comparably advanced LWRs (a nominal estimate of $\$ 200 / \mathrm{kW}_{\mathrm{e}}$ more than LWRs, with a range from no additional cost to $\$ 400 / \mathrm{kW}_{\mathrm{e}}$ ).

- Core loading of fuel, in kilograms of heavy metal per megawatt-electric-year (specified as $11.5 \mathrm{kgHM} / \mathrm{MW}_{\mathrm{e}} \mathrm{y}$ ). This figure, combined with the unit costs of fabricating and reprocessing core fuel, determines the costs for core fuel per unit of electricity generated. The figure we have chosen is identical to that used in the calculations by the Generation IV team. Assuming a net electrical efficiency of $38 \%$ (as the Generation IV team did), and assuming that all the reactor power comes from the core, this corresponds to a burnup of $84 \mathrm{MW}_{\mathrm{t}} \mathrm{d} / \mathrm{kgHM}$. We have not varied this figure, which is independent of the breeding ratio and is determined by the burnup of the core fuel that can be achieved. ${ }^{200}$ For the nominal case of a utility-owned reactor, and our other nominal unit prices, if technological advances allowed the burnup to be doubled (and hence core fuel input per unit of electricity cut in half), the breakeven uranium price would be reduced by $21 \%$, to approximately $\$ 320 / \mathrm{kgU}$.

- Blanket loading of fuel, examined at three different levels corresponding to the three breeding ratios described in the text $\left(19.0 \mathrm{kgHM} / \mathrm{MW}_{\mathrm{e}} \mathrm{y}\right.$ for a breeding ratio of 1.0 , $25.5 \mathrm{kgHM} / \mathrm{MW}_{\mathrm{e}} \mathrm{y}$ for a breeding ratio of 1.125 , and $31.9 \mathrm{kgHM} / \mathrm{MWe}-\mathrm{yr}$ for a breeding ratio of 1.25). The figures for breeding ratios of 1.0 and 1.25 are identical to those used by the Generation IV team, and the intermediate figure is a linear interpolation. As with core fuel, the amount of blanket fuel loaded each year, combined with the unit costs for its fabrication and reprocessing, determines the blanket fuel contribution to the electricity cost.

- Residence time of core and blanket elements. With the annual input of core and blanket fuel fixed as input parameters, the only effect of changing the residence time is to change the period over which the costs of these fuels are discounted. We use a 3 year residence time for core elements and a 3.25 year residence time for blanket elements, corresponding roughly to a weighted average of the residence times for

\footnotetext{
${ }^{199}$ DOE, Generation IV Roadmap: Report of the Fuel Cycle Crosscut Group, op. cit., Table A2.5.4, supplemented by personal communication from David Wade, February 2003.

${ }^{200}$ The NEA analysis uses a figure of 10 rather than 11.5; this difference has a trivial effect on uranium breakeven price.
} 
axial and radial blanket elements used by the Generation IV team ( 3 and 4 years, respectively). Varying the residence time has a minimal effect on uranium breakeven price.

- Capacity factor, in percent. This is the fraction of the potential electrical generating capacity of the reactor that is actually used. Following the Generation IV team, we have used a nominal value of $85 \%$; we have examined a range from $80 \%$ to $90 \%$. The lower figure would increase the uranium breakeven price by $\$ 13 / \mathrm{kgU}$ for the nominal case, while the higher figure would reduce it by $\$ 13 / \mathrm{kgU}$.

- The fraction of the blanket that is replaced by fresh uranium in each year, to compensate for the uranium that is either fissioned or transmuted into plutonium or minor actinides (or, in fact, is lost during the entirety of the fuel cycle process) is called the make-up fraction in the blanket. We have assumed a nominal figure of $2.4 \%$, obtained by taking the weighted average for the axial and radial blankets used by the Generation IV team. Varying this fraction has virtually no effect on uranium breakeven price. 



\section{Conclusions}

The conclusions of this report can be simply stated:

- At a reprocessing price of $\$ 1000$ per kilogram of heavy metal $(\mathrm{kgHM})$, and with our other central estimates for the key fuel cycle parameters, reprocessing and recycling plutonium in existing light-water reactors (LWRs) will be more expensive than direct disposal of spent fuel until the uranium price reaches over $\$ 360$ per kilogram of uranium $(\mathrm{kgU})$ - a price that is not likely to be seen for many decades, if then.

- At a uranium price of $\$ 40 / \mathrm{kgU}$ (comparable to current prices), reprocessing and recycling at a reprocessing price of $\$ 1000 / \mathrm{kgHM}$ would increase the cost of nuclear electricity by $1.3 \mathrm{mill} / \mathrm{kWh}$. Since the total back-end cost for the direct disposal is in the range of 1.5 mill/kWh, this represents more than an $80 \%$ increase in the costs attributable to spent fuel management (after taking account of appropriate credits or charges for recovered plutonium and uranium from reprocessing).

- These figures for breakeven uranium price and contribution to the cost of electricity are conservative, because, to ensure that our conclusions were robust, we have assumed:

- A central estimate of reprocessing cost, $\$ 1000 / \mathrm{kgHM}$, which is substantially below the cost that would pertain in privately financed facilities with identical costs and capacities to the large commercial facilities now in operation.

- A central estimate of plutonium fuel fabrication cost, $\$ 1500 / \mathrm{kgHM}$, which is significantly below the price actually offered to most utilities in the 1980s and 1990s.

- Zero charges for storage of separated plutonium or removal of americium.

- Zero additional security, licensing, or shut-down expenses for the use of plutonium fuels in existing reactors.

- A full charge for 40 years of interim storage in dry casks for all fuel going to direct disposal, and no interim storage charge for fuel going to reprocessing - even though most new reactors are built with storage capacity for their lifetime fuel generation, so few additional costs for interim storage need be incurred.

- Geological disposal of spent MOX fuel at the same cost as disposal of spent LEU fuel.

- Reprocessing and recycling plutonium in fast-neutron reactors (FRs) with an additional capital cost, compared to new LWRs, of $\$ 200 / \mathrm{kW}_{\mathrm{e}}$ installed will not be economically competitive with a once-through cycle in LWRs until the price of uranium reaches some $\$ 340 / \mathrm{kgU}$, given our central estimates of the other parameters. Even if the capital cost of new FRs could be reduced to equal that of new LWRs, recycling in FRs would not be economic until the uranium price reached some $\$ 140 / \mathrm{kgU}$.

- At a uranium price of $\$ 40 / \mathrm{kgU}$, electricity from a plutonium-recycling FR with an additional capital cost of $\$ 200 / \mathrm{kW}_{\mathrm{e}}$, and with our central estimates of the other parameters, would cost more than $7 \mathrm{mill} / \mathrm{kWh}$ more than electricity from a once-through LWR. Even if the additional capital cost could be eliminated, the extra electricity cost would be over 2 mill/kWh.

- As with reprocessing and recycling in LWRs, these figures on breakeven uranium price and extra electricity cost for FRs are conservative, as we have assumed:

- Zero cost for providing start-up plutonium for the FRs.

- Zero additional cost for reprocessing higher-plutonium-content FR fuel. 
- Zero additional cost for manufacturing higher-plutonium-content FR fuel.

- Zero additional operations and maintenance costs for FRs, compared to LWRs.

- Costs for the far more complex chemical separations processes and more difficult fuel fabrication processes needed for more complete separation and transmutation of nuclear wastes would be substantially higher than those estimated here for traditional reprocessing. Therefore the extra electricity cost, were these approaches to be pursued, would be even higher.

- World resources of uranium likely to be economically recoverable in future decades at prices far below the breakeven price amount to tens of millions of tons, probably enough to fuel a rapidly-growing nuclear enterprise using a once-through fuel cycle for a century or more.

In this report, we have focused only on the economic issues, and have not examined other issues in the broader debate over reprocessing. Nevertheless, given (a) the costs outlined above; (b) the significant proliferation concerns that have been raised (particularly with respect to those reprocessing approaches that result in fully separated plutonium suitable for use in nuclear explosives); and (c) the availability of safe, proven, low-cost dry cask storage technology that will allow spent fuel to be stored for many decades, the burden of proof clearly rests on those in favor of investing in reprocessing in the near term. 


\section{$\underline{\text { Appendix A. Fuel-cycle Cost Calculations }}$}

In this appendix we describe the fuel-cycle cost equations that were used to calculate differences in the cost of electricity between two fuel-cycle options. The difference in the cost of electricity depends on the price of natural uranium, as well as many other parameters; the "breakeven" uranium price is the price that would result in the same cost of electricity for both options, for a given set of other cost parameters. When uranium price is below the breakeven price, the fuel cycle with greater uranium requirements per kilowatt-hour (e.g., light-water reactors with direct disposal of spent fuel) is cheaper overall; when uranium price is above the breakeven price, the fuel cycle with lower uranium requirements (e.g., light-water or liquid-metal reactors operating with recycle of uranium and plutonium) is cheaper.

\section{A.1. Direct Disposal v. Reprocessing and Recycle in LWRs}

Here we take the point of view of a reactor operator that is deciding whether to reprocess spent fuel that has been discharged from a light-water reactor (LWR). If the utility decides not to reprocess, it would incur the costs of interim storage and permanent geological disposal of the spent fuel. Alternatively, the operator would pay to reprocess the spent fuel and to dispose of the resulting high-level waste (HLW) and other reprocessing wastes; these costs would be offset by the value of the recovered plutonium, which can be mixed with depleted uranium to produce mixed-oxide (MOX) fuel, as well as the value of the recovered uranium, which can be used to produce low-enriched uranium (LEU) fuel. (When natural uranium and enrichment are cheap, as is currently the case, the recovered plutonium and uranium may have no value, and may even represent additional costs to the utility if their storage is expensive, as is the case with plutonium.)

Reprocessing and disposal of the resulting HLW generally is more expensive than direct disposal of spent fuel, while the value of the recovered plutonium and uranium increases with the price of natural uranium. The price of uranium that gives the same net present cost for both options is the "breakeven" price. The breakeven uranium price satisfies the following equation:

$$
\left[\begin{array}{c}
\text { cost of interim storage } \\
\& \text { disposal of spent fuel }
\end{array}\right]=\left[\begin{array}{c}
\text { cost of reprocessing } \\
\& \text { disposal of HLW }
\end{array}\right]-\left[\begin{array}{c}
\text { value of recovered } \\
\text { plutonium \& uranium }
\end{array}\right]
$$

Uranium prices lower than the breakeven price favor direct-disposal; higher prices favor the reprocessing-recycle option. To simplify the analysis and ensure a level playing field, we assume that geological disposal costs of spent fuel and HLW are paid for at the same time after discharge, that spent MOX fuel is disposed of without reprocessing, ${ }^{201}$ and that other costscapital and non-fuel operations and maintenance costs—are equal for both options. ${ }^{202}$

\footnotetext{
${ }^{201}$ MOX fuel could be reprocessed and recycled, but undesirable isotopes build up with each recycling in light-water reactors, and there is a growing industry consensus that multiple recycling is not justified. For now, MOX spent fuel is being stored pending either geologic disposal or reprocessing to separate plutonium for use in fast-neutron reactors if they become commercially viable.

${ }^{202}$ Other costs may not be equal for both fuels, however. For example, there may be substantial costs to modify and license reactors to burn MOX and additional charges for secure storage of fresh MOX fuel at the reactor. The direct
} 


\section{A.1.1. Direct Disposal}

The direct-disposal option has two main cost components: interim storage and geological disposal of spent fuel. The net present cost at discharge of direct disposal per kilogram of spent fuel, $C_{d d}$ (dollars per kilogram of initial heavy metal, $\$ / \mathrm{kgHM}$ ) is

$$
C_{d d}=\frac{C_{i s}}{(1+i)^{t_{i s}}}+\frac{C_{d s}}{(1+i)^{t_{d s}}}
$$

where $C_{i s}$ is the cost of interim storage $(\$ / \mathrm{kgHM})$, including packaging and shipping, paid at time $t_{i s}$ after the fuel is discharged from the reactor, $C_{d s}$ is the cost of geological disposal $(\$ / \mathrm{kgHM})$, including shipping, paid at time $t_{d s}$, and $i$ is the discount rate $\left(\mathrm{y}^{-1}\right)$. As discussed in chapter 2, we set $t_{d s}=0$ so that $C_{d s}$ is the net present cost of geological disposal at discharge. In our reference case $C_{i s}=\$ 200 / \mathrm{kg}, t_{i s}=4 \mathrm{y}, i=0.05 \mathrm{y}^{-1}$, and $C_{d s}=\$ 400 / \mathrm{kg}$, which gives $C_{d d}=\$ 200 /(1.05)^{4}+$ $\$ 400=\$ 565 / \mathrm{kgHM}$.

The amount added to the cost of electricity, $c_{d d}$ (dollars per kilowatt-hour, $\$ / \mathrm{kW}_{\mathrm{e}} \mathrm{h}$ ) to pay for direct disposal is

$$
c_{d d}=\frac{C_{d d} F_{c}}{24,000 B \varepsilon}
$$

where $B$ is the batch-average burn-up of the spent fuel at discharge (thermal megawatt-days per kilogram of heavy metal, $\mathrm{MW}_{\mathrm{t}} \mathrm{d} / \mathrm{kgHM}$ ), $\varepsilon$ is the thermal efficiency of the power plant (net electrical kilowatts per thermal kilowatt, $\mathrm{kW}_{\mathrm{e}} / \mathrm{kW}_{\mathrm{t}}$ ), and 24,000 is the number of kilowatt-hours per megawatt-day. The carrying-charge factor, $F_{c}$, which accounts for fact that the electricity revenues to pay for disposal are collected over the time $\tau$ the fuel is in the reactor, is given by

$$
F_{c}=\frac{\tau i}{(1+i)^{\tau}-1}
$$

In our reference case, $B=43 \mathrm{MW}_{\mathrm{t}} \mathrm{d} / \mathrm{kgHM}, \tau=4 \mathrm{y}, \varepsilon=0.33$, and $i=0.05 \mathrm{y}^{-1}$, which gives $c_{d d}=$ $2.7 \cdot 10^{-6} C_{d d}=\$ 0.0015 / \mathrm{kWh}=1.5 \mathrm{mill} / \mathrm{kWh}$.

In the United States, a charge of $1 \mathrm{mill} / \mathrm{kWh}$ is added to the price of nuclear-generated electricity to cover the costs of geological disposal of spent LEU fuel. This charge of is equivalent to $C_{d s}=\$ 370 / \mathrm{kgHM}$, which can be compared to our reference value of $\$ 400 / \mathrm{kgHM}$.

\section{A.1.2. Reprocessing-recycle}

The reprocessing-recycle option has two main cost components: reprocessing the spent fuel and geological disposal of reprocessing wastes. Offsetting these costs are the values of the 
plutonium and uranium recovered during reprocessing, which can be used to produce fresh MOX and LEU fuel. The net present cost per kilogram of spent fuel, $C_{r r}(\$ / \mathrm{kgHM})$, is

$$
C_{r r}=\frac{C_{r}}{(1+i)^{t_{r}}}+\frac{C_{d h}}{(1+i)^{t_{d h}}}-\frac{M_{P u} C_{P u}}{(1+i)^{t_{P_{u}}}}-\frac{M_{r U} C_{r U}}{(1+i)^{t_{r U}}}
$$

where $C_{r}$ is the cost of reprocessing $(\$ / \mathrm{kgHM})$ paid at time $t_{r}$ after discharge (including transportation of spent fuel, short-term storage of spent fuel and plutonium, treatment and disposal of low- and intermediate-level wastes, and interim storage of HLW); $C_{d h}$ is the cost of geological disposal of HLW at time $t_{d h}(\$ / \mathrm{kgHM})$ including shipping (as above, $\left.t_{d h}=0\right) ; M_{P u}$ and $M_{r U}$ are the masses of plutonium and uranium recovered per kilogram of spent fuel reprocessed $(\mathrm{kg} / \mathrm{kgHM})$; and $C_{P u}$ and $C_{r U}$ are the expected values of recovered plutonium and uranium $(\$ / \mathrm{kg})$ at times $t_{P u}$ and $t_{r U}$ after discharge.

The mass of plutonium is adjusted for radioactive decay and losses during reprocessing:

$$
M_{P u}=\left(1-f_{r}\right) \sum_{i=238}^{242} x_{P u_{i}} e^{-\lambda_{P u_{i}} t_{r}}
$$

where $f_{r}$ is the fraction of plutonium not recovered during reprocessing (about 0.5 percent), $x_{P u i}$ is the fraction of plutonium isotope $i$ in the spent fuel at discharge, $\lambda_{P u i}$ is the decay constant of the isotope ( $\lambda=\log _{\mathrm{e}}(2) / t_{1 / 2}$, where $t_{1 / 2}$ is the half-life), $t_{r}$ is the time between discharge and reprocessing (assumed equal to the time between discharge and payment for reprocessing). The adjustment for radioactive decay is necessary only for plutonium-241, which has a half-life of 14 years. Similarly,

$$
M_{r U}=\left(1-f_{r}\right)\left(x_{U 235}+x_{U 236}+x_{U 238}\right)
$$

where $x_{U 235}$ is the concentration of uranium-235, and so forth. Because these uranium isotopes have very long half-lives, radioactive decay can be ignored. Table A.1 gives the concentrations of uranium and plutonium isotopes in spent LWR fuel for various discharge burn-ups.

In our reference case, $C_{r}=\$ 1000 / \mathrm{kgHM}, t_{r}=4 \mathrm{y}, C_{d h}=\$ 200 / \mathrm{kgHM}, B=43 \mathrm{MW} \mathrm{t} d / \mathrm{kgHM}$, $t_{P u}=t_{r U}=5 \mathrm{y}, f_{r}=0.005, M_{P u}=0.0104$, and $M_{r U}=0.94 \mathrm{~kg}$. The method for calculating the values of the recovered plutonium and uranium are discussed below; for a uranium price of $\$ 100 / \mathrm{kg}$ and reference values of other parameters, $C_{P u}=\$ 2,100 / \mathrm{kg}$ and $C_{r U}=\$ 63 / \mathrm{kg}$. Thus, $C_{r r}=$ $\$ 1000 / 1.05^{4}+\$ 200-(0.0104)(\$ 2,100) / 1.05^{5}-(0.940)(\$ 63) / 1.05^{5}=\$ 823+\$ 200-\$ 17-\$ 47=$ $\$ 959 / \mathrm{kgHM}(\$ 394 / \mathrm{kgHM}$ higher than direct disposal).

The cost of electricity, $c_{r r}\left(\$ / \mathrm{kW}_{\mathrm{e}} \mathrm{h}\right)$ attributable to reprocessing can be calculated using equation (A.3). For our reference case and a uranium price of $\$ 100 / \mathrm{kgU}, c_{r r}=\$ 0.0026 / \mathrm{kWh}=$ $2.6 \mathrm{mill} / \mathrm{kWh}$ (1.1 mill/kWh higher than direct disposal). 
Table A.1. Isotopic composition of fresh and spent LEU (kilograms per kilogram initial heavy metal), for design and discharge burn-ups of 33, 43, and $53 \mathrm{MW}_{\mathrm{t}} \mathrm{d} / \mathrm{kgHM}$.

\begin{tabular}{|c|c|c|c|c|c|c|}
\hline \multirow[b]{2}{*}{ Isotope } & \multicolumn{3}{|c|}{ Fresh LEU } & \multicolumn{3}{|c|}{ Spent LEU } \\
\hline & 33 & 43 & 53 & 33 & 43 & 53 \\
\hline U-235 & 0.03250 & 0.03700 & 0.04400 & 0.00884 & 0.00760 & 0.00768 \\
\hline U-236 & & & & 0.00391 & 0.00481 & 0.00594 \\
\hline U-238 & 0.96750 & 0.96300 & 0.95600 & 0.94372 & 0.93250 & 0.91983 \\
\hline $\mathrm{Pu}-238$ & & & & 0.00012 & 0.00021 & 0.00033 \\
\hline $\mathrm{Pu}-239$ & & & & 0.00540 & 0.00572 & 0.00607 \\
\hline $\mathrm{Pu}-240$ & & & & 0.00221 & 0.00262 & 0.00291 \\
\hline $\mathrm{Pu}-241$ & & & & 0.00132 & 0.00160 & 0.00183 \\
\hline $\mathrm{Pu}-242$ & & & & 0.00045 & 0.00068 & 0.00085 \\
\hline Am-241 & & & & 0.00003 & 0.00005 & 0.00006 \\
\hline Total & 1.00000 & 1.00000 & 1.00000 & 0.96600 & 0.95579 & 0.94550 \\
\hline
\end{tabular}

A.1.2.1. Value of recovered plutonium. The plutonium recovered from reprocessed spent fuel can be used to make MOX fuel. The value of this plutonium is derived from the ability of MOX to substitute for LEU fuel. Assuming MOX and LEU fuels with equal design burn-ups (and equal non-fuel costs), the value of recovered plutonium is given by

$$
C_{P u}=\frac{C_{l e u}-C_{m o x}}{x_{P u}}\left(1-f_{m}\right)
$$

where $C_{\text {leu }}$ is the cost of fresh LEU fuel $(\$ / \mathrm{kgHM}), C_{\text {mox }}$ is the cost of fresh MOX (excluding the cost of the plutonium), $x_{P u}$ is the fraction of plutonium in fresh MOX fuel, ${ }^{203}$ and $f_{m}$ is the fraction of plutonium lost during MOX fabrication. Table A.2 gives the composition of fresh MOX fuel for several design burn-ups, produced from depleted uranium and plutonium recovered from spent LEU with discharge burn-ups of 33 and $43 \mathrm{MW}_{\mathrm{t}} \mathrm{d} / \mathrm{kgHM}$. If $C_{\text {leu }}<C_{m o x}$, the value of the recovered plutonium is negative (i.e., producing MOX fuel would be more expensive than producing fresh LEU fuel even if plutonium was available at zero cost).

\footnotetext{
${ }^{203}$ Here $x_{P u}$ also includes americium-241, which results from the decay of plutonium-241 after reprocessing.
} 
Table A.2. Isotopic composition of fresh MOX fuel with design burn-ups of 33, 43 , and $53 \mathrm{MW}_{\mathrm{t}} \mathrm{d} / \mathrm{kgHM}$ produced with plutonium recovered from LEU with discharge burn-up of 33 and $43 \mathrm{MW}_{\mathrm{t}} \mathrm{d} / \mathrm{kgHM}$.

\begin{tabular}{lccccc}
\hline & \multicolumn{5}{c}{$33 \mathrm{MW}_{\mathrm{t}} \mathrm{d} / \mathrm{kgHM}$ LEU Pu } \\
\cline { 2 - 6 } & \multicolumn{5}{c}{ Design Burnup (MWtd/kgHM) } \\
\hline Isotope & 33 & 43 & 53 & 43 & 53 \\
\hline U-235 & 0.00213 & 0.00212 & 0.00209 & 0.00210 & 0.00207 \\
$\mathrm{U}-238$ & 0.94632 & 0.93871 & 0.92667 & 0.93053 & 0.91631 \\
$\mathrm{Pu}-238$ & 0.00070 & 0.00080 & 0.00096 & 0.00129 & 0.00156 \\
$\mathrm{Pu}-239$ & 0.03019 & 0.03465 & 0.04172 & 0.03678 & 0.04457 \\
$\mathrm{Pu}-240$ & 0.01215 & 0.01394 & 0.01679 & 0.01659 & 0.02010 \\
$\mathrm{Pu}-241$ & 0.00550 & 0.00631 & 0.00760 & 0.00768 & 0.00931 \\
$\mathrm{Pu}-242$ & 0.00248 & 0.00285 & 0.00343 & 0.00428 & 0.00519 \\
Am-241 & 0.00054 & 0.00062 & 0.00074 & 0.00075 & 0.00091 \\
\hline Total & 1.00000 & 1.00000 & 1.00000 & 1.00000 & 1.00000
\end{tabular}

Source: Nuclear Energy Agency, Plutonium Fuel: An Assessment (Paris: Organization for Economic Development and Cooperation, 1989), pp. 50-51.

The cost of fresh MOX fuel (\$/kgHM), excluding the cost of plutonium, is given by

$$
C_{m o x}=\frac{C_{m f}}{(1+i)^{t_{f}}}+\frac{\left(1-x_{P u}\right)}{\left(1-f_{m}\right)} \frac{C_{D U}}{(1+i)^{t_{D U}}}
$$

where $C_{m f}$ is the cost of MOX fuel fabrication $(\$ / \mathrm{kgHM}), C_{D U}$ is the cost of depleted uranium $(\$ / \mathrm{kgU}), f_{m}$ is the fraction of DU lost during fabrication, and $t_{f}$ and $t_{D U}$ are the times that fuel fabrication and depletion uranium are paid for after time $t_{P u}$. Here we will assume that the depleted uranium is free, except for the cost of chemical conversion to uranium oxide. For the reference case, $B=43 \mathrm{MW}_{\mathrm{t}} \mathrm{d} / \mathrm{kgHM}, x_{P u}=0.0674, C_{m f}=\$ 1500 / \mathrm{kgHM}, C_{D U}=\$ 6 / \mathrm{kgU}, f_{m}=$ $0.005, t_{f}=0.5$, and $t_{D U}=0$, for which $C_{m o x}=\$ 1464 / \mathrm{kgHM}$.

The cost of fresh LEU fuel has four components: uranium feed, chemical conversion, enrichment, and fuel fabrication. The cost of LEU fuel $(\$ / \mathrm{kgHM})$ is given by

$$
C_{\text {leu }}=\frac{1}{\left(1-f_{f}\right)}\left[\frac{R}{\left(1-f_{s}\right)}\left(\frac{C_{u}}{\left(1-f_{c}\right)(1+i)^{t_{u}}}+\frac{C_{c}}{(1+i)^{t_{c}}}\right)+\frac{S C_{s}}{(1+i)^{t_{s}}}\right]+\frac{C_{l f}}{(1+i)^{t_{f}}}
$$


where $C_{u}, C_{c}, C_{s}$, and $C_{f}$ are the costs of uranium feed $(\$ / \mathrm{kgU})$, chemical conversion $(\$ / \mathrm{kgU})$, separative work ( $\$ / \mathrm{SWU})$, and fuel fabrication $(\$ / \mathrm{kgHM}), t_{u}, t_{c}, t_{s}$, and $t_{f}$ are the times when these costs are paid relative to $t_{P u}(\mathrm{y})$, and $f_{c}, f_{s}$, and $f_{f}$ are the fractional losses during conversion, enrichment, and fuel fabrication. The ratio of uranium feed to enriched product, $R$, is given by

$$
R=\frac{x_{p}-x_{t}}{x_{f}-x_{t}}
$$

where $x_{p}, x_{f}$, and $x_{t}$ are the concentrations of uranium-235 in the product (i.e., fresh LEU fuel), feed, and tails, respectively. Values of $x_{p}$ for burn-ups of 33, 43, and $53 \mathrm{MW}_{\mathrm{t}} \mathrm{d} / \mathrm{kgHM}$ are given in table A.1. For natural uranium feed, $x_{f}=0.00711$. The separative work required to produce a kilogram of product, $S(\mathrm{SWU} / \mathrm{kg})$, is given by

$$
S=V\left(x_{p}\right)-V\left(x_{t}\right)-R\left[V\left(x_{f}\right)-V\left(x_{t}\right)\right]
$$

where $V(x)=(2 x-1) \log _{e}\left(\frac{x}{1-x}\right)$

For a given set of uranium, conversion, and enrichment costs, there is an optimum value of $x_{t}$ that minimizes the cost of the product. The optimum tails assay can be found by setting the derivative of equation (A.10) with respect to $x_{t}$ equal to zero $\left(\partial C_{l e u} / \partial x_{t}=0\right)$, which yields the following relationship:

$$
\frac{1}{x_{f}-x_{t}}=\chi\left[\frac{V\left(x_{f}\right)-V\left(x_{t}\right)}{x_{f}-x_{t}}+\frac{1-2 x_{t}}{x_{t}\left(1-x_{t}\right)}+\frac{2 V\left(x_{t}\right)}{1-2 x_{t}}\right]
$$

where, $\chi$, the enrichment-to-feed cost ratio, is given by

$$
\chi=\frac{\left(1-f_{s}\right) C_{s}}{\frac{C_{u}}{\left(1-f_{c}\right)(1+i)^{t_{u}-t_{s}}}+\frac{C_{c}}{(1+i)^{t_{c}-t_{s}}}} \cong \frac{\left(1-f_{s}\right) C_{s}}{\frac{C_{u}}{\left(1-f_{c}\right)}+C_{c}}
$$

Table A.3 gives the optimum tails assay for several values of the cost ratio. Equation (A.14) does not have an analytical solution, but the following approximation for natural uranium feed is accurate to within about 0.5 percent for $0.05<\chi<5$ :

$$
x_{t} \cong 10^{-0.1631\left(\log _{10} \chi\right)^{2}+0.47055 \log _{10} \chi-2.6453}
$$

For example, if $C_{u}=\$ 100 / \mathrm{kgU}, C_{c}=\$ 6 / \mathrm{kgU}, C_{s}=\$ 100 / \mathrm{SWU}$, and $f_{s}=f_{c}=0.005$, then $\chi=$ 0.93 and $x_{t}=0.0022$. If $B=43 \mathrm{MW}_{\mathrm{t}} \mathrm{d} / \mathrm{kgHM}$, then $x_{p}=0.037, R=7.08$, and $S=5.60$ $\mathrm{SWU} / \mathrm{kgHM}$. If $C_{l f}=\$ 250 / \mathrm{kgHM}, t_{u}=-1 \mathrm{y}, t_{c}=-0.5 \mathrm{y}, t_{s}=0 \mathrm{y}$, and $t_{f}=0.5 \mathrm{y}$, then $C_{l e u}=$ $\$ 1610 / \mathrm{kgHM}$. From above, $C_{m o x}=\$ 1464 / \mathrm{kgHM}$ for MOX fuel of equal design burnup; thus, in this case the value of the plutonium $C_{P u}=(0.995)(1610-1464) / 0.0674=\$ 2100 / \mathrm{kgPu}$. 
Table A.3. Optimum tails assay as a function of the separation-to-feed cost ratio (natural uranium feed).

\begin{tabular}{ccc}
\hline Cost Ratio & Uranium Price $^{*}$ & Tails Assay \\
$\chi$ & $C_{u}(\$ / \mathrm{kg})$ & $x_{t}$ \\
0.01 & 9,900 & 0.000067 \\
0.02 & 4,900 & 0.00013 \\
0.05 & 2,000 & 0.00029 \\
0.1 & 980 & 0.00052 \\
0.2 & 490 & 0.00088 \\
0.5 & 190 & 0.0016 \\
1 & 93 & 0.0023 \\
2 & 44 & 0.0030 \\
5 & 14 & 0.0040 \\
10 & 4 & 0.0047
\end{tabular}

*Assuming $C_{s}=\$ 100 / \mathrm{SWU}, C_{c}=\$ 6 / \mathrm{kgU}$, and $f_{s}=f_{c}=0.005$.

A.1.2.2. Value of recovered uranium. The uranium recovered from reprocessed spent fuel can be re-enriched and used to make LEU fuel. This would be economic only if the resulting fuel was no more expensive than fuel of the same design burn-up made using natural uranium. Unlike plutonium, the value of recovered uranium cannot be less than zero. This is because plutonium, which is hazardous and can be used to make nuclear weapons, incurs substantial storage charges if unused. Moreover, if separated plutonium remains in storage for a long time, it must be purified of radioactive decay products — at very high cost — before it can be used in the fabrication of reactor fuel. Recovered uranium does not have any of these liabilities. Thus, if the recycle of recovered uranium is uneconomical, the uranium can be stored at essentially zero cost for later use. The value of the recovered uranium, $C_{r U}$, can be estimated by setting the cost of LEU made from natural uranium equal to the cost of LEU made from recovered uranium:

$$
\begin{gathered}
\frac{1}{\left(1-f_{f}\right)}\left[\frac{R}{\left(1-f_{s}\right)}\left(\frac{C_{u}}{\left(1-f_{c}\right)(1+i)^{t_{u}}}+\frac{C_{c}}{(1+i)^{t_{c}}}\right)+\frac{S C_{s}}{(1+i)^{t_{s}}}\right]+\frac{C_{l f}}{(1+i)^{t_{f}}}= \\
\frac{1}{\left(1-f_{f}\right)}\left[\frac{R_{r}}{\left(1-f_{s}\right)}\left(\frac{C_{r U}}{\left(1-f_{c}\right)(1+i)^{t_{u}}}+\frac{C_{r c}}{(1+i)^{t_{c}}}\right)+\frac{S C_{r s}}{(1+i)^{t_{s}}}\right]+\frac{C_{r l f}}{(1+i)^{t_{f}}}
\end{gathered}
$$


where $R_{r}=\frac{x_{r p}-x_{r t}}{x_{r f}-x_{r t}}$

and $x_{r f}, x_{r p}$, and $x_{r t}$ are the concentrations of uranium-235 in the recovered uranium, the LEU produced from the recovered uranium, and the tails when enriching the recovered uranium, and $C_{r c}, C_{r s}$, and $C_{r l f}$ are the costs of conversion, enrichment, and fuel-fabrication of recovered uranium. Because recovered uranium is more radioactive than natural uranium, $C_{r c}, C_{r s}$, and $C_{r l f}$ are somewhat higher than $C_{c}, C_{s}$, and $C_{l f}$. Moreover, because the uranium-236 in recovered uranium absorbs neutrons, fuel made with recovered uranium must have a higher enrichment than fuel of the same design burn-up made from natural uranium. The required product enrichment, $x_{r p}$, is given approximately by ${ }^{204}$

$$
x_{r p}=\frac{x_{p}}{1-0.21 \frac{x_{236}}{x_{r f}}}
$$

where $x_{236}$ is the concentration of uranium-236 in the recovered uranium. (If laser-isotope separation is used this correction can be ignored and $x_{r p}=x_{p}$.) Values of $x_{r f}$ and $x_{236}$ are given in Table A.1. As before, $x_{r t}$ is optimized for the costs of conversion and enrichment and the value of the recovered uranium. The following approximation for $x_{r t}$ is good to within one percent for $0.007<x_{r f}<0.009$ and $0.05<\chi_{r}<5$ :

$$
x_{r t} \cong 10^{-\left(0.1626+0.06303 x_{r f}\right)\left(\log _{10} x_{r}\right)^{2}+\left(0.4705+0.00172 x_{r f}\right) \log _{10} x_{r}-3.032+54.529 x_{r f}}
$$

where $\chi_{r}=\frac{\left(1-f_{s}\right) C_{r s}}{\frac{C_{r u}}{\left(1-f_{c}\right)}+C_{r c}}$.

Because the value of recovered uranium depends on the tails assay, which in turn depends on the value of the recovered uranium, equation (A.17) must be solved numerically.

In our reference case, $C_{c}=\$ 6 / \mathrm{kgU}, C_{r c}=\$ 21 / \mathrm{kgU}, C_{s}=\$ 100 / \mathrm{SWU}, C_{r s}=\$ 105 / \mathrm{SWU}, C_{l f}=$ $\$ 250 / \mathrm{kgHM}, C_{r l f}=\$ 260 / \mathrm{kgHM}, B=43 \mathrm{MW} \mathrm{t} / \mathrm{kgHM}, x_{236}=0.00481$, and $x_{r p}=0.0427$; if $C_{u}=$ $\$ 100 / \mathrm{kgU}$, we find that $C_{r U}=\$ 63 / \mathrm{kg}$. ${ }^{205}$

\section{A.1.3. Breakeven Uranium Price}

In the reference case described above, for a uranium price of $\$ 100 / \mathrm{kgU}$ the reprocessingrecycle option costs $\$ 959 / \mathrm{kgHM}$ compared to only $\$ 565 / \mathrm{kgHM}$ for the direct-disposal option. The breakeven uranium price is therefore substantially greater than $\$ 100 / \mathrm{kgU}$. Using reference values of the various parameters we can solve equation (A.1) to find that the breakeven uranium

\footnotetext{
${ }^{204}$ Nuclear Energy Agency, Plutonium Fuel: An Assessment (Paris: Organization for Economic Development and Cooperation, 1989), p. 158. The original expressions in the OECD report can be rearranged to give equation (A.19). ${ }^{205}$ For this value of $C_{r U}, \chi_{r}=1.24, x_{t}=0.0027, R=8.10, S=5.84 \mathrm{SWU} / \mathrm{kgHM}$.
} 
price is $\$ 368 / \mathrm{kgU}$. When the price of uranium is equal to $\$ 368 / \mathrm{kgU}$, the cost of fresh LEU fuel in the reference case would rise to $\$ 3,417 / \mathrm{kgHM}$, the value of plutonium recovered from spent LEU fuel increases to $\$ 28,800 / \mathrm{kgPu}$ and the value of the recovered uranium rises to $\$ 303 / \mathrm{kgU}$. Thus, the net cost of the reprocessing-recycle option falls to $C_{r r}=\$ 1000 / 1.05^{4}+\$ 200-$ $(0.0104)(\$ 28,800) / 1.05^{5}-(0.940)(\$ 303) / 1.05^{5}=\$ 565 / \mathrm{kgHM}$, which is identical to the cost of the direct-disposal option.

\section{A.2. Direct Disposal vs. Recycling in Fast-Neutron Reactors}

Here we take the point of view of a firm that is deciding whether to build a new light-water reactor (with direct disposal of spent fuel) or a liquid-metal reactor (with breeding and recycle of plutonium). In a competitive market, the firm should build the reactor that would produce electricity at the lowest cost. The cost of electricity, $c_{\text {elec }}$, can be divided into three major components:

$$
c_{\text {elec }}=c_{\text {cap }}+c_{\text {om }}+c_{\text {fuel }}
$$

where $c_{\text {cap }}$, often referred to as the "capital cost," is the cost due to financing and repayment of construction costs (and other costs that are proportional to construction cost), $c_{o m}$ is the operations and maintenance cost, and $c_{f u e l}$ is the fuel cost.

\section{A.2.1. Capital Cost}

For both types of reactors, the cost of electricity attributable to the financing and repayment of construction costs (and other annual costs that are proportional to construction cost), $c_{c a p}$ $\left(\$ / \mathrm{kW}_{\mathrm{e}} \mathrm{h}\right)$, is given by

$$
c_{c a p}=\frac{C_{c a p}\left(1+F_{i d c}\right)\left(1+F_{\text {preop }}\right)\left(1+F_{c o n t}\right)}{8766 \eta}\left(F_{c r}+F_{\text {tax }}+F_{\text {ins }}\right)
$$

where $C_{c a p}$ is the total construction cost, in dollars per kilowatt of installed net electrical capacity $\left(\$ / \mathrm{kW}_{\mathrm{e}}\right), F_{\text {idc }}$ and $F_{\text {preop }}$ are factors that account for interest during construction and other costs before the plant begins full-scale operation, $F_{\text {cont }}$ is a contingency factor to provide for cost overruns and other unforeseen costs, $\eta$ is the capacity factor (the total amount of electricity produced in a year divided by the total amount that would be produced from continuous operation at full power), 8766 is the average number of hours in a year, and $F_{\text {tax }}$, and $F_{\text {ins }}$ are annual charges for property taxes and insurance $\left(\mathrm{y}^{-1}\right)$, which for simplicity are assumed to be proportional to the initial investment. The "fixed charge rate," $F_{c r}\left(\mathrm{y}^{-1}\right)$, is the fraction of the initial investment that must be collected each year to repay the initial costs, including interest or return on investment. We discuss $F_{i d c}$ and $F_{c r}$ in more detail below.

For example, if $C_{c a p}=\$ 2000 / \mathrm{kW}_{\mathrm{e}}$, and using reference values for other parameters suitable for a utility-owned reactor $\left(F_{i d c}=0.189, F_{\text {preop }}=F_{\text {cont }}=0.1,\left(F_{c r}+F_{\text {tax }}+F_{\text {ins }}\right)=0.123\right.$, and $\eta=$ $0.85), c_{c a p}=\$ 0.0475 / \mathrm{kWh}$. 
A.2.1.1. Interest during construction. The interest-during-construction factor, $F_{i d c}$, accounts for the fact that interest charges accumulate on money borrowed before reactor operation begins. If we assume that funds are borrowed at one-year intervals:

$$
F_{i d c}=\left[\sum_{k=1}^{n} f_{k}\left(1+i_{i d c}\right)^{n-k+1}\right]-1
$$

where $n$ is the construction time $(\mathrm{y}), f_{k}$ is the fraction of the total up-front costs borrowed at the beginning of year $k$, and $i_{i d c}$ is the interest rate. We model $f_{k}$ with a beta-binomial distribution:

$$
f_{k}=\frac{\Gamma(n) \Gamma(\alpha+k-1) \Gamma(n+\beta-k) \Gamma(\alpha+\beta)}{\Gamma(k) \Gamma(n-k+1) \Gamma(\alpha+\beta+n-1) \Gamma(\alpha) \Gamma(\beta)}
$$

where $\alpha$ and $\beta$ are parameters that determine the shape of the distribution. ${ }^{206}$ The following shape parameters give a good fit to the distribution of costs assumed in previous reports: ${ }^{207}$

$$
\begin{aligned}
& \alpha=1+e^{-0.432(n-11.5)} \\
& \beta=\frac{\alpha(1-p)}{p}
\end{aligned}
$$

where $p$ is the fraction of $n$ at which half of the total capital costs have been spent. We assume that $i_{i d c}$ is equal to the weighted cost of capital (see Table A.4). For the reference case $n=6 \mathrm{y}, i_{i d c}$ $=0.064 \mathrm{y}^{-1}$, and $p=0.65$, which gives $F_{i d c}=0.189$.

A.2.1.2. Fixed charge rate. The fixed charge rate, $F_{c r}\left(\mathrm{y}^{-1}\right)$, is the fraction of the initial investment that is collected each year to repay the principle (construction and other up-front costs) with a return on the investment. If the principle is repaid with interest at a fixed rate $i\left(\mathrm{y}^{-1}\right)$ during the lifetime of the facility $N(\mathrm{y})$, then $F_{c r}$ is simply

$$
F_{c r}=\frac{i}{1-(1+i)^{-N}}
$$

For example, assuming $N=30 \mathrm{y}$ and $i=0.04 \mathrm{y}^{-1}$ (appropriate for a government-owned and financed project), $F_{c r}=0.058 \mathrm{y}^{-1}$.

\footnotetext{
${ }^{206}$ The beta-binomial distribution was chosen for its extreme flexibility with a small number of parameters. If $\alpha=\beta$ $=1$, the distribution is uniform (i.e., $f_{k}=k / n$ ); if $\alpha$ and $\beta>1$, the distribution is convex (i.e., peaking in the middle); if $\alpha=\beta$, the distribution is symmetrical; if $\alpha>\beta$, the distribution is skewed to the left. The beta-binomial distribution approaches a binomial distribution with $\pi=\alpha /(\alpha+\beta)$ when $\alpha$ and $\beta>>1$.

${ }^{207}$ National Academy of Sciences, Committee on Separations Technology and Transmutation Systems, Nuclear Wastes: Technologies for Separations and Transmutations (Washington, DC: National Academy Press, 1996), p. 424; National Academy of Sciences, Committee on International Security and Arms Control, Management and Disposition of Excess Weapons Plutonium: Reactor-Related Options (Washington, DC: National Academy Press, 1995), p. 83.
} 
The situation for a privately owned and financed facility is different in two ways. First, principle is often raised with a combination of bonds (i.e., loans by investors) and equity (i.e., sale of stock giving part ownership of the facility by investors), with various rates of return. Second, private firms pay tax on net income, which excludes bond dividends and other business expenses.

To derive the fixed charge rate in the more general case, suppose that a firm raises principle $P$ to build a reactor, of which $b P$ is financed with a bond with a rate of return of $i_{b}$, and the remainder, $(1-b) P$, is financed with equity with a rate of return of $i_{e}$. For simplicity, assume that the term of the bond is equal to the lifetime of the reactor, $N$, and that the salvage value (i.e., the value of the reactor after year $N$ ) is zero. During the operation of the reactor, the annual net cash flow, $N C F$, is given by

$$
N C F=I_{G}-E-S-B-T
$$

where $I_{G}$ is the annual gross income of the plant, $E$ is the annual plant operating expenses, $S$ and $B$ are annual payments relating to equity and bond financing, and $T$ are taxes, given by

$$
T=I_{T} t_{e}=\left(I_{G}-E-D-B_{d}\right) t_{e}
$$

where $t_{e}$ is the income tax rate and $I_{T}$, the taxable income, is the gross income minus taxdeductible expenses and payments, which include depreciation, $D$, and dividends paid on the bond, $B_{d}$. The annual payment for equity financing, $S$, is given by

$$
S=\frac{(1-b) P i_{e}}{1-\left(1+i_{e}\right)^{-N}}
$$

The annual payment for bond financing consists of dividends $B_{d}$ (paid at rate $i_{b}$ on the entire principle for the term of the bond) and principle $B_{p}$; assuming equal annual payments invested at rate $i_{b}$ to repay the principle at the end of the term, we have

$$
\begin{aligned}
& B_{d}=b P i_{b} \\
& B=B_{d}+B_{p}=b P r_{b}+\frac{b P i_{b}}{\left(1+i_{b}\right)^{N}-1}=\frac{b P i_{b}}{1-\left(1+i_{b}\right)^{-N}}
\end{aligned}
$$

Assuming straight-line depreciation over the life of the plant, the annual depreciation expense is given by

$$
D=\frac{P}{N}
$$

Inserting equations (A.30) through (A.34) into equation (A.29), we have 


$$
N C F=I_{G}-E-\frac{(1-b) P i_{e}}{1-\left(1+i_{e}\right)^{-N}}-\frac{b P i_{b}}{1-\left(1+i_{b}\right)^{-N}}-\left(I_{G}-E-\frac{P}{N}-b P i_{b}\right) t_{e}
$$

which can be rearranged to give

$$
N C F=\left(I_{G}-E\right)\left(1-t_{e}\right)-P\left(\frac{(1-b) i_{e}}{1-\left(1+i_{e}\right)^{-N}}+\frac{b i_{b}}{1-\left(1+i_{b}\right)^{-n}}-\frac{t_{e}}{N}-b i_{b} t_{e}\right)
$$

In order to stay in business, $N C F \geq 0$, and so

$$
I_{G}-E \geq \frac{P}{1-t_{e}}\left(\frac{(1-b) i_{e}}{1-\left(1+i_{e}\right)^{-N}}+\frac{b i_{b}}{1-\left(1+i_{b}\right)^{-N}}-\frac{t_{e}}{N}-b i_{b} t_{e}\right)
$$

which can be written as

$$
I_{G} \geq F_{c r} P+E
$$

where $F_{c r}$, the fixed charge rate, is given by

$$
F_{c r}=\frac{1}{1-t_{e}}\left(\frac{(1-b) i_{e}}{1-\left(1+i_{e}\right)^{-N}}+\frac{b i_{b}}{1-\left(1+i_{b}\right)^{-N}}-\frac{t_{e}}{N}-b i_{b} t_{e}\right)
$$

Note that if the tax rate is zero $\left(t_{e}=0\right)$, this simplifies to

$$
F_{c r}=\frac{(1-b) i_{e}}{1-\left(1+i_{e}\right)^{-N}}+\frac{b i_{b}}{1-\left(1+i_{b}\right)^{-N}}
$$

which is simply equation (A.28) with the principle divided between bond and equity financing. Equation (A.39) easily can be generalized to different types of stocks and bonds having various rates of return.

As discussed in Chapter 1, we have relied on peer-reviewed estimates of the fixed charge rate for different financing arrangements developed by a panel of the National Academy of Sciences, which are summarized in table A.4. The fixed charge rates differ somewhat from those generated by equation (A.39), as they assume that the facilities are depreciated for tax purposes over half their useful life, rather than over the entire life, as is assume in (A.39). 
Table A.4. Fixed charge rates for reactors owned and financed by government, utility, and private ventures.

\begin{tabular}{|c|c|c|c|c|c|c|}
\hline \multirow[b]{3}{*}{ Financial structure } & \multicolumn{6}{|r|}{ Owner } \\
\hline & \multicolumn{2}{|c|}{ Government } & \multicolumn{3}{|c|}{ Utility } & \multirow{2}{*}{$\begin{array}{l}\text { Private } \\
i(\% / \mathrm{y} \\
\end{array}$} \\
\hline & $(\%)$ & $\underline{i(\% / \mathrm{y})}$ & $(\%)$ & $\underline{i(\% / \mathrm{y})}$ & $(\%)$ & \\
\hline Common stock & & & 46 & 8.5 & 70 & 16.0 \\
\hline Preferred stock & & & 8 & 4.1 & & \\
\hline Debt & 100 & 4.0 & 46 & 4.8 & 30 & 9.0 \\
\hline Weighted cost of capital & & 4.0 & & 6.4 & & 13.9 \\
\hline \multicolumn{7}{|l|}{ Tax assumptions } \\
\hline Income tax rate $(\%)$ & & & \multicolumn{2}{|c|}{38} & \multicolumn{2}{|c|}{38} \\
\hline Tax recovery period $(y)$ & & & \multicolumn{2}{|c|}{15} & \multicolumn{2}{|c|}{15} \\
\hline Book life (y) & & & \multicolumn{2}{|c|}{30} & \multicolumn{2}{|c|}{30} \\
\hline Property taxes, insurance $(\% / y)$ & & & \multicolumn{2}{|c|}{2} & \multicolumn{2}{|c|}{2} \\
\hline$F_{c r}+F_{t a x}+F_{i n s}(\% / \mathrm{y})$ & & 5.8 & \multicolumn{2}{|c|}{12.3} & \multicolumn{2}{|c|}{20.8} \\
\hline \multicolumn{7}{|c|}{$\begin{array}{l}\text { Source: National Academy of Sciences, Committee on Separations Technology and Transmutation } \\
\text { Systems, Nuclear Wastes: Technologies for Separations and Transmutations (Washington, DC: National } \\
\text { Academy Press, 1996), p. } 432 .\end{array}$} \\
\hline
\end{tabular}

\section{A.2.2. Operations and Maintenance Cost}

Operations and maintenance costs are continuing costs of running a plant that do not relate to its fuel-such as worker salaries and routine plant maintenance. Most of these costs do not depend on the amount of electricity produced by the plant, and so most calculations, including this one, assume a fixed annual expense. Provisions placed into a fund for eventual decommissioning of the plant are also included in most estimates of operations and maintenance costs. The contribution of these expenses to the cost of electricity is given by

$$
c_{o m}=\frac{C_{o m}+C_{d d} F_{d d}}{8766 \eta}
$$

where $C_{o m}$ is the annual non-fuel operations and maintenance cost $\left(\$ / \mathrm{kW}_{\mathrm{e}} \mathrm{y}\right), C_{d d}$ is the cost to dismantle and decommission the plant at the end of its operating life $\left(\$ / \mathrm{kW}_{\mathrm{e}}\right)$, and $F_{d d}\left(\mathrm{y}^{-1}\right)$ is the annual annuity factor, given by 


$$
F_{d d}=\frac{i_{d d}}{\left(1+i_{d d}\right)^{N}-1}
$$

where $i_{d d}$ is the annual rate of return on the funds invested and $N$ is the length of time the annuity is paid (usually the same as the period over which the construction costs are repaid). For example, if the rate of return is 3 percent per year and the annuity is paid over 30 years, $F_{d d}=$ 0.021 ; if $C_{o m}=\$ 80 / \mathrm{kW}_{\mathrm{e}}, C_{d d}=\$ 150 / \mathrm{kW}_{\mathrm{e}}$, and $\eta=0.85$, then $\mathrm{c}_{\mathrm{om}}=\$ 0.0112 / \mathrm{kW}_{\mathrm{e}} \mathrm{h}$.

\section{A.2.3. Fuel Cost}

A.2.3.1. LWR fuel. The fuel cost for an LWR with direct disposal of the spent fuel is

$$
c_{\text {fuel }}^{L W R}=\frac{\left[C_{\text {leu }}(1+i)^{t_{\text {leu }}}+C_{i s}(1+i)^{-t_{\text {is }}}+C_{d s}(1+i)^{-t_{d s}}\right] F_{c}}{24,000 B \varepsilon}
$$

where $C_{l e u}$ is the cost of LEU fuel (\$/kgHM) as given by equation (A.10), paid at time $t_{\text {leu }}$, and $B$, $\varepsilon, C_{i s}, C_{d s}, t_{i s}, t_{d s}$, and $i$ are as defined above in equations (A.2) and (A.3). All times are measured from the time the fuel is inserted into the reactor. The carrying-charge factor, $F_{c}$, is given by

$$
F_{c}=\frac{\tau i(1+i)^{\tau}}{(1+i)^{\tau}-1}
$$

where $\tau$ is the number of years that the fuel remains in the reactor. ${ }^{208}$

For our reference case, $B=43 \mathrm{MW}_{\mathrm{t}} \mathrm{d} / \mathrm{kgHM}, \tau=4 \mathrm{y}$, and $i=0.05 \mathrm{y}^{-1}$, so that $F_{c}=1.128$. If $C_{u}=\$ 100 / \mathrm{kgU}, C_{c}=\$ 6 / \mathrm{kgU}, C_{s}=\$ 100 / \mathrm{SWU}$, and $C_{l f}=\$ 250 / \mathrm{kgU}$, then $C_{\text {leu }}=\$ 1,690 / \mathrm{kg} .{ }^{209}$ If $\varepsilon$ $=0.33, C_{i s}=\$ 200 / \mathrm{kgHM}$ paid at $t_{i s}=8 \mathrm{y}$, and $C_{d s}=\$ 400$ paid at $t_{d s}=4 \mathrm{y}$, then

$$
c_{\text {fuel }}^{L W R}=\frac{\left[\frac{\$ 1692}{\mathrm{kgHM}}+\frac{\$ 200 / \mathrm{kgHM}}{(1.05)^{8}}+\frac{\$ 400 / \mathrm{kgHM}}{(1.05)^{4}}\right](1.128)}{\left(24,000 \frac{\mathrm{kWh}}{\mathrm{MWd}}\right)\left(43 \frac{\mathrm{MW}_{\mathrm{t}} \mathrm{d}}{\mathrm{kgHM}}\right)\left(0.33 \frac{\mathrm{MW}_{\mathrm{e}}}{\mathrm{MW}_{\mathrm{t}}}\right)}=\frac{\$ 0.0071}{\mathrm{~kW}_{\mathrm{e}} \mathrm{h}}
$$

\footnotetext{
${ }^{208}$ This differs from the carrying charge given by equation (A.4) by a factor $(1+i) \tau$, because this was applied to the value of the fuel at discharge.

${ }^{209}$ The cost ratio $\chi=0.93$, for which the optimum $x_{t}=0.0022$. If $x_{p}=0.037(B=43 \mathrm{MWtd} / \mathrm{kgHM})$, then $\mathrm{R}=7.08$ and $\mathrm{S}=5.60 \mathrm{SWU} / \mathrm{kg}$. Assuming $f_{c}=f_{s}=0.005, f_{f}=0.01$, and $t_{u}=2 \mathrm{y}, t_{c}=1.5 \mathrm{y}, t_{s}=1 \mathrm{y}, t_{f}=0.5 \mathrm{y}$, we have$$
C_{\text {leu }}=\frac{1}{0.99}\left[\frac{7.08}{0.995}\left(\frac{100(1.05)^{2}}{0.995}+6(1.05)^{1.5}\right)+5.60(100)(1.05)\right]+250(1.05)^{0.5}=\frac{\$ 1,692}{\mathrm{~kg}}
$$ 
A.2.3.2. LMR fuel. Liquid-metal breeder reactors have two types of fuel elements: core and blanket elements. Fresh core elements, which contain about $25 \%$ plutonium, produce most of the fission energy and neutrons; fresh blanket elements, which contain only uranium, absorb neutrons and produce plutonium. Both types of elements are reprocessed, and the recovered uranium and plutonium are used to produce fresh core and blanket elements. In equilibrium, only a small amount of fresh uranium (or natural or depleted uranium) is needed to make up for the uranium and plutonium that is consumed in the fission reactions.

The contribution of fuel costs to the cost of electricity from a breeder reactor is

$$
c_{\text {fuel }}^{L M R}=\frac{\left[\frac{C_{f c}}{(1+i)^{-t_{f c}}}+\frac{C_{r c}}{(1+i)^{t_{c c}}}+\frac{C_{d c}}{(1+i)^{t_{d c}}}\right] M_{c} F_{c c}+\left[\frac{C_{f b}+f_{u} C_{u}}{(1+i)^{-t_{f b}}}+\frac{C_{r c}}{(1+i)^{t_{r b}}}+\frac{C_{d b}}{(1+i)^{t_{d b}}}\right] M_{b} F_{c b}}{(8766)(1000)}
$$

where $C_{f c}$ and $C_{f b}$ are the costs of fabricating core and blanket fuel ( $\left.\$ / \mathrm{kgHM}\right), C_{r c}$ are $C_{r b}$ are the costs of reprocessing fuel $(\$ / \mathrm{kgHM}), C_{d c}$ and $C_{d b}$ are the costs of disposing of the resulting highlevel reprocessing wastes $(\$ / \mathrm{kgHM}), C_{u}$ is the cost of make-up uranium $(\$ / \mathrm{kgU})$ and $f_{u}$ is the fraction of natural uranium in blanket elements, $M_{c}$ and $M_{b}$ are the annual loading of core and blanket fuel elements $(\mathrm{kgHM} / \mathrm{MW} \mathrm{ey}), F_{c c}$ and $F_{c b}$ are carrying charges for core and blanket elements assuming residence times of $\tau_{c}$ and $\tau_{b}(\mathrm{y})$ in the reactor, and 1000 is the number of kilowatts per megawatt. As before, we assume that transportation, storage, and safeguardsrelated costs are included in fabrication, reprocessing and disposal costs.

Equation (A.46) is a good approximation in the steady-state situation for a large breeder reactor economy, in which there is no net breeding of plutonium and the plutonium recovered at the end of one reactor's life is used to start up a replacement reactor. If the number of breeder reactors is growing, the cost of the plutonium for the initial fuel loading would have to be included as well as the sale of excess plutonium produced by net breeding during the operation of the reactor (e.g., to start up additional reactors). Rough estimates indicate, however, that these factors offset each other for reasonable breeding ratios and discount factors. ${ }^{210}$

In the reference case, $C_{f c}=\$ 1500 / \mathrm{kgHM}, C_{f b}=\$ 250 / \mathrm{kgHM}, C_{r c}=C_{r b}=\$ 1000 / \mathrm{kgHM}, C_{u}=$ $\$ 6 / \mathrm{kgU}, C_{d c}=C_{d b}=\$ 200 / \mathrm{kgHM}, f_{u}=0.024, M_{c}=11.5 \mathrm{kgHM} / \mathrm{MW}_{\mathrm{e}} \mathrm{y}, M_{b}=25.5 \mathrm{kgHM} / \mathrm{MW}_{\mathrm{e}}$, $\tau_{c}=\tau_{b}=t_{d c}=t_{d b}=3 \mathrm{y}, i=0.05 \mathrm{y}^{-1}, t_{f c}=t_{f b}=0.5 \mathrm{y}$, and $t_{r c}=t_{r b}=4 \mathrm{y}$; this gives

$$
\begin{aligned}
c_{\text {fuel }}^{\text {LMR }} & =\frac{\left\{\left[\frac{1500}{1.05^{-0.5}}+\frac{1000}{1.05^{4}}+\frac{200}{1.05^{3}}\right] 11.5+\left[\frac{250+0.024(6)}{1.05^{-0.5}}+\frac{1000}{1.05^{4}}+\frac{200}{1.05^{3}}\right] 25.5\right\} 1.10}{(8766)(1000)} \\
& =\frac{\$ 0.0077}{\mathrm{kWh}}
\end{aligned}
$$

\footnotetext{
${ }^{210}$ Consider, for example, a reactor with an initial core containing $3000 \mathrm{kgPu}$, an annual core loading of 1000 $\mathrm{kgPu} / \mathrm{y}$, and an annual discharge (core + blanket) of $1100 \mathrm{kgPu} / \mathrm{y}$ (breeding ratio $\approx 1.25$ ). Discounting the flows of plutonium over the 30-y life of the reactor at a discount rate of 3\%/y gives a net present value of zero, assuming the initial plutonium is produced $1 \mathrm{y}$ before start-up and excess plutonium is available for sale $2 \mathrm{y}$ after discharge.
} 


\section{A.2.4. Breakeven Uranium Price}

The breakeven uranium price, $C_{u}$, is the uranium price for which the costs of electricity are equal for LWRs and LMRs:

$$
c_{\text {elec }}^{L W R}=c_{\text {elec }}^{L M R}
$$

To simplify the calculation, we assume that non-fuel operations and maintenance costs, $C_{\text {om }}$, are equal for both reactors and that all factors related to the cost of principal, interest, taxes, and insurance are equal, except for the total construction cost. In this case, equation (A.48) can be written as

$$
\frac{\Delta C_{c a p} F}{8766 \eta}=c_{f u e l}^{L W R}\left(C_{u}\right)-c_{f u e l}^{L M R}
$$

where $\mathrm{F}=\left(1+F_{\text {idc }}\right)\left(1+F_{\text {preop }}\right)\left(1+F_{\text {cont }}\right)\left(F_{c r}+F_{\text {tax }}+F_{\text {ins }}+F_{\text {refurb }}\right), \Delta C_{\text {cap }}$ is the difference in overnight construction costs between the LMR and LWR $\left(\$ / \mathrm{kW}_{\mathrm{e}}\right)$, and $c_{\text {fuel }}^{L W R}\left(C_{u}\right)$ is the cost of fresh LEU fuel as a function of the price of uranium.

In the reference case described above, with $C_{u}=\$ 100 / \mathrm{kgU}$, the right-hand side of equation (A.49) (i.e., the difference in fuel cost) $=0.00714-0.00766=-\$ 0.00052 / \mathrm{kWh}$. If both types of reactor produce electricity at the same cost, then $\Delta C_{c a p}=-\$ 22 / \mathrm{kWe}$; that is, the LMR must be $\$ 22 / \mathrm{kW}_{\mathrm{e}}$ less expensive than the LWR. To find the breakeven uranium price for a given difference in capital cost, we solve equation (A.49) numerically. For example, in our reference case, where $\Delta C_{c a p}=\$ 200 / \mathrm{kW}_{\mathrm{e}}$, the breakeven uranium price is $\$ 322 / \mathrm{kgU}$. 


\section{Appendix B. World Uranium Resources}

\section{B.1. Introduction}

"There will always be ample fuel for nuclear reactors-we will never run out. The only questions are from where, and at what cost."

\section{— James Graham, Chairman, Board of Governors, World Nuclear Fuel Market ${ }^{211}$}

For decades, consideration of reprocessing, recycling, and breeding plutonium has been driven in significant part by concerns that resources of uranium would not be sufficient to support a growing nuclear energy system operating on a once-through cycle for long. ${ }^{212}$ Advocates of reprocessing and breeding continue to argue that available resources of low-cost uranium are quite limited, making breeding and reprocessing essential in the relatively near term. ${ }^{213}$ This raises the obvious question: how much uranium is likely to be economically recoverable in the future?

Uranium is roughly as common as tin or arsenic; Table B.1 shows typical concentrations in various media. ${ }^{214}$ The total amount of uranium in the earth's crust is huge - on the order of $10^{8}$ Mt. How much of this vast resource of uranium will be recoverable for use in nuclear energy depends on both technology and price. Advancing technology increases the recoverable resource in two ways: by offering additional ways to find resources, and by making it possible to mine and process uranium at lower cost, making available resources that would previously not have been economic to recover. Increasing prices also increase the available resource in two ways: by making lower-grade resources economic to recover, and by motivating additional exploration. (Increasing prices also tend to depress growth in demand, by encouraging more efficient use of

\footnotetext{
${ }^{211}$ Remarks to the WNFM annual meeting, June 9, 2003.

${ }^{212}$ For a discussion from three decades ago (making the case that uranium resources were sufficient at that time to delay deployment of breeder reactors, which turned out to be more than correct), see John P. Holdren, "Uranium Availability and the Breeder Decision," Energy Systems and Policy, Vol. 1, No. 3, 1975.

${ }^{213}$ See, for example, U.S. Department of Energy, Office of Nuclear Energy, Science, and Technology, Report to Congress on Advanced Fuel Cycle Initiative: The Future Path for Advanced Spent Fuel Treatment and Transmutation Research (Washington, DC: January 2003, available as of December 16, 2003, at http://www.nuclear.gov/reports/AFCI_CongRpt2003.pdf), pp. I-4: uranium "is not an infinite resource. Expert organizations such as the World Nuclear Association project that between 2050 and 2080, nuclear power plants worldwide will encounter a serious shortage of the uranium needed to produce nuclear fuel." It is worth comparing this statement with the official World Nuclear Association (formerly the Uranium Institute) statement on "Supply of Uranium," available as of December 16, 2003 at http://www.world-nuclear.org/info/inf75.htm. That statement begins with the following sentences, emphasized in the original as the key points: "Uranium is a common metal, found in both rocks and seawater. Its availability to supply world energy needs is great both geologically and because of the technology for its use. All mineral resources are greater than commonly perceived." Later, it goes on to argue that: "Of course the resources of the earth are indeed finite, but... the limits of the supply of resources are so far away that the truism has no practical meaning."

${ }^{214}$ From Ian Hore-Lacy, Nuclear Electricity $7^{\text {th }}$ ed. (Melbourne: Uranium Information Centre, Ltd, and World Nuclear Association, 2003, available as of December 16, 2003, at http://www.uic.com.au/ne.htm), Chapter 3. While this reference lists "high-grade" ores as being $2 \%$ uranium by weight, mines in Canada are now recovering ores that are more than $20 \% \mathrm{U}_{3} \mathrm{O}_{8}$.
} 
available resources - for example, by leaving lower assays in enrichment tails or using reactors with higher conversion ratios.)

Table B.1. Typical Uranium Concentrations

\begin{tabular}{lc}
\hline Medium & $\begin{array}{c}\text { Average Concentration } \\
(\mathbf{p p m} \mathbf{U})\end{array}$ \\
\hline High-grade ore & 20,000 \\
Low-grade ore & 1,000 \\
Granite & 4 \\
Sedimentary rock & 2 \\
Earth's continental crust & 2.8 \\
Seawater & 0.003 \\
\hline
\end{tabular}

Estimates of how much uranium would be available in the future at a given price are inherently uncertain, and there have been few serious attempts at a global assessment of total uranium resources (going beyond those already known to be available and recoverable) in recent decades. Indeed, for many years investment in exploration for uranium resources has been low, because low prices and the availability of large, already known uranium reserves suggested there was little money to be made in finding new deposits. As a result, as one analyst has noted, "predictions of the future availability of any mineral, including uranium, which are based on current cost and price data and current geological knowledge are likely to be extremely conservative." 215 The uranium resources that would likely be found if the price rose enough to motivate substantial investments in further exploration are likely to be far higher than today's resource estimates.

To understand the available estimates of how much uranium might ultimately be recoverable at various prices, it is important to understand the difference between "resources" and "reserves". The term "resources" refers to all of the quantities of a particular material that might ultimately be found and become economically recoverable, taking into account future improvements in the technologies of exploration and extraction, as well as future increases in prices. The term "reserves", by contrast, refers to those subsets of the resources that have been identified with high confidence and that are economically extractable at current prices using current technology. Reserves can be increased through exploration to identify additional economically extractable resources and by improvements in technology and operational practices to make economical the extraction of already identified (but previously uneconomical) resources.

\footnotetext{
${ }^{215}$ Hore-Lacy, Nuclear Electricity, op. cit. It is worth noting that the statements on resources in this text which are quoted in this Appendix are all repeated verbatim in the World Nuclear Association statement "Supply of Uranium," op. cit.
} 
Exploration is expensive; hence, industries have little incentive to find and characterize more than the amount of material expected to be needed in the next few decades. Investments in exploration typically are just sufficient to keep reserves constant or slowly growing as a multiple of annual consumption; if annual consumption exceeds annual additions to reserves over a prolonged period, with the result that the reserves fall significantly, the result is generally an increase in price that, in itself, converts some of the known but previously subeconomic resources into reserves and also calls forth an expanded exploration effort. The amount of material that will ultimately prove to be economically recoverable - termed "ultimately recoverable resources"- depends not only on the underlying geologic realities but also on the scope for improvement in the technologies of exploration, extraction, and use and on the amount by which the price of the material can rise before substitutes for it become economical and limit the demand.

Given these definitions and relationships, it is natural that published estimates of reserves would be quite accurate (limited mainly by uncertainties in the characterization of known deposits, by variations in analysts' assumptions about the capabilities of existing extractive technologies, and perhaps by corporate or national proprietary interests in less than full disclosure), while estimates of the ultimately recoverable resources would necessarily be much more uncertain. For example, estimates of the total amount of oil that ultimately will be economically recoverable range over a factor of two for today's technology, and over a factor of four or more assuming significant improvements in technology over the next two decades. ${ }^{216}$ The uncertainties for natural gas are even larger. ${ }^{217}$ The uncertainties for uranium-given the very low investments in exploration in recent decades, the very small efforts that have been made to integrate the resource information on a global basis, and the large factors by which uranium prices could rise before significantly affecting the economics of nuclear energy overall—are larger still.

\section{B.2. Fallacy of the Traditional Economic Resource Model}

Classical economic theory suggests that the price of non-renewable resources should rise over time, as the fixed available stock grows scarcer and more and more costly resources have to be used. $^{218}$ Forecasters relying on this model have routinely predicted that the uranium price would imminently begin a steady rise as resources began to become scarce, and these forecasters have just as routinely been proved wrong.

\footnotetext{
${ }^{216}$ Hans-Holger Rogner, et al., "Energy Resources," chapter 5 in Jose Goldemberg, ed., World Energy Assessment: Energy and the Challenge of Sustainability (New York: United Nations Development Program, United Nations Department of Economic and Social Affairs, and World Energy Council, 2000), pp.139-144; available as of December 16, 2003 at http://stone.undp.org/undpweb/seed/wea/pdfs/chapter5.pdf.

217 Ibid., pp. 144-147.

${ }^{218}$ For a useful discussion of the logical flaws of this classical model — still amazingly widely used, especially in projections of future uranium prices_-see M.A. Adelman, "My Education in Mineral (Especially Oil) Economics," Annual Review of Energy and Environment, Vol. 22, 1997, pp. 13-46. Another excellent critique of the standard model (drawing on examples related to uranium resources) is Thomas L. Neff, "Are Energy Resources Inexhaustible?" presentation to the "Global Energy Prospects: Supply-Side Issues," London School of Economics and Political Science, November 11, 1985. Neff's basic answer is close to "yes," and with respect to uranium, he concludes "we were not so much captive of nature's limits as of our own in thinking about uranium reserves and resources."
} 
The classical model fails to take into account the pace of discovery of new resources or the development of new technologies that reduce the cost of recovering material from less attractive sources. Because of these factors, the stock of resources available at a given extraction cost is not fixed, but increases for as long as technological improvements and new discoveries of material outpace the depletion of known high-quality deposits. And the fact is that, throughout the $20^{\text {th }}$ century and for most mineral resources of interest, society has discovered new deposits and has improved the technologies of extraction at sufficient rates to more than compensate for the consumption of previously known reserves. In recent decades the ratio of current annual consumption to known reserves - the number of years left at current consumption rates - has increased for most types of mined resources, even as the rate of consumption has increased. ${ }^{219}$ Over the last 25 years, this ratio has increased from 30 to 40 years for oil, and from 50 to 60 years for gas - despite increasing consumption. ${ }^{220}$ Increases in price have stimulated the largest increases in reserves, but reserves have increased even in periods of constant or declining price. $^{221}$

Technological improvements in resource extraction industries have been dramatic. The average U.S. coal miner in 1990 produced 8000 tons/year, compared to only 2500 tons/year in 1960; in the copper industry, output per miner increased at a remarkable rate of $8.6 \%$ per year from 1976 to $1987 .^{222}$ The result, for a wide range of non-renewable resources, has been prices that have been declining in real terms - the opposite of the classical model's prediction. In the United States, for example, the real price of a broad range of metals declined throughout the $20^{\text {th }}$ century (just as the uranium price has been doing for the last 20 years). ${ }^{223}$ There is little reason to believe that this trend will suddenly be reversed in the case of uranium, leading to the steady price rises throughout the $21^{\text {st }}$ century that are often projected.

Even if the uranium price did begin to increase steadily, it does not appear likely to increase very quickly. For example, the Nuclear Energy Agency (NEA) of the Organization for Economic Cooperation and Development (OECD), in its last estimate of the future costs of the nuclear fuel cycle, assumed that uranium prices would increase $1.2 \%$ per year. $^{224}$ If we assume that prices rise to $\$ 45 / \mathrm{kgU}$ by 2020 (as commercial and military inventories are exhausted and prices have to rise to a level that will result in sufficient production to meet demand), and 1.2\% per year thereafter, it would be well into the twenty-second century before uranium prices reached a level at which reprocessing at $\$ 1000 / \mathrm{kgHM}$ would be economically competitive. ${ }^{225}$

\footnotetext{
${ }^{219}$ See, for example, Adelman, "My Education in Mineral (Especially Oil) Economics," op. cit.

${ }^{220}$ BP Statistical Review of World Energy 2003 (London: BP, June 2003); available as of December 16, 2003 at http://www.bp.com/files/16/statistical_review_1612.pdf.

$\frac{1}{221}$ Ibid.

${ }^{222}$ Craig B. Andrews, "Mineral Sector Technologies: Policy Implications for Developing Countries" (Washington, DC: The World Bank, 1992).

${ }^{223}$ Daniel E. Sullivan, John L. Sznopek, and Lorie A. Wagner, " $20^{\text {th }}$ Century U.S. Mineral Prices Decline in Constant Dollars" (Washington DC: U.S. Geological Survey, Open File Report 00-389, available as of December 16, 2003 at http://pubs.usgs.gov/openfile/of00-389/of00-389.pdf).

${ }^{224}$ OECD Nuclear Energy Agency, The Economics of the Nuclear Fuel Cycle (Paris, France: OECD/NEA, 1994), p. 36.

${ }^{225}$ For a reprocessing price of $\$ 1000 / \mathrm{kgHM}$, in chapter 2 we derive a central value of the breakeven uranium price of $\$ 370 / \mathrm{kgU}$, with a lower limit (5 percent confidence interval) of $\$ 220 / \mathrm{kgU}$. Assuming a price of $\$ 45 / \mathrm{kgU}$ in 2020
} 
Clearly, technological changes over that long period will make such a simple calculation focused on today's LWR and reprocessing technologies irrelevant, but the calculation using today's figures is enough to indicate that it is likely to be quite some time before the economic disadvantage of reprocessing evaporates.

\section{B.3. Estimates of Uranium Resources}

The most widely available estimates of uranium resources are those in the "Red Book": a compendium of data on uranium resources from around the world, published by the NEA and the International Atomic Energy Agency (IAEA). ${ }^{226}$

The 2001 edition of the Red Book estimates that total world "conventional" resources available at less than $\$ 130 / \mathrm{kgU}$ amount to 16.2 million metric tons of uranium (MtU). This figure is the sum of "reasonably assured resources" (RAR, essentially what would be referred to as "reserves" if the uranium price were already $\$ 130 / \mathrm{kgU})$, "estimated additional resources" (EAR, resources inferred to exist in extensions of known deposits and estimated to be economically harvestable at the indicated price ${ }^{227}$ ), and "speculative resources" (SR, resources that are expected to exist and to be discoverable and recoverable with existing technologies at a particular reported price level, based on geologic trends in particular areas). ${ }^{228}$ If already-mined inventories are included-commercial inventories, excess defense inventories, and re-enrichment of depleted uranium tails that would be economic if the uranium price were to rise to the range of $\$ 130 / \mathrm{kgU}$ - the total figure rises to $17.1 \mathrm{MtU} .{ }^{229}$ An international meeting sponsored by the IAEA in 2000 concluded that total resources available in this category likely amount to 20 $\mathrm{MtU}^{230}$

Several points should be made about the Red Book total. First, because of the lack of incentive for substantial investments in uranium exploration in recent years, there are almost certainly large quantities of uranium that are not yet included in these estimates. Many countries remain lightly explored for uranium. Despite past exploration, modest additional investments have led in recent years to dramatic increases in estimates of available resources: in early 2001, for example, the Canadian firm Cameco increased its estimate of the uranium available at its McArthur River mine (the world's richest, with ore consisting of over $20 \% \mathrm{U}_{3} \mathrm{O}_{8}$ ) by more than

and an increase of 1.2 percent per year thereafter, uranium price would reach $\$ 220$ and $\$ 370$ in about 2150 and 2200 , respectively.

${ }^{226}$ At this writing (mid-2003), the most recent edition is Uranium 2001: Resources, Production, and Demand (Paris, France: OECD Nuclear Energy Agency and International Atomic Energy Agency, 2002).

${ }^{227}$ Estimated additional resources (EAR) are reported in two categories, EAR-I and EAR-II. EAR-I represents additional resources for which the geologic evidence is direct, while EAR-II represents resources for which the evidence is more indirect. For more specific definitions - and how they correlate with how major uranium producing countries report their national resource estimates - see Uranium 2001, op. cit., pp. 13-15.

${ }_{228}$ RAR, EAR-I, EAR-II, and SR reported to be available at less than $\$ 130 / \mathrm{kgU}$ are, respectively, 2.853, 1.080 , 2.332, and 9.939 MtU. See Uranium 2001, op. cit., pp. 21-27.

${ }^{229}$ R. Price and J.R. Blaise, "Nuclear Fuel Resources: Enough to Last?" NEA News, No. 20.2, 2002, available as of December 16, 2003 at http://www.nea.fr/html/pub/newsletter/2002/20-2-Nuclear fuel resources.pdf.

230 "International Symposium on the Uranium Production Cycle and the Environment," October 2000, Vienna, reported in IAEA, "International Symposium Concluded That Uranium Supply for Nuclear Power is Secure," PR 2000/26 (Vienna, Austria: IAEA, October 6, 2000, available as of December 16, 2003 at http://www.iaea.org/worldatom/Press/P_release/2000/prn2600.shtml). 
50 percent, based on analyses of drilling at that site over the previous few years. ${ }^{231}$ It should be expected that this trend will continue in the future: the more energetically uranium firms look (when motivated to do so by increasing prices), the more uranium they will find.

Second, since uranium prices in recent years have been in the $\$ 20-40 / \mathrm{kgU}$ range, there has been no incentive to look for uranium in the higher-cost categories. Estimates of resources in these categories are therefore particularly uncertain, and very likely to be underestimates (probably by a large factor, as prices approaching $\$ 130 / \mathrm{kgU}$ would provoke intense exploration and technological improvements in recovering uranium from low-grade ores).

Third, the reported total figure has been increasing over time - despite the minimal global investments in uranium exploration in recent decades, and despite inflation eating away at the real value of the $\$ 130 / \mathrm{kgU}$ cap at which resources are reported - and can be expected to continue to do so in the future. The previous edition of the Red Book in 1999, for example, reported a comparable total of $15.4 \mathrm{MtU}$ recoverable at less than $\$ 130 / \mathrm{kgU}, 800,000$ tons less than the total reported two years later.

Fourth, because many countries do not report resources in all categories, these resources are omitted from the total. Only 28 countries report speculative resources, compared to 43 that report reasonably assured resources. Australia, for example, with some of the world's largest uranium resources, does not bother to estimate "speculative" resources because its better-known resources are so large already_ but as the 2001 Red Book points out in its understated way, "countries, such as Australia, are considered to have significant resource potential in sparsely explored areas." 232 The Red Book table of speculative resources specifically notes that these totals are merely those that countries reported, and "do not represent a complete account of world undiscovered conventional resources." ${ }^{233}$ Estimates based on extrapolations of Red Book data (to estimate resources in higher-cost and more speculative resource categories, and resources in countries for which no estimates are given) increase the total resource recoverable at costs less than or equal to $\$ 130 / \mathrm{kgU}$ by up to 45 percent, to about $24 \mathrm{MtU}$.

Fifth, this estimate includes only "conventional" resources-geologic resources where the uranium ore is rich enough to justify mining it by itself at the indicated price. In some cases, however, it may be attractive to produce uranium as a byproduct, as has been done with gold and phosphate mining. An additional $22 \mathrm{MtU}$ are estimated to be available in phosphate deposits worldwide (though at very low concentrations), ${ }^{234}$ and some noticeable fraction of this material may ultimately be economically recoverable as a byproduct of phosphate mining, as global demand for fertilizer continues to rise.

In short, despite the inclusion of "speculative resources" in the 17.1 MtU figure, there is a very high probability that the amount of uranium that will ultimately prove recoverable at or below $\$ 130 / \mathrm{kgU}$ will be significantly greater. Realistically, $17 \mathrm{MtU}$ should be considered a

\footnotetext{
${ }^{231}$ See Cameco, “Cameco Increases McArthur River Uranium Reserves,” press release, January 25, 2001.

${ }^{232}$ Uranium 2001, op. cit., p. 26.

${ }^{233}$ Uranium 2001, op. cit., p. 27.

${ }^{234}$ Uranium 2001, op. cit., p. 28.
} 
lower bound, not an upper bound, on the amount of uranium likely to be recoverable at $\$ 130 / \mathrm{kgU}$.

Another way to approach the problem is to estimate the shape of the curve of resource availability as a function of price. ${ }^{235}$ The limited available data make this estimation difficult. Based on geologic relationships, which indicate that exponentially larger resources are available at lower ore grades, it seems likely that the relationship between price and resources is roughly exponential. According to one industry observer, "a doubling of price from present levels could be expected to create about a tenfold increase in measured resources." 236 (The conservative nature of the Red Book figures, particularly in the higher cost ranges, can be judged from the fact that in its estimates of known conventional resources, doubling the price from $\$ 40 / \mathrm{kgU}$ to $\$ 80 / \mathrm{kgU}$ leads to only a $48 \%$ increase in resources estimated to be available.) If this correctly describes the relationship between price and resources, and if we calibrate the curve (very conservatively) by assuming that the $2.1 \mathrm{MtU}$ of known resources reported in the 2001 edition of the Red Book as recoverable at $\$ 40 / \mathrm{kgU}$ represent the sum total of all resources in the world that will ever be recoverable at that price, ${ }^{237}$ then the curve of resources as a function of price would be:

$$
R=2.1\left(\frac{p}{40}\right)^{\varepsilon}
$$

where $R$ is the total uranium resource $(\mathrm{MtU})$ recoverable at price $p(\$ / \mathrm{kgU})$ and $\varepsilon$ is the longterm price elasticity of supply. If a doubling of price leads to a tenfold increase in resources, then $\varepsilon=\log (10) / \log (2)=3.32$. By this crude estimate, doubling the price to $\$ 80 / \mathrm{kgU}$ would increase the recoverable resources to $21 \mathrm{MtU}$, and over $100 \mathrm{MtU}$ would be available at $\$ 130 / \mathrm{kgU}$.

\footnotetext{
${ }^{235}$ More precisely, decreasing quality and accessibility of ores would be expected (if technological improvements do not keep pace) to lead to increases in extraction cost. The relationship between extraction cost and market price is complex, having to do with monopoly or cartel power; expectations of future prices; costs of bringing additional production on-line; costs of shifting additional resources to reserves; elasticities of demand; and more. The uranium market, which is characterized by utility buyers for whom uranium is only a small part of the cost of electricity production, but which are extremely concerned to ensure that fuel will be available when they needed it, is particularly sensitive to perceptions of future shortages or surpluses (and hence the price has been quite volatile over the last two decades). Nevertheless, in general in the uranium market, additional production capacity is brought online whenever prices rise high enough for it to be profitable for producers to bring that capacity on-line (taking into account the risks, including the risk that the price will decline again). Rather than saving their limited reserves for later production when prices might be higher, in other words, producers tend to act "as if their finite stocks were infinite" (Adelman, "My Education in Mineral (Especially Oil) Economics," op. cit.). If this behavior continues, and no durable cartel is formed, long-term average prices should be related to costs of production plus competitive rates of profit. Hereinafter we will refer only to price, with the notion that price will in general be such as to allow producers to extract the resource and earn a competitive profit.

${ }^{236}$ Hore-Lacy, Nuclear Electricity, op. cit.

${ }^{237}$ The resources available at this low price are the best-explored and best-characterized, and therefore the best available basis for calibration of such a relationship. Nevertheless, they are certain to be quite conservative. The Red Book figures in this low-cost category include only the best-characterized deposits (equivalent to reserves, rather than resources); it is virtually certain that additional investment in exploration would substantially increase the quantity of material reported as available at this cost. Moreover, the Red Book itself points out that the total quantity of resources available at $\$ 40 / \mathrm{kgU}$ or less "are higher than reported in the tables because certain countries do not report resource estimates, mainly for reasons of confidentiality." Uranium 2001, op. cit., p. 22.
} 
One of the few serious attempts to estimate how much uranium is likely to be available worldwide concluded that a ten-fold reduction in ore concentration is associated with a 300 -fold increase in available resources. ${ }^{238}$ Although the authors made no attempt to associate costs of extraction with ore grades, if the phenomena reflected in equation (B.1) are similar to those examined in this geologic analysis, this would imply that doubling the price would make economical the exploitation of ores with uranium concentrations 2.5 times lower. This seems plausible, because not all of costs of uranium mining scale in direct proportion to the quantity of material that has to be mined and processed per ton of uranium recovered. If, at the other extreme, we assume that costs are inversely proportional to ore grade (as might be true at very low concentrations, when total costs became dominated by the amount of material mined and processed), the exponent $\varepsilon$ in equation (B.1) would be 2.48, and the expected resource available for $\$ 130 / \mathrm{kgU}$ or less (using the same calibration technique) would be about $40 \mathrm{MtU}$.

More recently, the Generation IV fuel cycle crosscut group advising the Department of Energy's Office of Nuclear Energy, basing itself on the amounts of uranium recently estimated to be available in the United States at $\$ 30 / \mathrm{kgU}$ and $\$ 50 / \mathrm{kgU}$, also predicted an exponential relationship between resources and price, and judged that the exponent $\varepsilon$ in equation B.1 might be as low as 2.35. ${ }^{239}$ Calibrating by the Red Book estimate of $2.1 \mathrm{MtU}$ available at $\$ 40 / \mathrm{kgU}$ or less gives $34 \mathrm{MtU}$ available at $\$ 130 / \mathrm{kgU}$ or less. ${ }^{240}$ Table B. 2 summarizes these estimates.

\footnotetext{
${ }^{238}$ Kenneth S. Deffeyes and Ian D. MacGregor, "World Uranium Resources," Scientific American, January 1980. This article is based on Kenneth S. Deffeyes and Ian D. MacGregor, Uranium Distribution in Mined Deposits and in the Earth's Crust: Final Report GJBX-1(79) (Princeton, NJ: Department of Geological and Geophysical Sciences, Princeton University, 1978). It should be noted that Deffeyes is very far from being a wild-eyed resource optimist: his most recent book is Hubbert's Peak: The Impending World Oil Shortage (Princeton: Princeton University Press, 2001). For a quite different effort to assess world uranium resources, from the same period (which also concluded even then that resources were likely larger than now reported in the Red Book), see DeVerle P. Harris, "World Uranium Resources," Annual Review of Energy 1979 4:403-32. See also Neff, "Are Energy Resources Inexhaustible?" op. cit. More recently, see Thomas C. Pool, "Uranium Resources for Long-Term, Large-Scale Nuclear Power Requirements," Nonrenewable Resources, Vol. 3 No. 4, 1994, pp. 257-265. Like Neff, Pool is so confident that "availability of uranium resources is unlikely to place any major constraint on the future development of large-scale nuclear power" that he does not attempt to put a number on the total resource likely to be available.

${ }^{239}$ U.S. Department of Energy, Office of Nuclear Energy, Generation IV Roadmap: Report of the Fuel Cycle Crosscut Group (Washington, DC: DOE, March 18, 2001, available at http://www.ne.doe.gov/reports/GenIVRoadmapFCCG.pdf.), pp. 1-30.

${ }^{240}$ Inexplicably, the Generation IV fuel cycle crosscut group appears to mis-calibrate their equation, offering a constant of 77.4, which would result in resources at all reported prices far below those reported in the "Red Book." Report of the Fuel Cycle Crosscut Group, op. cit., pp. 1-30. This error is not an important one for the group's work, however, as the actual model they use for estimating uranium resources as a function of price is based on linear interpolation of the 1999 "Red Book" figures (see discussion on pp. A2-12-A2-14), and bears no relation to the exponential equation offered on pp. 1-30.
} 
Table B.2. Uranium resource estimates, based on equation (B.1).

\begin{tabular}{lccc}
\hline & Elasticity of & \multicolumn{2}{c}{$\boldsymbol{R}(\mathbf{M t U})$} \\
Source & Supply, $\boldsymbol{\varepsilon}$ & $\boldsymbol{p} \leq \mathbf{\$ 8 0} / \mathbf{k g U}$ & $\boldsymbol{p} \leq \mathbf{\$ 1 3 0 / \mathbf { k U }}$ \\
\hline Uranium Information Centre & 3.32 & 21 & 105 \\
Deffeyes \& MacGregor & 2.48 & 12 & 40 \\
Generation IV Group & 2.35 & 11 & 34 \\
\hline
\end{tabular}

These are very crude estimates of the relationship between price and available resources, based on extremely limited data. It may turn out that the curve does not have a continuously exponential shape, but rather has steeper and flatter portions. ${ }^{241}$ More research on the actual quantity of uranium available worldwide in different price ranges is clearly needed.

Nevertheless, the following points can be made about these relations:

- All of them suggest that the total amount of uranium recoverable at prices at or below $\$ 130 / \mathrm{kgU}$ is likely to be substantially larger than the amount reported in the Red Bookfrom two to six times larger.

- All of them use the very conservative estimate of the amount of uranium available at prices at or below $\$ 40 / \mathrm{kgU}$. If world resources available at that price turn out to be twice as large, then the total resource available at less than $\$ 130 / \mathrm{kgU}$ also would be doubled.

- The relationships that result in smaller resource estimates are estimated based solely on geologic relationships, without including the likelihood that technology for recovering uranium at lower cost will improve in the future. As technological improvement is virtually certain, total resources recoverable at a given price decades in the future are likely to be larger than these estimates suggest_-possibly enormously larger. The history of copper production is illustrative: as a result of improved technology, the real price declined by half from 1900 to 2000 despite a 25 -fold increase in demand ${ }^{242}$ and a decline in the average ore

\footnotetext{
${ }^{241}$ For example, one model includes, in addition to costs increasing as ore grade decreases, costs at any given ore grade increasing roughly linearly with the amount of material at that grade that has been extracted, as the most accessible ores of that grade are mined and less accessible ores must be pursued. This more complex model predicts a flatter curve (and therefore lower expectations of total world resources extractable at higher prices). See Clifford E. Singer, "An Analytical Uranium Sources Model," in Proceedings of the Technical Committee Meeting on Recent Developments in Uranium Resources, Production, and Demand (Vienna, 10-13 June, 1997) (Vienna, Austria: International Atomic Energy Agency, 1998), pp. 27-38. We have based the discussion in this chapter on the simpler model based on exponential distributions of ore grade, in part because the existing experience with a range of mineral resources suggests that to date, extraction costs in real terms have not in fact been rising at given ore grades (perhaps because reductions in cost resulting from technological progress are counteracting increases in cost from exploitation of less accessible deposits). An examination of U.S. Geological Survey data covering a broad range of mined commodities over several decades, for example, demonstrates that real prices are typically flat or declining, and that price tends to decline slightly, rather than increasing, for those commodities for which annual demand has increased by the largest factor. (William Sailor, personal communication, 2003.)

${ }^{242}$ Kenneth E. Porter and Daniel L. Edelstein, "Copper Statistics," (Washington, DC: U.S. Geological Survey, August 28, 2002, available as of December 16, 2003 at http://minerals.usgs.gov/minerals/pubs/of01006/copper.html). This estimate of a cut by a factor of two over the period is based on fitting a trend line to the statistics reported there; the actual ratio of the 2000 real price to the 1900 real price is 3.8 , because there was a price
} 
grade from 2 to 0.85 percent. $^{243}$ Despite the dramatic increase in annual consumption, there is little risk that the world will soon run out of copper. In the case of uranium, ores with concentrations as low as 4.5 parts per million-less than twice the average abundance in the earth's crust - have been recovered as byproducts from copper mines, at costs of less than $\$ 52 / \mathrm{kgU}^{244}$

Finally, it is important to note that $\$ 130 / \mathrm{kgU}$ is considerably less than the price at which recycling would be economic. As indicated in chapter 2 , a uranium price of more than $\$ 360 / \mathrm{kgU}$ would likely be needed to make recycle at a reprocessing price of $\$ 1000 / \mathrm{kgHM}$ economically competitive, which would likely increase recoverable resources by more than a factor of 10 .

\section{B.4. Uranium from Seawater}

Even if, in the distant future, mineral ores are thoroughly depleted, it is not obvious that reprocessing and recycle would become economical. At the extreme of low-grade resources is the huge amount of uranium-4500 MtU_-dissolved in the world's oceans at a concentration of about 3 parts per billion. Research has demonstrated that, using modern adsorbents, uranium can be recovered from seawater. The primary research programs in recent years have been in Japan, and, to a lesser extent, in France.

To date, only small amounts of uranium have been recovered by these methods. The resources devoted to these research efforts have been extremely small—probably a thousand times less than has been spent in recent years on R\&D for reprocessing and breeding. Substantial further research and development would be needed to determine whether recovery of uranium from seawater could be done at an industrial scale and what the price of the recovered uranium might be.

The somewhat speculative estimates of the cost of recovering uranium from seawater that have been made in recent years have varied greatly from one study to another. Early approaches involved pumping seawater through the adsorbent. A pilot plant was built in Japan and operated for 2 years, but the pumping required more energy than would be provided by the recovered uranium, so this approach was abandoned. ${ }^{245}$ Very high early cost estimates (well over $\$ 1000 / \mathrm{kgU})$ may have been associated with this pumped-water approach.

More recent approaches rely on ocean currents to move seawater through fixed arrays of adsorbents, with a ship collecting the uranium-bearing adsorbents for on-board processing or delivery to a shore-based processing facility. Japanese estimates for this latter approach in the

dip around 2000 and a price spike around 1900. (The authors are grateful to William Sailor of Los Alamos National Laboratory for discussions on this point.)

${ }^{243}$ Oscar Groenveld, “The Technology Environment for the $21^{\text {st }}$ Century-The Mining Industry," presentation to the Australian Academy of Technological Sciences and Engineering, 1998, available as of December 16, 2003 at http://www.atse.org.au/publications/symposia/proc-1998p1.htm.

${ }^{244}$ Described in Pool, "Uranium Resources for Long-Term, Large-Scale Nuclear Power Requirements," op. cit.

${ }^{245}$ This is briefly discussed, for example, in T. Kato, K. Okugawa, Y. Sugihara, and T. Matsumura, "Conceptual Design of Uranium Recovery Plant From Seawater," Journal of the Thermal and Nuclear Power Engineering Society (in Japanese), 50, 1999, pp. 71-77. 
early to mid-1990s were in the range of $\$ 200-\$ 260 / \mathrm{kgU}$ (then-year dollars). ${ }^{246}$ In the late $1990 \mathrm{~s}$, both Japanese and French researchers put forward estimates as low as $\$ 100 / \mathrm{kgU}$, though these were acknowledged to be highly uncertain and not backed by detailed engineering studies. ${ }^{247}$ Such low total costs seem unlikely for facilities that must pay typical costs of money for privately owned facilities, as well as corporate income taxes. Since then, as might be expected, estimates have increased again. A Japanese paper from 1999 provides a detailed listing of the cost elements considered and arrives at an estimate of some $\$ 1200 / \mathrm{kgU}^{248}$ This paper appears to include unrealistically low rates of return on invested capital (at least for U.S. and European markets); incorporating financial assumptions comparable to those we have used for a regulated utility with a guaranteed rate of return would increase the estimate to over $\$ 1700 / \mathrm{kgU}$. In 2000 , French researchers put forward an estimate of roughly $\$ 250 / \mathrm{kgU}$, but this is based on simple payback of capital with no return on investment and no payment of corporate taxes; using our financing assumptions for a regulated utility would almost double this estimate. ${ }^{249}$ The most recent Japanese paper of which we are aware, published in 2001, argued for a cost in the range of 5-10 times the current cost of mined uranium; if we take that cost to be similar to current contract prices in the range of $\$ 35 / \mathrm{kgU}$, this suggests a cost in the range of $\$ 175-\$ 350 / \mathrm{kgU}$, essentially comparable to the estimates for seawater uranium made a decade ago. ${ }^{250}$ Faced with these varying estimates, the 2001 edition of the Red Book chose a value of $\$ 300 / \mathrm{kgU}$ as representative of current thinking. ${ }^{251}$

The cost of such an operation would be quite sensitive to the properties of the adsorbent material. The more uranium adsorbed per kilogram of adsorbent (and the shorter the time in the ocean required for this to occur), the cheaper the operation would be. Progress in developing improved adsorbent materials over the past decade has been substantial, and it is possible that there will be further progress in the future, reducing costs. Indeed, both French and Japanese researchers in this area have suggested that this is likely to be the case.

\footnotetext{
${ }^{246}$ See Toru Hiraoka, "Nuclear Electricity Generation by Seawater Uranium," Journal of the Atomic Energy Society of Japan (in Japanese), Vol. 36, No. 7 (1994), pp. 644-645 (approximately \$200/kgU), and H. Nobukawa et. al, "Development of a Floating Type System for Uranium Extraction from Seawater Using Sea Current and Wave Power," Proceedings of the 4th International Offshore and Polar Engineering Conference, Osaka, Japan, April 1015, 1994, pp. 294-300 (approximately $\$ 260 / \mathrm{kgU}$ ).

${ }^{247}$ Tadao Seguchi, director of material development at the Japan Atomic Energy Research Institute, estimated a cost of about $\$ 100 / \mathrm{kgU}$ (paper presented at Tokyo University-Harvard University workshop, Tokyo, May 23, 1998); Seguchi later put the cost at $\$ 100-\$ 300 / \mathrm{kgU}$ in a plant producing $200 \mathrm{tU} / \mathrm{yr}$, but emphasized that his specialty was adsorbent development, not cost estimation (personal communication to Richard L. Garwin, October 23, 1998). Jacques Foos, President of the CNAM Laboratory of Nuclear Sciences, prepared a report which, based on a review of the literature, suggested a range of $\$ 300-\$ 370 / \mathrm{kgU}$ using then-existing technology, but suggested that this might be reduced to $\$ 80 / \mathrm{kgU}$ by the use of more advanced technologies being researched in his laboratory-while emphasizing that this estimate was very preliminary. (Foos, personal communication to J. Syrota, forwarded to Richard L. Garwin and Georges Charpak, April 3, 1997.)

${ }^{248}$ Kato, et al., "Conceptual Design of Uranium Recovery Plant From Seawater," op. cit.

${ }^{249}$ Jacques Foos, estimate described in detail in Richard L. Garwin, "Uranium From Seawater-A Green Fuel for the Future?" forthcoming.

${ }^{250}$ T. Sugo et al., "Recovery System For Uranium From Seawater With Fibrous Adsorbent and its Preliminary Cost Estimation," Journal of the Atomic Energy Society of Japan (in Japanese) 43 (10): 1010-1016, October 2001. See also the earlier T. Sugo and K. Saito, "Progress in Recovery Technology of Uranium From Seawater," Journal of the Atomic Energy Society of Japan (in Japanese), 36, 619-623, 1999.

${ }^{251}$ See Uranium 2001, op. cit. p. 28. The Generation IV crosscut team chose a value of $\$ 200 / \mathrm{kgU}$, noting that such estimates are "highly speculative." Report of the Fuel Cycle Crosscut Group, op. cit. pp. 1-20, pp. 1-30.
} 
The performance of current adsorbents is highly dependent on temperature, and they are thus effectively limited to warm surface waters. Moreover, to minimize costs, current concepts typically involve placement in currents close to the shore. However, horizontal and vertical mixing of the ocean would make seawater uranium accessible in warm surface waters at essentially constant concentration for many centuries, so long as the rate of extraction did not exceed $\sim 2 \mathrm{MtU} / \mathrm{y}$ (30 times current consumption rates). ${ }^{252}$

These cost estimates do not include the value of the other metals that are co-recovered with the uranium. Current adsorbents used in Japan recover almost twice as much vanadium as uranium. Other metals such as cobalt, titanium, and molybdenum can also be co-recovered. ${ }^{253}$ At today's prices, such co-recovered materials would pay for only a very small fraction of the cost of the recovery operation. If such materials became scarce and expensive in the future, however - as might occur by the time uranium became scarce and expensive enough for seawater extraction to be considered - the value of these co-recovered materials might be sufficient to substantially reduce the net per-kilogram recovery cost for uranium.

If uranium could be recovered from seawater economically, this would represent a vast energy resource for the future and could postpone for many centuries any need for breeding or reprocessing plutonium. But as the discussion above makes clear, it is not yet by any means certain whether uranium can be recovered from seawater at an industrial scale at a price below the reprocessing breakeven price. Given that all estimates of the cost of recovery from seawater are far above the current uranium price, industry has no incentive to fund further development of these concepts. We recommend a significant government program to explore both the total terrestrial resources likely to be recoverable as a function of price, and the possibilities for recovering uranium from seawater.

\section{B.5. Uranium Consumption}

If the above estimates of resource availability are matched to estimates of future uranium consumption, it is clear that uranium resources will not run out for a very long time to come. World uranium requirements in 2001 were roughly 64,000 tU. ${ }^{254}$ Hence the Red Book estimate of $17 \mathrm{MtU}$ available at less than $\$ 130 / \mathrm{kgU}$ represents more than 250 years' supply at current rates.

It is quite possible, however, that nuclear energy will grow in the future, and that if the world nuclear energy system relied primarily on once-through cycles without reprocessing, annual world uranium requirements would increase substantially. A recent study by the NEA on the potential contribution of nuclear energy to reducing greenhouse gas emissions envisioned

\footnotetext{
${ }^{252}$ This is a rough estimate by the authors based on the flow rate between surface and deep ocean waters and vertical and horizontal mixing within surface waters, assuming the extraction of uranium is distributed throughout the five major ocean areas (north/south Pacific, north/south Atlantic, and Indian oceans).

${ }^{253}$ See, for example, Takanobu Sugo, "Uranium Recovery From Seawater" (Tokyo, Japan: Japan Atomic Energy Research Institute, 1999).

${ }^{254}$ Uranium 2001, p. 49.
} 
three possible scenarios of future nuclear growth. The highest-growth scenario would consume only 5.6 MtU- one-third of the $17 \mathrm{MtU}$ Red Book figure- by 2050. ${ }^{255}$ While some official documents have raised the possibility of a uranium shortage arising even sooner, they are confusing the possibility that commercial investment in bringing mines on-line will not respond rapidly enough to imagined future nuclear energy growth - an issue of industrial structure and price signals in the market - with actually running out of low-cost uranium resources. ${ }^{256}$

Higher projections of nuclear growth are, of course, possible. In a detailed study of future energy scenarios in 1998, the World Energy Council (WEC) and the International Institute for Applied Systems Analysis (IIASA) outlined a wide range of scenarios for future energy supply, including nuclear energy. ${ }^{257}$ "Case B," which the group considered the most plausible, was among the high-uranium-demand cases, and was used as the "base case" by the Generation IV fuel cycle crosscut team to examine the impact of large-scale future nuclear growth. ${ }^{258}$ In Case B, global installed nuclear capacity would grow from $380 \mathrm{GWe}$ in 1990 to $800 \mathrm{GWe}$ in 2020, roughly 2000 GWe in 2050, and 5500 GWe in 2100. During 2000-2100, nuclear energy would provide 1.4 million terawatt-hours (TWh) of electricity. ${ }^{259}$ How much uranium would be consumed by providing that much electricity using a once-through cycle depends on assumptions about what types of reactors are used, with what burnup, and how much U-235 is left in the depleted tails from enrichment plants. Assuming, quite conservatively, that the reactors are LWRs with an average burnup over the entire period of only $50 \mathrm{GWd} / \mathrm{tHM}$, and a tails assay of $0.2 \% \mathrm{U}-235$, then $19 \mathrm{tU} / \mathrm{TWh}$ would be needed, for a total consumption of $26 \mathrm{MtU}$ by $2100{ }^{260}$ This is modestly higher than the $17 \mathrm{MtU}$ estimated by the Red Book to be available at $\$ 130 / \mathrm{kgU}$ or less, but smaller than the 33 to $100 \mathrm{MtU}$ given equation (B.1) using the values of $\varepsilon$ discussed above. Other reactor systems designed for more efficient once-through uranium use could significantly reduce the uranium requirement in such a high-growth scenario.

In short, it seems very likely that uranium resources will continue to be available at substantially below the breakeven price for reprocessing at $\$ 1000 / \mathrm{kgHM}$ throughout the $21^{\text {st }}$ century.

\footnotetext{
${ }^{255}$ OECD Nuclear Energy Agency, Nuclear Power and Climate Change (Paris, France: OECD/NEA, 1998, available as of December 16, 2003 at http://www.nea.fr/html/ndd/climate/climate.pdf). The $5.6 \mathrm{MtU}$ figure is likely to be an overestimate for the amount of nuclear energy generated in the scenario, as it does not appear to have included allowance for reduced tails assays as uranium became more expensive.

${ }^{256}$ See, for example, DOE, Report to Congress on Advanced Fuel Cycle Initiative, op. cit., pp. I-4-I-5, describing a study that indicated that production from presently planned and projected mines would only supply half of projected requirements in a "high case" scenario by 2030. The conclusion drawn that this "demonstrates" that "nuclear fuel from mined uranium could become a serious restraint on the growth potential of nuclear power in the not-too-distant future" is simply incorrect - as is the implication that any of the technologies being pursued in the Advanced Fuel Cycle Initiative could be developed and deployed in time to have much effect on supplies by 2030 if this were a serious problem.

${ }^{257}$ N. Nakicenovic, A. Grübler, and A. McDonald, eds., Global Energy Perspectives (Cambridge, UK: Cambridge University Press, 1998).

${ }^{258}$ Report of the Fuel Cycle Crosscut Group, op. cit. pp. 1-33.

${ }^{259}$ Calculated using data available at International Institute of Applied Systems Analysis, "Global Energy

Perspectives Database," available as of December 16, 2003 at http://www.iiasa.ac.at/cgi-

bin/ecs/book_dyn/bookent.py.

${ }^{260}$ Steve Fetter, "Comments on 'Report of the Fuel Cycle Crosscut Group,"” unpublished memorandum, April 2002. A tails assay of $0.2 \%$ would minimize total fuel cycle costs when uranium price is about 1.3 times enrichment price (e.g., $\$ 130 / \mathrm{kgU}$ for $\$ 100 / \mathrm{SWU}$ ).
} 